\title{
Problemas de Corte e Empacotamento: Uma abordagem em Grafo E/OU
}

\author{
Andréa Carla Gonçalves Vianna \\ Orientador: Prof. Dr. Marcos Nereu Arenales \\ Co-orientador: Prof. Dr. Reinaldo Morabito Neto
}

Tese apresentada ao Instituto de Ciências Matemáticas e de Computação - ICMC-USP, como parte dos requisitos para obtenção do título de Doutor em Ciências de Computação e Matemática Computacional. 
Ao meu marido, Carlos, e aos meus filhos, Lucas e Laura. 


\section{AGRADECIMENTOS}

Ao Professor Marcos Arenales pela orientação, dedicação, incentivo e amizade durante todo o doutorado.

Ao Professor Reinaldo Morabito pela orientação e sugestões.

Aos meus amigos pela ajuda e amizade, principalmente Edméa Cássia Baptista, Lúcia Kumoto Katsuki, Márcia Aparecida Zanoli Meira e Silva, Marco Antônio Rahal Sacoman e Vanilda Miziara Mello Chueiri.

Aos meus pais, Valdemir e Cleide, meu marido e meus filhos, pelo amor, apoio, compreensão e paciência.

A toda minha familia pelo carinho e apoio, que de maneira indireta, contribuiram sensivelmente para a realizaçāo deste trabalho. 


\section{SUMÁRIO}

Página

Lista de Figuras ..................... vii

Lista de Tabelas .......................... xi

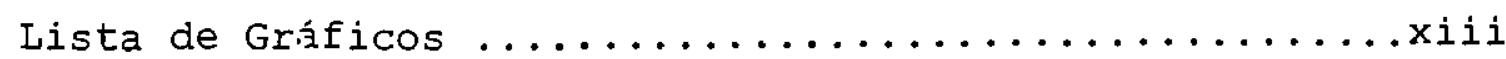

Resumo .............................. xiv

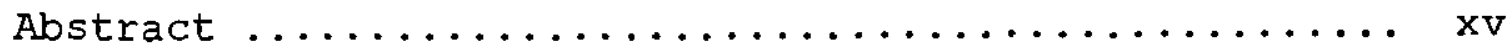

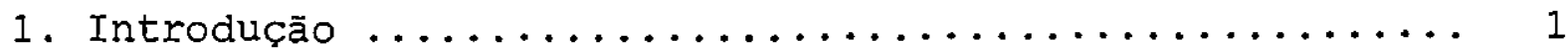

2. Definição de Problemas de Corte ................ 4

2.1. Classificação dos Problemas ............... 4

2.2. O Problema de Corte Bidimensional ............. 9

2.2.1. Padrão de corte com placa defeituosa ..... 13

2.2.2. Padrão de corte com limitação no número de tipo de peças .................. 14

2.2.3. Padrão com corte-cabeça .............. 15

2.2.4. Padrão de corte com peças do tipo L ...... 16

2.2.5. Padrão com corte não-guilhotinado ........ 18

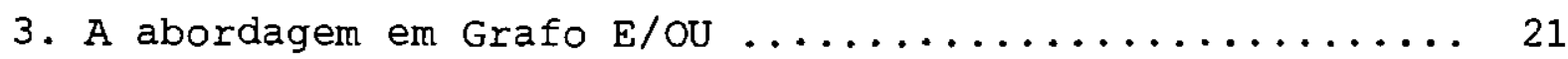

3.1. Representação em Grafo E/OU ................ 22

3.2. Representação de Padrões de Corte Especiais...... 26

3.2.1. Padrão de corte k-estagiado ........... 26

3.2.2. Padrão de corte restrito ............. 27

3.2.3. Padrão de corte com placa defeituosa ...... 28

3.2.4. Padrão de corte com limitação no número de tipo de peças ................... 30

3.2.5. Padrão com corte-cabeça .............. 31

3.2.6. Padrão de corte com peças do tipo L ...... 32

3.2.7. Padrão com corte não-guilhotinado ....... 34

4. Método de Enumeração fmplicita................ 37

4.1. Geração do conjunto de discretização ......... 37

4.2. Limitantes Inferiores .................. 43

4.2 .1 . Solução Homogênea ............... 43

4.2.1.1. Problema Restrito............ 44

4.2.1.2. Problema k-estagiado ......... 45 
4.2.2. Solução Homogênea Composta ............ 46

4.2.2.1. Problema Restrito.......... 46

4.2.2.2. Problema com placa defeituosa .... 47

4.2.2.3. Problema com peças em L ....... 48

4.2.3. Solução 2-estágios ................. 49

4.3. Limitantes Superiores .................. 51

4.3.1. Limitante superior trivial ........... 51

4.3.2. Limitante superior para problemas restritos 52

4.3.3. Limitante superior para um problema com placa defeituosa ................. 52

4.3.4. Limitante superior para problemas com peças

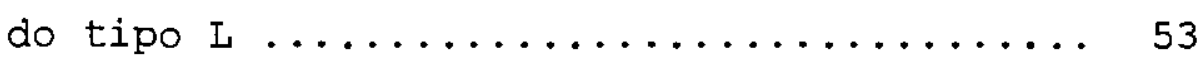

4.4. Estratégia de busca ................. 53

4.5. Algoritmo BT-HC ................... 55

4.6. Conjectura do Problema de Corte Restrito ........ 56

5. Heuristicas ........................... 57

6. Experiências Computacionais ................. 62

6.1 . Problema Irrestrito .................. 63

6.1.1. Escolha sequencial crescente dos cortes ... 64

6.1.2. Escolha sequencial decrescente dos cortes. 65

6.1.3. Escolha aleatória dos cortes .......... 67

6.1.4. Limitante Inferior: Solução Homogênea ..... 68

6.1.5. Limitante Inferior: Solução 2-estágios .... 70

6.2. Problema Restrito ................... 72

6.2.1. Limitante Inferior: Solução Homogênea Com-

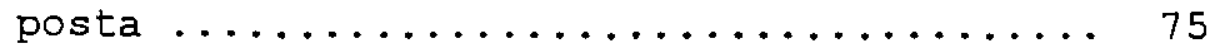

6.2.2. Eracionamento do vetor b .............. 77

6.3. Problema Estagiado .................. 78

6.4. Problema com placa defeituosa ............. 85

6.5. Problema com limitação no número de tipo de peças 88

6.6. Problema com corte-cabeça ................. 91

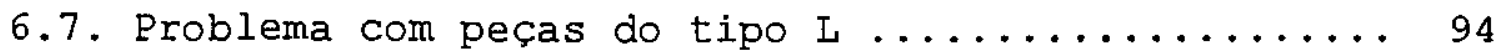

7. Aplicação do Problema de Corte numa Indústria de Esquadrias Metálicas ....................... 96 
7.1. Algoritmo Guloso ................... 98

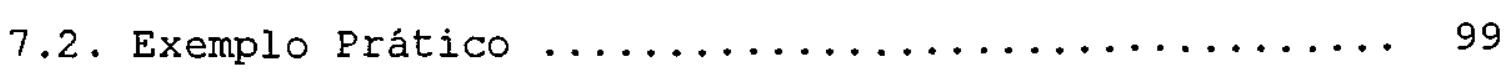

8. Conclusões e Perspectivas Futuras ................. 104

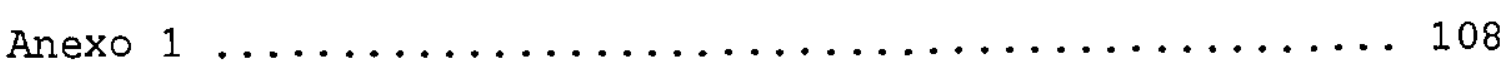

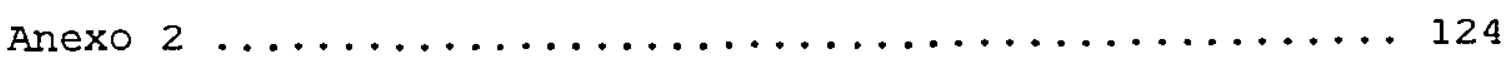

Referências Bibliográficas .................... 127 


\section{IISTA DE FIGURAS}

Página

2.1. Problema de corte unidimensional ............. 6

2.2. Padrão de corte unidimensional $\ldots \ldots \ldots \ldots \ldots \ldots \ldots$

2.3. Problema de corte bidimensional .............. 7

2.4. Padrão de corte bidimensional $\ldots \ldots \ldots \ldots \ldots \ldots \ldots \ldots .8$

2.5. Problema de corte tridimensional ............. 8

2.6. Padrão de corte tridimensional ............... 9

2.7. Corte guilhotinado horizontal e vertical ......... 11

2.8. Padrões de corte guilhotinado ............... 11

2.9. Padrão de corte guilhotinado 2-estágios, 3-estágios

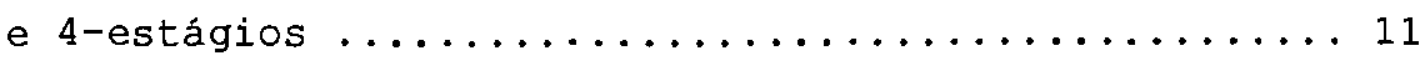

2.10. Padrão de corte guilhotinado 2-estágios não-exato ... 12

2.11. Placa defeituosa e placa a ser tratada .......... 13

2.12. Padrão de corte em uma placa defeituosa .......... 13

2.13. Produção com o máximo de 3 tipos de peças ........ 14

2.14. Padrão de corte com limitação no número de tipo de

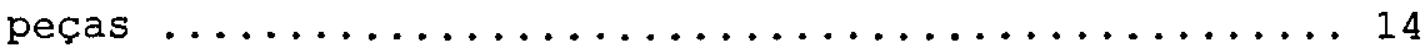

2.15. Corte-cabeça ......................... 15

2.16. Cortes do tipo degrau ................... 16

2.17. Problema bidimensional com peças do tipo L . . . . . . 17

2.18. Padrão de corte com peças do tipo L ........... 17

2.19. Problema de corte de espuma ................ 18

2.20. Corte não-guilhotinado de 1 a ordem $\ldots \ldots \ldots \ldots \ldots \ldots$

2.21. Padrões de corte não-guilhotinado ............. 19

2.22. Sequência de cortes na geração do corte não-guilhotinado da Figura $2.20 \ldots \ldots \ldots \ldots \ldots \ldots$

2.23. Padrão de corte não-guilhotinado de ordem superior .. 19

3.1. Representação de grafo .................... 22

3.2. Representação de hipergrafo ................ 22

3.3. Representação de grafo $E / O U$................. 23

3.4. Padrão de corte ....................... 24

3.5. Grafo E/OU representando o padrão da Figura $3.4 \ldots 25$

3.6. Grafo E/OU representando padrões de corte alternati- 


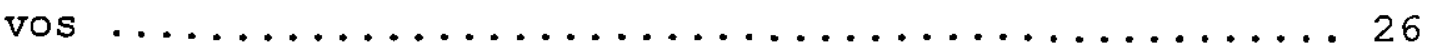

3.7. Padrão de corte k-estagiado $\ldots \ldots \ldots \ldots \ldots \ldots \ldots \ldots 27$

3.8. Corte de um problema restrito $\ldots \ldots \ldots \ldots \ldots \ldots \ldots 28$

3.9. Padrão de corte numa placa defeituosa ........... 29

3.10. Possíveis cortes numa placa com mais de um defeito .. 29

3.11. Corte com limitação no número de tipo de peças ..... 31

3.12. Padrão de corte gerado pelo corte-cabeça ......... 32

3.13. Padrão de corte com peças retangulares e/ou do tipo L 33

3.14. Possíveis cortes no nó retangular ............ 34

3.15. Possiveis cortes no nó do tipo $\mathrm{L} \ldots \ldots \ldots \ldots \ldots \ldots 34$

3.16. Padrão de corte não-guilhotinado e sua representação

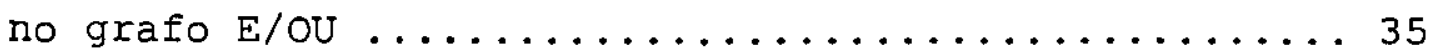

3.17. Padrăo de corte não-guilhotinado gerado através de cortes guilhotinado e do tipo degrau ........... 36

4.1. Combinação linear dos comprimentos $\left(x=\ell_{1}+2 . \ell_{2}\right) \ldots \ldots 38$

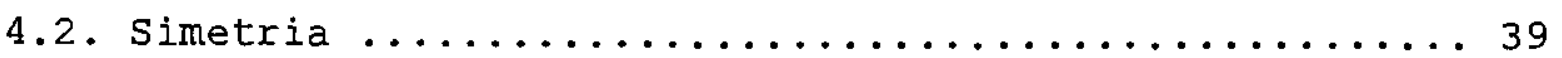

4.3. Exclusão: $x=\ell_{1}+\ell_{2}$ pode ser excluído do conjunto $x$, no

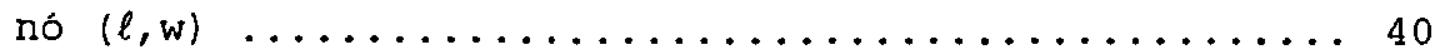

4.4. Caminhos alternativos produzindo padrões equivalentes 42

4.5. Padrão de corte homogêneo ............... 43

4.6. Padrão homogêneo com apenas cortes verticais ......44

4.7. Padrão homogêneo quando $b_{j}^{N}<<\left\lfloor\frac{x}{\ell_{j}}\right\rfloor \mid\left\lfloor\frac{y}{w_{j}}\right\rfloor \ldots \ldots \ldots \ldots \ldots 45$

4.8. Padrão de corte homogêneo composto . . . . . . . . 47

4.9. Soluções homogêneas de uma placa defeituosa . . . . . 47

4.10. Soluções homogêneas com peças do tipo L .........48

4.11. Soluções homogêneas dos retângulos $\ldots \ldots \ldots \ldots \ldots \ldots 49$

4.12. Solução homogênea do nó do tipo L ............ 49

5.1. Eliminação de $\ell_{j}$ na geração do conjunto $x \ldots \ldots \ldots \ldots 61$

6.1. Soluçăo do exemplo de Herz (1972) ..............69 69

6.2. Solução do exemplo de Beasley (1985) com $|x|<50$ e $|\mathrm{Y}|<50$ (Heurística H5) $\ldots \ldots \ldots \ldots \ldots \ldots \ldots \ldots \ldots \ldots \ldots \ldots \ldots \ldots$

6.3. Solução do exemplo WI (Wang, 1983) .............73 
6.4. Solução do exemplo w2 (Wang, 1983) $\ldots \ldots \ldots \ldots \ldots 73$

6.5. Solução do exemplo W3 (Wang, 1983) ............. 74

6.6. Solução do exemplo OF1 (Oliveira e Ferreira, 1990) . 75

6.7. Solução do exemplo OF2 (O1iveira e Ferreira, 1990) . 75

6.8. Solução do problema 2 -estágios $\ldots \ldots \ldots \ldots \ldots \ldots \ldots 78$

6.9. Solução do problema não-estagiado . . . . . . . . . 79

6.10. Solução do problema restrito Z-estágios ......... 79

6.11 . Solução do problema restrito não-estagiado $\ldots \ldots \ldots .80$

6.12. Soluções ótimas dos exemplos restritos $(m=3) \ldots \ldots .82$

6.13. Soluçōes ótimas dos exemplos restritos $(m=5) \ldots \ldots .83$

6.14. Soluções ótimas dos exemplos restritos $(m=10) \ldots \ldots 84$

6.15. Soluções ótimas dos exemplos restritos $(m=30) \ldots .84$

6.16. Exemplo 1 (solução=166) e exemplo 2 (solução=167) $\ldots 87$

6.17. Exemplo 3 (solução=166) e exemplo 4 (solução=158) . . 88

6.18. Exemplo 5 (solução=167) e exemplo 6 (solução=164) .. 88

6.19. Exemplo 7 (solução=159) e exemplo 8 (solução=156) ...88

6.20. Exemplo W2 com limitação de 2 e 3 tipos de peças ... 89

6.21. Exemplo W3 com limitação de 2 e 3 tipos de peças ....990

6.22. Exemplo OF1 com limitação de 3 e 4 tipos de peças ...99

6.23. Exemplo OF2 com limitação de 3 e 4 tipos de peças ... 91

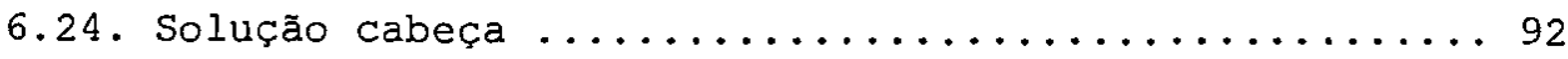

6.25. Solução cabeça com 1 imitação na posição do corte ... 92

6.26 . Solução cabeça $\ldots \ldots \ldots \ldots \ldots \ldots \ldots \ldots \ldots \ldots \ldots \ldots \ldots \ldots \ldots \ldots$

6.27. Solução cabeça com limitação na posição do corte ... 93

6.28. Solução com peças do tipo $L(m=3) \ldots \ldots \ldots \ldots \ldots . \ldots 95$

7.1. Problema de corte com $k$ placas $(k=3) \ldots \ldots \ldots \ldots . \ldots 9$

7.2. Relatório obtido com a execução do problema .......100

7.3. Seis melhores padrões de cortes ................101

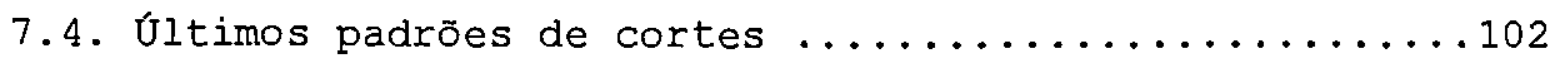

8.1. Combinação de diferentes tipos de peças ..........105

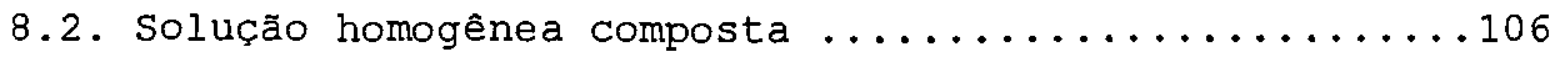

9.3. Padrão de corte tabuleiro .................. 107

A.1. Lista sequencial .......................110

A.2. Lista encadeada ........................110 


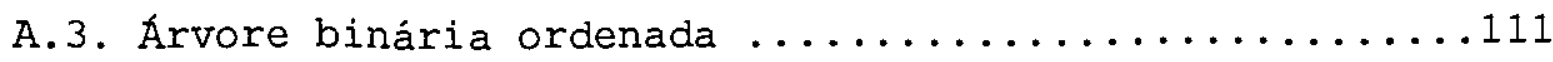

A.4. Dados armazenados em cada nó do grafo em problemas

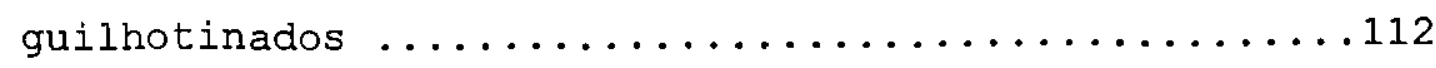

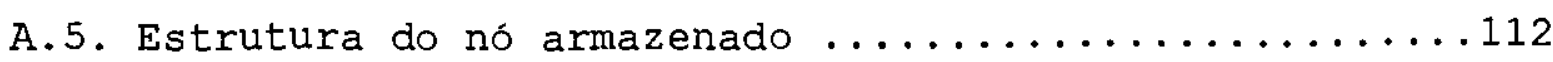

A.6. Dados armazenados em cada nó do grafo em problemas

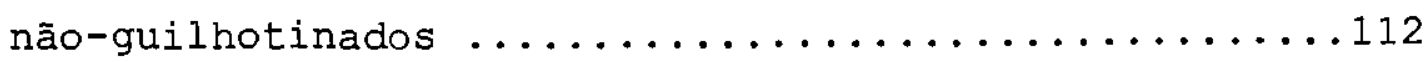

A.7. Estrutura do nó gerado pelo corte não-guilhotinado . .113

A.8. Dados armazenados em cada nó do grafo em problemas guilhotinados (Morabito, 1992) ................113

A.9. Estrutura gerada por Morabito (1992) ............113 
Página

6.1 . Exemplos pequenos $\ldots \ldots \ldots \ldots \ldots \ldots \ldots \ldots \ldots \ldots \ldots \ldots$

6.2. Exemplos grandes ...................... 65

6.3 . Exemplos pequenos ..................... 66

6.4. Exemplos grandes ...................... 66

6.5. Exemplos pequenos .................... 67

6.6. Exemplos grandes ...................... 68

6.7. Resultados obtidos do exemplo de Beasley (1985) ....70

6.8. Exemplos pequenos .................... 71

6.9. Exemplos grandes ...................... 71

6.10. Resultados obtidos dos exemplo de Wang (1983) .....73

6.11. Resultados obtidos dos exemplos de Oliveira e Ferrei-

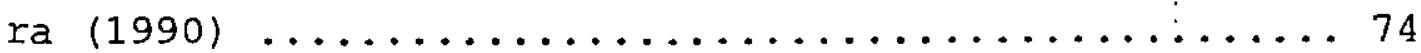

6.12 . Exemplos com demanda pequena ............... 76

6.13. Exemplos com demanda grande ................ 76

6.14. Exemplos pequenos ...................... 77

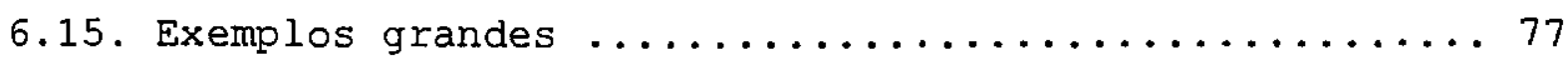

6.16. Exemplos pequenos ..................... 81

6.17. Exemplos grandes ..................... 81

6.18. Exemplo pequeno e grande com $m=3 \ldots \ldots \ldots \ldots \ldots \ldots . \ldots 8$

6.19. Exemplo pequeno e grande $\mathrm{com} m=5 \ldots \ldots \ldots \ldots \ldots \ldots$

6.20. Exemplo pequeno e grande com $\mathrm{m}=10 \ldots \ldots \ldots \ldots \ldots . \ldots$.

6.21. Exemplo pequeno e grande com $\mathrm{m}=30 \ldots \ldots \ldots \ldots \ldots$

6.22. Exemplo de Carnieri et al.(1993) ............. 86

6.23. Defeitos e soluções obtidas por Carnieri et al.(1993) 86

6.24. Defeitos e soluções obtidas por Grafo E/OU .......87

6.25. Exemplos de Wang (1993) com limitação no número de tipo de peças ......................... 89

6.26. Exemplos de Oliveira e Ferreira (1990) com limitação no número de tipo de peças .................. 90

6.27. Exemplos com peças do tipo $\mathrm{E} \ldots \ldots \ldots \ldots \ldots . \ldots . \ldots 94$

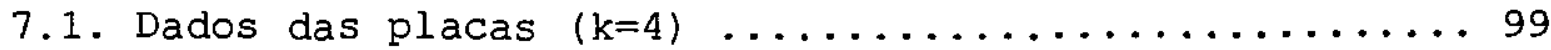

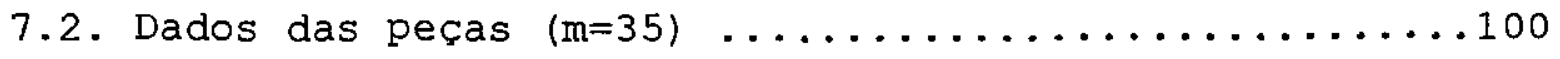


7.3. Resultados obtidos com a heurística H6 ...........103

A.1. Discretização nos exemplos pequenos $\ldots \ldots \ldots \ldots \ldots \ldots 16$

A.2. Discretização nos exemplos grandes . . . . . . . . . 117

A.3. Discretizaçăo nos exemplos pequenos (com simetria) . .119

A.4. Discretização nos exemplos grandes (com simetria) ...120

A.5. Discretização nos exemplos pequenos com $|x|<100$ e

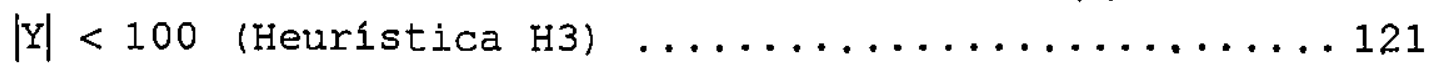

A.6. Discretização nos exemplos grandes com $|\mathrm{X}|<100$ e

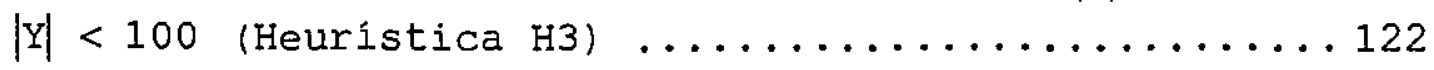




\section{IISTA DE GRÁFICOS}

Página

A.1. Discretização nos exemplos pequenos ...........118

A.2. Discretização ros exemplos grandes .............118

A.3. Discretização nos exemplos pequenos com $|X|<100$ e

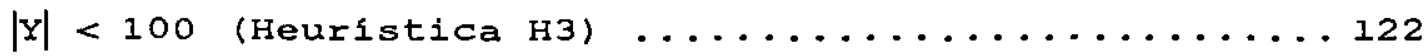

A. 6. Discretização nos exemplos grandes com $|X|<100$ e $|\mathrm{Y}|<100$ (Heuristica H3) .................... 123 


\section{RESUMO}

O problema de corte consiste no corte de objetos maiores para produção de peças menores, de modo que uma certa função objetivo seja otimizada, por exemplo, a perda seja minimizada. O problema de empacotamento pode também ser visto como um problema de corte, onde as peças menores são arranjadas dentro dos objetos.

Uma abordagem em grafo E/OU para a resolução de problemas de corte e empacotamento foi proposta inicialmente por Morabito (1989) para problemas de corte bidimensionais e, mais tarde, estendida para problemas tridimensionais (Morabito, 1992). Nesta abordagem foi utilizada uma técnica de busca híbrida, onde se combinou a busca em profundidade primeiro com limite de profundidade e a busca hill-climbing, utilizando-se heurísticas baseadas nos limitantes superiores e inferiores. Experiências computacionais mostraram a viabilidade de uso na prática desta abordagem.

Mais tarde, Arenales (1993) generalizou esta a abordagem em grafo E/OU mostrando como diferentes problemas de corte poderiam ser resolvidos, independentemente da dimensão, formas dos objetos e itens, baseado em simples hipóteses, sem realizar, entretanto, estudos computacionais.

O presente trabalho tem por objetivo estender a abordagem em grafo E/OU para tratar outros casos não analisados pelos trabalhos anteriores, tais como situações envolvendo diferentes processos de corte, bem como a implementação computacional de métodos baseados na abordagem em grafo E/OU, mostrando, assim, a versatilidade da abordagem para tratar diversas situações práticas de problemas de corte e sua viabilidade computacional.

Palavras-chave: Problemas de corte e empacotamento, busca em grafoE/OU, otimização combinatória, heurísticas. 


\section{ABSTRACT}

The cutting problem consists of cutting larger objects in order to produce smaller pieces, in such a way as to optimizing a given objective function, for example, minimizing the waste. The packing problem can also be seen as a cutting problem, where the position that each smaller piece is arranged inside of the objects can be seen as the place it was cut from.

An AND/OR-graph approach to solve cutting and packing problems was initially proposed by Morabito (1989) for two-dimensional cutting problem and, later, extended to threedimensional problems (Morabito, 1992). That approach uses a hybrid search, which combines depth-first search under depth bound and hill-climbing strategy. Heuristics were devised based on upper and lower bounds. Computational experiences demonstrated its practical feasibility.

The AND/OR-graph approach was later generalized by Arenales (1993) based on simple hypothesis. He showed that different cutting problems could be solved using the AND/ORgraph approach, independently of the dimension and shapes.

The main objective of this thesis is the practical extension of the AND/OR-graph approach to handle other cases not considered by previous works. It was considered different cutting processes, as well as the analysis of computational implementation, showing how can it be adapted to many classes of practical cutting and packing problems.

Keywords: Cutting and packing problems, AND/OR-graph search, combinatorial optimization, heuristics. 


\section{Introdução}

O Problema de Corte, genericamente, consiste em cortar unidades maiores (objetos) em unidades menores (itens), otimizando uma determinada função (por exemplo, minimização da perda). Este tipo de problema aparece em diversos processos industriais de corte, tais como no corte de bobinas de papel e aluminio, barras de aço, chapas metálicas e de madeira, placas de circuito impresso, caixas de papelão, rolos de tecidos, entre outros.

Análogo ao Problema de Corte, o Problema de Empacotamento consiste em empacotar unidades menores em unidades maiores, otimizando determinada função (por exemplo, minimização do espaço ociosol e satisfazendo um conjunto de restrições. Exemplos do Problema de Empacotamento ocorrem quando se carregam produtos embalados sobre paletēs, ou dentro de contêineres e caminhões.

Estas duas classes de problemas de otimização estão intimamente relacionadas e são tratadas na literatura como Problemas de Corte e Empacotamento (Dyckhoff, 1990).

o número de aplicações para os Problemas de Corte e Empacotamento é muito grande. Na literatura existem diversas abordagens para resolvê-los, conforme mostram os exames especiais de periódicos em Brown (1971), Golden (1976), Hin- 
xman (1980), Dyckhoff e Waescher (1990), Lirov (1992), Dowsland e Dowsland (1992), Sweeney e Paternoster (1992), Dyckhoff e Finke (1992), Martello (1994a, 1994b), Bischoff e Waescher (1995), Mukhacheva (1997), Dyckhoff et al. (1997), Arenales et al. (1999) e Special Interest Group on Cutting and Packing (SICUP, 1999).

Uma abordagem de solução baseada numa busca em grafo E/OU para problemas que envolvam objetos de mesma forma, barras (caso unidimensional), retângulos (caso bidimensional) e caixas (caso tridimensional) foi apresentada por Morabito (1992). Nesta abordagem foi utilizada uma técnica de busca híbrida (semi-informada), onde se combinaram a busca em profundidade com limite e a busca hill-climbing. Utilizaram-se, também, heurísticas baseadas nos limitantes superiores e inferiores.

Arenales (1993) generalizou a abordagem, sem, entretanto, realizar estudos de casos e apresentar resultados computacionais.

O presente trabalho tem por objetivo estender a abordagem em grafo E/OU para tratar outros casos não analisados por trabalhos anteriores, envolvendo diferentes processos de corte, tais como corte com placa defeituosa, corte-cabeça, corte com limitação no número de tipo de itens, corte com peças não retangulares (por exemplo, tipo L), etc. Tem também por objetivo, a implementação computacional usando a abordagem em grafo E/OU para tratar diversas situações práticas dos problemas de corte.

- trabalho apresenta, ainda, limitantes inferiores diferentes dos propostos por Morabito e Arenales (1996), novas heuristicas para tornar a abordagem mais eficiente, e uma importante conjectura para o problema de corte restrito. 


\section{Organização da Tese}

Esta tese está dividida em 8 capitulos. No segundo capítulo, é feita uma classificação dos problemas de corte, assim como um estudo do problema de corte bidimensional e suas particularidades, já que este é o objeto principal do presente estudo.

- capítulo 3 trata da representação em grafo E/OU do problema de corte para diferentes padrões. Neste é feito um estudo sobre a abordagem em grafo E/OU aplicada a cada classe de problema.

No capítulo 4 é visto um método de enumeração implícita para a busca no grafo E/OU, onde são utilizados limitantes. A estratégia de busca apresentada combina busca em profundidade com busca informada (hill-climbing). Heurísticas são incluídas no capítulo 5 para viabilizar computacionalmente a resolução do problema.

No sexto capitulo são apresentados e analisados os resultados obtidos com a implementação computacional nos diferentes problemas de corte bidimensional.

No capítulo 7 é feito um estudo de caso do problema de corte bidimensional restrito em uma Indústria de Esquadrias Metálicas, onde determina-se uma sequência de padrões de corte para atender uma demanda com uma perda mínima de material.

As conclusões e perspectivas futuras desta tese são discutidas no oitavo capítulo. 


\section{Definição de Problemas de Corte}

Neste capítulo é apresentada uma classificação dos problemas de corte, segundo Dyckhoff (1990), e um estudo mais detalhado do problema de corte bidimensional.

\subsection{Classificação dos Problemas}

O Problema de Corte consiste, basicamente, em cortar unidades maiores em unidades menores, otimizando um determinado objetivo. Entretanto, os problemas podem aparecer numa diversidade muito grande de casos.

Diversas classificações de problemas de corte foram discutidas em exames, entre elas, Golden (1976), Hinxman (1980), Dyckhoff et al. (1985) . Em particular, Dyckhoff (1990) propôs um sistema de classificação a partir das quatro principais caracteristicas dos problemas:

- a dimensão do problema
(1) unidimensional
(2) bidimensional
(3) tridimensional
(n) n-dimensional, para $n>3$ 
- a forma de alocação das unidades

(V) seleção de unidades grandes

(um conjunto de unidades grandes deve ser escolhido para incluir todas as unidades pequenas)

(B) seleção de unidades pequenas

(um conjunto de unidades pequenas deve ser escolhido para ocupar todas as unidades grandes)

- sortimento de unidades grandes

(0) uma unidade

(uma única unidade grande)

(I) unidades de tamanhos iguais

(todas as unidades grandes são iguais)

(D) unidades de tamanhos diferentes

(as unidades grandes têm tamanhos diferentes)

- sortimento de unidades pequenas

(F) poucas unidades de tamanhos diferentes

(poucas unidades pequenas, geralmente de tamanhos diferentes)

(M) muitas unidades de muitos tamanhos diferentes (muitas unidades pequenas e a maioria delas em tamanhos diferentes)

(R) muitas unidades de poucos tamanhos diferentes (muitas unidades pequenas com poucos tamanhos diferentes)

(C) unidades de tamanhos iguais

(todas as unidades pequenas são iguais)

Estas quatro características permitem obter 96 tipos diferentes para problemas de corte e empacotamento e a tipologia é definida pela quadra $\alpha / \beta / \gamma / \sigma$. Cada um dos símbolos corresponde a uma das caracteristicas citadas.

Um problema de corte de estoque definido pela 
quadra 2/V/I/R significa que o problema é bidimensional (2), todas as unidades pequenas devem ser alocadas numa seleção de unidades grandes (V), todas de tamanhos iguais (I) e com muitas unidades pequenas de relativamente poucos tamanhos diferentes $(R)$.

Considerando somente estas quatro caracteristicas, os problemas apresentam ainda muitas diferenças quanto às suas restrições, por exemplo, problemas restritos e irrestritos, guilhotinado e não-guilhotinado etc.

A seguir, são definidos problemas de corte, classificando-os pelas suas dimensões.

- problema de corte unidimensional apresenta apenas uma das dimensões relevante para o processo de corte. Considere um objeto, por exemplo, uma barra como na Figura 2.1, que deve ser cortado ao longo de seu comprimento em itens de comprimento especificado. Cada item tem um valor associado, chamado de valor de utilidade. Então, o problema consiste em maximizar o valor de utilidade total.

o modo como os itens estão arranjados ao longo do objeto é chamado de padrão de corte. Para o problema da Figura 2.1, um possível padrão de corte é ilustrado na Figura 2.2 .

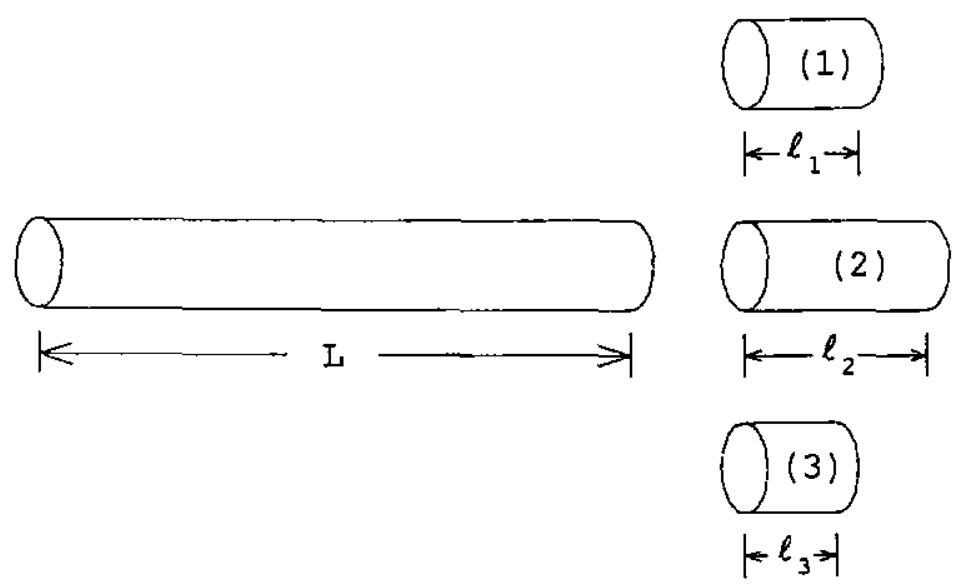

Figura 2.1 - Problema de corte unidimensional 


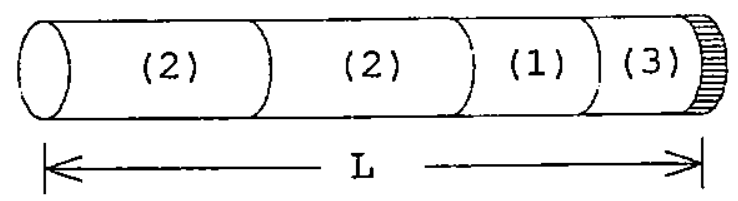

Figura 2.2 - Padrão de corte unidimensional

No problema de corte bidimensional são relevantes duas dimensões, sendo a geometria neste problema determinante, pois a forma e as medidas do objeto e dos itens determinam os padrões de corte.

As Figuras 2.3 e 2.4 representam, respectivamente, um problema de corte bidimensional com objeto e itens retangulares e um padrão de corte do problema.

Na próxima seção o problema de corte bidimensional é discutido com mais detalhes, pois este é o objeto de estudo do trabalho.
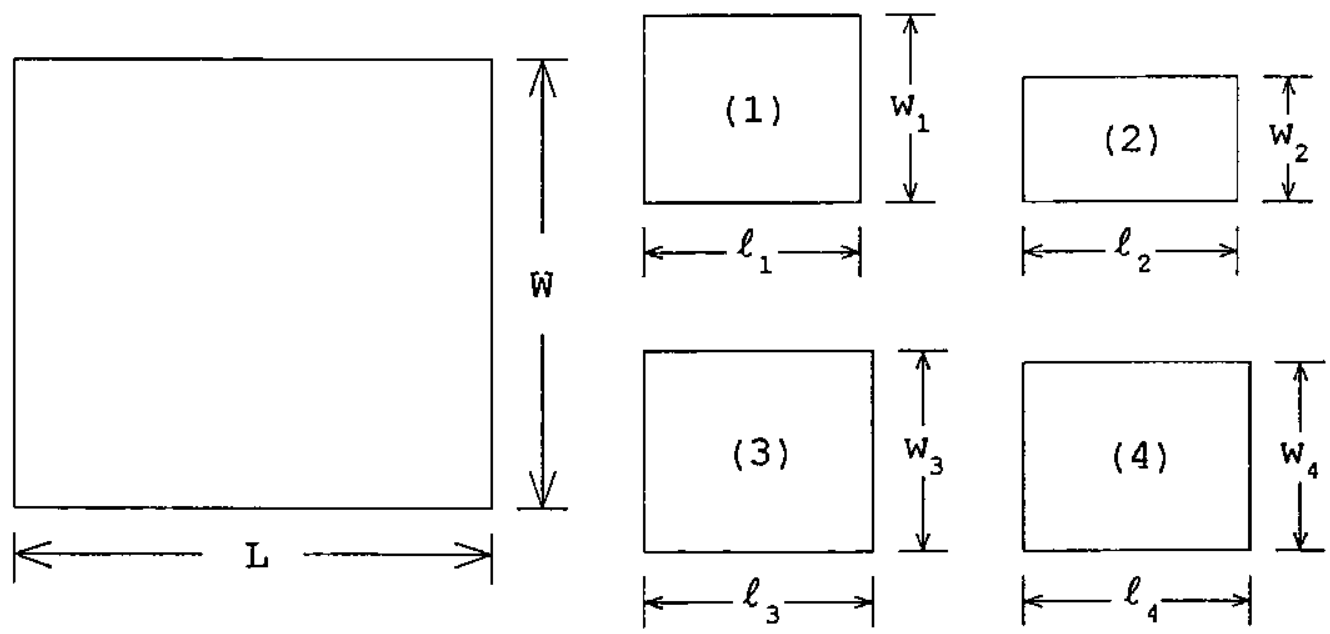

Figura 2.3 - Problema de corte bidimensional 


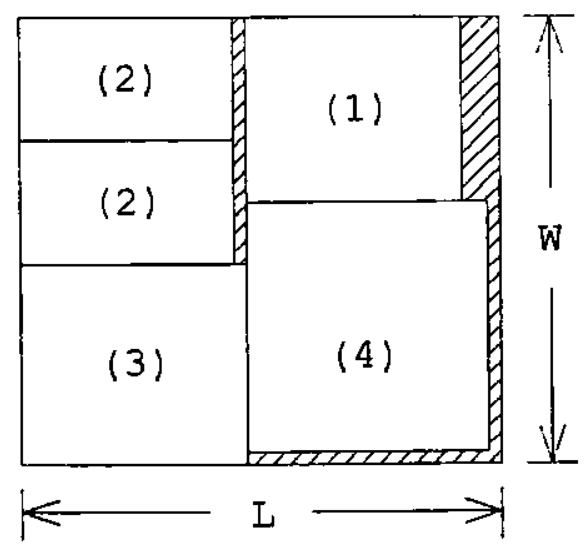

Figura 2.4 - Padrăo de corte bidimensional

No problema de corte tridimensional, três dimensões são relevantes; este problema surge, principalmente, na alocação de caixas dentro de caixas maiores. o problema de corte tridimensional e um possível padrão de corte são apresentados nas Figuras 2.5 e 2.6 , respectivamente.
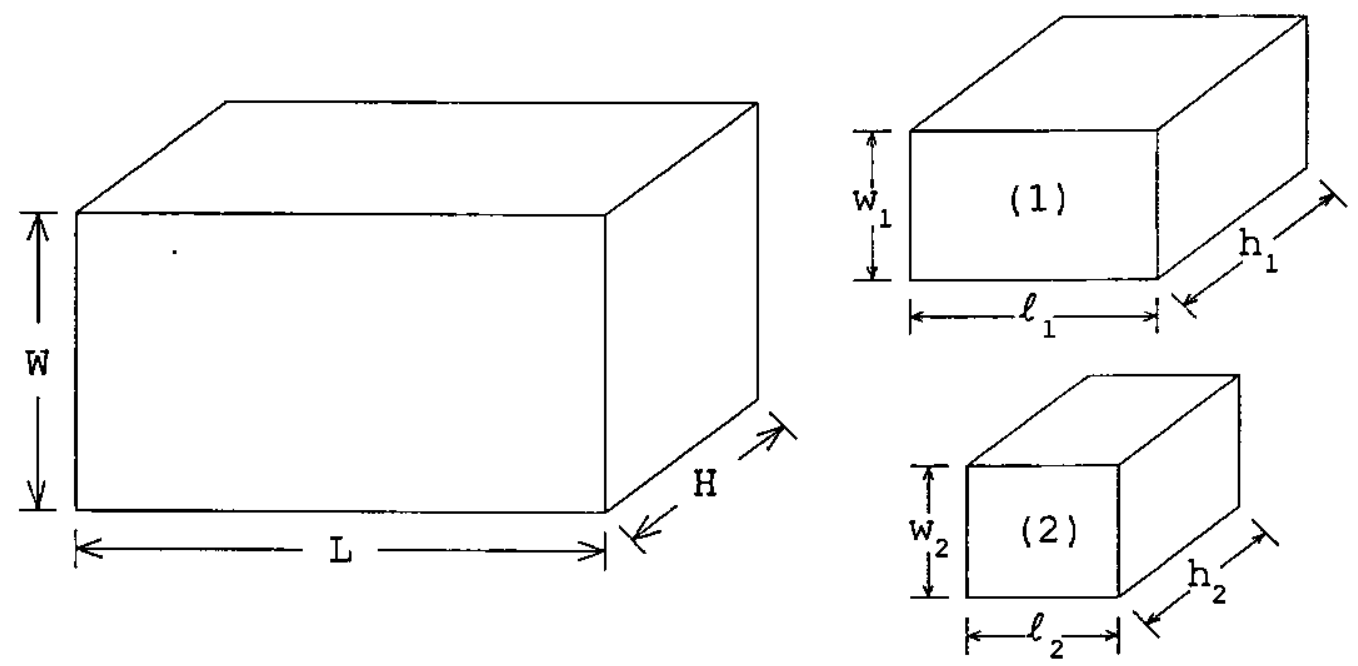

Figura 2.5 - Problema de corte tridimensional 


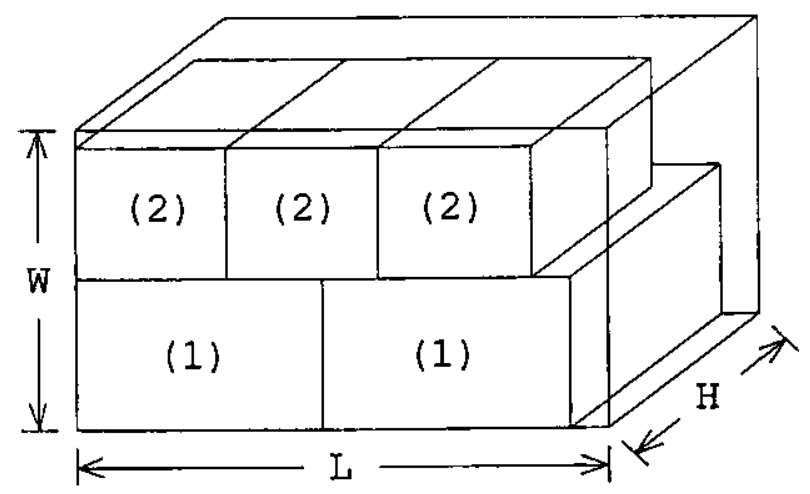

Figura 2.6 - Padrão de corte tridimensional

\subsection{O Problema de Corte Bidimensional}

Esta classe de problemas de corte tem sido bastante estudada desde o trabalho pioneiro de Gilmore e Gomory (1965), onde um método de programação dinâmica foi proposto. Herz (1972), Christofides e Whitlock (1977), Wang (1983) e Beasley (1985) representam marcos importantes para esta classe de problemas. Mais tarde, Morabito et.al. (1992) e Morabito e Arenales (1996) estenderam $\circ$ trabalho de Herz (1972), propondo métodos de enumeração implícita utilizando Iimitantes, como métodos de busca num grafo E/OU, constituindo a ferramenta principal para este trabalho.

Considere uma placa retangular (objeto) de dimensões $(L, W)$, onde $L$ é o comprimento e $W$ é a largura, e um conjunto de $m$ peças retangulares (itens) de dimensão $\left(\ell_{1}, w_{1}\right)$, onde $\ell_{1}$ é comprimento e $w_{1}$ a largura da peça $i$, e valor de utilidade $v_{i}, i=1, \ldots, m$. Um problema de corte bidimensional consiste em cortar a placa retangular em peças menores, de forma a otimizar um determinado objetivo, ou seja, 
$\operatorname{maximizar} \sum_{i=1}^{m} v_{1} \cdot a_{1}$

sujeito a: $\left(a_{1}, a_{2}, \ldots, a_{m}\right)$ corresponde a um padrão de corte $a_{i} \geq 0$, inteiro, $i=1, \ldots, m$,

onde $a_{i}$ corresponde ao número de peças $i$ alocadas na placa $(L, W)$. Obviamente, há regras para a definição de padrões de corte como será visto adiante.

o problema de corte é chamado irrestrito quando não há limitação no número de peças presentes no padrão. Caso contrário, o problema de corte é chamado restrito, ou seja,

$\operatorname{maximizar} \sum_{i=1}^{\mathrm{m}} \mathrm{v}_{\mathrm{i}} \cdot \mathrm{a}_{\mathrm{i}}$

sujeito a: $\left(a_{1}, a_{2}, \ldots, a_{m}\right)$ corresponde a um padrão de corte $0 \leq a_{1} \leq b_{1}$, inteiro, $i=1, \ldots, m$,

onde $b_{i}$ é a quantidade máxima de peça do tipo i no padrão, para $i=1, \ldots, m$. Embora apenas um pequeno detalhe na formulação seja alterado, a limitação no número de peças no padrão introduz grandes dificuldades de resolução.

- corte é chamado guilhotinado quando, aplicado em um retângulo, produz dois novos retângulos, ou seja, o retângulo é cortado somente de modo horizontal ou vertical, conforme a Figura 2.7. Um padrão de corte é do tipo guilhotinado se for obtido por cortes guilhotinados sucessivos (Figura 2.8$)$. 

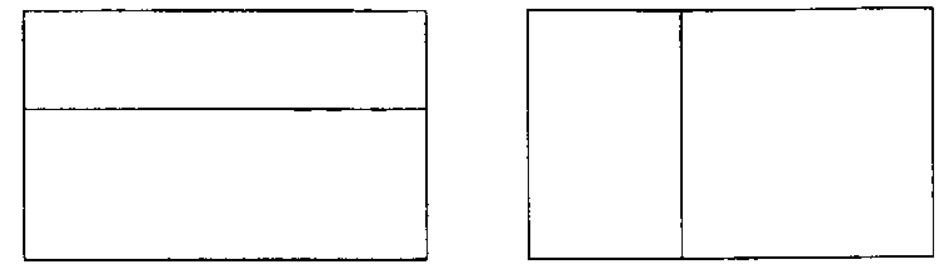

Figura 2.7 - Corte guilhotinado horizontal e vertical
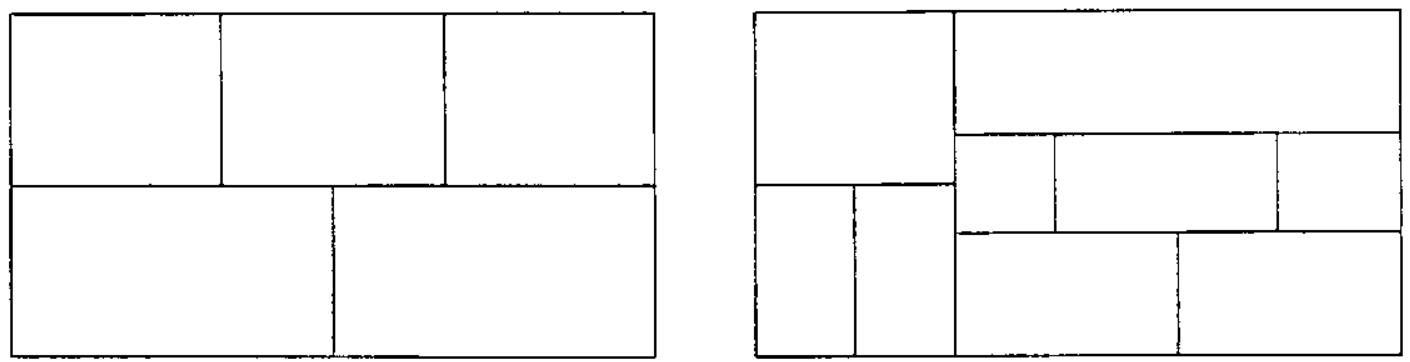

Figura 2.8 - Padrões de corte guilhotinado

Um padrão de corte guilhotinado pode ser do tipo estagiado (k-estágios) ou não-estagiado. No primeiro estágio, todos os cortes são feitos de forma paralela a um dos lados da placa, por exemplo, cortes guilhotinados verticais; no segundo estágio, os cortes são ortogonais aos do estágio anterior e assim por diante. Se há um limite k para o número máximo de estágios, o problema é classificado como um problema de corte guilhotinado k-estagiado; caso contrário, o problema é não-estagiado (Figura 2.9) .
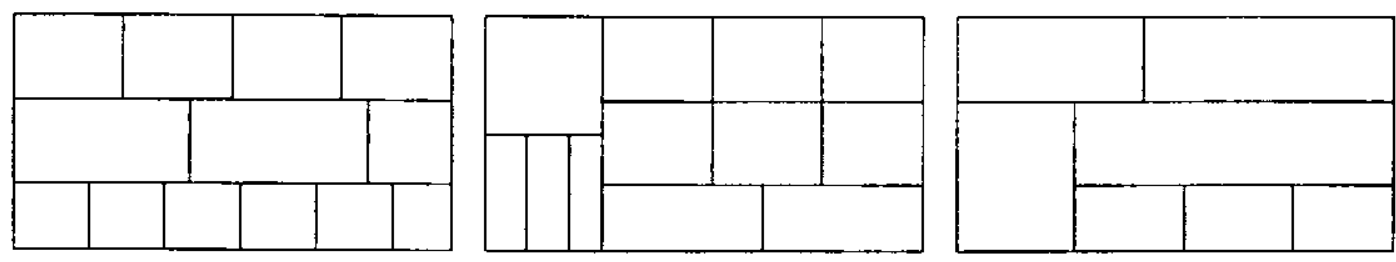

Figura 2.9 - Padrões de corte guilhotinado 2-estágios, 3-estágios e 4-estágios

Um problema de corte k-estagiado é não-exato quando permite um estágio posterior somente para fazer a úl- 
tima apara na direção perpendicular à direção dos cortes do estágio anterior. A Figura 2.10 apresenta um exemplo de um problema 2-estágios não-exato.

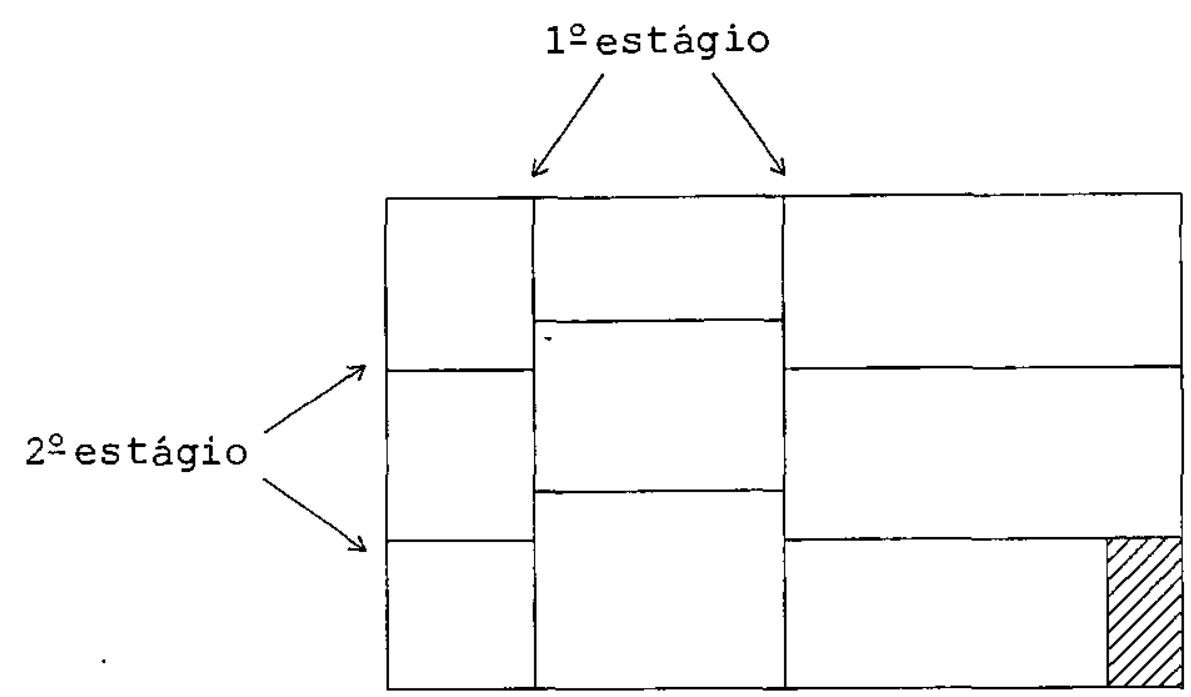

Figura 2.10 - Padrão de corte guilhotinado 2-estágios não-exato

Convém observar que o problema de corte estagiado foi definido e estudado no artigo pioneiro de Gilmore e Gomory (1965). Ainda hoje, o método por eles proposto para a resolução do problema em 2-estágios (o problema é decomposto em vários problemas unidimensionais) é o mais utilizado. Entretanto, quando a limitação no número de peças é incluída, o modelo matemático torna-se de otimização inteira não-linear (veja anexo 2) e seu método não é trivialmente estendido. Outros autores tratam o problema de corte guilhotinado estagiado restrito (Christofides e Whitlock, 1977; Christofides e Hadjiconstantinou, 1995). Em particular, Morabito e Arenales (1996) utilizaram a abordagem em grafo E/OU para estudar tal problema, porém, sem apresentar um estudo computacional quando ambas as restrições são impostas. No capítulo 6 é feito um estudo da abordagem em grafo E/OU, comparando com a relaxação lagrangiana apresentada em Gramani (1997). 
Em alguns problemas práticos, por limitação dos equipamentos de corte ou propriedades do material, é necessário trabalhar com padrões que tenham restrições especiais, entre eles, padrão com placa defaituosa, padrão com limitação no número de tipo de itens, padrão com corte-cabeça e padrão com peças do tipo L.

\subsubsection{Padrão de corte com placa defeituosa}

A placa $(L, W)$ considerada até o momento é uma placa perfeita, ou seja, é possível alocar peças $\left(\ell_{1}, w_{1}\right)$, $i=1, \ldots, m$, em qualquer posição da placa.

Há casos em que isto nem sempre ocorre, por exemplo, uma chapa de madeira com pequenos defeitos de fabricação (placa defeituosa). Neste trabalho, são tratadas as áreas defeituosas de maneira retangular (Figura 2.11). A Figura 2.12 apresenta um padrão de corte em uma placa defeituosa.
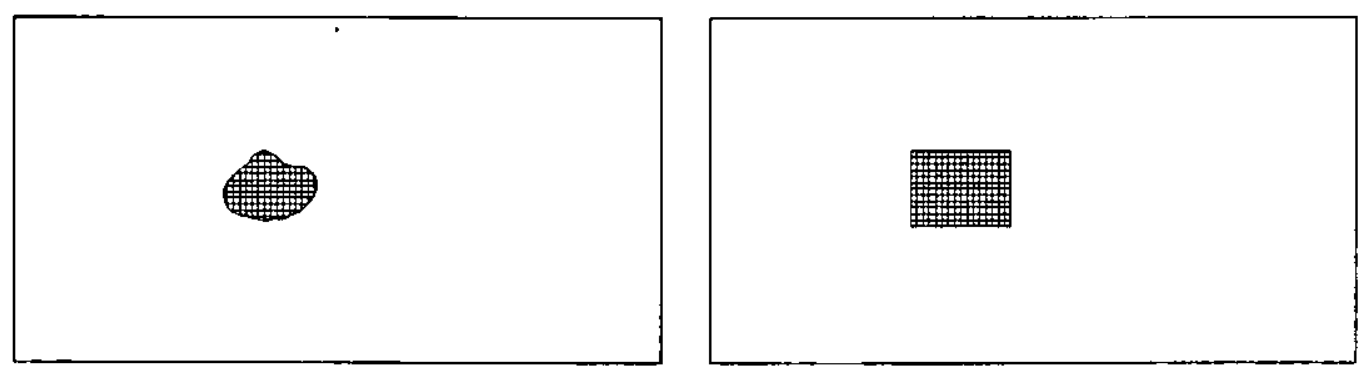

Figura 2.11 - Placa defeituosa e placa a ser tratada

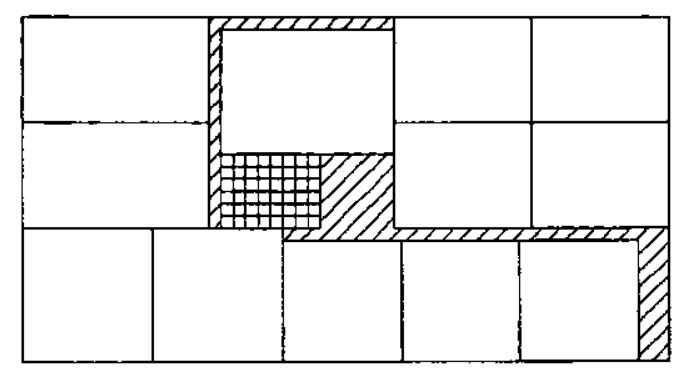

Figura 2.12 - Padrão de corte em uma placa defeituosa 
Problemas de cortes com placas defeituosas foram pouco estudados na literatura (Carnieri et al., 1993; Hahn, 1968).

2.2.2. Padrão de corte com limitação no número de tipo de peças

Considere um problema onde, por motivo de restrição do equipamento, é necessário limitar o número máximo de tipos de peças no padrão. No exemplo da Figura 2.13, é possivel produzir no máximo 3 tipos de peças por padrão de corte, pois o equipamento de corte (serra automática) possui apenas 3 saídas para os itens cortados. Um padrão de corte é representado na Figura 2.14 .

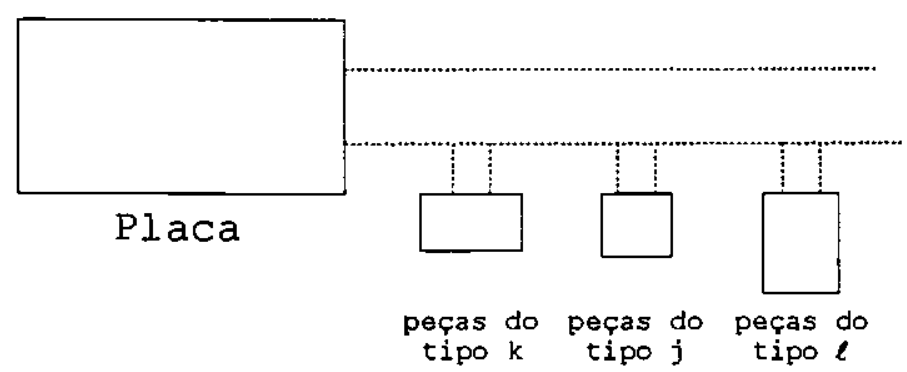

Figura 2.13 - Produção com o máximo de 3 tipos de peças

\begin{tabular}{|c|c|c|c|}
\hline$(k)$ & $(j)$ & $(j)$ & $(j)$ \\
\cline { 1 - 1 }$(k)$ & $(\ell)$ & $(\ell)$ & $(j)$ \\
\cline { 1 - 1 } & & \\
\hline
\end{tabular}

Figura 2.14-Padrão de corte com limitação no número tipo de peças

Neste caso, é necessário incluir no modelo 
inicial variáveis binárias relacionadas com cada tipo de peça e novas restrições

$$
\left\{\begin{array}{l}
\sum_{i=1}^{m} y_{i} \leq B \\
y_{i} \in\{0,1\}, i=1, \ldots, m
\end{array}\right.
$$

onde $B$ é o número máximo permitido de tipos de peças no padrão; e $y_{1}=1$, se o item $i$ for produzido; $y_{1}=0$, caso contrário.

Embora este problema surja na prática com serras automáticas de grande porte (por exemplo, certas serras encontradas nas fábricas de chapas duras), é muito pouco estudado na literatura. Em particular, Morabito e Garcia (1998) estudaram este problema (com algumas restrições adicionais, devido à característica do equipamentol e propuseram um método de programação dinâmica. Neste trabalho, uma abordagem por grafo E/OU é proposta.

\subsubsection{Padrão com corte-cabeça}

Considere um equipamento para guilhotinar placas com limitação mínima e máxima na posição do corte (Figura 2.15). Este corte é chamado de corte-cabeça, ou seja, após o corte a sub-placa à esquerda só pode gerar itens finais (problema unidimensional), enquanto que a outra sub-placa pode ser novamente posicionada para um novo corte. É permitido dar um giro de $90^{\circ}$ na placa antes do novo corte. 


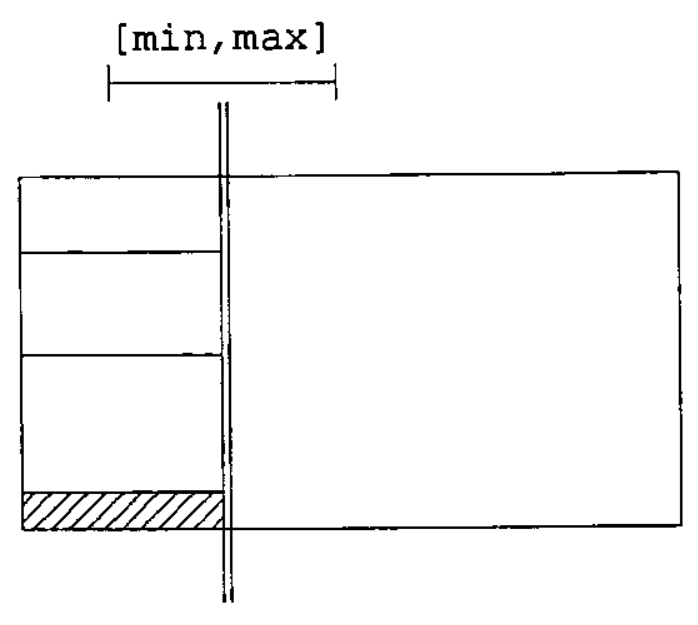

Figura 2.15 - Corte-cabeça

Não foi encontrado registro na literatura de métodos de solução para esta classe de problemas, embora possa ser encontrado na prática (serra encontrada numa fábrica de chapas duras). Neste trabalho, mostra-se como a abordagem em grafo E/OU pode ser facilmente estendida para gerar padrões com corte-cabeça.

\subsubsection{Padrão de corte com peças do tipo L}

Até o momento, todas as placas e peças citadas nos problemas foram retangulares e os cortes guilhotinados. Considere agora peças retangulares e/ou do tipo $L$, de modo que cortes guilhotinados não produzem todos os itens. Os cortes neste padrão são, então, guilhotinados e/ou do tipo degrau. Cortes do tipo degrau são ilustrados pela Figura 2.16.
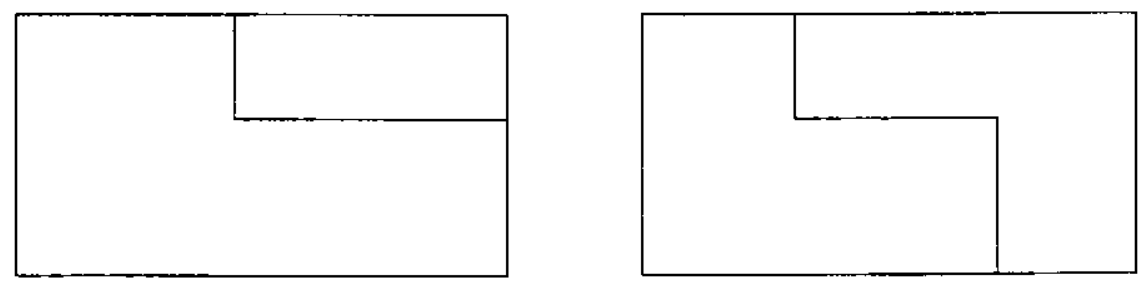

Figura 2.16 - Cortes do tipo degrau 
Considere, conforme a Figura 2.17, uma placa retangular $(\mathrm{L}, \mathrm{W})$, onde $\mathrm{L}$ é a largura $e \mathrm{~W}$ o comprimento da placa, e um conjunto de $m$ peças $\left(\ell_{1}^{1}, w_{1}^{1}, \ell_{1}^{2}, w_{1}^{2}\right), i=1, \ldots, m$, onde $\ell_{1}^{1}$ e $\ell_{i}^{2}$ são, respectivamente, o comprimento inferior e superior e $w_{1}^{1}$ e $w_{1}^{2}$ são, respectivamente, a largura à esquerda e à direita da peça $i$ (se $\ell_{1}^{1}=\ell_{i}^{2}$ ou $w_{1}^{1}=w_{i}^{2}$, a peça $i$ é retangular), com valor de utilidade $v_{1}, i=1, \ldots, m$. O problema consiste em alocar estas peças maximizando o valor de utilidade total. A Figura 2.18 representa um padrão de corte com peças do tipo L.
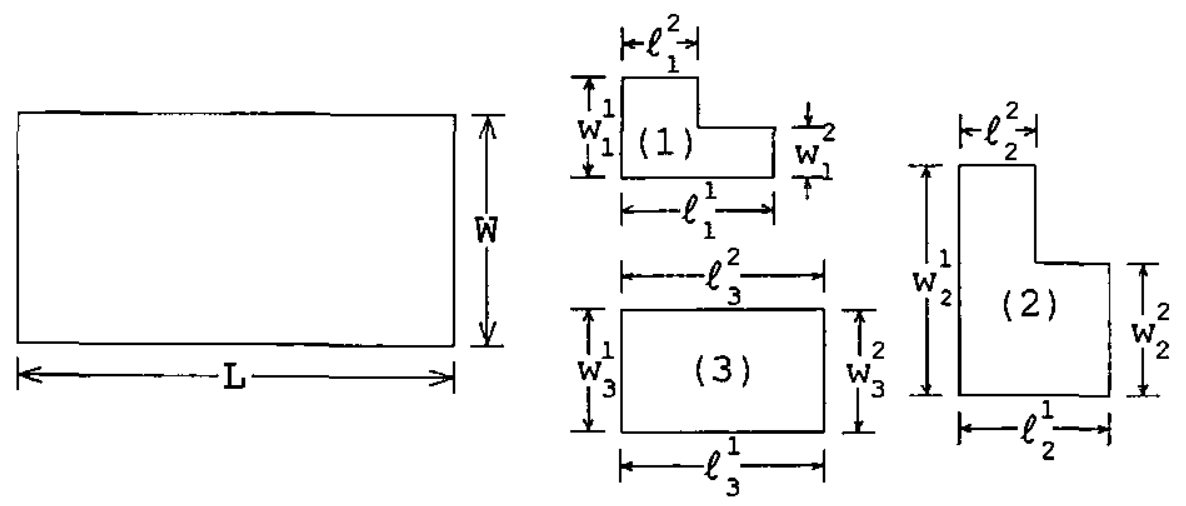

Figura 2.17 - Problema bidimensional com peças do tipo L

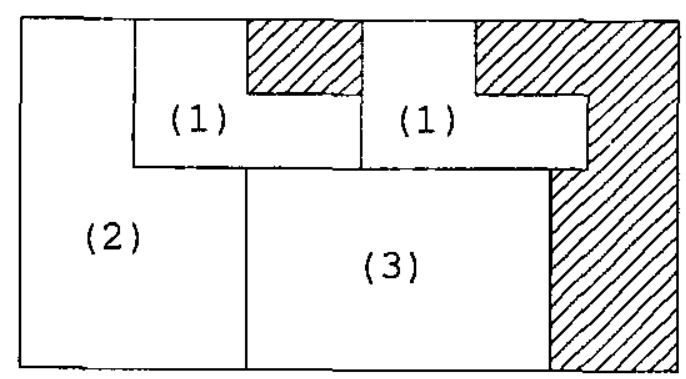

Eigura 2.18 - Padrão de corte com peças do tipo L

Embora haja uma literatura crescente para a determinação de padrões de corte com peças irregulares, um tratamento especial para peças do tipo L e retângulos não foi 
encontrado na literatura. Este tipo de padrão foi detectado na prática de corte de espuma para produção de colchões, travesseiros, etc. (Embora o problema de corte de espuma seja tridimensional, o corte em $L$ ocorre apenas na vertical, veja Figura 2.19). No próximo capítulo, a abordagem em grafo E/OU é estendida para a resolução desta classe de problemas.

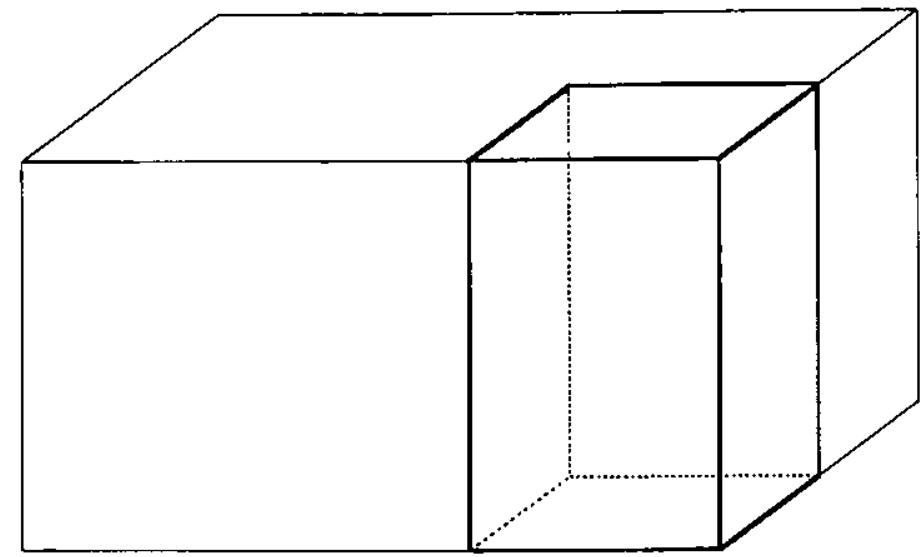

Figura 2.19 - Problema de corte de espuma

\subsubsection{Padrão com corte não-guilhotinado}

Um corte é do tipo não-guilhotinado se ele produz novos retângulos arranjados de forma que não formam um padrão de corte guilhotinado. Arenales e Morabito (1995) definiram o corte da Figura 2.20 como um corte não-guilhotinado de $1-$ ordem. Um padrão de corte não-guilhotinado é de 1 - ordem se for obtido por cortes sucessivos guilhotinados e/ou de 1ordem não-guilhotinados.

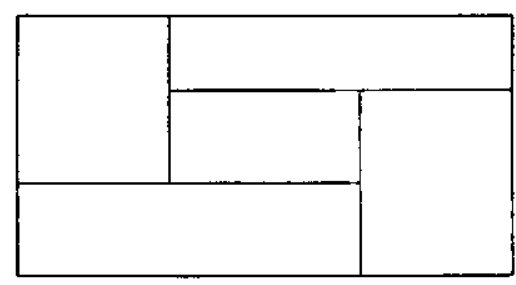

Figura 2.20 - Corte não-guilhotinado de $1^{\text {å }}$ ordem 
A Figura 2.21 apresenta padrões de corte nãoguilhotinado de $1^{\text {a }}$ ordem.
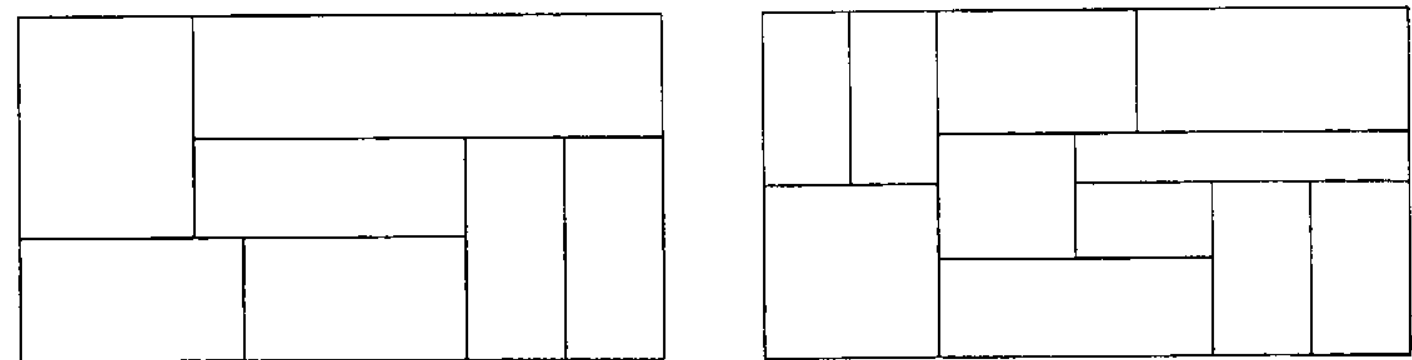

Figura 2.21 - Padrões de corte não-guilhotinado

o padrão de corte não-guilhotinado de 1- ordem (Figura 2.20) pode ser gerado combinando cortes guilhotinado e/ou do tipo degrau (Figura 2.22).
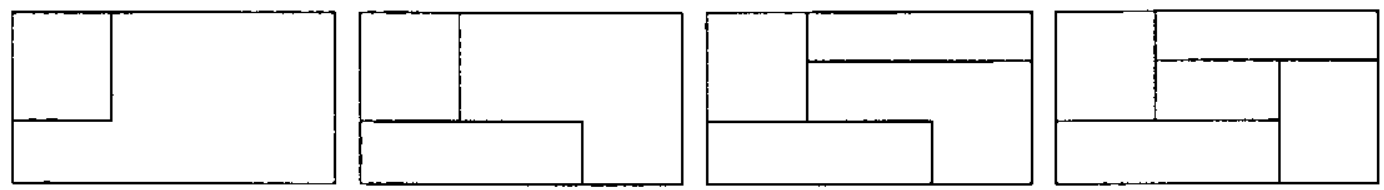

Figura 2.22 - Sequiência de cortes na geração do corte não-guilhotinado da Figura 2.20

Há padrões de corte não-guilhotinados de ordens superiores, conforme mostra a Figura 2.23. Estes padrões de corte não serão considerados neste trabalho.

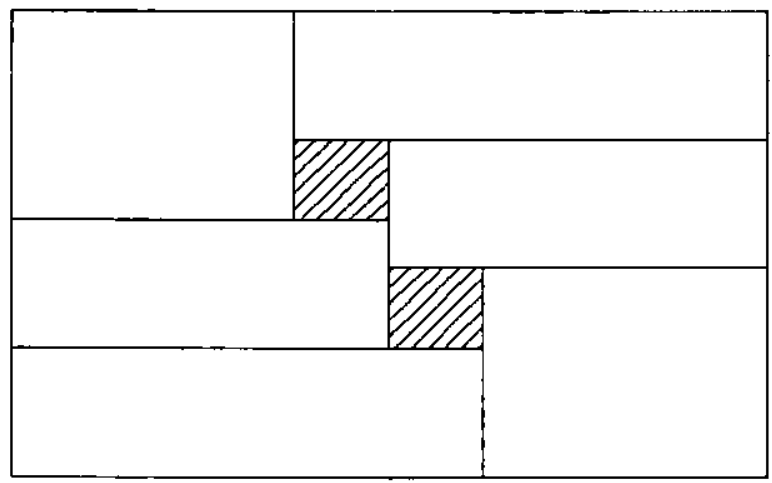

Figura 2.23 - Padrão de corte não-guilhotinado de ordem superior 
O problema de corte não-guilhotinado tem uma importante aplicação no carregamento de paletes e conteinêres, conforme discutido em Morabito e Arenales (1994), Morabito e Morales (1998), Morabito et al. (2000).

No próximo capitulo, é apresentada a resolução do problema de corte bidimensional usando a abordagem em grafo E/OU para estes diversos tipos de padroes de corte. 


\section{A abordagem em Grafo E/OU}

A abordagem em Grafo E/OU para a resolução de Problemas de Corte foi inicialmente proposta por Morabito (1989), para problemas de corte guilhotinado bidimensional irrestrito e não-estagiado. Morabito (1992) estendeu esta abordagem para problemas de corte guilhotinado irrestrito e restrito, considerando as dimensões unidimensional, bidimensional e tridimensional. Ainda restrito a problemas guilhotinados, Morabito e Arenales (1996) apresentaram a abordagem em grafo E/OU para a resolução de problemas estagiados e restritos.

Esta abordagem também foi proposta para problemas de corte não-guilhotinado em Salomão (1993) e, mais tarde, implementada em Arenales e Morabito (1995). Arenales (1993) mostrou como esta abordagem poderia ser generalizada para problemas de diferentes dimensões e formas geométricas, porém sem se preocupar com questões de implementações. Este trabalho constitui uma extensão do trabalho de Arenales (1993), pois além de discutir questões de implementação, incluindo-se peças irregulares do tipo $L$, estende a generalidade da abordagem em grafo E/OU para diferentes processos de cortagem encontrados na prática, apresentados no capítulo 2 . 


\subsection{Representação em Grafo E/OU}

Um grafo $G=(V, \varepsilon)$ consiste de um conjunto finito não-vazio de nós (ou vértices) $V=\{1,2, \ldots, r\}$ e um conjunto de arcos (ou aresitas) $\varepsilon=\left\{e_{1}, e_{2}, \ldots, e_{s}\right\}$, cujos elementos são subconjuntos de $V$ de tamanho 2 , isto é, $e_{u}=(i, j)$, onde $i, j \in V$. observe que um arco define a relação entre dois nós (Figura $3.1)$.

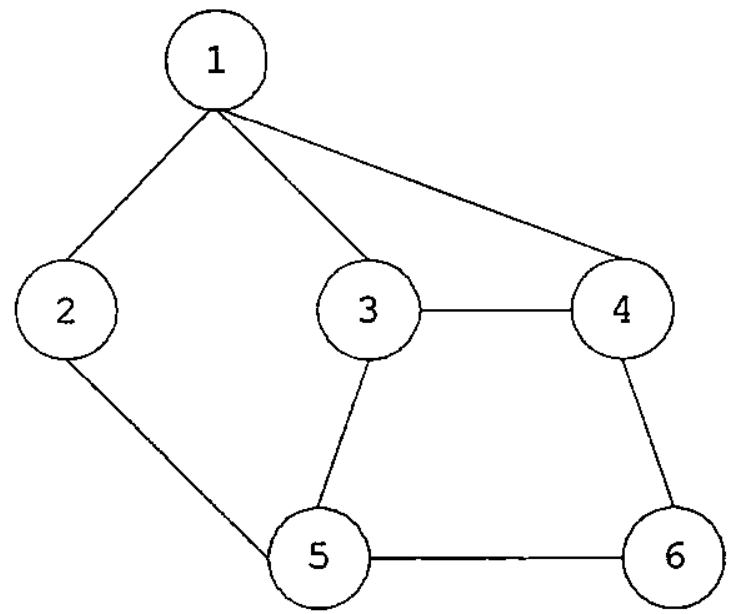

Figura 3.1 - Representação de grafo

Uma maneira de generalizar um grafo é permitir arcos no conjunto $\varepsilon$ de diferentes tamanhos, definindo uma relação entre um subconjunto de nós, por exemplo, um arco $e_{u}=(i, j, k), i, j, k \in V$. Deste modo, o grafo é chamado de hipergrafo. A Figura 3.2 representa um hipergrafo, onde $\mathrm{V}=\{1,2,3,4\}$ e $\varepsilon=\{(1,2),(2,3,4)\}$.

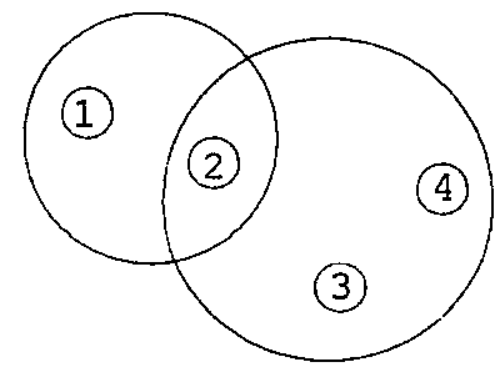

Figura 3.2 - Representação de hipergrafo 
Outra maneira de generalizar um grafo é definir arcos como pares $e_{u}=\left(i, V_{u}\right)$, onde $i \in V$ e $V_{u} \subset V$, representando a relação entre um nó e um subconjunto de nós, por exemplo, um arco $e_{u}=(i,\{j, k\})$, onde $i \in V \in\{j, k\} \subset V$. Se $v_{u}$ tem cardinalidade maior que 1 , então $e_{u}$ é chamado um arco $E$. Os vértices de $V_{u}$ são sucessores de i. A Figura 3.3, com $V=\{1,2,3,4,5\}$ e $\varepsilon=\{\{(1,\{2,3\}),(3,\{4,5\})\}$, ilustra este tipo de grafo, conhecido por grafo E/OU (um grafo E/OU é um hipergrafo particular).

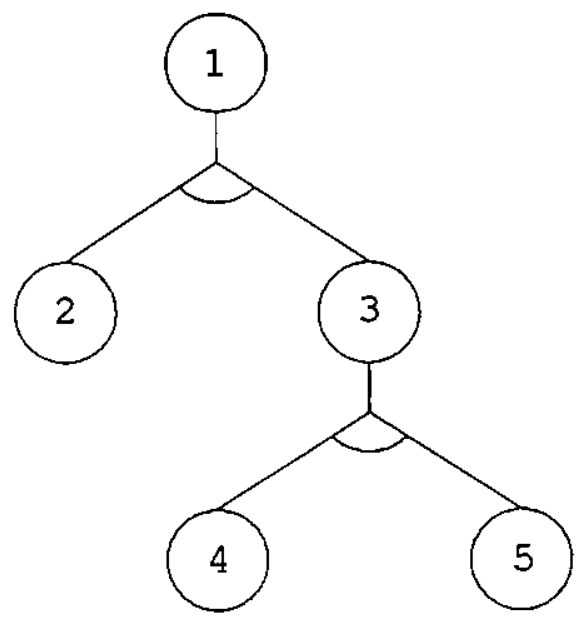

Figura 3.3 - Representação de grafo E/OU

Observe que um arco de um grafo define uma relação entre dois nós, um arco de um hipergrafo define uma relação entre um subconjunto de nós e, um arco de um grafo E/OU define uma relação entre um nó e um subconjunto de nós.

Um grafo E/OU pode ser definido para representar todos os possiveis padrões do problema de corte, onde os nós representam retângulos (no caso do problema de corte bidimensional guilhotinado, com objeto e peças retangulares) e os arcos representam cortes. Observe que um arco (corte) estabelece uma relação entre um nó $N$ do grafo (retângulo), com dois outros nós $\mathrm{N}_{1}$ e $\mathrm{N}_{2}$, portanto, um arco-E. Os nós $\mathrm{N}_{1}$ e $\mathrm{N}_{2}$ são chamados sucessores de $\mathrm{N}$ e, $\mathrm{N}$ predecessor de $\mathrm{N}_{1}$ e $\mathrm{N}_{2}$. Os padrões são gerados examinando-se todas as possibilidades de corte (daí, arcos-OU) e uma delas é reproduzir o próprio retângulo (corte- 
0, lê-se corte zero), ao qual nenhum outro corte será feito, indicando o final do processo de corte. Um corte-o é representado por um arco comum. O nó inicial é representado pela placa $(L, W)$ e os nós finais são aqueles originados de um corte-o (sem perda de generalidade, associam-se aos retângulos finais um ou mais itens idênticos. Veja Figura 3.6). As Figuras 3.4 e 3.5 ilustram, respectivamente, um padrão de corte e sua representação no grafo $E / O U$, onde $R_{1}(i=8,9,10,13,16,17)$ são os retângulos finais e $\mathrm{C}_{\mathrm{k}}(\mathrm{k}=1,2,3,4,5)$ os cortes aplicados durante - processo de cortagem. Nesta representação, um padrão de corte é representado por um caminho completo no grafo E/OU, que consiste no seguinte: a partir do nó inicial, escolha um e somente um arco (arco-E, corte-0) e, a partir de cada nó sucessor apontado por este arco, escolha novamente um e somente um arco e assim em diante, até que todos os sucessores sejam nós finais.

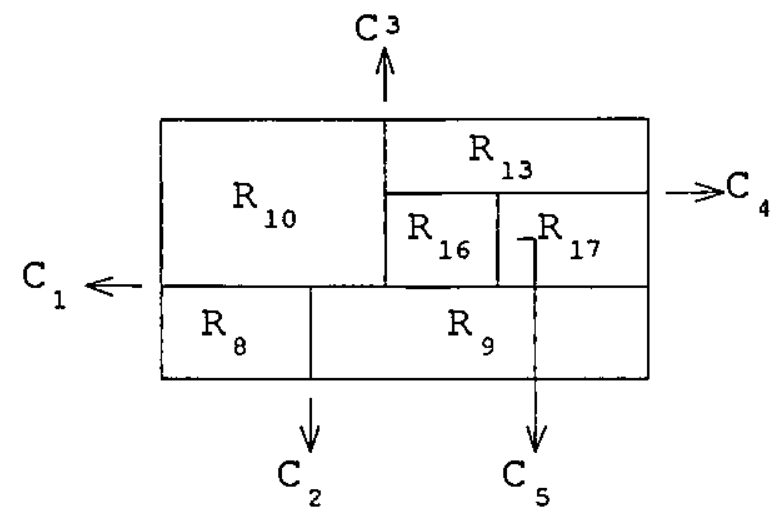

Figura 3.4 - Padrão de corte 


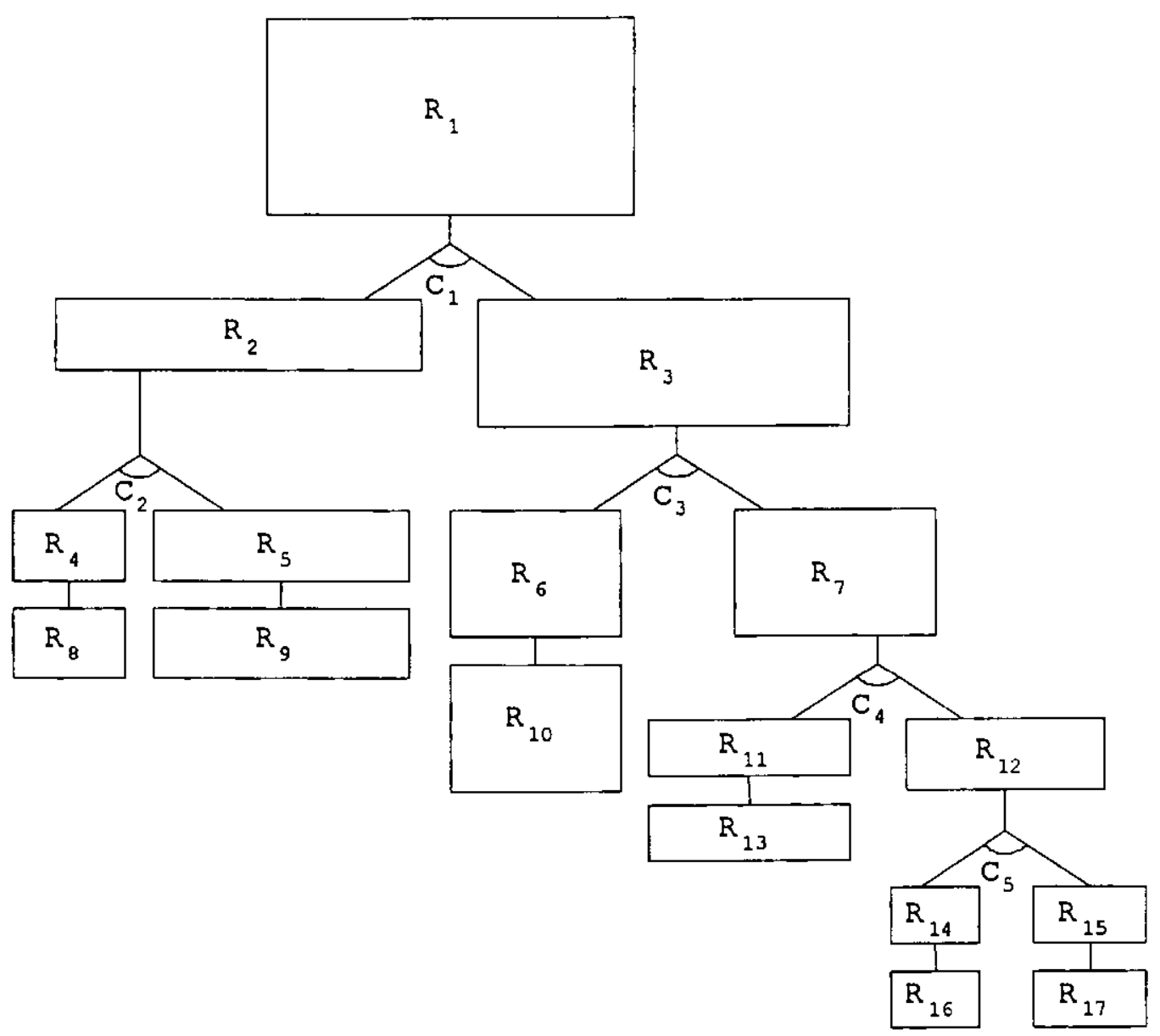

Figura 3.5 - Grafo E/OU representando o padrão da Figura 3.4

Os cortes (verticais ou horizontais) podem ser restritos, sem perda de generalidade, a um conjunto finito formado pelas combinaçōes lineares não-negativas dos tamanhos dos itens (veja seção 4.1), de modo que o grafo que representa todos os possiveis padrões de corte é finito. Arenales (1993) mostrou que esta afirmação é válida para qualquer problema de corte, independentemente das dimensões e das formas geométricas dos objetos e itens.

E fácil perceber que há somente um padrão correspondendo a cada caminho completo no grafo E/OU, mas pode haver diferentes caminhos completos correspondendo a um mesmo padrão de corte. 


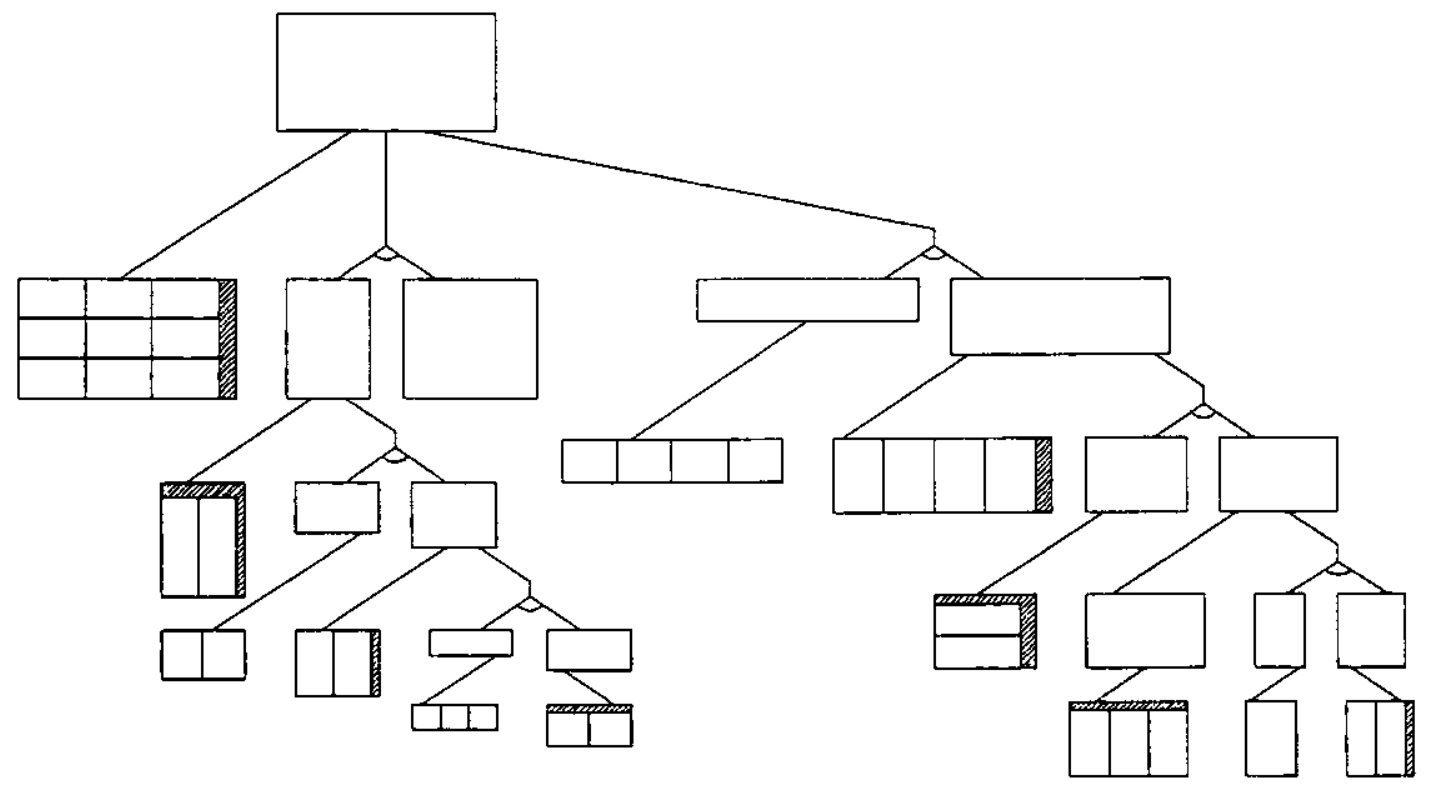

Figura 3.6 - Grafo E/OU representando padrões de corte alternativos

A seguir, a abordagem em grafo E/OU é estendida para padrões com restrições especiais, vistos no capitulo anterior.

\subsection{Representação de Padrões de Corte Especiais}

Nesta seção, são considerados problemas com algumas restrições adicionais que surgem durante o processo de corte.

\subsubsection{Padrão de corte k-estagiado}

Neste tipo de padrão restrito a cortes guilhoti- nados, conforme foi visto na seção 2.2, há um limite para o número de estágios de corte do problema.

Considere um nó $N$ do grafo E/OU e $N_{1}$ e $N_{2}$ um par de sucessores de $N$, obtidos de um corte guilhotinado, seja ele do tipo vertical ou horizontal. Se o tipo do corte que gerou $\mathrm{N}_{1}$ e $\mathrm{N}_{2}$ for diferente do tipo do corte que gerou $\mathrm{N}$, deve-se incrementar o número de estágios; caso contrário, o número de está- 
gios permanece o mesmo. Portanto, quando for atingido o número $\mathrm{k}$ de estágios e este foi gerado por cortes horizontais, a partir de então é permitido somente cortes horizontais. o procedimento é análogo se atingir o número máximo de estágios com cortes verticais.

A representação do problema usando a abordagem grafo E/OU permanece a mesma, incluindo estas restrições na geração dos cortes (Figura 3.7).

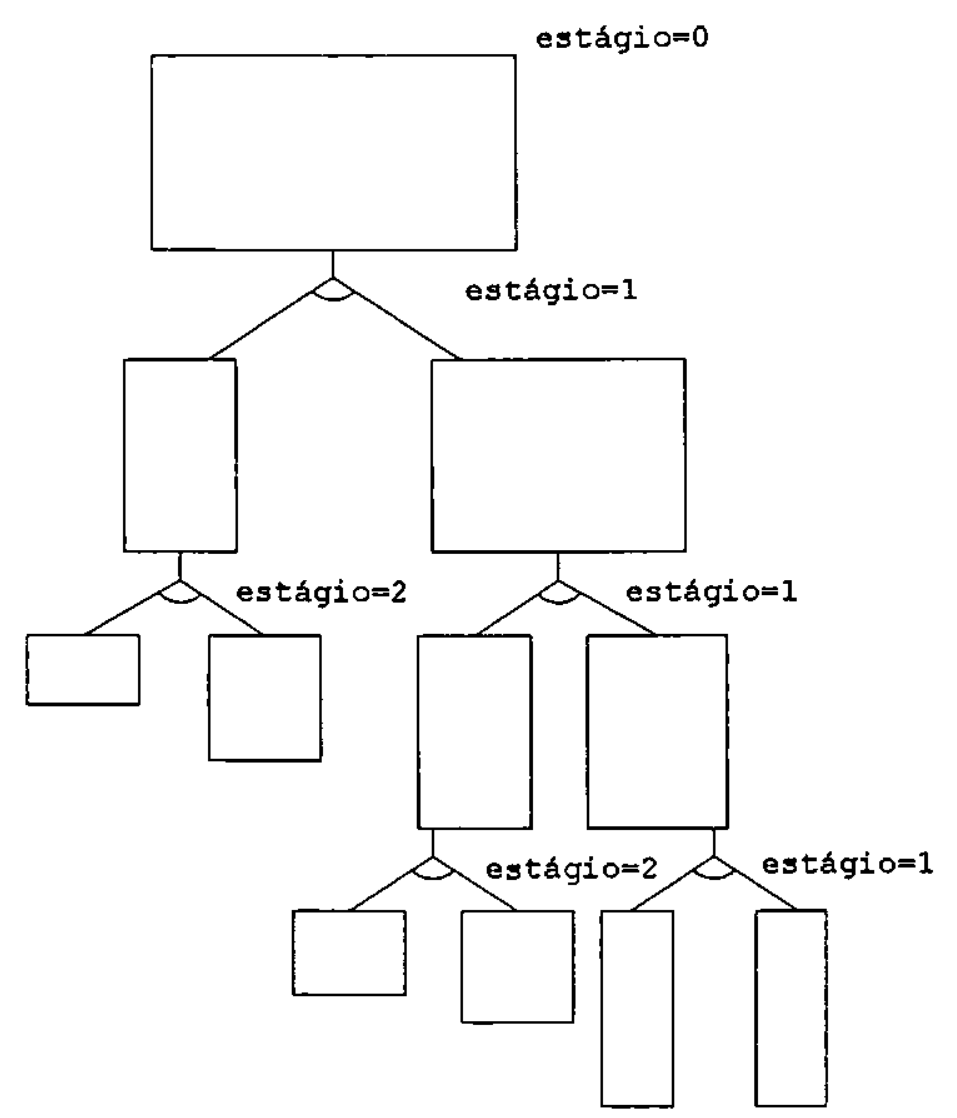

Eigura 3.7 - Padrão de corte k-estagiado

\subsubsection{Padräo de corte restrito}

Neste caso, o problema apresenta uma limitação no número de cada tipo de peças presentes no padrão. Portanto, a decisão de produzir uma peça do tipo i num determinado nó depende da produção desta peça nos demais nós do mesmo caminho Convém lembrar que um caminho completo representa um padrão de 
corte.

Considere um nó $N$, seus sucessores $N_{1}$ e $N_{2}, a_{i}^{N} \circ$ número de peças do tipo $i$ produzidas no nó $N$ e, $b_{i}^{N} \circ$ número máximo de peças do tipo $i$ que podem ser produzidas no nó N. Então, a soma do número de peças $i$ produzidas em $N_{1}\left(a_{1}^{N_{1}}\right)$ com 0 número de peças $i$ produzidas em $N_{2}\left(a_{i}^{N_{2}}\right)$ näo deve ser superior $a b_{i}^{N}$, ou seja, $a_{i}^{N_{1}}+a_{i}^{N_{2}} \leq b_{i}^{N}$ (Figura 3.8).

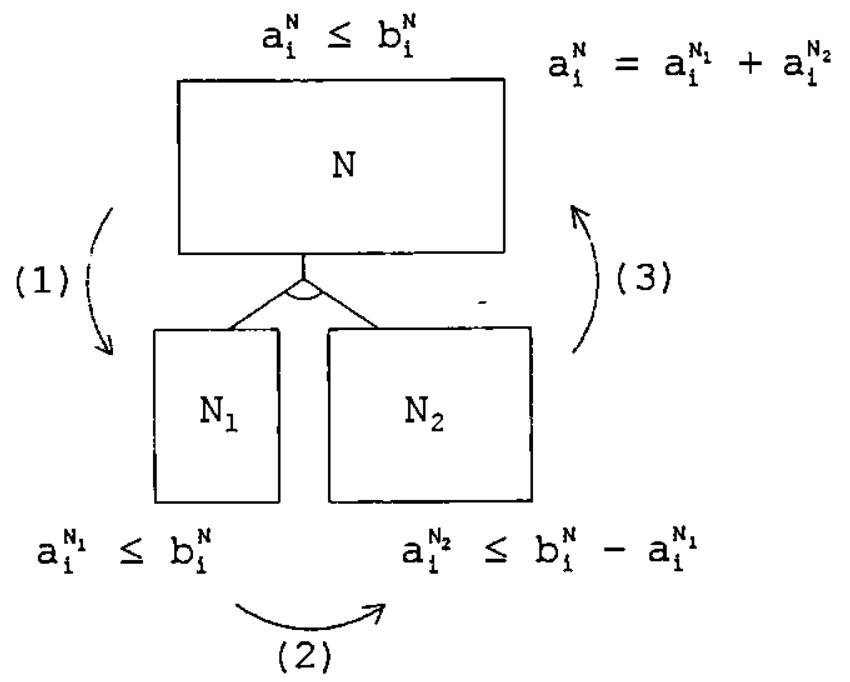

Figura 3.8 - Corte de um problema restrito

Desta forma, o limite sobre o número de itens do tipo i para o nó $\mathrm{N}_{2}$ depende do resultado do nó $\mathrm{N}_{1}$, o qual deve ser resolvido antes de $\mathrm{N}_{2}$. Isto define uma maneira particular de percorrer o grafo (estratégia gulosa) e, aparentemente, pode reduzir os padröes de corte, deixando de investigar possíveis padrões. Na seção 4.6 conjectura-se que a limitação na busca (resolve-se $\mathrm{N}_{1}$ para então resolver $\mathrm{N}_{2}$ ) não perde generalidade.

3.2.3. Padrão de corte com placa defeituosa

Considere o problema de corte com placa defeituosa apresentado na seção 2.2.1. Na representação atṛavés de 
grafo E/OU, sem perda de generalidade, os cortes podem ser tais que o defeito esteja inteiramente num dos retângulos gerados, isto é, podem-se evitar cortes sobre o defeito.

Um sequência de cortes na placa defeituosa pode ser cbservada na Figura 3.9.

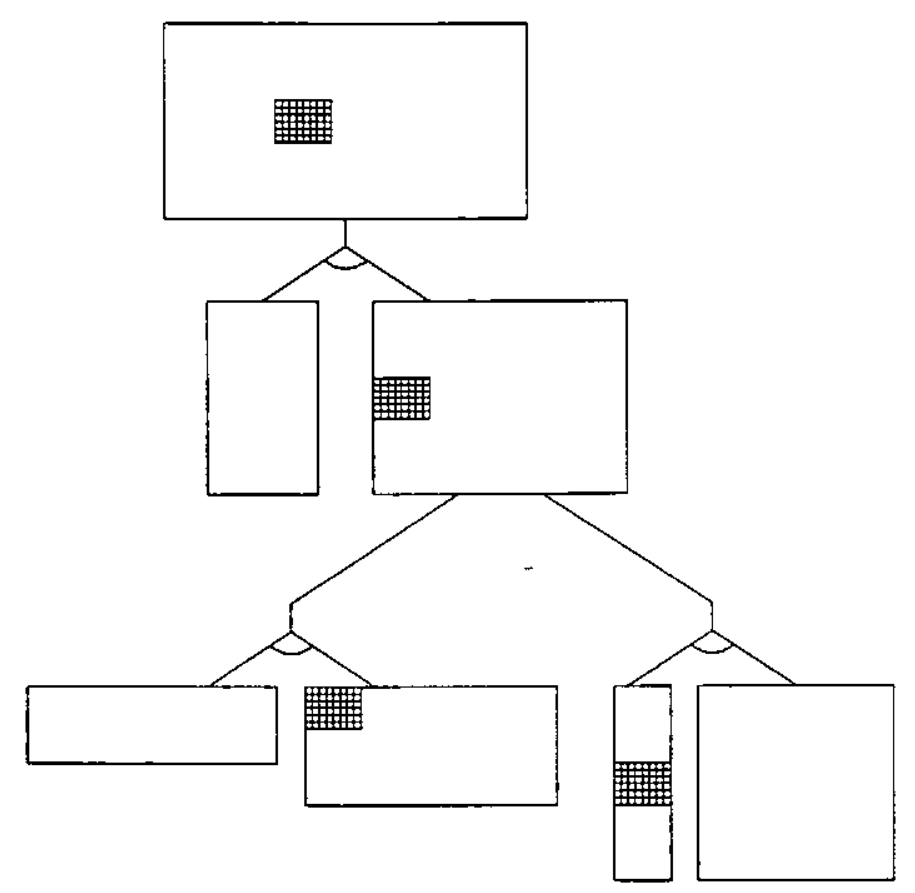

Figura 3.9 - Padrão de corte numa placa defeituosa

É possivel que se tenha uma placa com mais de um defeito; usando o critério anterior, a sequência de cortes é feita de maneira análoga (Figura 3.10).

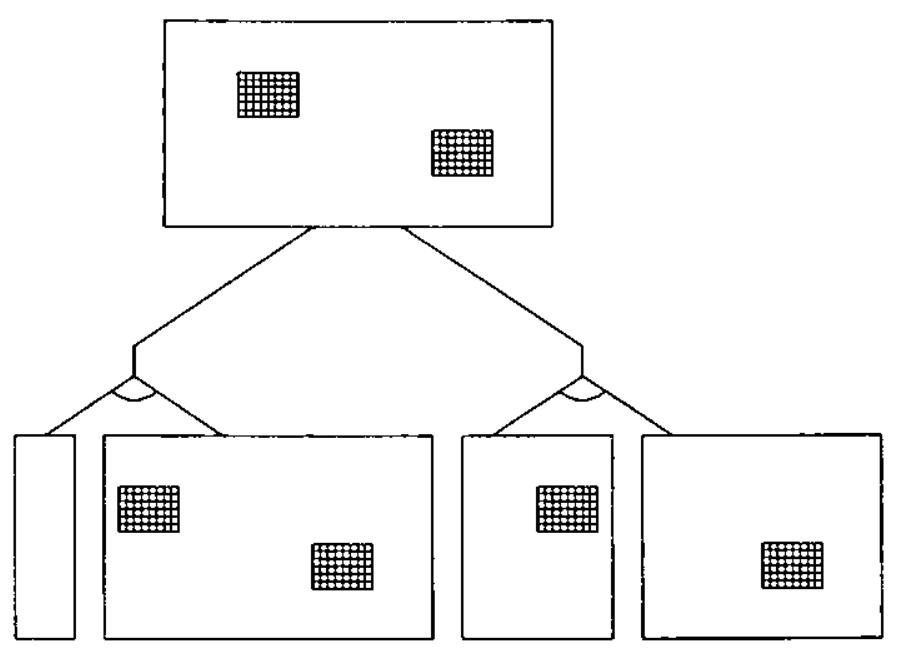

Figura 3.10 - Possiveis cortes numa placa com mais de um defeito 
3.2.4. Padrão de corte com limitação no número de tipo de peças

Conforme apresentado na seção 2.2.2, neste tipo de padrão deve-se controlar o número de tipo de peças produzidas no decorrer dos cortes, evitando a geração de padrões inviáveis.

Considere um nó $\mathrm{N}$, e seja $\mathrm{B}$ o número máximo de tipos admissivel no padrão e a definição do conjunto $Y(N)=\left\{i \mid y_{i}^{N}=1\right\}$, onde $y_{1}^{N}=1$, se 0 item $i j a ́$ estiver sido utilizado no caminho até o nó $\mathrm{N}$ (inclusive o nó $\mathrm{N}$ ), e zero, caso contrário. Note que no nó inicial, no inicio do processo, este conjunto é vazio.

Sejam $\mathrm{N}_{1}$ e $\mathrm{N}_{2}$ os sucessores de $\mathrm{N}$. Inicialmente, resolve-se o nó $N_{1}$, com $Y\left(N_{1}\right)=Y(N)$ e $\sum_{1=1}^{m} Y_{1}^{N_{1}} \leq B$, isto é, $N_{1}$ herda todas as informaçōes de seu predecessor $N$. Quando $\mathrm{N}_{1}$ estiver resolvido, redefine-se $\mathrm{Y}\left(\mathrm{N}_{1}\right)$ tal que $\mathrm{Y}\left(\mathrm{N}_{1}\right)=\mathrm{Y}\left(\mathrm{N}_{1}\right)+\left\{i \mid \mathrm{Y}_{1}^{\mathrm{N}_{1}}=1\right\}$. Deve-se, então, resolver $\circ$ nó $\mathrm{N}_{2}$ com os dados herdados de $\mathrm{N}_{1}$, ou seja, $Y\left(N_{2}\right)=Y\left(N_{1}\right)$ e $\sum_{i=1}^{m} Y_{1}^{N_{2}} \leq B$ (Figura 3.11). Tão logo $N_{2}$ esteja resolvido, redefine-se $\mathrm{Y}\left(\mathrm{N}_{2}\right)$ de modo análogo.

Note que $\mathrm{Y}(\mathrm{N})$ não foi alterado, então, após $\mathrm{N}_{1}$ e $\mathrm{N}_{2}$ serem resolvidos, retorna-se ao nó $\mathrm{N}$ para investigação de novos caminhos. Tão logo o nó $\mathrm{N}$ esteja resolvido (isto é, quando todos os sucessores tiverem sido investigados), atualiza-se $\mathrm{Y}(\mathrm{N})=\mathrm{Y}\left(\mathrm{N}_{2}\right)$, onde $\mathrm{N}_{2}$ é o sucessor (juntamente com $\mathrm{N}_{\mathrm{I}}$ ) que fornece o melhor caminho a partir de $\mathrm{N}$. 


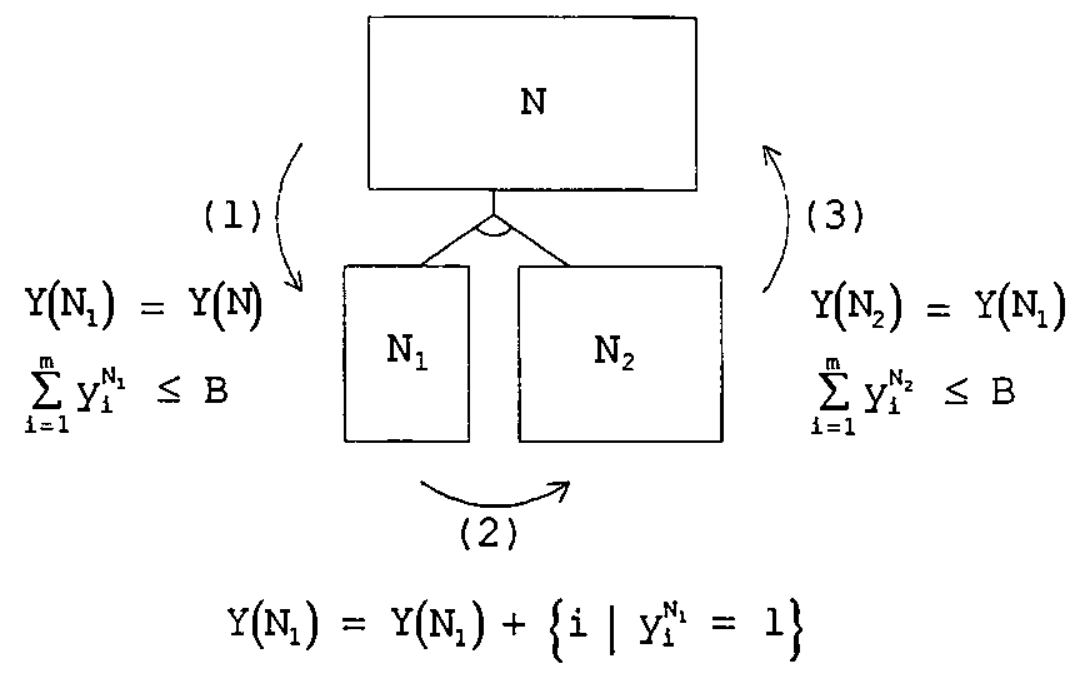

Figura 3.11 - Corte com limitação no número de tipo de peças

\subsubsection{Padrão com corte-cabeça}

Neste tipo de padrão de corte, visto na seção 2.2.3, cada corte realizado gera dois novos retângulos, onde um deles somente gera itens finais (cabeça) e o outro (principal), após dar ou näo um giro de $90^{\circ}$, pode ser cortado novamente.

Uma seqüência de retângulos é obtida. Cada retângulo principal tem um atributo adicional que contabiliza o número de giros realizados até então, diz-se "giro" (esta variável é iniciada com zero e acrescida de um, cada vez que o retângulo principal for girado). Se o total de giros for limitado por $G$, então, quando giro=G, nenhum giro adicional é permitido.

Este tipo de padrão de corte no grafo E/OU é representado por um caminho conforme a Figura 3.12, onde um dos nós é considerado nó final com um padrão unidimensional associado. Deve-se observar nesta figura, que o número de giros foi incrementado, no último nivel do grafo (giro=2), devido a serra utilizada neste corte ser vertical, necessitando assim de um giro para fazer os cortes. 


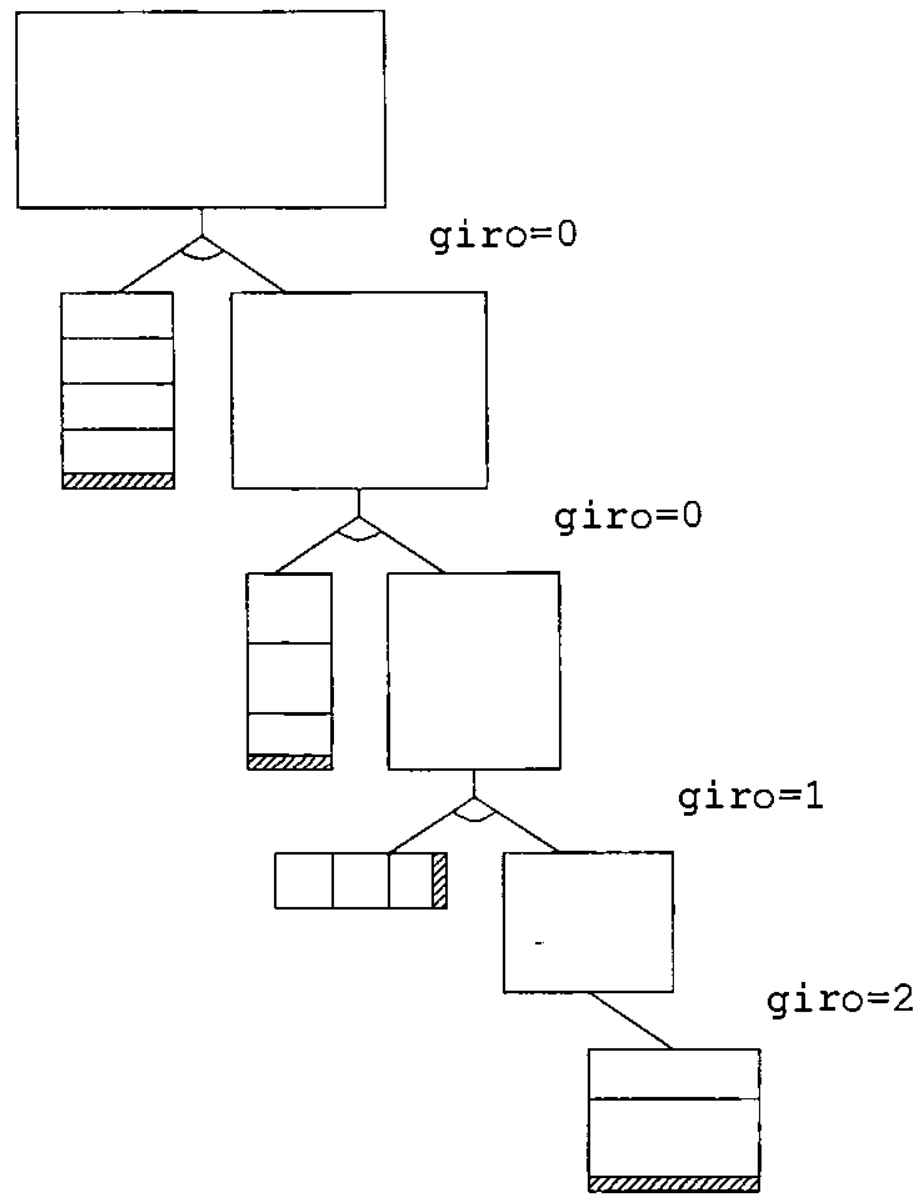

Figura 3.12 - Padrão de corte gerado pelo corte-cabeça

3.2.6. Padrão de corte com peças do tipo I

Considere o problema apresentado na seção 2.2.4, onde a partir de uma placa retangular é possivel gerar peças retangulares e/ou do tipo $\mathrm{L}$.

Neste problema, os cortes são do tipo guilhotinado e/ou do tipo degrau e cada nó do grafo representa um retângulo ou um objeto do tipo L. Observe um padrão de corte ilustrado pela Figura 3.13. 


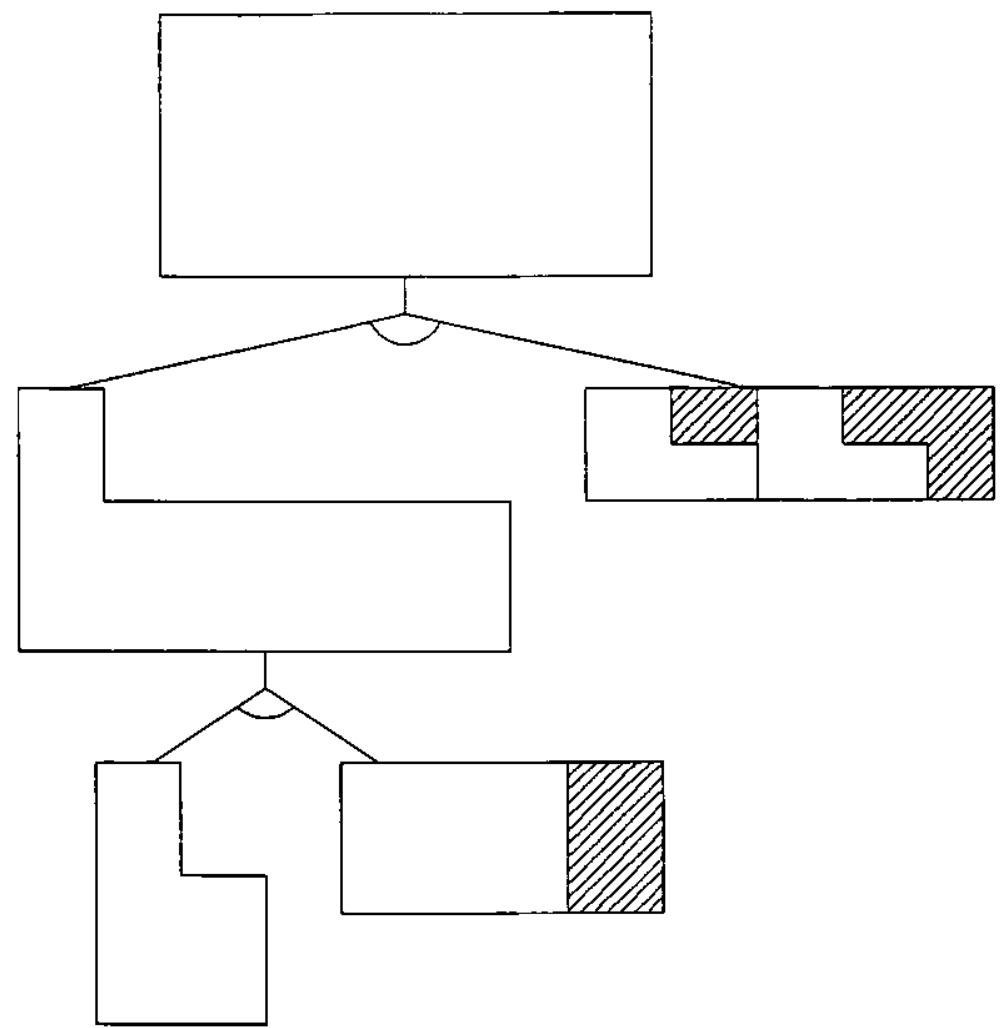

Figura.3.13 - Padrão de corte com peças retangulares e/ou do tipo L

Para que se torne computacionalmente viável a resolução deste tipo de problema, é necessário definir algumas regras para a geração dos cortes:

- um nó que representa um retângulo pode gerar dois novos retângulos, através de um corte guilhotinado horizontal ou vertical, ou gerar, através de um corte degrau, dois novos objetos do tipo $\mathrm{L}$, ou um novo retângulo e um objeto do tipo L. A Figura 3.14 ilustra os possíveis cortes neste tipo de nó.

- um nó que representa um objeto do tipo L pode ser cortado apenas por cortes guilhotinados, conforme a Figura 3.15. Deste modo, não é permitido gerar dois novos nós do tipo L. Esta restrição foi imposta para que se torne viável a resolução do problema, limitando as formas geométricas que surgem durante - processo de corte. Caso contrário, o número de formas geométricas dos objetos intermediários cresceria sem controle, 
necessitando de um número de parâmetros crescente para representá-los. Segundo Arenales (1993), isto caracterizaria um problema irregular.

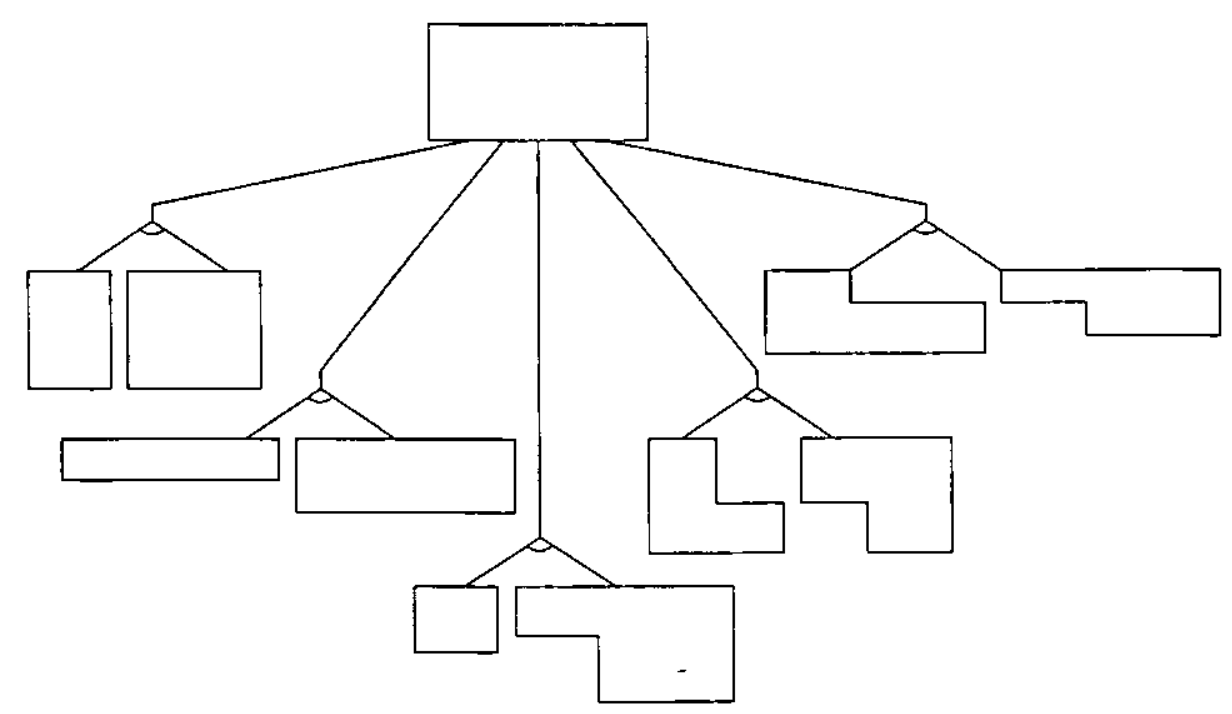

Figura 3.14 - Possíveis cortes no nó retangular

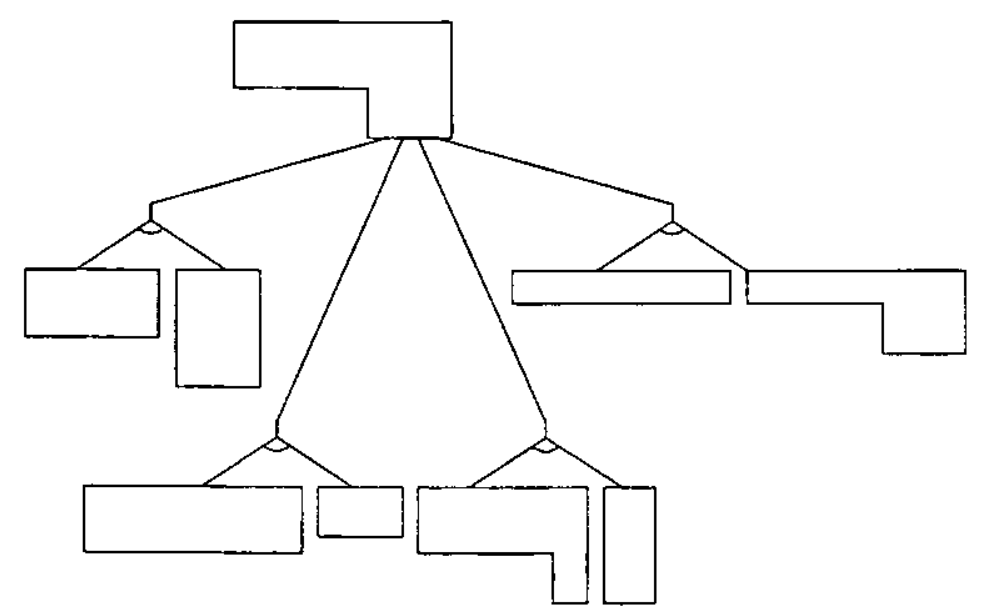

Figura 3.15 - Possiveis cortes nō nó do tipo L

\subsubsection{Padrão com corte não-guilhotinado}

A representação em grafo E/OU de um padrão de corte não-guilhotinado de 1- ordem é ilustrada na Figura 3.16, onde cada arco (corte) emergindo de um nó $\mathrm{N}$ terá cinco nós sucessores distintos $N_{1}, N_{2}, N_{3}, N_{4}$ e $N_{5}$. 

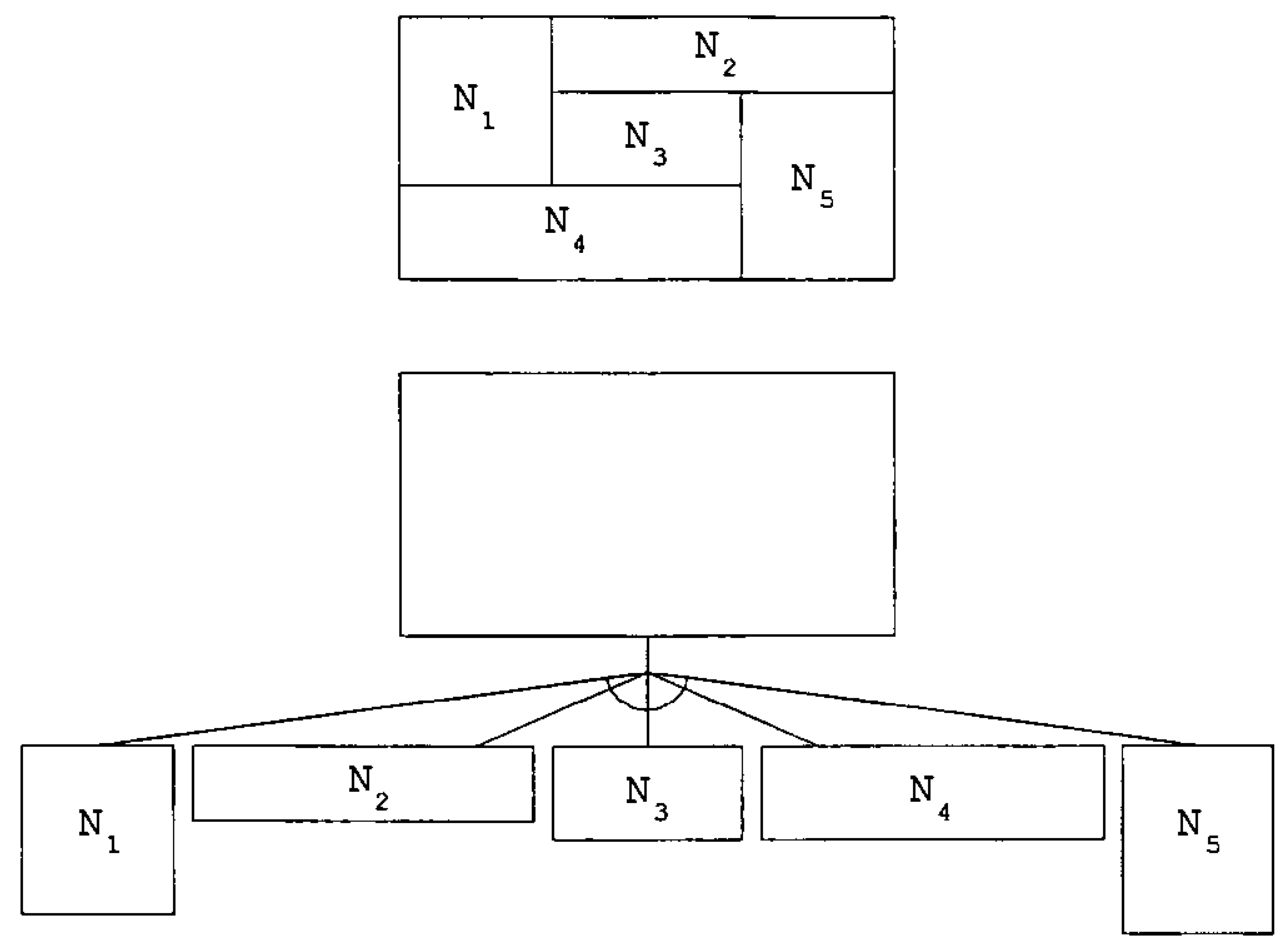

Figura 3.16 - Padrão de corte não-guilhotinado e sua representação no grafo $\mathrm{E} / \mathrm{OU}$

Observe que este processo pode continuar a partir de cada nó, com a possibilidade também de cortes guilhotinados, produzindo padrões não-guilhotinados de 1- ordem.

o padrão de corte não-guilhotinado de $1^{a}$ ordem pode ser gerado também, através de cortes guilhotinado e do tipo degrau (seção 2.2.5), conforme a Figura 3.17 . 


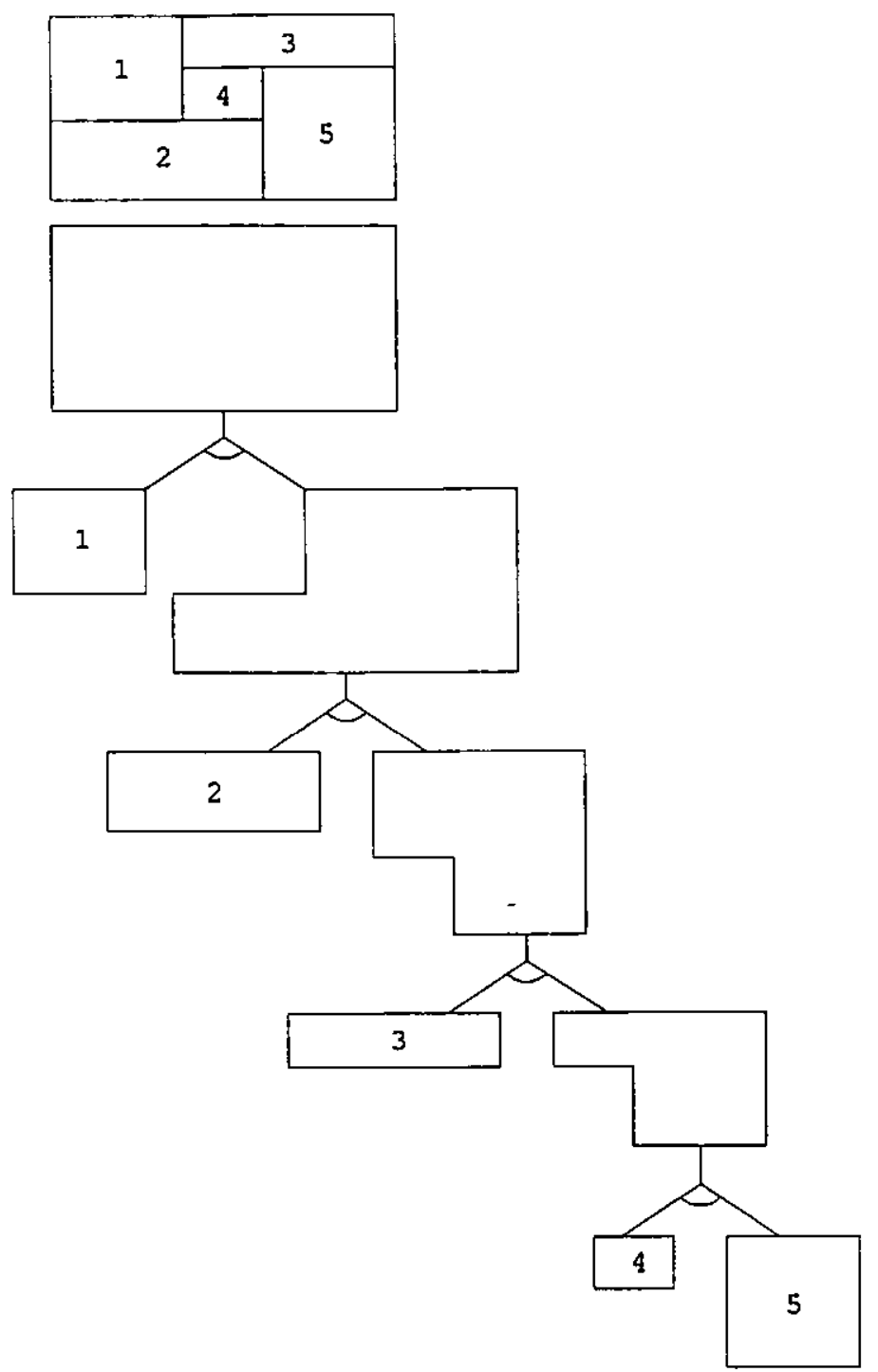

Figura 3.17 - Padrão de corte não-guilhotinado gerado através de cortes guilhotinado e do tipo degrau

No próximo capítulo é apresentado um método de enumeração implícita para a resolução do- problema de corte e seus diferentes padrōes, baseado numa busca no grafo E/OU que descreve o espaço de soluçōes possíveis. 


\section{Método de Enumeração Implícita}

Este capítulo apresenta um método de enumeração implícita para a busca no grafo E/OU, onde são utilizados limitantes, evitando assim caminhos não promissores. A estratégia de busca apresentada combina busca em profundidade com busca informada (hill-climbing).

\subsection{Geração do conjunto de discretização}

Durante o processo de busca é possivel reduzir o número de nós explicitamente gerados, utilizando as regras apresentadas a seguir.

- Padrões Normais

Herz (1972) e, mais tarde, Christofides e Whitlock (1977) mostraram, sem perda de generalidade, que os cortes guilhotinados (Arenales e Morabito, 1995, estenderam para cortes não-guilhotinados) podem ser combinações lineares nãonegativas das dimensões das peças, ou seja, é possivel reduzir os cortes verticais ao longo do comprimento $L$ aos elementos do conjunto $x$. Este resultado já vinha sendo utilizado na resoluçăo do problema da mochila - problema de corte unidimensional 
- segundo Salkin e Kluyver (1975)):

$$
x=\left\{x \mid x=\sum_{i=1}^{m} \alpha_{i} \cdot \ell_{i}, 1 \leq x \leq L-\ell_{0}, \alpha_{i} \geq 0 \text { e inteiro }\right\}
$$

onde $\ell_{0}=\min \left\{\ell_{i}, i=1, \ldots, \mathrm{m}\right\}$.

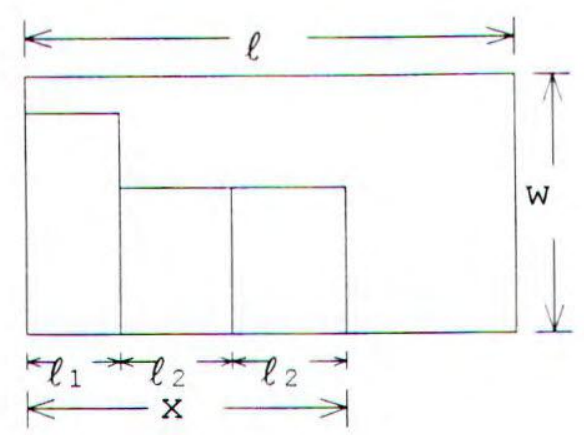

Figura 4.1 - Combinação linear dos comprimentos $\left(x=\ell_{1}+2 \cdot \ell_{2}\right)$

Analogamente, o conjunto $Y$ é definido para os cortes horizontais, ao longo da largura W:

$$
Y=\left\{y \mid y=\sum_{i=1}^{m} \beta_{i} \cdot w_{i}, 1 \leq y \leq W-w_{0}, \beta_{i} \geq 0 \text { e inteiro }\right\}
$$

onde $w_{0}=\min \left\{w_{1}, i=1, \ldots, m\right\}$.

Os conjuntos $\mathrm{X}$ e $\mathrm{Y}$ são chamados de conjuntos de discretização. Os padrões de corte, tais que todos os cortes feitos pertencem aos conjuntos de discretização, são chamados padrões de corte normais. Existem outros conjuntos de discretização (por exemplo, raster point sets, Morabito e Morales, 1998), que não serão considerados neste trabalho.

\section{- Simetria}

Herz também mostrou, sem perda de generalidade, para o problema irrestrito, que o conjunto $\mathrm{X}$ pode ser reduzido 
para evitar padrões simétricos. Demonstrou o seguinte teorema: Para todo padrão de corte na placa $(L, W)$, existe um padrão normal com mesmo valor de utilidade (soma dos valores de utilidade das peças produzidas) tal que a coordenada do primeiro corte é no máximo igual à metade da dimensão da placa.

Considere um nó $(\ell, w)$ e um corte vertical $\mathrm{x}_{1} \in \mathrm{X}$ e $\mathrm{x}_{1} \leq \ell-\ell_{0}$, gerando os nós $\left(\mathrm{x}_{1}, \mathrm{w}\right)$ e $\left(\ell-\mathrm{x}_{1}, \mathrm{w}\right)$. Considere, agora, um outro corte $x_{2}=\ell-x_{1}$, logo $x_{1}=\ell-x_{2}$. Se $x_{2} \in x$, então os nós $\left(\mathrm{x}_{2}, \mathrm{w}\right)$ e $\left(\ell-\mathrm{x}_{2}, \mathrm{w}\right)$ também são gerados, produzindo uma duplicação dos nós $\left(\mathrm{x}_{1}, \mathrm{w}\right)$ e $\left(\mathrm{x}_{2}, \mathrm{w}\right)$ (Figura 4.2 ). Se $\mathrm{x}_{2} \notin \mathrm{X}$, basta considerar $\left\lfloor x_{2}\right\rfloor_{x}$ (maior elemento de $x$ menor ou igual a $x_{2}$ ) e todo padrão possivel para a ramificação à esquerda na Figura 4.2, é também obtido com corte em $\left\lfloor x_{2}\right\rfloor_{x}$. O conjunto $x$ pode ser reduzido a:

$$
x=\left\{x \mid x=\sum_{i=1}^{m} \alpha_{i} \cdot \ell_{i}, 1 \leq x \leq\left\lfloor\frac{I}{2}\right\rfloor, \alpha_{i} \geq 0 \text { e inteiro }\right\}
$$

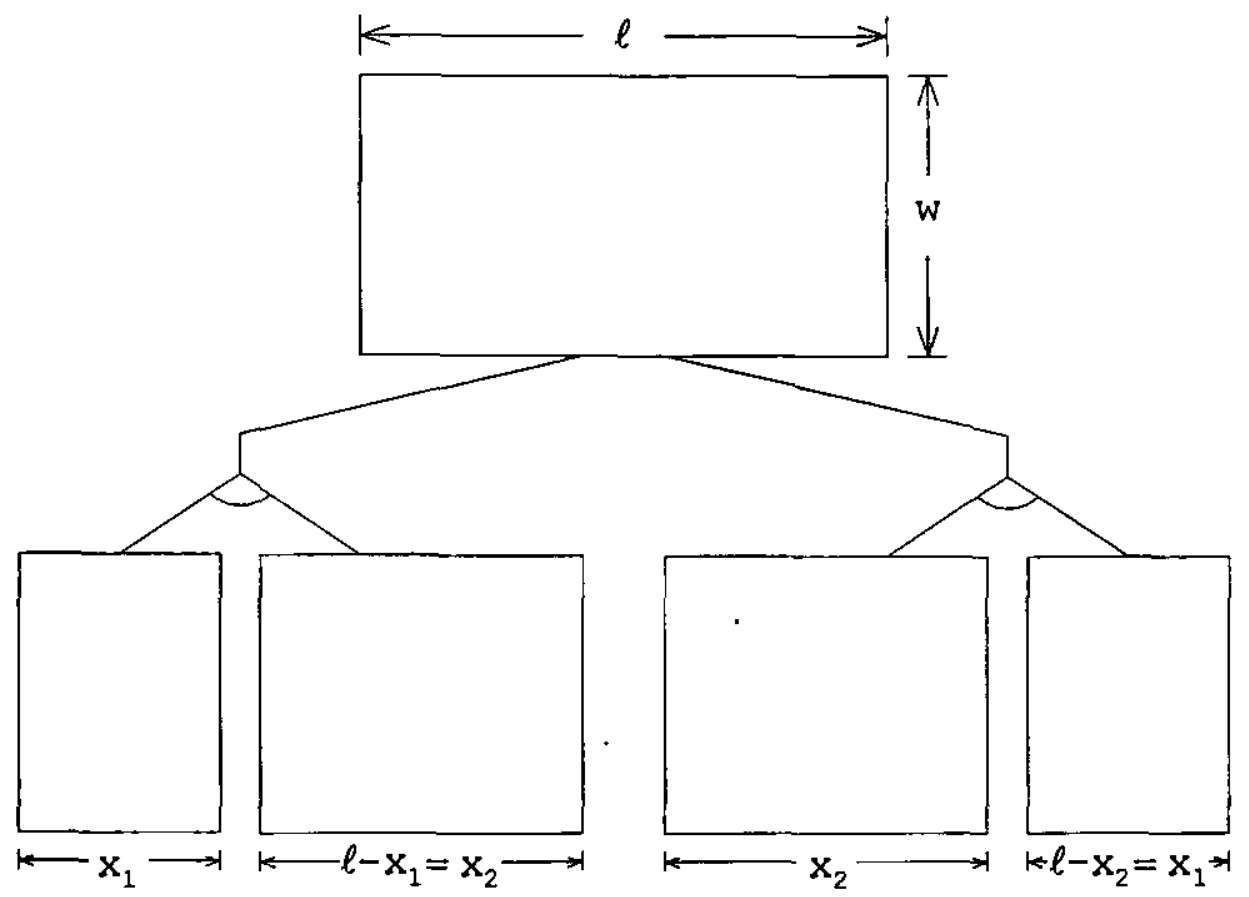

Figura 4.2 - Simetria 
A eliminação de simetrias também é aplicada na geração do conjunto $Y$ dos cortes horizontais.

\section{- Exclusão}

Herz também propôs outra regra para diminuir 0 conjunto de discretização, sem perda de generalidade. A regra de exclusão é usada para descartar elementos de X durante o processo de busca. Considere $\circ$ retângulo $(\ell, w)$ e $\circ$ corte $x=\ell_{1}+\ell_{2}$, tal que $w_{1}<w$ e $w_{2}>w$ (Figura 4.3). Observe que este corte deve -ser descartado pois, apesar de $x=\ell_{1}+\ell_{2}$ e, portanto, $\mathrm{x} \in \mathrm{X}$, as peças $\left(\ell_{1}, w_{1}\right)$ e $\left(\ell_{2}, w_{2}\right)$ não podem ser alocadas no retângulo $(\ell, w)$.

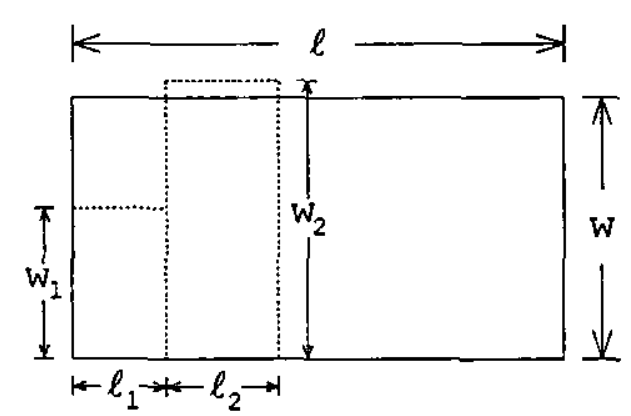

Figura 4.3 - Exclusão: $\mathrm{x}=\ell_{1}+\ell_{2}$ pode ser excluído do conjunto $\mathrm{x}$, no nó $(\ell, w)$

Assim, o conjunto $\mathrm{X}$ pode novamente ser reduzido a:

$$
X=\left\{x \mid x=\sum_{i=1}^{m} \alpha_{i} \cdot \ell_{1},\left(\text { se } w_{1}>w \Rightarrow \alpha_{1}=0\right), 1 \leq x \leq\left\lfloor\frac{L}{2}\right\rfloor, \alpha_{1} \geq 0 \text { e inteiro }\right\}
$$

o conceito de exclusão é aplicado também na geração dos cortes horizontais do conjunto $Y$.

$\lfloor x\rfloor$ denota o maior inteiro menor ou igual a $x$ 
Herz (1972) e, mais tarde, Christofides e Whitlock (1977) propuseram uma fórmula recursiva para a geração do conjunto de discretização $X$ e $Y$, onde as regras de simetria e exclusão são aplicadas. Os conjuntos de discretização são determinados para o nó inicial $(L, W)$ e, depois disto, eles são facilmente determinados para qualquer nó $\mathrm{N}$.

Considere $\ell_{1} \leq \ell_{2} \leq \ldots \leq \ell_{m}$ e $F_{i}(x)$ o mínimo da maior largura das peças $1,2, \ldots, i(i \leq m)$ que pode ser combinada para formar $x$. Então,

$$
F_{1}(x)=\left\{\begin{array}{lr}
\min \left\{E_{1-1}(x) ; \max \left\{w_{1}, \min _{p}\left\{\left(F_{1-1}\left(x-\rho \ell_{1}\right), 1 \leq \rho \leq\left\lfloor\frac{x}{\ell_{1}}\right\rfloor\right.\right.\right.\right. & \text { inteiro }\}\}\} \\
E_{1-1}(x), 0<x<\ell_{1}, & \left.\ell_{1} \leq x \leq \mid \frac{L}{2}\right\rfloor
\end{array}\right.
$$

sendo $F_{0}(x)=\infty$, para $x=1,2, \ldots\left\lfloor\frac{L}{2}\right\rfloor$, e $E_{i}(0)=0$.

Se $F_{l}(x)<\infty$, então $x=\sum_{j=1}^{1} \alpha_{j} \cdot \ell_{j}$, para $\alpha_{j} \geq 0$ e inteiro, $j=1, \ldots, i$; $\log 0 x \in X$.

Já que $F_{i}(x)$ independe do nó, o conjunto de discretização $X$ pode ser gerado antes do início do processo de busca. Depois, o conjunto de discretização do nó $N, X(N)$, pode ser gerado facilmente. Suponha que o nó $\mathrm{N}$ represente o retângulo $(\ell, w)$; então $x \in X(N) \Leftrightarrow E_{m}(x) \leq w$.

De maneira análoga, o conjunto $Y$ é determinado.

\section{- Ordenação de cortes}

Considere o retangulo $(\ell, w)$ representado por um determinado nó $\mathrm{N}$ e seja $\mathrm{x}_{1} \in \mathrm{X}$ o corte vertical aplicado ao re- 
tângulo, originando dois novos retângulos $\left(x_{1}, w\right)$ e $\left(\ell-x_{1}, w\right)$. A seguir, considere que o retângulo gerado $\left(\ell-x_{1}, w\right)$ seja novamente verticalmente cortado em $x_{2} \in X$, originando os retângulos $\left(x_{2}, w\right)$ e $\left(\ell-x_{1}-x_{2}, w\right)$. Estes três retângulos, $\left(x_{1}, w\right),\left(x_{2}, w\right)$ e $(\ell-$ $\left.\mathbf{x}_{1}-\mathbf{x}_{2}, w\right)$, também podem ser gerados aplicando inicialmente 0 corte $x_{2} \in X$, gerando $\left(x_{2}, w\right)$ e $\left(\ell-x_{2}, w\right)$ e, a seguir, aplicandose $\circ$ corte $x_{1} \in X$ em $\left(\ell-x_{2}, w\right)$, gerando $\left(x_{1}, w\right)$ e $\left(\ell-x_{2}-x_{1}, w\right)$ (Figura 4.4).

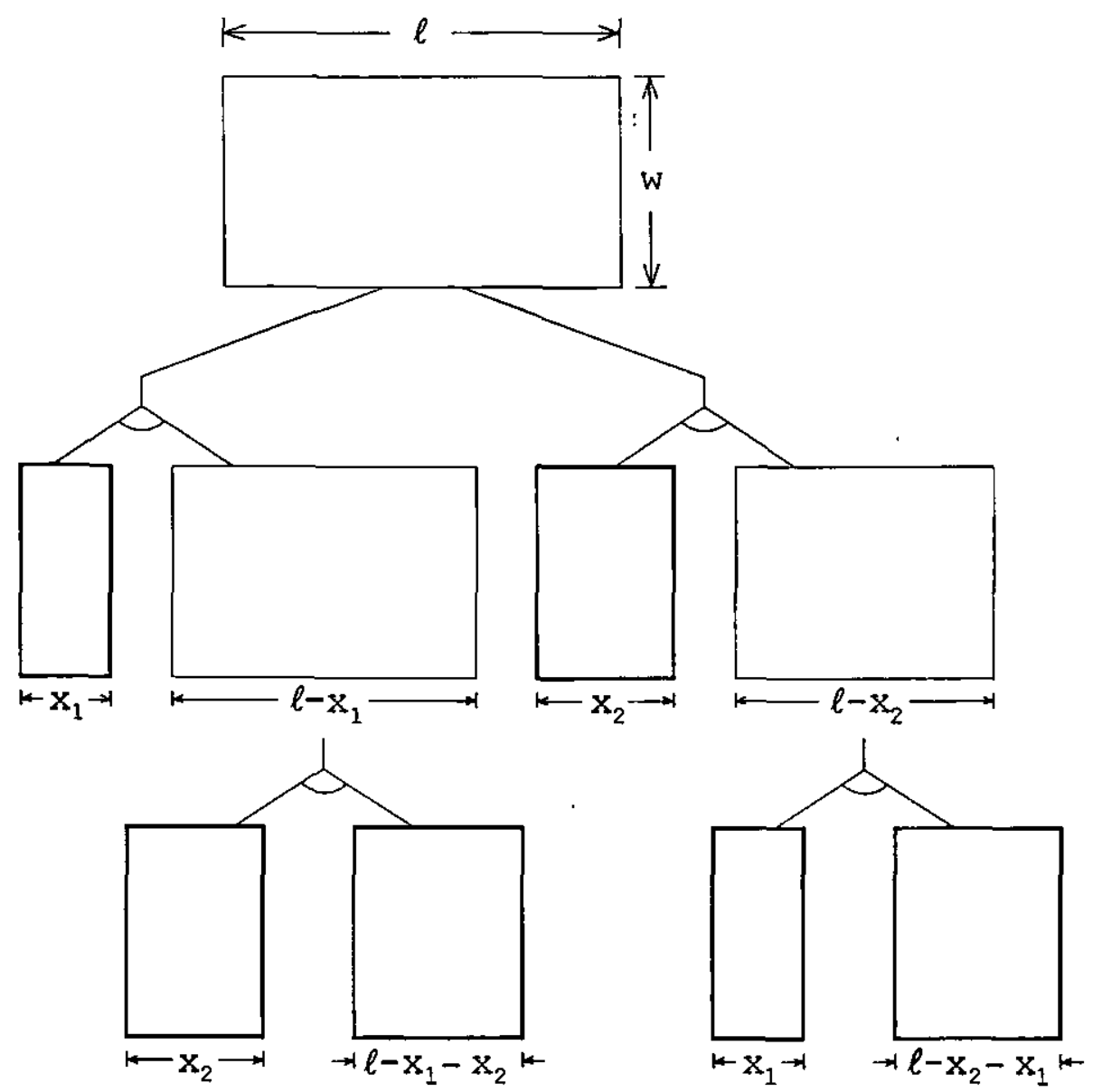

Figura 4.4 - Caminhos alternativos produzindo padrões equivalentes

Sem perda de generalidade, esta duplicação pode ser evitada utilizando uma ordem arbitrária nos sucessivos cortes verticais. Por exemplo, suponha que um retângulo seja cortado verticalmente em $\mathrm{x}_{1}$; então os cortes verticais subse- 
quientes podem ser maiores ou iguais a $x_{1}$, sem perda de generalidade. Este critério é válido também para os cortes horizontais (Christofides e Whitlock, 1977).

Durante o processo de busca, enumerar explicitamente todos os caminhos do grafo é, na maioria das vezes, inviável. As soluçōes podem ser enumeradas implicitamente, ou seja, é possível descartar a expansão de um nó sem perder a solução ótima, usando limitantes.

\subsection{Limitantes Inferiores}

É usual, em problemas de otimização (maximizaÇão), a determinação de limitantes inferiores através da obtenção de soluções viáveis. Nos problemas de corte, soluções viáveis são facilmente determinadas.

\subsubsection{Solução homogênea}

Uma solução trivial para o subproblema do nó $(x, y)$ é preenchê-lo somente com peças iguais, conforme os padrões das Figuras 4.5 e 4.6. Um padrão de corte que contém peças todas iguais é denominado padrão de corte homogêneo.

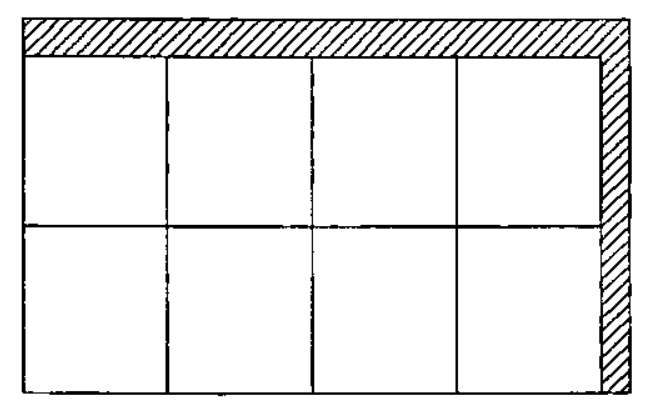

Figura 4.5 - Padrão de corte homogêneo 


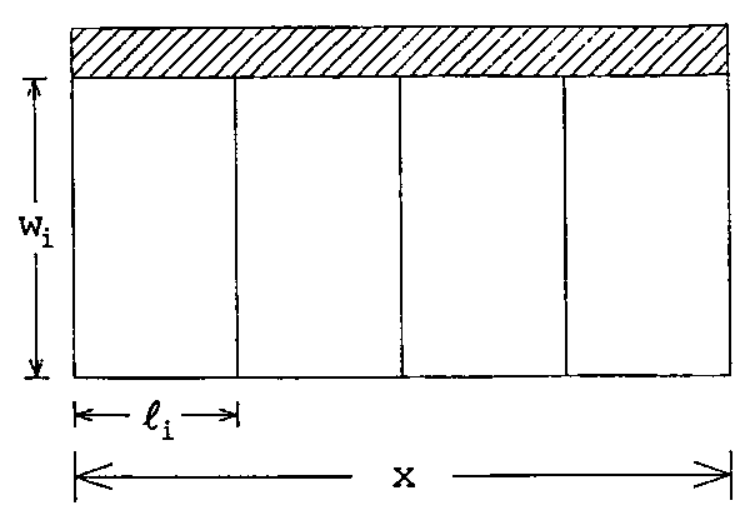

Figura 4.6 - Padrão homogêneo com apenas cortes verticais

Escolhendo-se o melhor dentre estes padrões, tem-se o limitante inferior dado por:

$$
\begin{aligned}
\operatorname{LI}(\mathrm{x}, \mathrm{y}) & =\max _{1 \leq 1 \leq \mathrm{m}}\left\{v_{1} \cdot\left\lfloor\frac{\mathrm{x}}{\ell_{1}}\right\rfloor \cdot\left\lfloor\frac{y}{w_{1}}\right\rfloor\right\} \\
& =v_{j} \cdot\left\lfloor\frac{\mathrm{x}}{\ell_{j}}\right\rfloor \cdot\left\lfloor\frac{y}{w_{f}}\right\rfloor
\end{aligned}
$$

ou, no caso de apenas cortes verticais:

$$
\operatorname{LI}(x, y)=\max _{1 \leq i \leq m}\left\{v_{1} \cdot\left\lfloor\frac{x}{\ell_{1}}\right\rfloor\right\}
$$

Particularmente, esta última solução será útil quando houver um problema estagiado, como é visto na seção $4.2 .1 .2 \ldots$

\subsubsection{Problema restrito}

Quando o problema de corte é restrito, a solução homogênea no nó $\mathrm{N}$ que representa o retângulo $(x, y)$ é definida por: 


$$
\begin{aligned}
\operatorname{LI}_{R}(x, y) & =\max _{1 \leq 1 \leq m}\left\{v_{i} \cdot \min \left\{\left\lfloor\frac{x}{\ell_{1}}\right\rfloor \cdot\left\lfloor\frac{y}{w_{i}}\right\rfloor, b_{1}^{N}\right\}\right\} \\
& \left.=v_{j} \cdot \min \left\{\left\lfloor\frac{x}{\ell_{j}}\right\rfloor \cdot \mid \frac{y}{w_{j}}\right\rfloor, b_{j}^{N}\right\}
\end{aligned}
$$

onde $b_{j}^{N}$ é o número máximo de peças do tipo $j$ que podem ser produzidas no nó $\mathrm{N}$.

$$
\text { Note que, se } b_{j}^{N} \text { for muito menor que }\left\lfloor\frac{x}{\ell_{j}}\right\rfloor \cdot\left\lfloor\frac{y}{w_{j}}\right\rfloor, a
$$

solução homogênea apresenta uma perda muito grande (Figura $4.7)$, que pode ser usada por outros tipos de peças.

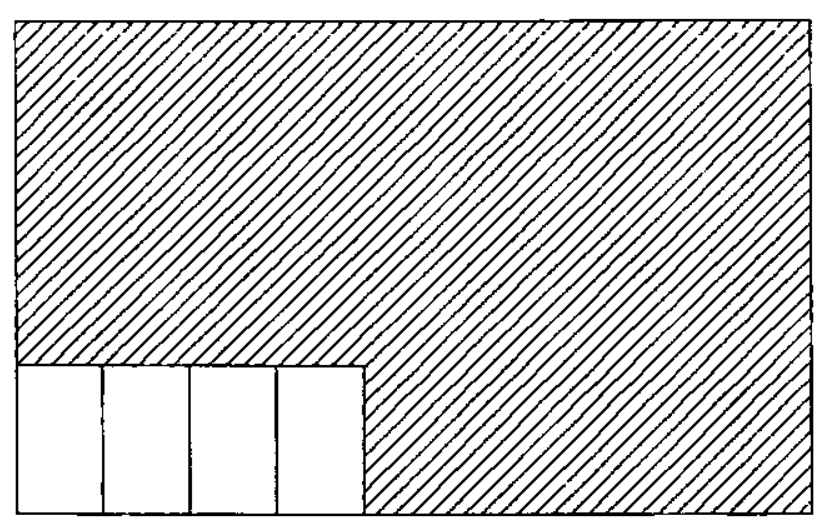

Figura 4.7 - Padrão homogêneo quando $b_{j}^{N}<<\left\lfloor\frac{x}{\ell_{j}}\right\rfloor \cdot\left\lfloor\frac{y}{w_{j}}\right\rfloor$

\subsubsection{Problema k-estagiado}

Neste tipo de problema, é necessário observar que, quando um determinado nó $\mathrm{N}$, representando o retângulo $(\mathrm{x}, \mathrm{y})$, atinge o número máximo de estágios com corte vertical, deve-se definir seu limitante inferior de modo que apenas cortes verticais sejam feitos na sequiencia. O mesmo deve ser feito quando o último estágio é atingido por cortes horizontais.

Assim sendo, quando um nó atinge o número máximo 
de estágios, seu limitante inferior é calculado por:

$$
L I_{E}(x, y)=\left\{\begin{array}{l}
\max _{1 \leq i \leq m}\left\{v_{1} \cdot\left\lfloor\frac{x}{\ell_{1}}\right]\right\}, \text { se }(x, y) \text { gerado por corte vertical } \\
\max _{1 \leq 1 \leq m}\left\{v_{1} \cdot\left\lfloor\frac{y}{w_{i}}\right]\right\}, \text { se }(x, y) \text { gerado por corte horizontal }
\end{array}\right.
$$

\subsubsection{Solução homogênea composta}

\subsubsection{Problema restrito}

Esta solução é aplicada quando se tem um problema de corte restrito e $b_{f}^{N}<\left\lfloor\frac{x}{\ell_{j}}\right\rfloor \cdot\left[\frac{y}{w_{j}}\right\rfloor$. A solução combina soluções homogêneas de diversos tipos de peças.

Considere $\circ$ nó $(x, y)$ e seu limitante inferior dado pela solução homogênea da peça j, ou seja,

$$
\begin{aligned}
& L I_{R C}(x, y)=v_{j} \cdot \min \left\{\left\lfloor\frac{x}{\ell_{j}}\right\rfloor \cdot\left\lfloor\frac{y}{w_{j}}\right\rfloor, b_{j}^{N}\right\} \\
& \text { Note que, se } b_{j}^{N}<\left\lfloor\frac{x}{\ell_{j}}\right\rfloor \cdot\left[\frac{y}{w_{j}}\right\rfloor, \text { às vezes, é possível }
\end{aligned}
$$

alocar outro tipo de peça no retângulo $(x, y)$. Neste caso, o limitante inferior do nó $(x, y)$ é dado pela soma da solução homogênea da peça j com a solução do retângulo $\left.x, y-\left[\theta_{j}\right] w_{j}\right)$ com $\left.\theta_{j}=\min \left\{\frac{y}{w_{j}}\right\rfloor, \frac{b_{j}^{N}}{\left.\mid \frac{x}{\ell_{j}}\right]}\right\}$.

- procedimento é repetido no retângulo

$\lceil\mathrm{x}\rceil$ denota o menor inteiro maior ou igual a $\mathrm{x}$ 
$\left(x, y-\theta_{j} \cdot w_{j}\right)$ e assim por diante, até que não seja mais possível alocar peças no retângulo. A solução homogênea composta do nó $(\mathrm{x}, \mathrm{y})$ é dada pela soma de todas estas soluções homogêneas.

Uma solução homogênea composta formada por dois tipos de peças é apresentada na Figura 4.8 .

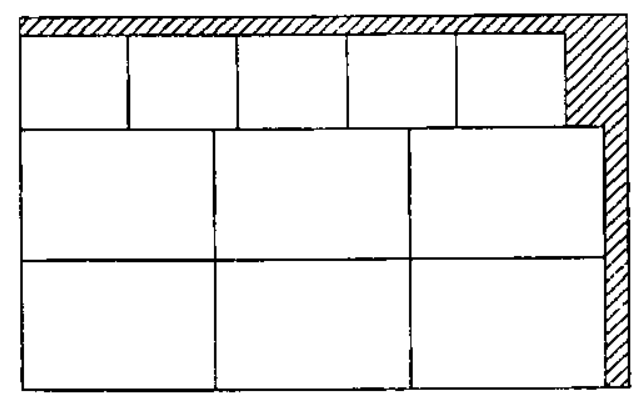

Figura 4.8 - Padrão de corte homogêneo composto

A solução homogênea composta também pode ser definida alocando as peças por colunas.

\subsubsection{Problema com placa defeituosa}

Quando se tem um problema com um nó representando um retângulo defeituoso de dimensão $(x, y)$ e um defeito nas coordenadas $\left(x_{1}, y_{1}\right)$ e $\left(x_{2}, y_{2}\right)$, a solução trivial é preenchê-lo com peças sem sobrepor o defeito.

o preenchimento desta placa pode ser reduzido ao preenchimento dos retângulos formados ao redor do defeito, conforme a Figura 4.9. Note que o preenchimento pode ser feito dividindo a placa de maneira vertical (a) ou horizontal (b).

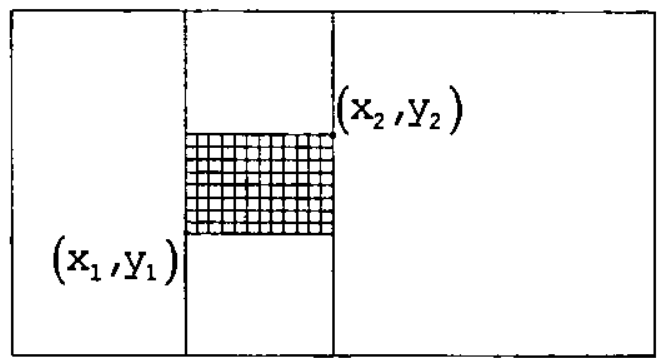

(a)

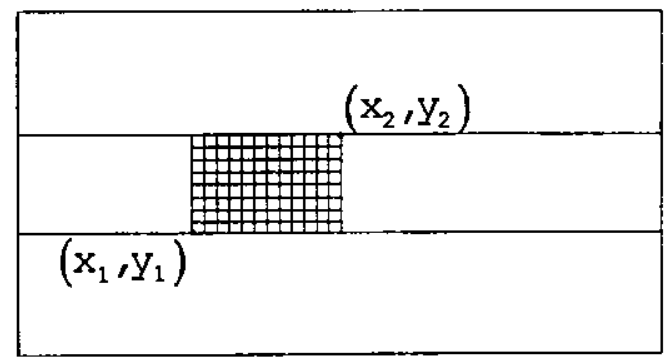

(b)

Figura 4.9 - Soluções homogêneas de uma placa defeituosa 
Como cada retângulo é preenchido com o maior número de peças iguais (solução homogênea trivial), a soma deles fornece uma soluçāo homogênea composta. Assim sendo, o Iimitante inferior de um probiema com placa defeituosa é dado por:

$$
L I_{D}=\max \left\{\begin{array}{l}
L I\left(x_{1}, y\right)+L I\left(x_{2}-x_{1}, y-y_{2}\right)+L I\left(x_{2}-x_{1}, y_{1}\right)+L I\left(x-x_{2}, y\right), \\
L I\left(x_{1} y_{1}\right)+L I\left(x_{1}, y_{2}-y_{1}\right)+L I\left(x-x_{2}, y_{2}-y_{1}\right)+L I\left(x, y-y_{2}\right)
\end{array}\right\}
$$

o procedimento é análogo quando se tem mais defeitos sobre o retângulo.

\subsubsection{Problema com peças em L}

Neste tipo de problema, o nó $\mathrm{N}$ pode representar um retângulo ou uma peça do tipo L.

Para o nó retangular, utiliza-se a solução homogênea das peças, e para peças do tipo L poderse combinar duas peças iguais formando um retângulo e, assim, formar uma solução homogênea para o nó N. A Figura 4.10 apresenta duas soluções homogêneas com peças do tipo L.
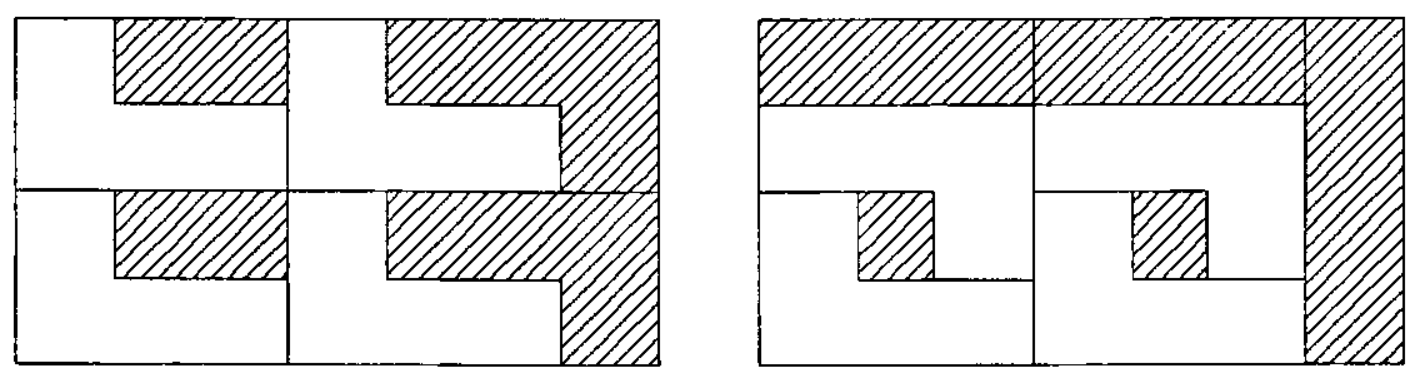

Figura 4.10 - Soluções homogêneas com peças do tipo I

Para o nó do tipo L, a solução é dada pela soma das soluções homogêneas dos retângulos (Figura 4.11). Note que calculam-se as duas soluçōes (a e b da Figura 11), e assume-se - maior valor obtido. Também é verificada a sobreposição de una peça do tipo L no nó (Figura 4.12). 


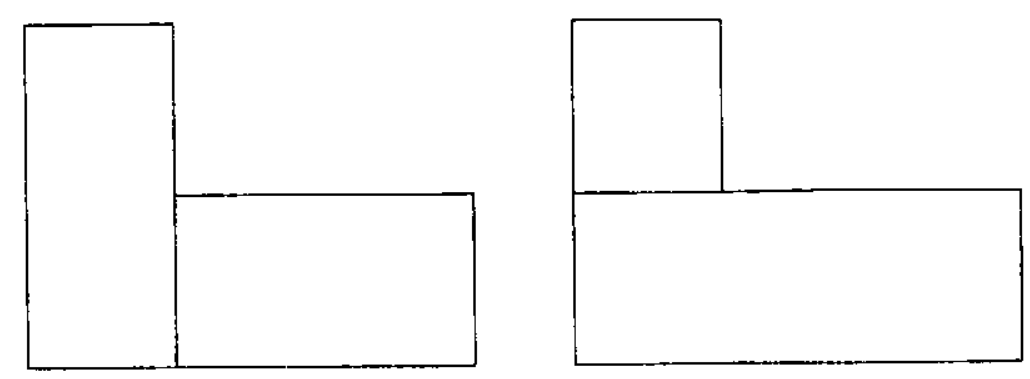

Figura 4.11 - Soluçōes homogêneas dos retângulos

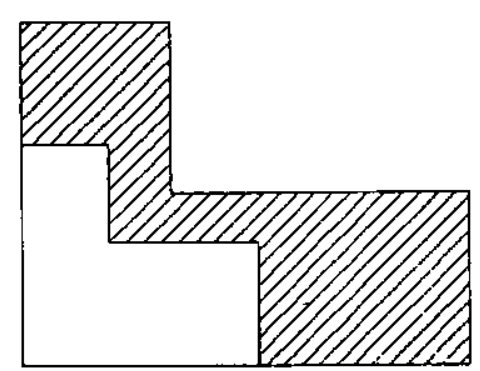

Figura 4.12 - Solução homogênea do nó do tipo L

\subsubsection{Solução 2-estágios}

Esta solução apresenta um limitante inferior muito poderoso para o problema de corte irrestrito; entretanto, os cálculos não são tão simples. Morabito e Arenales (1995) mostraram que, muitas vezes, a solução ótima do problema em 2-estágios é melhor que a solução obtida por heurísticas, mesmo que não tenha limitação no número de estágios. Gilmore e Gomory (1965) apresentaram um método que envolve duas etapas.

Considere a placa de dimensões $(L, W)$ e m peças de dimensōes $\left(\ell_{i}, w_{1}\right)$ com $\circ$ valor de utilidade $v_{i}$. Na primeira etapa, deve-se decidir qual o padrão de corte a ser utilizado em cada faixa $\left(I, w_{j}\right)$ e, na segunda, quantas vezes este padrão é repetido na placa $(L, W)$.

Considere o conjunto $w_{j}=\left\{i \mid w_{1} \leq w_{j}\right\}$. Na primeira etapa, as peças $\left(\ell_{i}, W_{i}\right), i \in W_{j}$, são arranjadas em faixas do 
tipo $\left(L, w_{j}\right), j=1, \ldots, m$, produzindo os valores $v_{j}$, que são determinados resolvendo os $m$ problemas:

$$
\begin{aligned}
\mathrm{V}_{j}=\operatorname{maximizar} & \sum_{1 \in \mathrm{W}_{j}} \mathrm{v}_{1} \cdot \alpha_{1}^{j} \\
\text { sujeito a : } & \sum_{1 \in W_{j}} \ell_{1} \cdot \alpha_{1}^{j} \leq \mathrm{L} \\
& \alpha_{i}^{j} \geq 0, \text { inteiro, } i \in W_{j}
\end{aligned}
$$$$
j=1, \ldots, m
$$

onde $\alpha_{i}^{j}$ é o número de peças tipo $i$ arranjadas na faixa j.

A seguir, com o melhor padrão já definido para Cada faixa $w$, deve-se decidir quantas vezes estas faixas são repetidas na placa $(L, W)$, isto é, deve-se resolver o seguinte problema:

$$
\begin{aligned}
\operatorname{maximizar} & \sum_{j=1}^{m} v_{j} \cdot \beta_{j} \\
\text { sujeito a }: & \sum_{j=1}^{m} w_{j} \cdot \beta_{j} \leq w \\
& \beta_{j} \geq 0, \text { inteiro, } j=1, \ldots, m
\end{aligned}
$$

sendo $\beta_{y} \circ$ número de faixas j na placa $(L, W)$.

$$
\text { Note que são resolvidos, no máximo, }(m+1) \text { pro- }
$$
blemas da mochila, já que pode-se ter $w_{j}=w_{k}$, com $j \neq k$, de modo que apenas um problema da mochila é resolvido para as duas faixas. Convém lembrar que, Morabito (1992) e Hifi (1997), mostram que este problema pode ser resolvido com apenas 2 problemas da mochila se for usado programação dinâmica.

o processo é repetido considerando os cortes do primeiro estágio paralelos à largura, ou seja, deve-se, inicialmente, decidir qual o padrão de corte a ser utilizado em cada faixa $\left(\ell_{j}, W\right)$, para depois decidir quantas vezes este padrão é repetido na placa $(L, W)$; o que resulta em outros $(m+1)$ problemas da mochila. 
Observe que este método (decomposição numa sequiência de problemas da mochila) resolve o modelo matemático do problema de corte bidimensional em 2-estágios, o qual pode ser formulado por (Gramani, 1997):

$$
\begin{aligned}
\text { maximizar } & \sum_{i=1}^{m} \sum_{j=1}^{m} \sum_{k=1}^{k_{j}} \alpha_{k j}^{i} \cdot \beta_{k j} \cdot v_{1} \\
\text { sujeito a : } & \sum_{i=1}^{m} \alpha_{k j}^{i} \cdot \ell_{1} \leq L, j=1, \ldots, m ; k=1, \ldots, K_{j} \\
& \sum_{j=1}^{m} w_{j} \cdot \sum_{k=1}^{k_{j}} \beta_{k j} \leq W \\
& \alpha_{k j}^{i} \geq 0, \beta_{k j} \geq 0, \text { inteiro, } j=1, \ldots, m
\end{aligned}
$$

onde $\left(\alpha_{k j}^{1}, \alpha_{k j}^{2}, \ldots, \alpha_{k j}^{n}\right)$ é o k-ésimo padrão unidimensional para a faixa $\left(L, w_{j}\right)$ (chamado de padrão- $\left.(k, j)\right), K_{f}$ é o número máximo de padrões de corte da faixa $\left(L, w_{j}\right)$ e, $\beta_{k j}$ é o número de vezes que o padrão- $(k, j)$ é repetido na placa $(I, W)$. Este modelo terá importância quando houver limitantes no número de peças no padrão (problema restrito) e o método de decomposição de Gilmore e Gomory não mais se aplica. Neste caso, a relaxação lagrangiana pode ser usada e uma seqüência de problemas irrestritos são resolvidos, utilizando-se a decomposição acima. No Anexo 2, este caso é introduzido.

\subsection{Limitantes Superiores}

Como é usual em problemas de otimização (maximização), um limitante superior é obtido pela relaxação do problema.

\subsubsection{Limitante superior trivial}

Um limitante superior para o nó $(x, y)$ é definido relaxando-se o problema de corte, considerando-se apenas que a área dos itens alocados não exceda a área do retângulo, ou 
seja,

$$
\begin{aligned}
\operatorname{LS}(x, y)= & \operatorname{maximizar} \sum_{i \in A(x, y)} v_{1} \cdot a_{1} \\
\text { sujeito a }: & \sum_{i \in A(x, y)}\left(\ell_{1} \cdot w_{1}\right) \cdot a_{1} \leq(x . y) \\
& a_{1} \geq 0, i \in A(x, y)
\end{aligned}
$$

onde $A(x, y)=\left\{i \mid \ell_{1} \leq x e w_{1} \leq y\right\}$, com a seguinte solução trivial

$$
L S(x, y)=\left\{\begin{array}{l}
\max _{1 \in A(x, y)}\left\{v_{1} \cdot\left(\frac{x}{\ell_{1}}\right) \cdot\left(\frac{y}{W_{1}}\right)\right\} \\
0, \text { se } A(x, y)=\phi
\end{array}\right.
$$

Este limitante foi inicialmente utilizado por Herz (1972) e mais tarde por Morabito et al. (1992).

\subsubsection{Iimitante superior para problemas restritos}

Suponha, por simplicidade de notação, que $\mathrm{v}_{1} /\left(\ell_{1} \cdot \mathrm{w}_{1}\right) \leq \mathrm{v}_{2} /\left(\ell_{2} \cdot \mathrm{w}_{2}\right) \leq \ldots \leq \mathrm{v}_{\mathrm{m}} /\left(\ell_{\mathrm{m}} \cdot \mathrm{w}_{\mathrm{m}}\right.$. Então, um limitante superior é dado por:

$$
\operatorname{LS}(x, y)=\sum_{i=1}^{m} v_{1} \cdot \bar{a}_{1}
$$

onde $\bar{a}_{1}=\min \left\{b_{1},\left(\frac{x}{l_{1}}\right)\left(\frac{y}{w_{1}}\right)\right\}$ e $\bar{a}_{k}=\min \left\{b_{k},\left(x \cdot y-\sum_{j=1}^{k-1} l_{j} \cdot w_{j} \cdot \bar{a}_{j}\right) /\left(l_{k} \cdot w_{k}\right)\right\}$, $\mathrm{k}=1, \ldots, \mathrm{m}$.

4.3.3. Limitante superior para um problema com placa defeituosa

Para o problema de corte com peças defeituosas, - limitante superior de um nó $(x, y)$ é calculado pela sua área, 
ou seja, a área total do nó $(\mathrm{x}, \mathrm{y})$, decrementada das áreas defeituosas.

\subsubsection{Limitante superior para problemas com peças do tipo I}

Nesta classe de problemas, o limitante superior é calculado pela área total do nó, seja ele retangular ou do tipo L.

\subsection{Estratégia de busca}

Há diversas maneiras de percorrer um grafo, chamadas estratégias de busca (Nilsson, 1971; Rich, 1983; Pearl, 1984). O objetivo é percorrer o grafo de modo a determinar um caminho completo mais valioso, uma vez que os padrões de corte são representados no grafo E/OU como caminhos completos (veja seção 3.1 ).

Uma estratégia de busca utilizada por Morabito (1989, 1992) para resolver problemas de corte e empacotamento, consistiu na combinação de duas estratégias básicas: backtracking (BT) e hill-climbing (HC). Backtracking é uma variação da estratégia de busca em profundidade (depth-first), que consiste em ramificar primeiro os nós gerados mais recentemente, de modo que todos os caminhos do grafo sejam percorridos. Hill-climbing, por outro lado, é uma estratégia de busca míope, baseada em otimização local, que escolhe a melhor solução (um nó ou, no caso da abordagem em grafo E/OU, um caminho completol encontrada até então, e descarta as demais soluções. Esta escolha é baseada numa avaliação dos limitantes inferior e superior da solução.

Estas duas estratégias básicas podem ser combinadas, buscando uma solução mais promissora dentre descendentes de um nó, um pouco além de seus sucessores imediatos. Para 
isto, é necéssário a noção de profundidade de um nó no grafo. A profundidade de um nó no grafo é definida tal que, o nó raiz tem profundidade zero e, a profundidade de qualquer outro nó é igual à profundidade de seu predecessor imediato, acrescido de 1. As estratégias podem, então, ser combinadas, de modo que BT investiga todos os possiveis caminhos até uma profundidade máxima e, HC escolhe o mais promissor, descartando-se os demais (se a profundidade máxima for igual a 1, então tem-se HC pura, se infinito, tem-se BT purol. Cada nó no caminho mais promissor com profundidade máxima é novamente investigado por BT até a profundidade máxima, e assim por diante.

Considere um nó $N$, seus nós sucessores $\mathrm{N}_{1}$ e $\mathrm{N}_{2}$ e seja $V(N)$ o valor do nó $N$ dado por uma solução viável (por exemplo, a solução homogênea, ou outra melhọ quando disponível). Durante a expansão deste nó, utilizam-se os limitantes inferiores e superiores para evitar a geração de nós desnecessários, descartando caminhos não promissores. Assim,

- se $v(N)=L S(N)$, então a solução que fornece $v(N)$ é solução ótima para o nó $\mathrm{N}$.

- se $v(N)<\operatorname{LI}\left(N_{1}\right)+\operatorname{LI}\left(N_{2}\right)$, então o valor do nó $N$ é atualizado por $v(N)=L I\left(N_{1}\right)+L I\left(N_{2}\right) \quad$ (uma nova solução viável é fornecida pela composição das soluções de nós sucessores).

- se $V(N) \geq \operatorname{LS}\left(N_{1}\right)+L S\left(N_{2}\right)$, ou seja, se o valor de uma solução viável no nó $\mathrm{N}$ é melhor que a soma dos limitantes superiores de seus sucessores, então não é necessário investigar os nós $\mathrm{N}_{1}$ e $\mathrm{N}_{2}$.

Observe que o valor de um caminho completo é a . soma dos valores dos nós finais e, o melhor caminho a partir do nó $\mathrm{N}$ é determinado por aquele que apresenta o melhor valor $\mathrm{v}(\mathrm{N})$. 
Note que, com o limitante na profundidade do grafo e a estratégia hill-climbing, a otimalidade do problema de corte pode ser perdida.

A seguir, é apresentado o algoritmo para esta estratégia de busca híbrida.

\subsection{Algoritino $\mathrm{BT}-\mathrm{HC}$}

$\underline{\text { Passo } 0}$

Considere a placa $(L, W)$, as peças $\left(\ell_{1}, W_{1}\right), i=1, \ldots, m$, e MP, a profundidade máxima permitida na estratégia de busca. Considere o nó raiz como o nó que contém as informações da placa inicial.

\section{Passo 1 - Backtracking}

Aplique a estratégia de busca backtracking com profundidade MP a partir do nó raiz, armazenando o caminho que apresenta - melhor valor para este nó.

\section{Passo 2 - Hill-Climbing}

Para cada nó final (profundidade MP) do caminho gerado pela estratégia backtracking, verifique se é possível expandi-lo. Se for, retorne ao Passo 1, considerando-o como nó raiz.

O algoritmo, apesar de percorrer todo o conjunto de discretização $X$ e $Y$, ou seja, gerar muito cortes, não requer muita memória computacional, uma vez que ele armazena somente o melhor caminho em cada nó.

No algoritmo $\mathrm{BT}-\mathrm{HC}$ há diversas sugestões para o cálculo do limitante inferior (solução viável) em cada nó:

- solução homogênea e homogênea composta no problema de corte irrestrito e restrito, respectivamente; 
- solução 2-estágios no nó raiz e, nos demais nós, a solução homogênea ;

- solução 2-estágios nos retângulos considerados relativamente grandes, ou seja, dado um nó $(x, y)$, se $\left(x>q \cdot l_{\max }\right)$ e $\left(y>q \cdot w_{\max }\right)$ , onde $q$ é um inteiro (por exemplo $q=3, \ell_{\max }=\max _{1 \leq \mathrm{s} s \mathrm{~m}}\left\{\ell_{\mathrm{i}}\right\}$ e $\left.\mathrm{w}_{\max }=\max _{1 \leq 1 \leq \mathrm{m}}\left\{\mathrm{w}_{\mathrm{i}}\right\}\right)$, aplica-se a solução 2-estágios, caso contrário, a solução homogênea. Convém observar que Hifi (1997) analisou o uso da solução 2-estágios para todos os nós, usando um procedimento de programação dinâmica.

\subsection{Conjectura do Problema de Corte Restrito}

Conjectura: No problema de corte restrito, se o conjunto de discretização estiver completo (isto é, regras de simetria e ordenação descartadas) e a estratégia backtracking for aplicada com profundidade ilimitada (isto é, HC descartada), a otimalidade do problema é garantida, ou seja, a forma de percorrer o grafo, sugerida na seção 3.2.2, onde apenas um nó sucessor herda a limitação de nó precedente, não é gulosa.

Esta conjectura garante que a abordagem baseada no grafo E/OU determina sempre a solução ótima para o problema de corte restrito quando se retiram a regra de simetria e ordenação e a limitação de profundidade do grafo. Assim sendo, abordagem em grafo E/OU gera implicitamente todas as combinações possiveis de padrões de corte, obtendo a melhor delas.

No capitulo 6 são apresentados alguns exemplos, onde se compararam as soluções obtidas com exemplos ótimos obtidos através de Relaxação Lagrangiana (Gramani, 1997).

No próximo capítulo são apresentadas algumas heuristicas visando diminuir o espaço de busca no grafo E/OU. 


\section{Heurísticas}

Para reduzir o espaço de busca, recorre-se a algumas heuristicas que podem ser-aplicadas no algoritmo, de forma a diminuir o espaço de busca (Morabito et al., 1992; Arenales e. Morabito, 1995; Morabito e Arenales, 1996). Considere um nó qualquer $\mathrm{N}$ e seus sucessores $\mathrm{N}_{1}$ e $\mathrm{N}_{2}$.

- H1 (Morabito et al., 1992)

Se $\left(1+\lambda_{1}\right) \cdot v(N) \geq L S\left(N_{1}\right)+L S\left(N_{2}\right) \operatorname{com} \lambda_{1}>0$, os nós $N_{1}$ e $N_{2}$ são descartados como não-promissores.

Experimentos numéricos têm sugerido valores para $\lambda_{1}$ no intervalo $[0.01,0.1]$, com bons resultados. Note que, se $\lambda_{1}$ tiver o valor nulo, os nós $\mathrm{N}_{1}$ e $\mathrm{N}_{2}$ podem ser descartados sem perda de generalidade.

Esta heurística faz uma aposta de que se os limitantes superiores para os nós sucessores (que não é necessariamente um limitante superior para o nó $N$ ) não for muito me1hor que o valor da solução viável já disponível no nó, então isto é uma indicação de que este não é um bom caminho a ser investigado. 
- H2 (Morabito et al., 1992)

Se $\lambda_{2} \cdot \operatorname{LI}(\mathrm{N}) \geq \operatorname{LI}\left(\mathrm{N}_{1}\right)+\operatorname{LI}\left(\mathrm{N}_{2}\right)$ com $0<\lambda_{2}<1$, os nós $\mathrm{N}_{1}$ e $\mathrm{N}_{2}$ são descartados.

Experimentos numéricos sugerem que o parămetro $\lambda_{2}$ deva ter valores entre 0.90 e 0.95 .

Esta heuristica faz uma aposta de que se a soluÇão composta pelas soluções homogêneas nos nós sucessores não forem razoavelmente melhor que a solução homogênea do nó $N$, então este caminho não é promissor.

Em Arenales e Morabito (1995), onde o problema de corte não-guilhotinado foi estudado, alguns experimentos computacionais para o problema de carregamento de paletes do produtor (apenas um tipo de retãngulo, com possibilidade de giro de $90^{\circ}$ ) mostraram que os parâmetros $\lambda_{1}$ e $\lambda_{2}$ podem ser dependentes dos dados com resultados muito bons. Embora não tenha sido explorada esta alternativa nesta tese, um estudo mais cuidadoso da escolha destes parâmetros merece ainda atenção.

- H3 (Morabito e Arenales, 1996)

No caso do problema restrito, quando é aplicada a estratégia gulosa (seção 3.2.2) utilizando-se a busca em profundidade com limitação e hill-climbing, junto com as regras de ordenação e simetria (seção 4.1), perde-se a garantia de otimalidade do problema.

- $\mathrm{H} 4$

Uma sugestăo no caso do problema restrito é que, ao invés dé limitar $a_{i}^{1} \leq b_{i}^{N}$ (H3), quando o nó $N_{1}$ for expandido, limitar o valor da peça $i$ em uma porcentagem de $b_{i}^{N}$, ou seja, $a_{i}^{1} \leq K . b_{i}^{N}$ 
$\operatorname{com} 0<K<1$

Experimentos numéricos sugerem que o parâmetro $K$ deva ter valores no intervalo $[0.8,1$ ) (veja seção 6.2.2).

- H5 (Beasley, 1985)

Esta heuristica introduz uma limitação no número de elementos dos conjuntos de discretização $X$ e $Y$.

Considere $\mathrm{N}$ o conjunto com o Indice das peças utilizadas para a geração do conjunto $x$, sendo, inicialmente, $N=\{1,2, \ldots, m\}$, $x$ ○ número de elementos deste conjunto, onde $\mathrm{x}=\left\{\mathrm{x} \mid \mathrm{x}=\sum_{1 \in \mathbb{N}} \alpha_{i} \ell_{1}, 1 \leq \mathrm{x} \leq \mathrm{L}-\min \left\{\ell_{1}, j \in \mathrm{N}\right\} \alpha_{i} \geq 0\right.$ e inteiro $\}$

A heurística consiste em diminuir o tamanho do conjunto $X$ da maneira que segue, sendo XMax o tamanho máximo permitido:

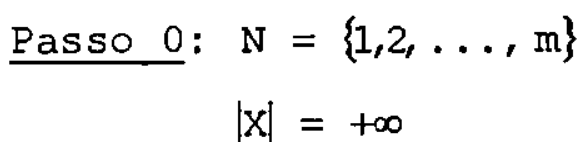

Passo 1: Enquanto $\mathrm{X}>\mathrm{XMax}$ faça

Geração do conjunto $X$

Se $X>x \max$ então

$$
\ell_{j}=\min \left\{\ell_{1}, i \in N\right\}
$$$$
\mathrm{N}=\mathrm{N}-\{j\}
$$

Fim se

Fim enquanto

o procedimento é análogo para o conjunto de discretização Y.

- $\mathrm{H} 6$

Uma sugestão, ainda para diminuir o tamanho do conjunto de discretização, é eliminar $\ell_{j}$ tal que $\left|\ell_{i}-\ell_{j}\right|<\delta$.L, $0<\delta<1$, 
quando da geração do conjunto X (Figura 5.1). Note que este procedimento é diferente do utilizado por Hifi (1997), onde foi feita uma modificação na função recursiva de Christofides e Whitlock (1977), vista na seção 4.1 .

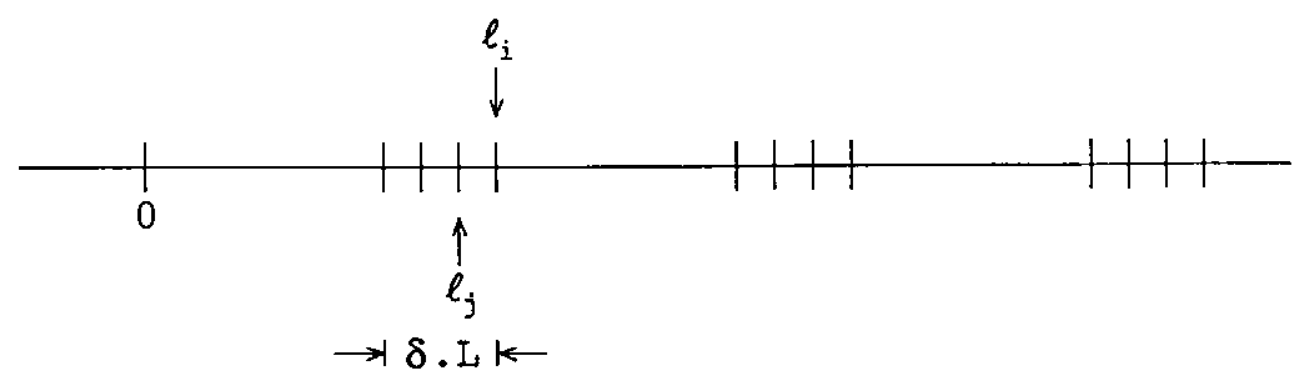

Figura 5.1 - Eliminação de $\ell_{j}$ na geração do conjunto X

Neste caso, primeiramente redefine-se o conjunto $\mathrm{N}$ e, a seguir, gera-se o conjunto x uma única vez.

$$
\begin{aligned}
\text { Passo } 0: N & =\{1,2, \ldots, \mathrm{m}\} \\
1_{0} & =-\infty \\
\ell_{1} & \leq \ell_{2} \leq \ldots \leq \ell_{\mathrm{m}} \\
\mathrm{k} & =\mathrm{m}
\end{aligned}
$$

Passo 1: Repita

$$
\begin{aligned}
& j=k-1 \\
& \text { Enquanto } \left.\ell_{k}-\ell_{j}<\delta . L\right) \text { e }(j \neq 0 \text { faça } \\
& \quad N=N-\{j) \\
& \quad j=j-1
\end{aligned}
$$$$
\text { Fim enquanto }
$$$$
\mathrm{k}=\mathrm{j}
$$$$
\text { Até } \mathrm{k}=0
$$

Passo 2: Geração do conjunto $x$ tal que

$$
x=\left\{x \mid x=\sum_{1 \in N} \alpha_{1}, \ell_{1}, 1 \leq x \leq L-\min \left\{\ell_{y}, j \in N\right\}, \alpha_{i} \geq 0 \text { e inteiro }\right\} .
$$

A sugestão também é válida para a geração do conjunto Y. 
dados de problemas reais (veja capitulo 7), onde ocorriam, frequentemente, dimensões relativamente próximas das peças demandadas.

- $\mathrm{H} 7$

Esta sugestão se refere à ordem de seleção dos pontos nos conjuntos de discretização $X$ e $Y$, ou seja, o modo como eles serão examinados:

- percorrê-lo em ordem crescente, examinando assim, na estratégia backtracking, sempre os menores retângulos primeiro;

- percorrê-10 em ordem decrescente, preenchendo primeiro os retângulos maiores;

- percorrê-lo de maneira aleatória, ou seja, não é possível prever como serão feitos os cortes.

No capítulo 6 são apresentados os resultados computacionais obtidos com estas heuristicas para problemas estudados. 


\section{Experiências Computacionais}

A implementação computacional foi desenvolvida na linguagem Pascal, utilizando o compilador Borland Pascal versão 7.0, em um microcomputador Pentium, $167 \mathrm{Mhz}$ com 32 Mbytes de RAM.

Foram desenvolvidos algoritmos para cada classe de problema estudado, ou seja, problema irrestrito, restrito, estagiado, com placa defeituosa, com limitação no número de tipo de peças, com corte-cabeça e também com peças do tipo L.

A implementação foi feita para problemas de corte bidimensional, mas a abordagem em grafo $E / O U$ pode ser facilmente estendida para problemas tridimensionais, necessitando apenas de alguns ajustes na estrutura de dados do programa, assim como no código computacional.

A estrutura de dados utilizada na implementação dos algoritmos, assim como a maneira como foi implementado o conjunto de discretização, encontra-se em Gonçalves-Vianna et al. (2000).

Em todos os algoritmos implementados há limitaÇão em relação à quantidade de memória disponível, ou seja, antes de se gerar um novo nó verifica-se se há uma quantidade mínima de memória. Esta quantidade varia de acordo com o problema e os dados armazenados em cada nó.

Para análise dos resultados obtidos de algumas 
classes de problemas foram gerados exemplos aleatoriamente. Estes exemplos foram divididos em duas classes, exemplos pequenos e grandes, de acordo com Morabito (1992).

- Exemplos pequenos: nesta classe de problema, us conjuntos de discretização resultam com poucos elementos. Os valores $\ell_{1}$ e $w_{1}, i=1, \ldots, m$, foram gerados aleatoriamente $e$, em seguida, arredondados, dentro dos intervalos [0.25L,0.75L] e $[0.25 \mathrm{~W}, 0.75 \mathrm{~W}]$, respectivamente.

- Exemplos grandes: os conjuntos de discretização resultam com muitos elementos, tendo sido os valores $\ell_{1}$ e $w_{1}, i=1, \ldots, m$, gerados aleatoriamente $e$, em seguida, arredondados, dentro dos intervalos $[0.10 \mathrm{~L}, 0.50 \mathrm{~L}]$ e $[0.10 \mathrm{~W}, 0.50 \mathrm{~W}]$, respectivamente.

Nas duas classes de problema, os valores $v_{1}$, $i=1, \ldots, m$, foram obtidos por $v_{1}=\frac{\ell_{1} \cdot W_{1}}{L \cdot W}$.

\subsection{Problema Irrestrito}

Nesta seção são apresentados os resultados obtidos com o problema de corte irrestrito.

Foram feitos testes com diferentes tipos de conjuntos de discretização. Aqui, são apresentados os dados obtidos com o problema irrestrito não-estagiado, percorrendo os conjuntos de discretização de maneira ordenada crescente e decrescente e também aleatória. Na geração dos conjuntos, utilizaram-se as regras para geração dos conjuntos de discretização (seção 4.1), profundidade máxima de 4 na estratégia de busca e parâmetros $\lambda_{1}=1 \%$ e $\lambda_{1}=95 \%$ (Heuristicas $\mathrm{H} 1$ e H2, respectivamente, vistas no capitulo 5). 


\subsubsection{Escolha seqüencial crescente dos cortes}

A seguir, nas Tabelas 6.1 e 6.2 , são apresentados os resultados obtidos percorrendo os conjuntos de cortes de maneira ordenada sequiencial crescente, que foram limitados em 100 elementos (heurística H5, vista no capítulo 5). Para cada conjunto de problemas foram gerados 50 exemplos.

A tabela foi dividida em 6 colunas, onde a primeira, segunda e terceira colunas se referem ao número de peças (m) e dimensões da placa $(L, W)$, respectivamente. A quarta, quinta e sexta colunas contém, respectivamente, a média aritmética das soluçōes, do número de nós e do tempo computacional (em segundos) obtidos com cada conjunto de exemplos.

Tabela 6.1 - Exemplos pequenos

\begin{tabular}{|c|c|c|c|c|c|}
\hline $\mathrm{m}$ & L & $w$ & Solução & № nós & $t(s)$ \\
\hline 5 & 100 & 100 & 0.8776 & 8.00 & $0 . \overline{01}$ \\
\hline$\overline{10}$ & 100 & 100 & 0.9362 & 20.30 & $\overline{0.01}$ \\
\hline 20 & 100 & 100 & 0.9792 & 52.52 & 0.05 \\
\hline \multicolumn{3}{|r|}{ Média } & 0.9310 & 26.94 & 0.02 \\
\hline 5 & 1000 & 1000 & 0.8583 & 7.14 & 0.00 \\
\hline 10 & 1000 & 1000 & 0.9383 & 28.00 & 0.02 \\
\hline 20 & 1000 & 1000 & 0.9530 & 70.72 & 0.06 \\
\hline 30 & 1000 & 1000 & 0.9690 & 209.16 & 0.21 \\
\hline \multicolumn{3}{|r|}{ Média } & 0.9297 & 78.76 & 0.07 \\
\hline 5 & 3000 & 3000 & $0 . \overline{9240}$ & 8.10 & 0.00 \\
\hline 10 & 3000 & 3000 & 0.9382 & 18.18 & 0.02 \\
\hline 20 & 3000 & 3000 & 0.9565 & 70.54 & 0.08 \\
\hline 30 & 3000 & 3000 & 0.9651 & 194.54 & 0.28 \\
\hline \multicolumn{3}{|r|}{ Média } & 0.9460 & 72.84 & 0.10 \\
\hline \multicolumn{3}{|c|}{ Média total } & 0.9356 & 59.51 & 0.06 \\
\hline
\end{tabular}


Tabela 6.2 - Exemplos grandes

\begin{tabular}{|c|c|c|c|c|c|}
\hline$m$ & $\mathrm{~L}$ & $W$ & Solução & № nós & $t(s)$ \\
\hline 5 & 100 & 100 & 0.9661 & 35.00 & 0.03 \\
\hline 10 & 100 & 100 & 0.9893 & 350.60 & 0.40 \\
\hline 20 & 100 & 100 & 0.9964 & 83.00 & 0.37 \\
\hline \multicolumn{3}{|c|}{ Média } & 0.9839 & 156.20 & 0.27 \\
\hline 5 & 1000 & 1000 & 0.9758 & 15.80 & 0.02 \\
\hline 10 & 1000 & 1000 & 0.9914 & 254.60 & 0.58 \\
\hline 20 & 1000 & 1000 & 0.9926 & 309.87 & 1.16 \\
\hline 30 & 1000 & 1000 & 0.9908 & 457.32 & 3.30 \\
\hline \multicolumn{3}{|c|}{ Média } & 0.9877 & 259.40 & 1.27 \\
\hline 5 & 3000 & 3000 & 0.9832 & 34.20 & 0.06 \\
\hline 10 & 3000 & 3000 & 0.9958 & 361.80 & 0.51 \\
\hline 20 & 3000 & 3000 & 0.9932 & 595.40 & 3.51 \\
\hline 30 & 3000 & 3000 & 0.9445 & 895.12 & 12.03 \\
\hline \multicolumn{3}{|c|}{ Média } & 0.9792 & 471.63 & $\overline{4.03}$ \\
\hline \multicolumn{3}{|c|}{ Média total } & 0.9836 & 295.74 & 1.86 \\
\hline
\end{tabular}

Observe na segunda linha da Tabela 6.2, quando $\mathrm{m}=10, \mathrm{~L}=100$ e $\mathrm{W}=100$, que o número de nós é superior ao da terceira linha, quando $m=20$. Isto ocorreu porque dois exemplos do conjunto de problemas gerados, para $m=20$, obtiveram a solução com um número muito grande de nós, elevando desta maneira a média aritmética dos nós do conjunto.

\subsubsection{Escolha seqüencial decrescente dos cortes}

A seguir, são apresentados os resultados obtidos com os mesmos exemplos da seção anterior, percorrendo os conjuntos de cortes de maneira ordenada decrescentemente, limitados também em 100 elementos. 
Tabela 6.3 - Exemplos pequenos

\begin{tabular}{|c|c|c|c|c|c|}
\hline$m$ & $\bar{L}$ & $\overline{\mathrm{W}}$ & Solução & $N^{E}$ nós & $t(s)$ \\
\hline 5 & 100 & 100 & 0.8775 & 9.01 & 0.02 \\
\hline 10 & 100 & 100 & 0.9360 & $18 . \overline{23}$ & 0.02 \\
\hline 20 & 100 & 100 & 0.9783 & 44.66 & 0.04 \\
\hline \multicolumn{3}{|c|}{ Média } & $0 . \overline{9306}$ & 23.97 & 0.03 \\
\hline 5 & 1000 & 1000 & $0 . \overline{8498}$ & 6.55 & 0.01 \\
\hline 10 & 1000 & 1000 & 0.9380 & 22.70 & 0.03 \\
\hline 20 & 1000 & 1000 & 0.9529 & 69.96 & 0.07 \\
\hline 30 & 1000 & 1000 & 0.9687 & 165.03 & 0.20 \\
\hline \multicolumn{3}{|c|}{ Média } & 0.9274 & 66.06 & 0.08 \\
\hline 5 & 3000 & 3000 & 0.9234 & 5.98 & 0.01 \\
\hline 10 & 3000 & 3000 & 0.9381 & $\overline{15.11}$ & 0.03 \\
\hline 20 & 3000 & 3000 & 0.9559 & 59.01 & 0.01 \\
\hline 30 & 3000 & 3000 & 0.9649 & 136.01 & 0.24 \\
\hline \multicolumn{3}{|c|}{ Média } & 0.9456 & 54.03 & 0.07 \\
\hline \multicolumn{3}{|c|}{ Média total } & 0.9345 & 48.02 & 0.06 \\
\hline
\end{tabular}

Tabela 6.4 - Exemplos grandes

\begin{tabular}{|c|c|c|c|c|c|}
\hline $\mathrm{m}$ & $\bar{I}$ & $\bar{W}$ & Solução & № nós & $t(s)$ \\
\hline 5 & 100 & 100 & 0.9660 & 36.20 & 0.03 \\
\hline 10 & 100 & 100 & 0.9890 & 366.10 & 0.47 \\
\hline 20 & 100 & 100 & 0.9964 & 130.12 & 0.46 \\
\hline \multicolumn{3}{|r|}{ Média } & 0.9838 & 177.47 & 0.32 \\
\hline 5 & 1000 & 1000 & 0.9758 & 15.96 & 0.02 \\
\hline 10 & 1000 & 1000 & $\overline{0.9912}$ & 301.01 & 0.61 \\
\hline 20 & 1000 & 1000 & 0.9926 & 371.22 & 1.22 \\
\hline 30 & 1000 & 1000 & 0.9908 & 484.83 & 3.20 \\
\hline \multicolumn{3}{|r|}{ Média } & 0.9876 & 293.26 & 1.26 \\
\hline 5 & 3000 & 3000 & 0.9832 & 37.27 & 0.05 \\
\hline 10 & 3000 & 3000 & 0.9961 & 390.12 & 0.55 \\
\hline 20 & 3000 & 3000 & 0.9932 & 621.87 & 3.13 \\
\hline 30 & 3000 & 3000 & 0.9438 & 900.01 & 16.10 \\
\hline \multicolumn{3}{|r|}{ Média } & 0.9791 & 487.32 & 4.96 \\
\hline \multicolumn{3}{|c|}{ Média final } & 0.9835 & 319.35 & 2.18 \\
\hline
\end{tabular}

Deve-se observar que a média do número de nós da segunda linha da Tabela 6.4, com $\mathrm{m}=10$, também é superior a mé- 
dia do número de nós da terceira linha, quando $\mathrm{m}=20$. Os mesmo exemplos que obtiveram um número de nós elevado na determinação da solução percorrendo o conjunto de discretização de maneira ordenada crescente (conforme observado em 6.1.1.), aqui também obtiveram um número superior aos demais exemplos deste conjunto.

\subsubsection{Escolha aleatória dos cortes}

Neste caso, os conjuntos de discretização são percorridos de maneira aleatoria (heuristica $\mathrm{H} 7$, do capítulo 5). As Tabelas 6.5 e 6.6 apresentam os mesmos exemplos utilizados com a escolha sequiencial dos cortes.

Tabela 6.5 - Exemplos pequenos

\begin{tabular}{|c|c|c|c|c|c|}
\hline $\mathrm{m}$ & $\bar{L}$ & $\bar{W}$ & Solução & № nós & $t(s)$ \\
\hline 5 & 100 & 100 & 0.8776 & 8.40 & 0.01 \\
\hline 10 & 100 & $\overline{100}$ & 0.9360 & 20.88 & 0.01 \\
\hline 20 & 100 & 100 & 0.9789 & 57.64 & 0.09 \\
\hline \multicolumn{3}{|c|}{ Média } & 0.9308 & 28.97 & 0.04 \\
\hline 5 & 1000 & 1000 & 0.8580 & 7.44 & 0.01 \\
\hline 10 & 1000 & 1000 & 0.9383 & 30.10 & 0.03 \\
\hline 20 & 1000 & 1000 & 0.9530 & 78.14 & 0.13 \\
\hline 30 & 1000 & 1000 & 0.9688 & 427.01 & 0.44 \\
\hline \multicolumn{3}{|c|}{ Média } & 0.9295 & 135.67 & 0.15 \\
\hline 5 & 3000 & 3000 & 0.9238 & 8.68 & 0.00 \\
\hline 10 & 3000 & 3000 & 0.9371 & 19.80 & 0.03 \\
\hline 20 & 3000 & 3000 & 0.9562 & 177.54 & 0.12 \\
\hline 30 & 3000 & 3000 & 0.9650 & 506.98 & 1.01 \\
\hline \multicolumn{3}{|r|}{ Média } & 0.9455 & 178.25 & 0.29 \\
\hline \multicolumn{3}{|c|}{ Média final } & 0.9353 & 114.30 & 0.16 \\
\hline
\end{tabular}


Tabela 6.6 - Exemplos grandes

\begin{tabular}{|c|c|c|c|c|c|}
\hline $\mathrm{m}$ & L & W & Solução & $\mathrm{N}^{\underline{c}}$ nós & $t(s)$ \\
\hline 5 & 100 & 100 & 0.9660 & 43.89 & 0.07 \\
\hline 10 & 100 & 100 & 0.9893 & 525.76 & 0.88 \\
\hline 20 & 100 & 100 & 0.9963 & 173.40 & 0.75 \\
\hline \multicolumn{3}{|c|}{ Média } & 0.9839 & 247.68 & 0.57 \\
\hline 5 & 1000 & 1000 & 0.9758 & 17.80 & 0.01 \\
\hline 10 & 1000 & 1000 & 0.9914 & 450.60 & 1.19 \\
\hline 20 & 1000 & 1000 & 0.9926 & 245.17 & 1.02 \\
\hline 30 & 1000 & 1000 & 0.9908 & 187.69 & 4.56 \\
\hline \multicolumn{3}{|c|}{ Média } & 0.9877 & 225.32 & 1.70 \\
\hline 5 & 3000 & 3000 & 0.9832 & 77.80 & 0.10 \\
\hline 10 & 3000 & 3000 & 0.9960 & 593.03 & 1.41 \\
\hline 20 & 3000 & 3000 & 0.9929 & 347.49 & 4.23 \\
\hline 30 & 3000 & 3000 & 0.9439 & 885.38 & 6.81 \\
\hline \multicolumn{3}{|c|}{ Média } & $0.9790^{-}$ & 475.93 & 3.14 \\
\hline \multicolumn{3}{|c|}{ Média final } & 0.9835 & 316.31 & 1.80 \\
\hline
\end{tabular}

Em geral, os resultados obtidos percorrendo os conjuntos de discretização de maneira ordenada sequiencial crescente são um pouco melhores que os obtidos percorrendo o conjunto de maneira decrescente e aleatória (nos exemplos pequenos, $0.12 \%$ e $0.03 \%$, respectivamente; nos exemplos grandes, $0.01 \%$ em ambos os casos), porém a melhoria foi desprezivel, que sugere que a ordenação não é um fator relevante para desempenho da abordagem.

\subsubsection{Limitante Inferior: Solução Homogênea}

A seguir são apresentados dois exemplos da literatura para o problema de corte irrestrito.

Herz (1972) apresentou um problema irrestrito, com uma placa de dimensão $(127,98)$ e 5 peças de dimensões $(18,65),(24,27),(21,13),(36,17)$ e $(54,20)$, com $v_{1}=1170$, $\mathrm{v}_{2}=273, \mathrm{v}_{3}=648, \mathrm{v}_{4}=612, \mathrm{v}_{\mathrm{S}}=1080$, com solução ótima igual a 12348 e 99,21: de aproveitamento da área. A Figura 6.1 apresenta $\circ$ 
resultado obtido com a abordagem em grafo E/OU, utilizando as regras de geração do conjuntos de discretização, vistas na seção 4.1, limite de profundidade igual a 3 e os parâmetros $\lambda_{1}=108$ e $\lambda_{2}=958$. Este resultado foi obtido em $0.39 \mathrm{~s}$. Observe que esta solução é igual a solução ótima obtida por Herz (1972).

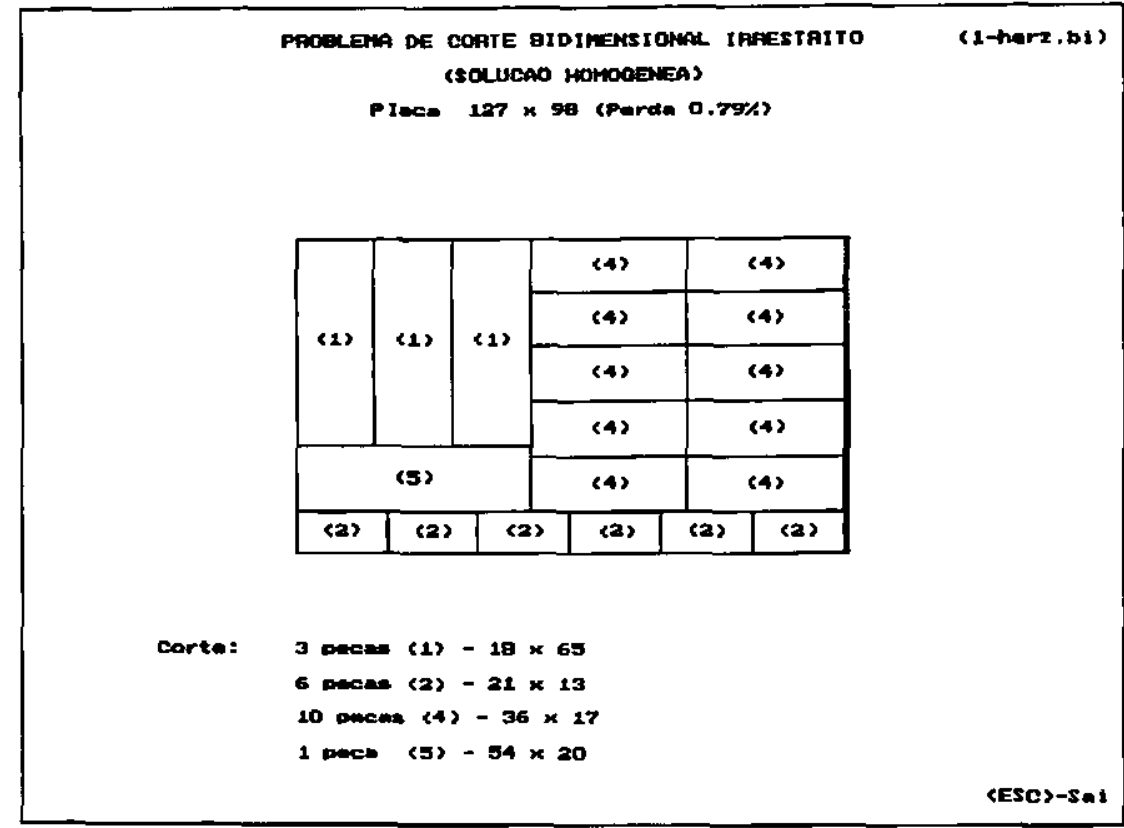

Figura 6.1 - Solução do exemplo de Herz (1972)

Beasley (1985) apresentou um problema irrestrito com dados reais (uma placa de dimensão $(3000,3000)$ e 32 tipos de peças) com uma solução heurística de 98.488 de aproveitamento da área, limitando a cardinalidade dos conjuntos de discretização em 100 unidades. Utilizando as heurísticas apresentadas no capítulo 5, H1 e H2, que limitam o espaço de busca, e também a heurítica H5, que limita o tamanho do conjunto de discretização, obtiveram-se os resultados apresentados na Tabela 6.7. As colunas Xmax e Ymax indicam a limitação dos conjuntos de discretização $\mathrm{X}$ e $\mathrm{Y}$, respectivamente. 
Tabela 6.7 - Resultados obtidos do exemplo de Beasley (1985)

\begin{tabular}{|r|c|c|c|c|r|r|}
\hline $\mathrm{Xmax}$ & $Y \max$ & $\lambda_{1}$ & $\lambda_{2}$ & Solução & No nós & $t(\mathbf{s})$ \\
\hline 50 & 50 & 0.05 & 1.00 & 0.97844 & 1 & 0.02 \\
\hline 50 & 50 & 0.01 & 0.95 & 0.99126 & 33 & 0.06 \\
\hline 50 & 50 & 0.01 & 0.90 & 0.99126 & 33 & 0.05 \\
\hline 100 & 100 & 0.01 & 0.95 & 0.99572 & 18735 & 14.23 \\
\hline 50 & 50 & 0.001 & 0.95 & 0.99975 & 5741 & 4.33 \\
\hline
\end{tabular}

A Figura 6.2 apresenta a melhor solução obtida com a abordagem em grafo E/OU, com o tamanho dos conjuntos de discretização limitado em 50. Observe que esta solução é melhor do que a solução heurística obtida por Beasley (1985), apesar de não saber se ela é ótima.

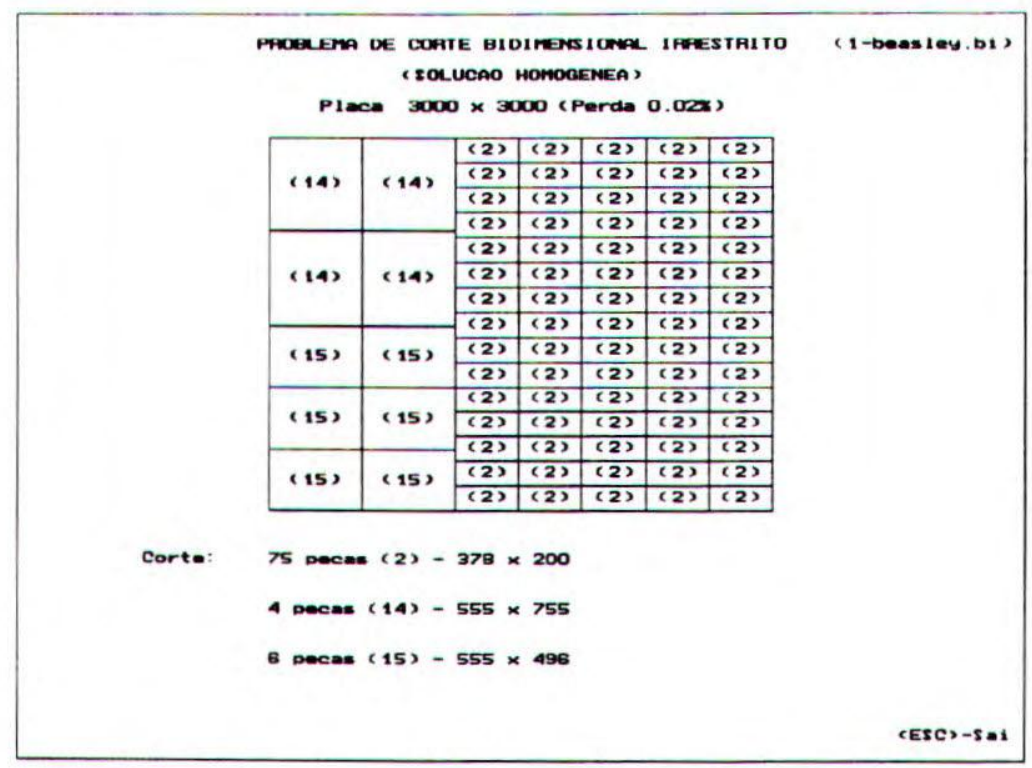

Figura 6.2 - Solução do exemplo de Beasley (1985) com $|\mathrm{X}|<50$ e $|\mathrm{Y}|<50 \quad$ (Heurística H5)

\subsubsection{Limitante Inferior: Solução 2-estágios}

As Tabelas 6.8 e 6.9 apresentam os resultados obtidos com problemas irrestritos não-estagiados (conjuntos com 50 exemplos de cada classe), com os conjuntos de discretização ordenados e limitados em 100 elementos, variando somente - limitante inferior. Este limitante é calculado através da 
solução homogênea na solução 1. Na solução 2, o limitante é dado através da solução 2-estágios, no nó inicial, e, nos demais nós do grafo, é dado pela solução homogênea.

Tabela 6.8 - Exemplos pequenos

\begin{tabular}{|c|c|c|c|c|c|c|}
\hline$m$ & $\bar{I}$ & $\bar{W}$ & Solução 1 & $t(s)$ & Solução 2 & $t(s)$ \\
\hline 5 & $\overline{100}$ & 100 & 0.8776 & 0.01 & 0.8776 & 0.03 \\
\hline 10 & 100 & 100 & 0.9367 & 0.01 & 0.9367 & 0.05 \\
\hline 20 & 100 & 100 & 0.9792 & 0.05 & 0.9792 & 0.12 \\
\hline \multicolumn{3}{|c|}{ Média } & 0.9312 & 0.02 & 0.9312 & 0.07 \\
\hline 5 & 1000 & 1000 & 0.8583 & 0.00 & 0.8583 & 0.03 \\
\hline 10 & 1000 & 1000 & 0.9383 & 0.02 & 0.9383 & 0.10 \\
\hline 20 & 1000 & 1000 & 0.9530 & 0.06 & 0.9530 & 0.30 \\
\hline 30 & 1000 & 1000 & 0.9690 & 0.21 & 0.9693 & 0.48 \\
\hline \multicolumn{3}{|c|}{ Média } & 0.9297 & 0.07 & 0.9297 & 0.23 \\
\hline 5 & 3000 & 3000 & 0.9240 & 0.00 & 0.9240 & 0.07 \\
\hline 10 & 3000 & 3000 & 0.9382 & 0.02 & 0.9382 & 0.21 \\
\hline 20 & 3000 & 3000 & 0.9565 & 0.08 & 0.9565 & 0.63 \\
\hline 30 & 3000 & 3000 & 0.9651 & 0.28 & 0.9651 & 1.03 \\
\hline \multicolumn{3}{|c|}{ Média } & 0.9460 & 0.10 & 0.9460 & 0.49 \\
\hline \multicolumn{3}{|c|}{ Média final } & 0.9356 & 0.06 & 0.9356 & 0.26 \\
\hline
\end{tabular}

Tabela 6.9 - Exemplos grandes

\begin{tabular}{|c|c|c|c|c|c|c|}
\hline $\mathrm{m}$ & I & $\bar{W}$ & Solução 1 & $t(s)$ & Solução 2 & $t(s)$ \\
\hline 5 & 100 & 100 & 0.9661 & 0.03 & 0.9661 & 0.02 \\
\hline 10 & 100 & 100 & 0.9893 & 0.40 & 0.9893 & 0.09 \\
\hline 20 & 100 & 100 & 0.9964 & 0.37 & 0.9964 & 0.17 \\
\hline \multicolumn{3}{|c|}{ Média } & 0.9839 & 0.27 & 0.9839 & 0.09 \\
\hline 5 & 1000 & 1000 & 0.9758 & 0.02 & 0.9758 & 0.04 \\
\hline 10 & 1000 & 1000 & 0.9914 & 0.58 & 0.9917 & 0.16 \\
\hline 20 & 1000 & 1000 & 0.9926 & 1.16 & 0.9926 & 0.55 \\
\hline 30 & 1000 & 1000 & 0.9908 & 3.30 & 0.9908 & 0.99 \\
\hline \multicolumn{3}{|c|}{ Média } & 0.9877 & 1.27 & 0.9877 & 0.44 \\
\hline 5 & 3000 & 3000 & 0.9832 & 0.06 & 0.9832 & 0.09 \\
\hline 10 & 3000 & 3000 & 0.9958 & 0.51 & 0.9958 & 0.36 \\
\hline 20 & 3000 & 3000 & 0.9932 & 3.51 & 0.9945 & 1.02 \\
\hline 30 & 3000 & 3000 & 0.9445 & 12.03 & 0.9448 & 1.74 \\
\hline \multicolumn{3}{|c|}{ Média } & 0.9792 & 4.03 & 0.9796 & 0.80 \\
\hline \multicolumn{3}{|c|}{ Média final } & 0.9836 & 1.86 & 0.9837 & 0.44 \\
\hline
\end{tabular}


Como se pode observar nas tabelas apresentadas, - tempo computacional diminui bastante com o uso de um um limitante inferior mais poderoso (solução 2-estágios no nó inicial) nos exemplos grandes. O tempo médio obtido com a Solução 2 é $23,65 z$ do tempo médio obtido com a solução homogênea. Nos exemplos pequenos, o tempo médio computacional obtido com a solução homogênea é $23.07 \%$ da Solução 2 .

\subsection{Problema Restrito}

Nesta seção são apresentados os resultados obtidos com o problema de corte restrito. Os exemplos foram novamente classificados, de acordo com a demanda das peças:

- Exemplos com demanda pequena: nesta classe de problema, os valores de $b_{i}, i=1, \ldots, m$, foram gerados aleatoriamente $e$, em seguida, arredondados, dentro dos intervalos que variam de $10 z$ a $50 \%$ de $\frac{L}{\ell_{i}} \cdot \frac{W}{W_{i}}$.

- Exemplos com demanda grande: os valores de $b_{i}, i=1, \ldots, m$, foram gerados aleatoriamente e, em seguida, arredondados, dentro dos intervalos que variam de $40 \%$ a $80 \%$ de $\frac{L}{\ell_{i}} \cdot \frac{W}{W_{i}}$.

A seguir, são apresentados os resultados obtidos pela abordagem em grafo E/OU aplicados aos exemplos propostos por Wang (1983), denotados por W1, W2 e W3 (todos com 20 tipos de peças). Nos exemplos de Wang (1993), o valor de utilidade das peças, $v_{i}(i=1, \ldots, 20)$, assume um valor diferente da área da peça. A Tabela 6.10 apresenta os resultados obtidos com $|\mathrm{X}|<100,|\mathrm{Y}|<100$, a profundidade máxima igual a 3 , $\lambda_{1}=0.1$ 号 e $\lambda_{2}=95 \%$. 
Tabela 6.10 - Resultados obtidos dos exemplo de Wang (1983)

\begin{tabular}{|c|c|c|c|}
\hline Exemplo & Solução & № nós & $t(s)$ \\
\hline W1 & 2277 & 1 & 0.00 \\
\hline W2 & 2694 & 221 & 0.16 \\
\hline W3 & 2721 & 365 & 0.22 \\
\hline
\end{tabular}

Todas as soluções encontradas com abordagem em grafo E/OU apresentadas pela Tabela 6.10 são ótimas. As Figuras $6.3,6.4$ e 6.5 mostram os padrões de corte obtidos.

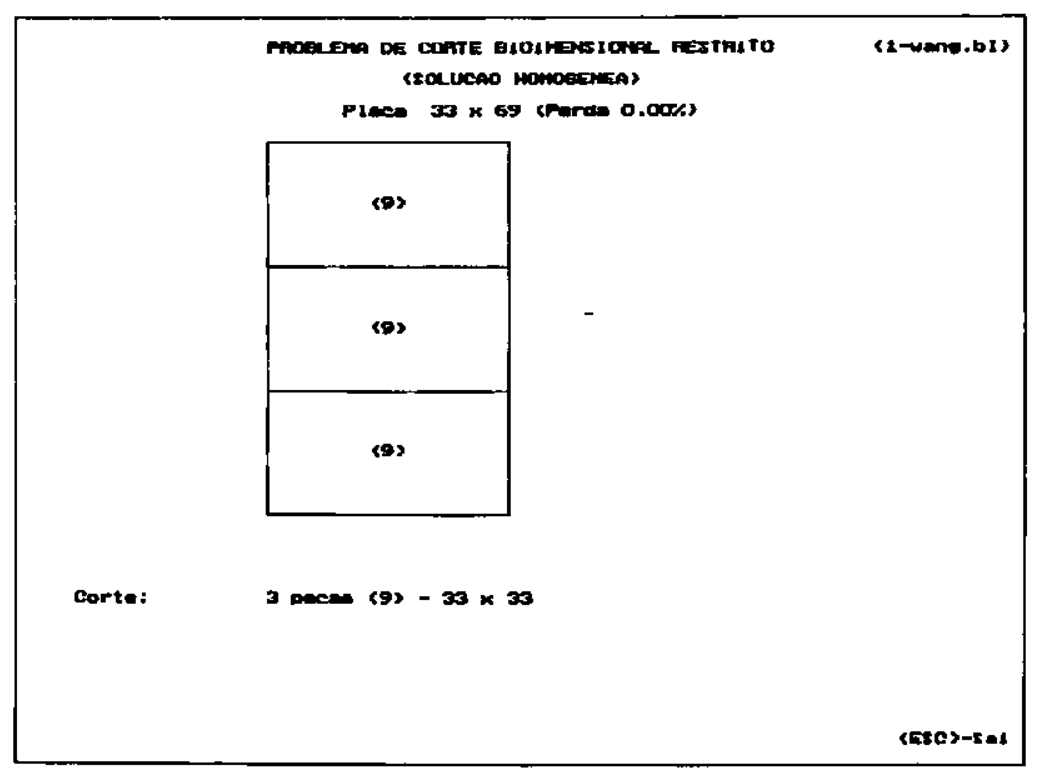

Figura 6.3 - Solução do exemplo W1 (Wang, 1983)

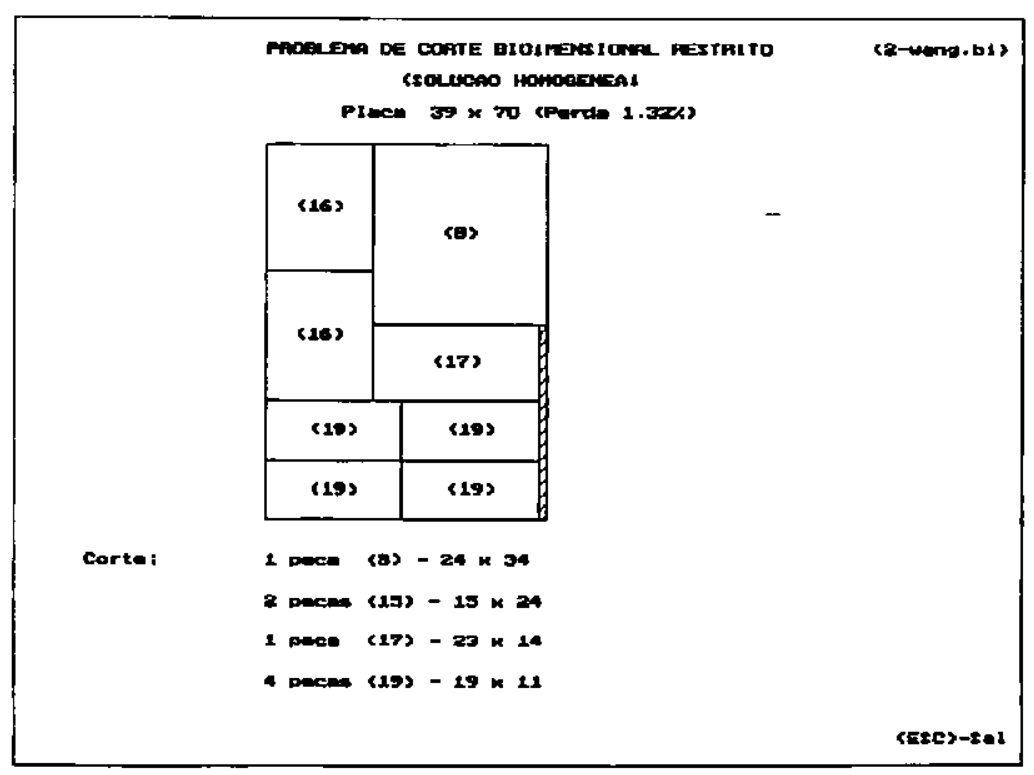

Figura 6.4 - Solução do exemplo W2 (Wang, 1983) 


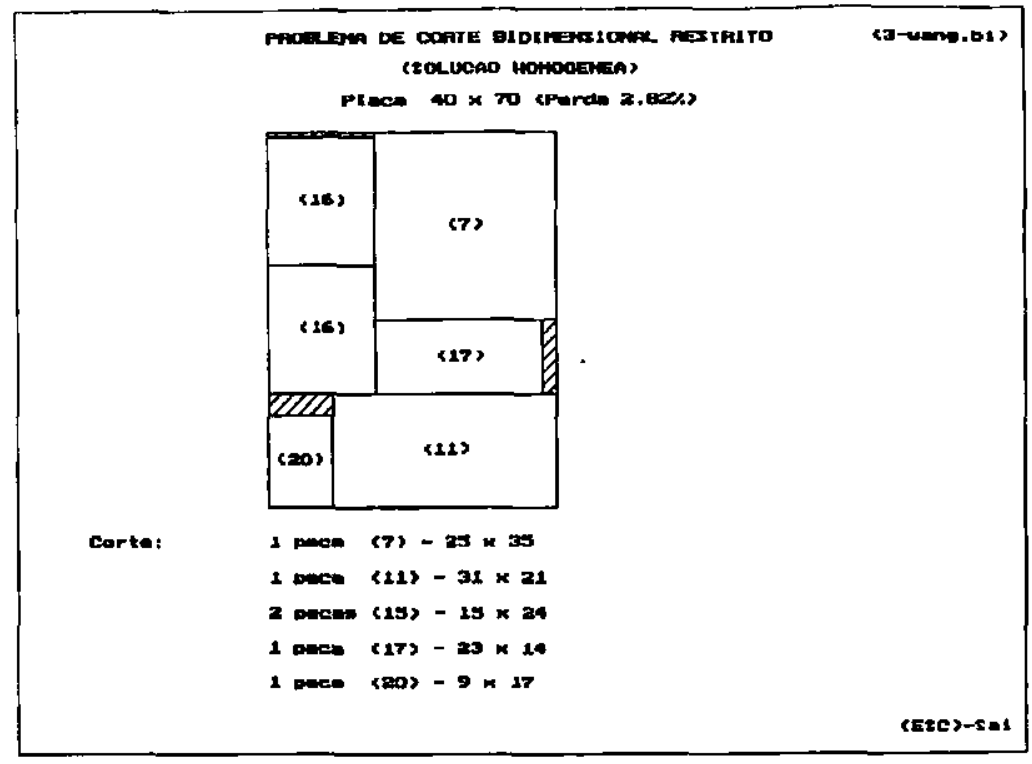

Figura 6.5 - Solução do exemplo W3 (Wang, 1983)

A Tabela 6.11 apresenta os resultados dos exemplos apresentados por Oliveira e Ferreira (1990). Os resultados foram obtidos com a abordagem em grafo E/OU utilizando os parâmetros $\lambda_{1}=0.1 \%$ e $\lambda_{2}=95 \%$. Observe que a solução ótima do primeiro exemplo só é alcançada com profundidade igual a 5.

Tabela 6.11 - Resultados obtidos dos exemplos de Oliveira e Ferreira (1990)

\begin{tabular}{|c|c|c|c|c|}
\hline Exemplo & Profundidade & Solução & № nós & $t(s)$ \\
\hline OF1 & 3 & 2713 & 3759 & 0.55 \\
\hline & 5 & 2737 & 5581 & 1.06 \\
\hline OF2 & 3 & 2690 & 2769 & 1.69 \\
\hline
\end{tabular}

As Figuras 6.6 e 6.7 apresentam os padrões ótimos obtidos pelas soluçōes da Tabela 6.11 . 


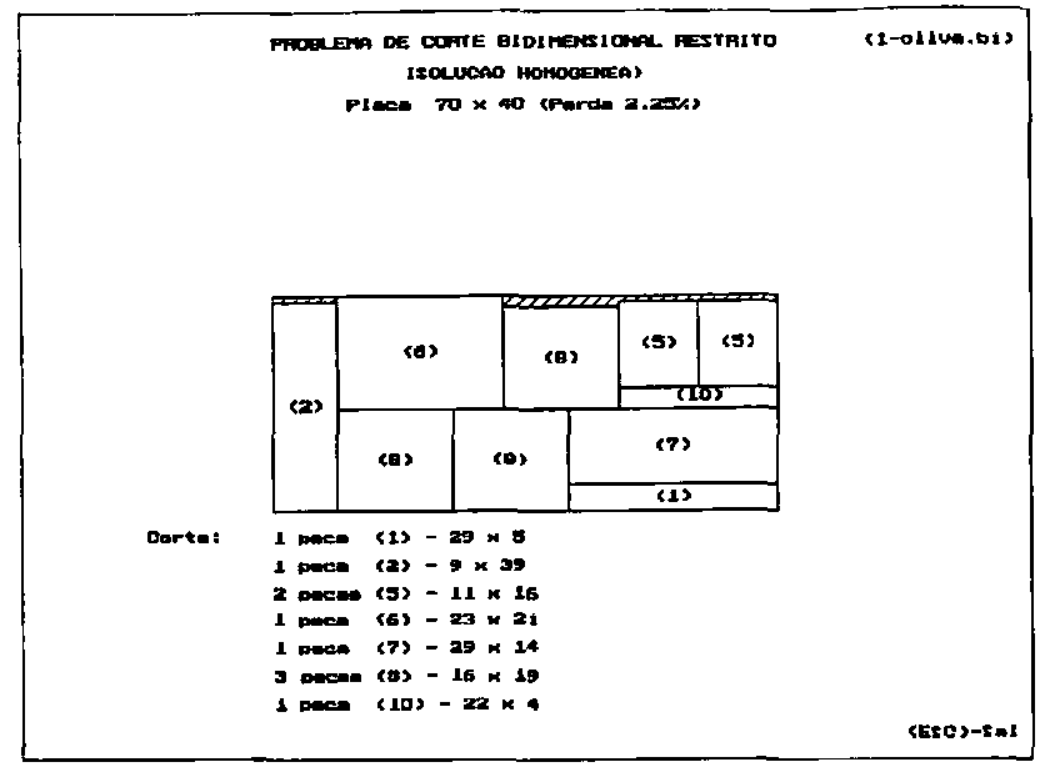

Figura 6.6 - Solução do exemplo OF1 (Oliveira e Ferreira, 1990)

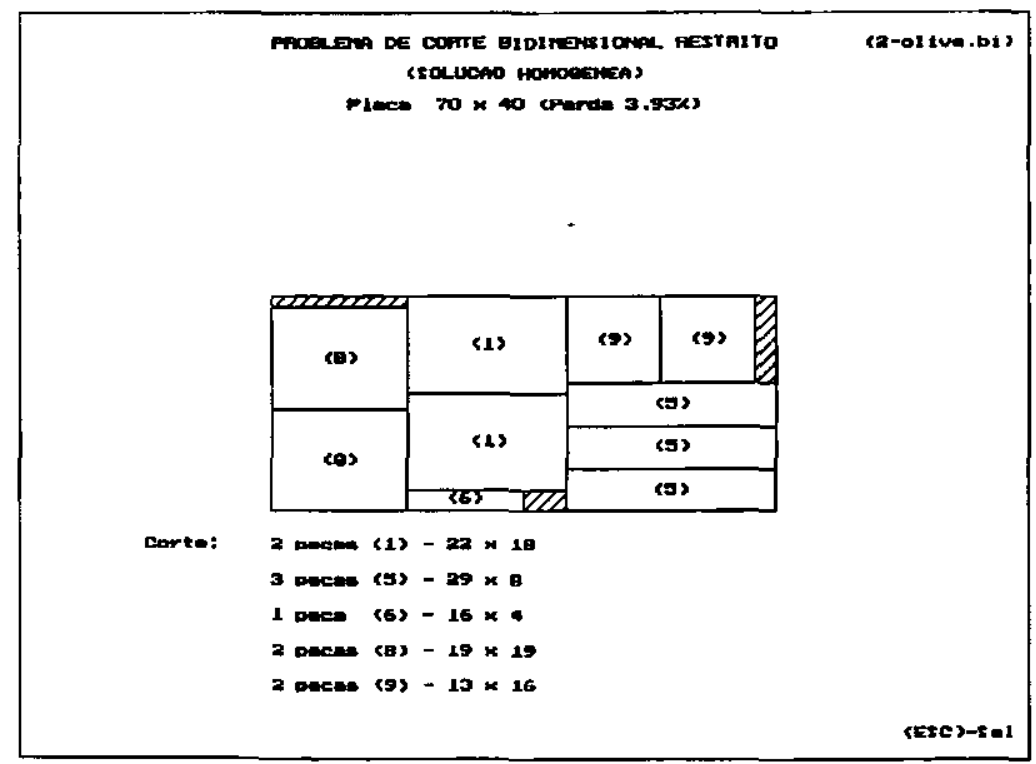

Figura 6.7 - Solução do exemplo OF2 (Oliveira e Ferreira, 1990)

\subsubsection{Limitante Inferior: Solução Homogênea Composta}

As Tabelas 6.12 e 6.13 apresentam os resultados obtidos com problemas restritos não-estagiados, com $|\mathrm{X}|<100,|\mathrm{Y}|<100$, a profundidade máxima igual a 3, $\lambda_{1}=0.1 \%$ e $\lambda_{2}=95 \%$, variando somente $\circ$ limitante inferior. Este limitante é calculado através da solução homogênea (seção 4.2.1.1) na Solução 1. Na Solução 2, o limitante é dado atra- 
vés da solução homogênea composta (seção 4.2.2.1). A tabela apresenta a média obtida com 50 exemplos de cada classe de problemas.

Tabela 6.12- Exemplos com demanda pequena

\begin{tabular}{|c|c|c|c|c|c|c|c|c|}
\hline m & I & $\bar{w}$ & Solução 1 & $\mathrm{~N}^{2}$ nós & $t(s)$ & Solução 2 & Nón nós & $t(s)$ \\
\hline 5 & 100 & 100 & 0.8725 & 67.50 & 0.06 & 0.9066 & 33.21 & 0.00 \\
\hline 10 & 100 & 100 & 0.8395 & 186.96 & 0.07 & 0.8486 & 87.13 & 0.07 \\
\hline 20 & 100 & 100 & 0.9588 & 481.77 & 0.22 & 0.9588 & 355.34 & 0.27 \\
\hline \multicolumn{3}{|r|}{ Média } & 0.8903 & 245.41 & 0.12 & 0.9047 & 158.56 & 0.11 \\
\hline 5 & 1000 & $\overline{1000}$ & 0.6489 & 32.80 & 0.01 & 0.6612 & 18.12 & 0.01 \\
\hline$\overline{10}$ & 1000 & 1000 & 0.7991 & $122 . \overline{92}$ & 0.05 & 0.8052 & 77.56 & 0.05 \\
\hline 20 & 1000 & 1000 & 0.8287 & 521.34 & 0.56 & $0 . \overline{8301}$ & 110.09 & 1.12 \\
\hline \multicolumn{3}{|r|}{ Média } & 0.7589 & 225.69 & 0.21 & 0.7655 & 68.59 & 0.39 \\
\hline \multicolumn{3}{|c|}{ Média final } & 0.8246 & 235.55 & 0.17 & 0.8351 & 113.58 & 0.25 \\
\hline
\end{tabular}

Observe nesta tabela que a média final da solução homogênea composta apresenta melhor resultado (1.27\%) com um número de nós menor (48.22\%), entretanto com um tempo computacional maior $(47,068)$. Apesar do tempo computacional ser superior quando se utiliza esta solução, na prática este tempo é totalmente viável.

Tabela 6.13 - Exemplos com demanda grande

\begin{tabular}{|c|c|c|c|c|c|c|c|c|}
\hline $\bar{m}$ & I & $\bar{w}$ & Solução 1 & №́nós & $t(s)$ & Solução 2 & $N^{\circ}$ nós & $t(s)$ \\
\hline 5 & 100 & 100 & 0.8248 & 45.68 & 0.02 & 0.8252 & 36.60 & 0.02 \\
\hline 10 & 100 & 100 & 0.9251 & 209.64 & 0.07 & 0.9259 & 190.20 & 0.10 \\
\hline 20 & 100 & 100 & 0.9691 & 623.64 & 0.34 & 0.9689 & 581.44 & 0.50 \\
\hline \multicolumn{3}{|c|}{ Média } & 0.9063 & 292.99 & 0.14 & 0.9067 & 269.41 & 0.21 \\
\hline 5 & 1000 & 1000 & 0.7875 & 39.60 & 0.01 & 0.7952 & 36.92 & 0.01 \\
\hline 10 & 1000 & 1000 & 0.9096 & 188.24 & 0.07 & $0 . \overline{102}$ & 170.36 & 0.09 \\
\hline 20 & 1000 & 1000 & 0.9548 & 720.16 & 0.41 & 0.9552 & 648.60 & 0.57 \\
\hline \multicolumn{3}{|c|}{ Média } & $0 . \overline{8840}$ & 316.00 & 0.16 & 0.8869 & 285.29 & 0.22 \\
\hline \multicolumn{3}{|c|}{ Média final } & 0.8952 & 304.50 & 0.15 & 0.8968 & 277.35 & 0.22 \\
\hline
\end{tabular}


Com os resultados apresentados acima, e com uma variedade grande de outros exemplos testados, conclui-se que a solução homogênea composta é um bom limitante inferior para problemas com demanda pequena.

\subsubsection{Fracionamento do vetor b}

Aplicando a heuristica $\mathrm{H} 4$, proposta no capitulo 5, não se obtiveram resultados significativos, como é possivel observar nos exemplos das tabelas 6.14 e 6.15 , com uma placa $(100,100)$ e 10 peças. Foram também gerados 50 exemplos para cada classe de problemas.

Tabela 6.14 - Exemplos pequenos

\begin{tabular}{|c|c|c|c|}
\hline$K$ & Solução & No nós & $t(s)$ \\
\hline 0.30 & 0.8344 & 44.24 & 0.04 \\
\hline 0.50 & 0.9249 & 192.76 & 0.08 \\
\hline 0.80 & 0.9251 & 199.36 & 0.08 \\
\hline 1.00 & 0.9251 & 209.64 & 0.08 \\
\hline
\end{tabular}

Tabela 6.15 - Exemplos grandes

\begin{tabular}{|c|c|c|c|}
\hline $\mathrm{K}$ & Solução & $\mathrm{N}^{o}$ nós & $\mathrm{t}(\mathrm{s})$ \\
\hline 0.30 & 0.5982 & 59.56 & 0.04 \\
\hline 0.50 & 0.7598 & 156.12 & 0.06 \\
\hline 0.80 & 0.7498 & 135.72 & 0.06 \\
\hline 1.00 & 0.8486 & 186.96 & 0.07 \\
\hline
\end{tabular}

Observe que quando $\mathrm{K}$ assume o valor 1 , percorrese o grafo de maneira gulosa, conforme foi visto na seção 3.2 .2 .

Com os testes realizados, pode-se concluir que a variação do parâmetro $\mathrm{K}$ tende a 1 , para que se possa obter resultados significativos. Assim sendo, pode-se descartar a estratégia de fracionamento do vetor $b$, pois apesar do tempo computacional crescer, o resultado obtido também melhora quan- 
do não é feito o fracionamento.

\subsection{Problema Estagiado}

- problema de corte estagiado foi implementado para problemas irrestritos e restrito.

A seguir, são apresentados resultados obtidos com um problema irrestrito. As Figuras 6.8 e 6.9 apresentam a solução 2-estágios e não-estagiada, respectivamente, de um problema com uma placa $(100,100)$ e 5 peças de dimensōes $(14,29),(15,45),(22,13),(26,30)$ e $(39,45)$. Para a execuçăo dos problemas, limitou-se a profundidade da estratégia de busca backtracking em 3 e os parâmetros $\lambda_{1}=108$ e $\lambda_{z}=95 \%$. 0 tempo computacional obtido com o caso estagiado e não estagiado foi de $0.82 \mathrm{~s}$ e $1.59 \mathrm{~s}$, respectivamente.

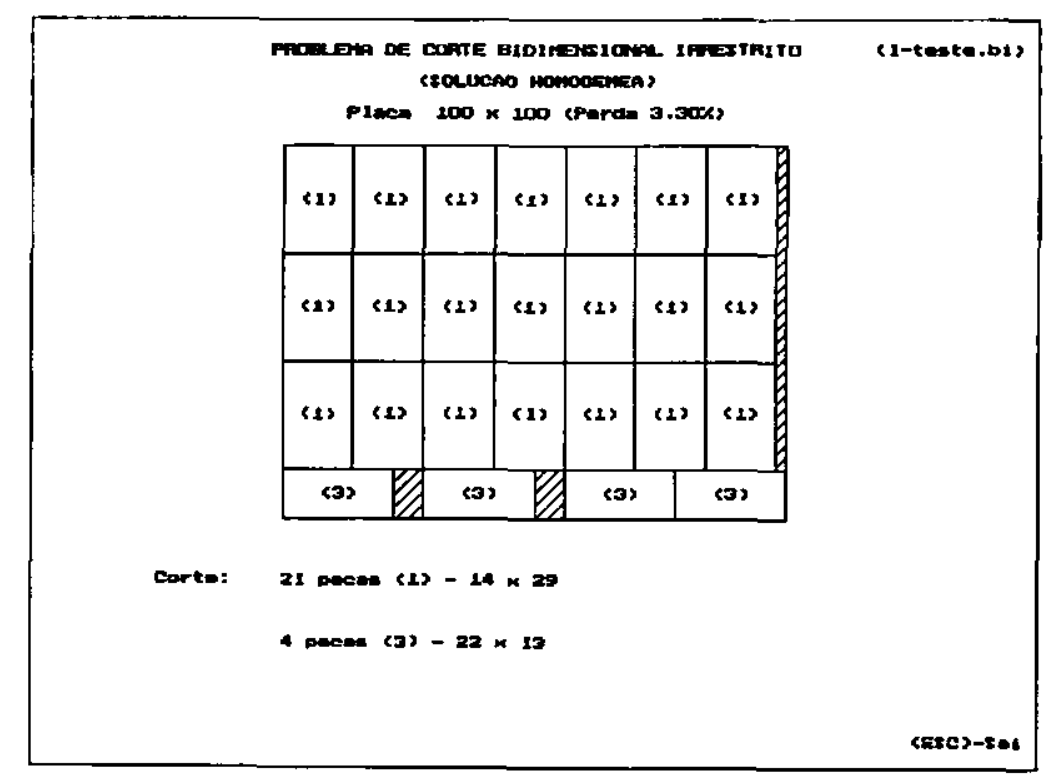

Figura 6.8 - Solução do problema 2-estágios 


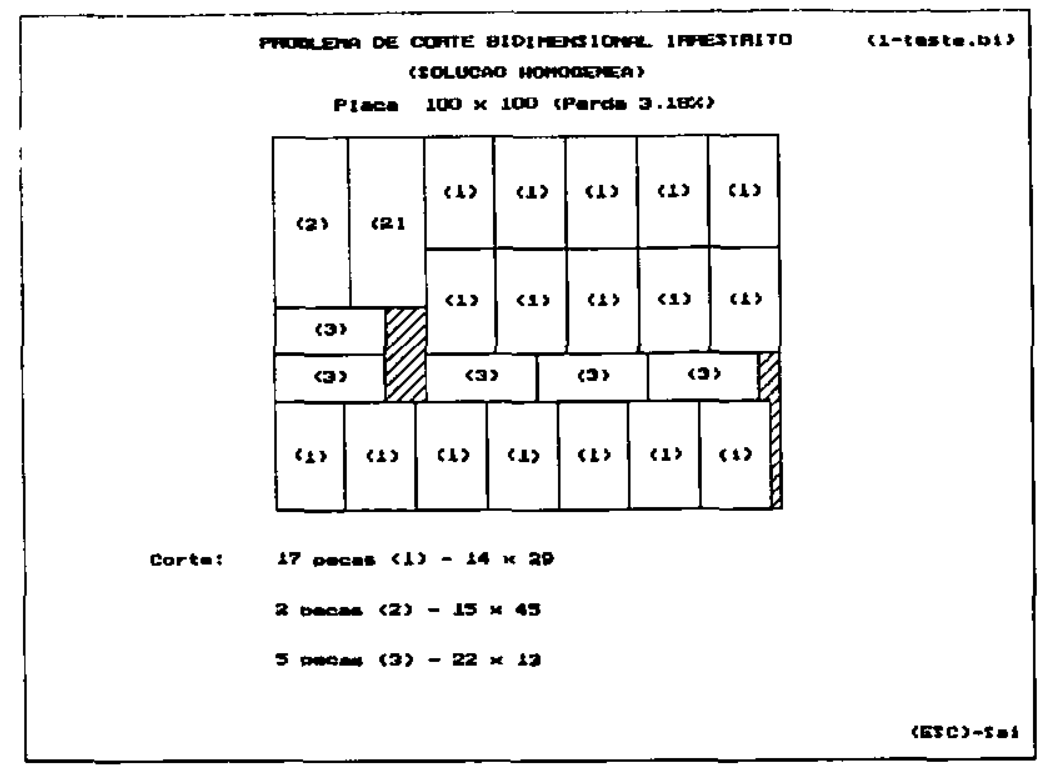

Figura 6.9 - Solução do problema não-estagiado

Incluindo um limite máximo para a produção de cada peça, $b_{i}$, no exemplo acima, de $7,12,5,9$ e 3 unidades, respectivamente, obtiveram-se os resultados apresentados pela Figuras 6.10 e 6.11 para o problema 2-estágios restrito e nãoestagiado restrito.

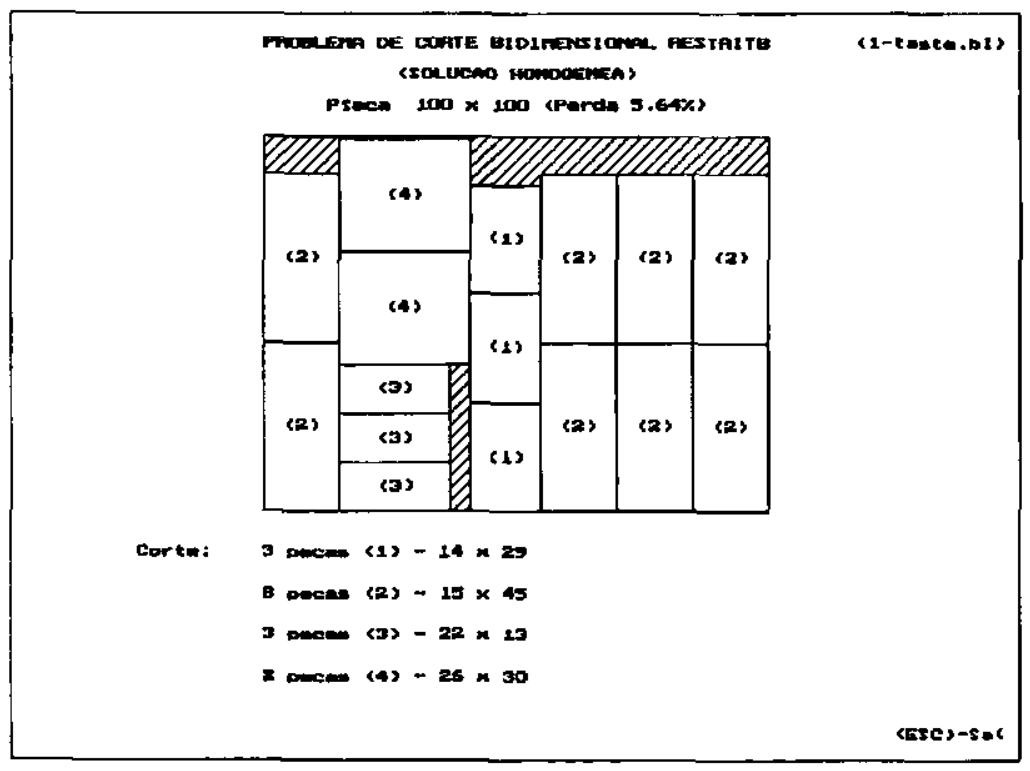

Figura 6.10 - Solução do problema restrito 2-estágios 


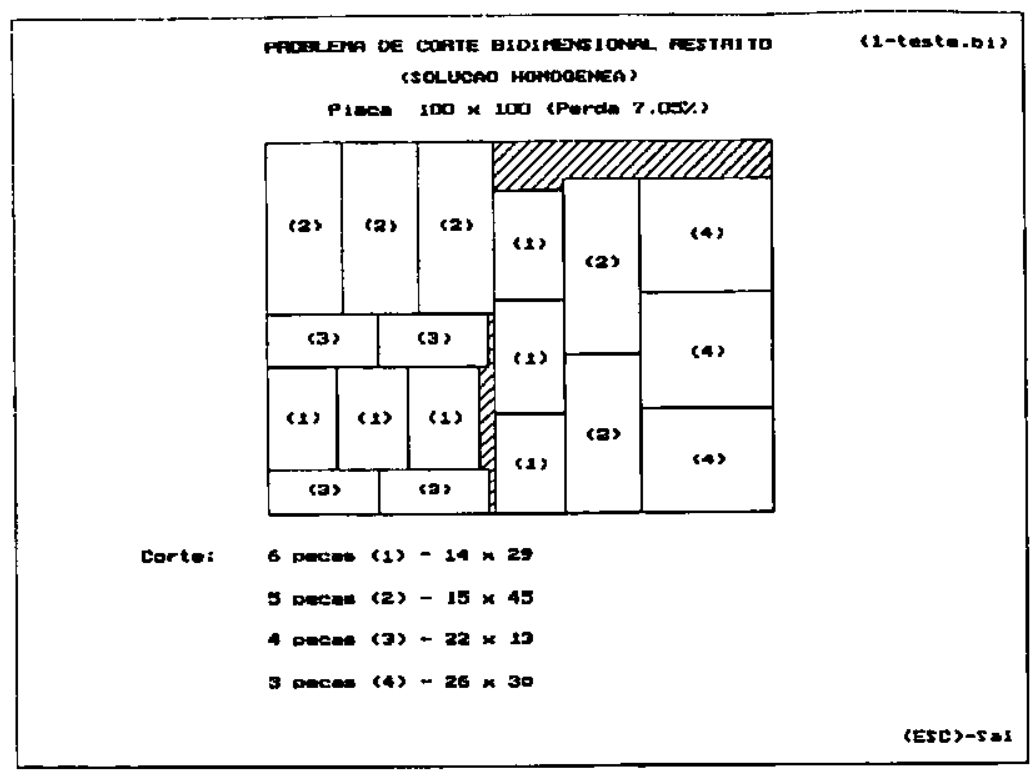

Figura 6.11 - Solução do problema restrito não-estagiado

As Tabelas 6.16 e 6.17 apresentam resultados obtidos com problemas guilhotinados 2-estágios irrestrito. Foram feitos testes com 50 exemplos de cada classe de problema. A Coluna Solução Grafo E/OU apresenta a média das soluçōes heurísticas obtidas com o algoritmo grafo E/OU limitado para 2estágios, com profundidade máxima limitada em 3. A coluna Solução 2-estágios apresenta a média dos resultados obtidos com a soluçāo ótima 2-estágios de Gilmore e Gomory (1965), apresentada na seção 4.2 .3 .

A resolução do problema 2-estágios usando a abordagem em grafo E/OU apresenta resultado ótimo, ou perto do ótimo, devido à limitação da profundidade do grafo. Nos exemplos pequenos a diferença das médias dos resultados é de 0.0025 e, nos exemplos grande de 0.0051 . Note que, em problemas pequenos, o tempo de execução médio na abordagem grafo E/OU é menor que $1 / 4$ do tempo de execução médio na abordagem 2-estágio; em problemas grandes, este tempo é de quase 3 vezes. 
Tabela 6.16 - Exemplos pequenos

\begin{tabular}{|c|c|c|c|c|c|c|}
\hline $\mathrm{m}$ & I & $\bar{W}$ & $\begin{array}{c}\text { Solução } \\
\text { Grafo E/OU }\end{array}$ & $t(s)$ & $\begin{array}{c}\text { Solução } \\
\text { 2-estágios }\end{array}$ & $t(s)$ \\
\hline 5 & 100 & 100 & 0.8476 & 0.00 & 0.8576 & 0.02 \\
\hline 10 & 100 & $\overline{100}$ & 0.9367 & 0.01 & 0.9367 & 0.05 \\
\hline 20 & 100 & 100 & 0.9762 & 0.05 & 0.9780 & 0.10 \\
\hline \multicolumn{3}{|c|}{ Média } & 0.9201 & $\overline{0.02}$ & 0.9241 & 0.05 \\
\hline 5 & 1000 & 1000 & 0.8411 & 0.00 & 0.8411 & 0.05 \\
\hline 10 & 1000 & 1000 & 0.9290 & 0.02 & 0.9327 & 0.09 \\
\hline 20 & 1000 & 1000 & 0.9507 & 0.05 & 0.9519 & 0.27 \\
\hline 50 & 1000 & 1000 & 0.9689 & 0.21 & 0.9693 & 0.46 \\
\hline \multicolumn{3}{|c|}{ Média } & 0.9224 & 0.07 & 0.9238 & 0.22 \\
\hline 5 & 3000 & 3000 & 0.8791 & 0.00 & 0.8860 & 0.07 \\
\hline 10 & 3000 & 3000 & 0.9113 & 0.02 & 0.9115 & 0.20 \\
\hline 20 & 3000 & 3000 & 0.9452 & 0.08 & 0.9460 & 0.60 \\
\hline 50 & 3000 & 3000 & 0.9573 & 0.28 & 0.9578 & 1.11 \\
\hline \multicolumn{3}{|r|}{ Média } & 0.9232 & 0.10 & 0.9253 & 0.50 \\
\hline \multicolumn{3}{|c|}{ Média final } & 0.9219 & 0.06 & 0.9244 & 0.26 \\
\hline
\end{tabular}

Tabela 6.17 - Exemplos grandes

\begin{tabular}{|c|c|c|c|c|c|c|}
\hline $\mathrm{m}$ & $\bar{L}$ & $\bar{w}$ & $\begin{array}{c}\text { Solução } \\
\text { Grafo E/oU }\end{array}$ & $t(s)$ & $\begin{array}{c}\text { Solução } \\
\text { 2-estágios }\end{array}$ & $t(s)$ \\
\hline 5 & 100 & 100 & 0.9601 & 0.03 & 0.9604 & 0.03 \\
\hline 10 & 100 & 100 & 0.9874 & 0.39 & 0.9890 & 0.04 \\
\hline 20 & 100 & 100 & 0.9952 & 0.38 & 0.9958 & 0.12 \\
\hline \multicolumn{3}{|r|}{ Média } & 0.9809 & 0.27 & 0.9817 & 0.06 \\
\hline 5 & 1000 & 1000 & 0.9358 & 0.03 & 0.9486 & 0.05 \\
\hline 10 & 1000 & 1000 & 0.9624 & 0.58 & 0.9712 & 0.12 \\
\hline 20 & 1000 & 1000 & 0.9851 & 0.51 & 0.9911 & 0.24 \\
\hline 30 & 1000 & 1000 & 0.9895 & 2.04 & 0.9925 & 0.61 \\
\hline \multicolumn{3}{|r|}{ Média } & 0.9682 & 0.79 & 0.9759 & 0.26 \\
\hline 5 & 3000 & 3000 & 0.9832 & 0.06 & 0.9901 & 0.08 \\
\hline 10 & 3000 & 3000 & 0.9738 & 0.51 & 0.9805 & 0.32 \\
\hline 20 & 3000 & 3000 & 0.9932 & 3.34 & 0.9954 & 0.82 \\
\hline 30 & 3000 & 3000 & 0.9245 & 3.48 & 0.9359 & 1.44 \\
\hline \multicolumn{3}{|r|}{ Média } & 0.9687 & 1.85 & 0.9755 & 0.67 \\
\hline \multicolumn{3}{|c|}{ Média final } & 0.9726 & 0.97 & 0.9777 & 0.33 \\
\hline
\end{tabular}

Com os resultados obtidos por Gramani (1997) 
utilizando Relaxação Lagrangiana para problemas de corte guiIhotinados 2-estágios restrito (veja anexo 2), pôde-se comparar os resultados da abordagem em grafo E/OU, utilizando o conjunto de discretização completo e a estratégia backtracking com profundidade ilimitada (conjectura do problema de corte restrito da seção 4.6). A seguir, são apresentados problemas, pequenos e grandes, com 3, 5, 10 e 30 peças, respectivamente, e suas soluções. Estes problemas apresentam soluções ótimas, reforçando, assim, a conjectura do problema de corte restrito.

- Exemplos com 3 peças

Considere uma placa $(100,100)$. A Tabela 6.18 apresenta os dados de um problema pequeno e grande com 3 peças. Obtiveram-se as soluções que são ótimas, o que reforça a conjectura da seção 4.6, de 0.8066 e 0.8312, para o problema pequeno e grande. Os tempos computacionais obtidos foram de $3.19 \mathrm{~s}$ e 6.92s, respectivamente. A Figura 6.12 apresenta os padrões ótimos.

Tabela 6.18 - Exemplo pequeno e grande com $\mathrm{m}=3$

\begin{tabular}{|c|c|c|c|}
\hline $\mathbf{i}$ & $\ell i$ & $w_{1}$ & $b_{1}$ \\
\hline 1 & 35 & 27 & 2 \\
\hline 2 & 27 & 48 & 3 \\
\hline 3 & 32 & 56 & 3 \\
\hline
\end{tabular}

\begin{tabular}{|c|c|c|c|}
\hline$i$ & $\ell i$ & $w_{i}$ & $b_{i}$ \\
\hline 1 & 38 & 11 & 2 \\
\hline 2 & 38 & 26 & 3 \\
\hline 3 & 47 & 48 & 2 \\
\hline
\end{tabular}
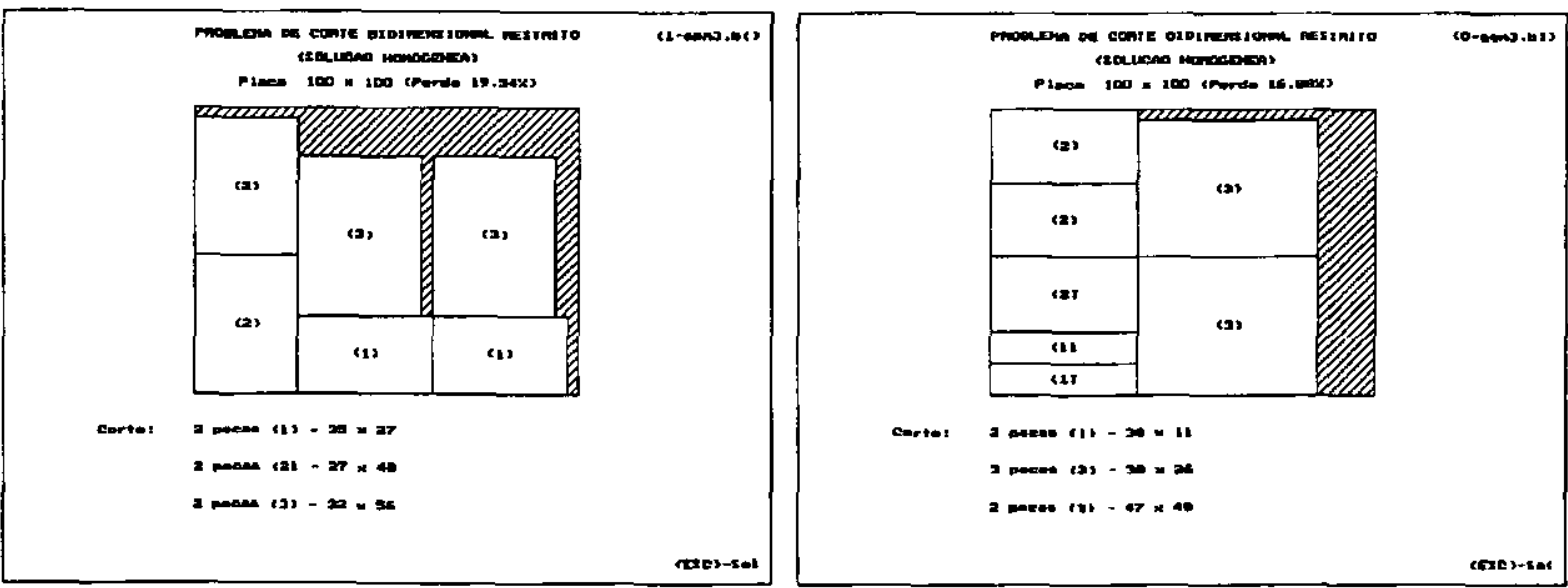

Figura 6.12 - Soluções ótimas dos exemplos restritos $(m=3)$ 
- Exemplos com 5 peças

A seguir, sāo apresentados um problema pequeno e grande com uma placa $(100,100)$ e 5 peças. A Tabela 6.19 mostra os dados destes problemas. As soluçōes, que também são ótimas, obtidas para cada exemplo foram 0.8855 e 0.9744 , com um tempo computacional $1.42 \mathrm{~s}$ e $0.49 \mathrm{~s}$, respectivamente (Figura 6.13).

Tabela 6.19 - Exemplo pequeno e grande com $\mathrm{m}=5$

\begin{tabular}{|c|c|c|c|}
\hline$i$ & $\ell i$ & $w_{1}$ & $b_{1}$ \\
\hline 1 & 71 & 50 & 2 \\
\hline 2 & 27 & 65 & 2 \\
\hline 3 & 57 & 66 & 3 \\
\hline 4 & 43 & 72 & 1 \\
\hline 5 & 45 & 72 & 1 \\
\hline
\end{tabular}

\begin{tabular}{|c|c|c|c|}
\hline 1 & $\ell_{i}$ & $w_{1}$ & $b_{1}$ \\
\hline 1 & 47 & 14 & 14 \\
\hline 2 & 40 & 18 & 5 \\
\hline 3 & 28 & 35 & 2 \\
\hline 4 & 35 & 41 & 4 \\
\hline 5 & 49 & 43 & 4 \\
\hline
\end{tabular}
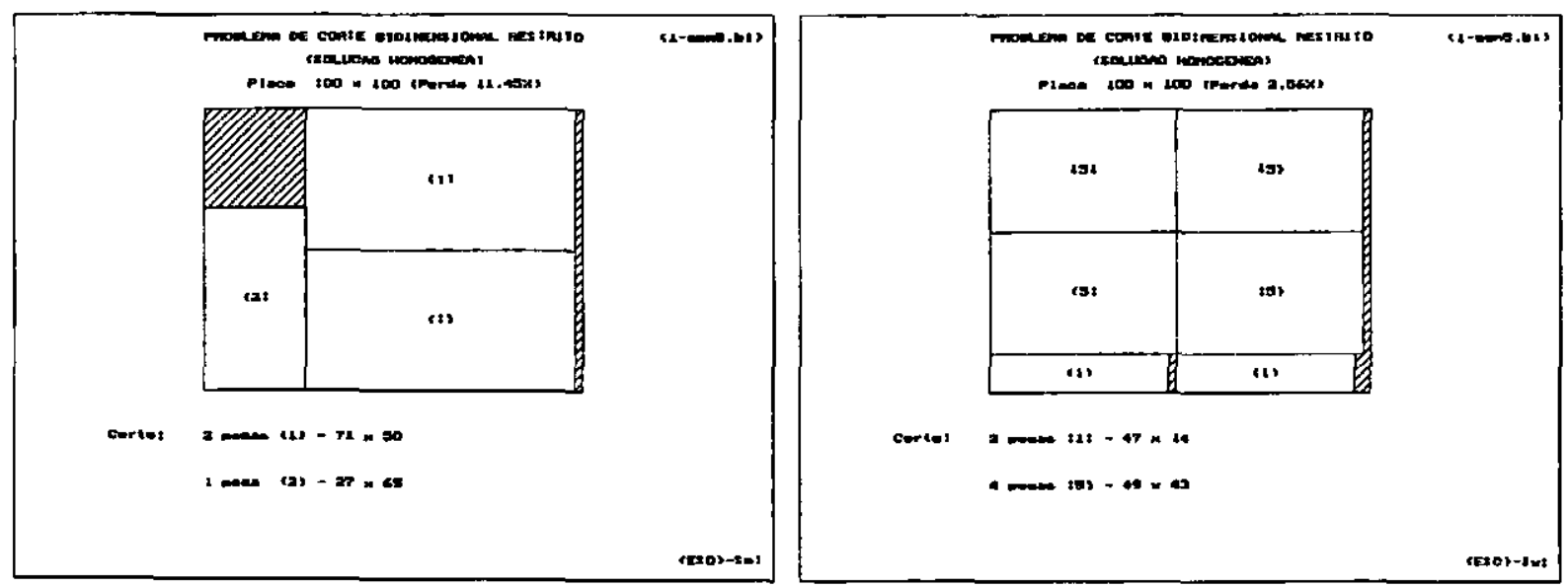

Figura 6.13 - Soluções ótimas dos exemplos restritos $(m=5)$

- Exemplos com 10 peças

São gerados novamente exemplos com placa $(100,100)$ com 10 tipos de peças (Tabela 6.20). As soluções, que também são ótimas, para o exemplo pequeno e grande são 0.9242 e 0.9828 , respectivamente, com tempo computacional de $1.86 \mathrm{~s}$ e 19.71s. A Figura 6.14 ilustra estas soluçoes. 
Tabela 6.20 - Exemplo pequeno e grande com $\mathrm{m}=10$

\begin{tabular}{|c|c|c|c|}
\hline$i$ & $\ell i$ & $w_{1}$ & $b_{1}$ \\
\hline 1 & 55 & 25 & 1 \\
\hline 2 & 49 & 33 & 2 \\
\hline 3 & 60 & 38 & 2 \\
\hline 4 & 66 & 43 & 1 \\
\hline 5 & 51 & 53 & 3 \\
\hline 6 & 28 & 57 & 3 \\
\hline 7 & 34 & 60 & 2 \\
\hline 8 & 27 & 61 & 3 \\
\hline 9 & 62 & 64 & 3 \\
\hline 10 & 67 & 69 & 1 \\
\hline
\end{tabular}

\begin{tabular}{|c|c|c|c|}
\hline$i$ & $\ell_{i}$ & $w_{i}$ & $b_{i}$ \\
\hline 1 & 39 & 11 & 2 \\
\hline 2 & 47 & 12 & 3 \\
\hline 3 & 35 & 14 & 9 \\
\hline 4 & 42 & 16 & 9 \\
\hline 5 & 31 & 17 & 4 \\
\hline 6 & 35 & 25 & 3 \\
\hline 7 & 20 & 26 & 14 \\
\hline 8 & 25 & 35 & 8 \\
\hline 9 & 19 & 35 & 5 \\
\hline 10 & 42 & 48 & 1 \\
\hline
\end{tabular}
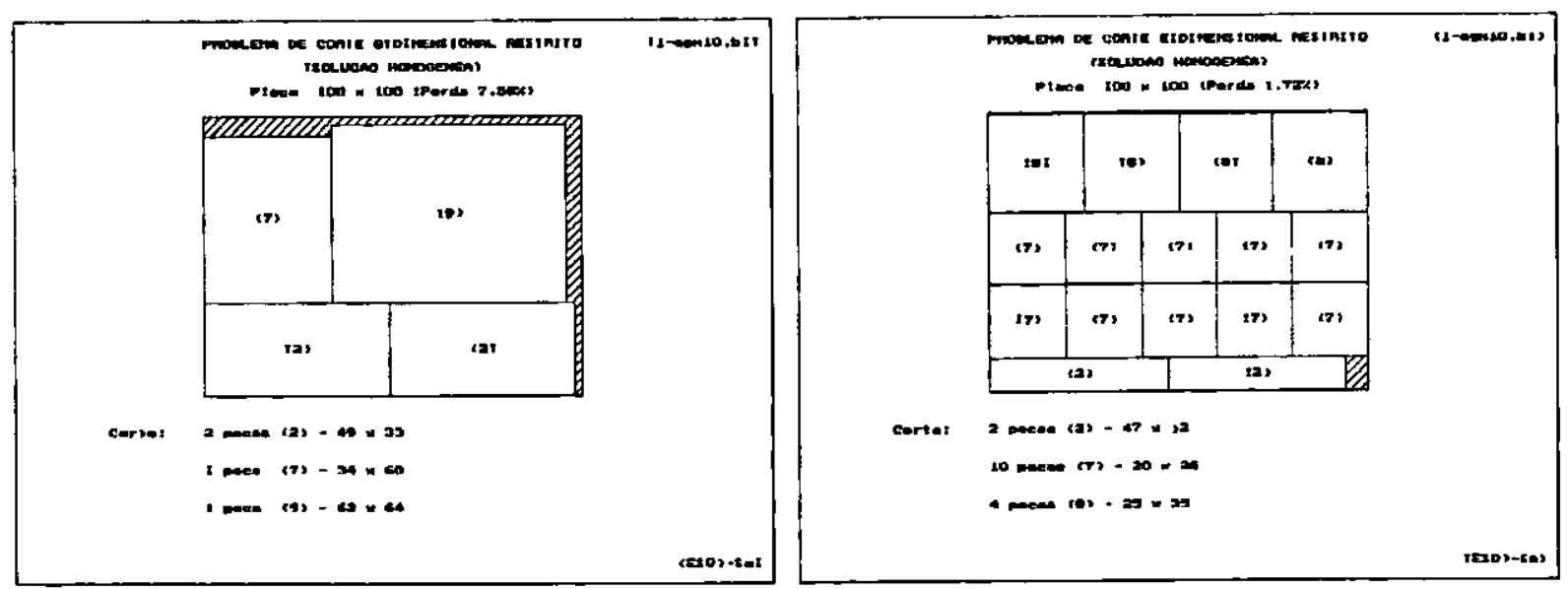

Figura 6.14 - Soluções ótimas dos exemplos restritos $(m=10)$

- Exemplos com 30 peças

Considere, ainda, uma placa $(100,100)$ e os dados da Tabela 6.21, com 30 peças. Os padrões ótimos da Figura 6.15 tem solução 0.9786 e 1.0000 , respectivamente, com um tempo computacional de $0.38 \mathrm{~s}$ e $0.50 \mathrm{~s}$.
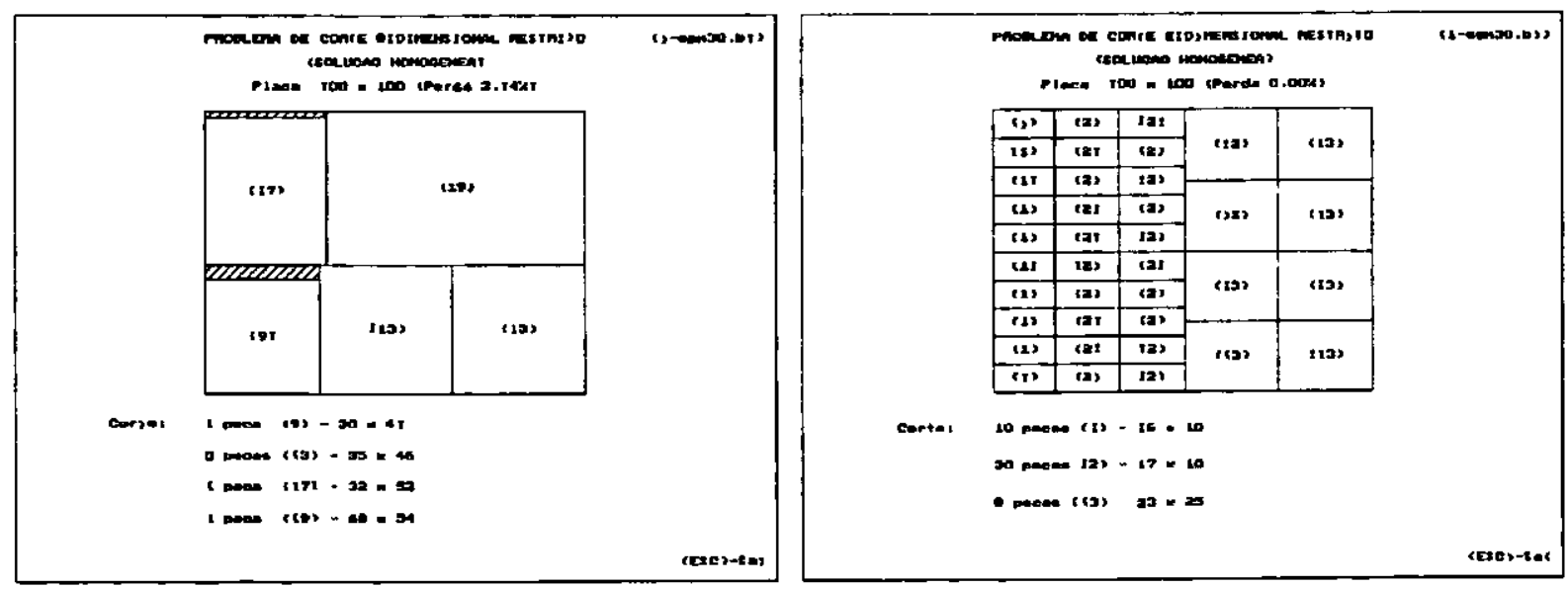

Figura 6.15 - Soluções ótimas dos exemplos restritos $(m=30)$ 
Tabela 6.21 - Exemplo pequeno e grande com $\mathrm{m}=30$

\begin{tabular}{|c|c|c|c|}
\hline$i$ & $\ell i$ & $w_{i}$ & $b_{i}$ \\
\hline 1 & 38 & 27 & 6 \\
\hline 2 & 42 & 27 & 1 \\
\hline 3 & 41 & 28 & 3 \\
\hline 4 & 65 & 31 & 3 \\
\hline 5 & 52 & 32 & 1 \\
\hline 6 & 54 & 32 & 1 \\
\hline 7 & 28 & 37 & 2 \\
\hline 8 & 29 & 40 & 3 \\
\hline 9 & 30 & 41 & 2 \\
\hline 10 & 54 & 43 & 2 \\
\hline 11 & 43 & 43 & 2 \\
\hline 12 & 61 & 43 & 1 \\
\hline 13 & 35 & 46 & 4 \\
\hline 14 & 68 & 47 & 1 \\
\hline 15 & 56 & 50 & 1 \\
\hline 16 & 70 & 51 & 1 \\
\hline 17 & 32 & 52 & 1 \\
\hline 18 & 26 & 52 & 2 \\
\hline 19 & 68 & 54 & 1 \\
\hline 20 & 40 & 55 & 2 \\
\hline 21 & 71 & 57 & 1 \\
\hline 22 & 55 & 58 & 1 \\
\hline 23 & 33 & 59 & 1 \\
\hline 24 & 45 & 65 & 1 \\
\hline 25 & 30 & 67 & 1 \\
\hline 26 & 62 & 68 & 1 \\
\hline 27 & 72 & 68 & 1 \\
\hline 28 & 46 & 70 & 1 \\
\hline 29 & 46 & 73 & 1 \\
\hline 30 & 65 & 74 & 1 \\
\hline & & & \\
\hline
\end{tabular}

\begin{tabular}{|c|c|c|c|}
\hline$i$ & $\ell \dot{i}$ & $w_{1}$ & $b_{1}$ \\
\hline 1 & 16 & 10 & 24 \\
\hline 2 & 17 & 10 & 20 \\
\hline 3 & 17 & 12 & 38 \\
\hline 4 & 37 & 16 & 7 \\
\hline 5 & 11 & 16 & 3 \\
\hline 6 & 18 & 17 & 2 \\
\hline 7 & 24 & 18 & 10 \\
\hline 8 & 29 & 19 & 15 \\
\hline 9 & 14 & 19 & 35 \\
\hline 10 & 32 & 20 & 10 \\
\hline 11 & 16 & 22 & 23 \\
\hline 12 & 36 & 24 & 3 \\
\hline 13 & 25 & 25 & 12 \\
\hline 14 & 13 & 27 & 9 \\
\hline 15 & 35 & 28 & 4 \\
\hline 16 & 43 & 32 & 2 \\
\hline 17 & 12 & 35 & 6 \\
\hline 18 & 21 & 36 & 7 \\
\hline 19 & 25 & 38 & 1 \\
\hline 20 & 26 & 40 & 4 \\
\hline 21 & 21 & 43 & 3 \\
\hline 22 & 39 & 43 & 2 \\
\hline 23 & 11 & 43 & 16 \\
\hline 24 & 19 & 45 & 9 \\
\hline 25 & 27 & 46 & 2 \\
\hline 26 & 40 & 46 & 4 \\
\hline 27 & 21 & 48 & 1 \\
\hline 28 & 24 & 49 & 3 \\
\hline 29 & 13 & 49 & 12 \\
\hline 30 & 16 & 49 & 1 \\
\hline
\end{tabular}

\subsection{Problema com placa defeituosa}

Os problemas de corte com placas defeituosas foram pouco estudados na literatura (Carnieri et al., 1993).

$\mathrm{Na}$ implementação deste problema não foi considerada uma quantidade máxima de cada tipo de peças, mas a implementação da abordagem em grafo $\mathrm{E} / \mathrm{OU}$ permite este ajuste incluindo informações adicionais em cada nó.

A seguir, são mostrados os resultados obtidos com o exemplo apresentado por Carnieri et al. (1993), em uma placa de dimensões $(100,200)$ e 5 peças conforme os dados Tabela 6.22 . 
Tabela 6.22 - Exemplo de Carnieri et al. (1993)

\begin{tabular}{|c|c|c|c|}
\hline$i$ & $\ell_{1}$ & $w_{i}$ & $v_{1}$ \\
\hline 1 & 40 & 30 & 10 \\
\hline 2 & 68 & 26 & 12 \\
\hline 3 & 50 & 20 & 8 \\
\hline 4 & 60 & 35 & 18 \\
\hline 5 & 45 & 22 & 9 \\
\hline
\end{tabular}

Foram 8 testes com este exemplo, mudando a posição do defeito. As posições dos defeitos, assim como os resultados obtidos por Carnieri et al. (1993), são apresentados na Tabela 6.23.

Tabela 6.23 - Defeitos e soluções obtidas por Carnieri et al. (1993)

\begin{tabular}{|c|cc|c|}
\hline Exemplo & \multicolumn{2}{|c|}{ Defeito } & Solução \\
\hline 1 & $(50,100)$ & $(54,105)$ & 166 \\
\hline 2 & $(40,100)$ & $(44,105)$ & 160 \\
\hline 3 & $(60,100)$ & $(66,105)$ & 162 \\
\hline 4 & $(20,125)$ & $(30,132)$ & 158 \\
\hline 5 & $(71,125)$ & $(79,132)$ & 164 \\
\hline 6 & $(30,30)$ & $(40,40)$ & 164 \\
\hline 7 & $(40,80)$ & $(58,110)$ & 157 \\
\hline 8 & $(40,80)$ & $(58,118)$ & 154 \\
\hline
\end{tabular}

Com a implementação usando grafo E/OU obtiveramse os resultados da Tabela 6.24. Note que para todos os exemplos foi encontrada uma solução igual ou melhor, entretanto, em alguns casos foi necessário não utilizar a regra de simetria para obter tal solução.

As Figuras 6.16, 6.17, 6,18 e 6.19, apresentam 0 melhor padrão de corte obtido nos exemplos da Tabela 6.24 . 
Tabela 6.24 - Defeitos e soluções obtidas por grafo E/OU

\begin{tabular}{|c|c|c|c|c|c|c|c|}
\hline Exemplo & $\lambda_{1}$ & $\overline{\lambda_{1}}$ & Prof. & Simetria & №.nós & Solução & $t(s)$ \\
\hline 1 & 0.01 & 0.95 & 3 & $s$ & 2767 & $16 \overline{6}$ & 3.18 \\
\hline 2 & & 0.95 & 3 & $s$ & 2249 & 167 & 2.31 \\
\hline 3 & & $0 . \overline{95}$ & 3 & $\mathrm{~s}$ & 8133 & 164 & 8.07 \\
\hline \multirow[t]{8}{*}{4} & & 0.95 & 3 & $\bar{n}$ & 5203 & 158 & 2.47 \\
\hline & & & & $s$ & 3531 & 155 & 2.31 \\
\hline & & & 4 & $n$ & 31527 & 158 & 15.21 \\
\hline & & & & $s$ & 8837 & 155 & 4.55 \\
\hline & & 0.90 & 3 & $\mathrm{n}$ & 9423 & 158 & 3.68 \\
\hline & & & & $s$ & 6889 & 157 & 3.46 \\
\hline & & & 4 & $\mathrm{n}$ & 74255 & 158 & 30.05 \\
\hline & & & & $s$ & 20235 & 157 & 8.67 \\
\hline \multirow[t]{6}{*}{5} & & 0.95 & 3 & $n$ & 19321 & 167 & 14.01 \\
\hline & & & & $s$ & 15369 & 162 & 20.82 \\
\hline & & & 4 & $\mathrm{n}$ & 91915 & 167 & 69.65 \\
\hline & & & & $\mathrm{s}$ & 19477 & 165 & 32.30 \\
\hline & & 0.90 & 3 & $\mathrm{n}$ & 37487 & 167 & 24.34 \\
\hline & & & & $s$ & 23033 & 162 & 31.42 \\
\hline \multirow[t]{4}{*}{6} & & 0.95 & 3 & $s$ & 1309 & 160 & 0.77 \\
\hline & & & 4 & $s$ & 9657 & 164 & 4.94 \\
\hline & & 0.90 & 3 & $\mathbf{s}$ & 1085 & 160 & 0.44 \\
\hline & & & 4 & $s$ & 7103 & 164 & 2.41 \\
\hline 7 & & 0.95 & 3 & $s$ & 697 & 159 & 0.60 \\
\hline \multirow[t]{2}{*}{8} & & 0.95 & 3 & $s$ & 591 & 153 & 0.60 \\
\hline & & 0.90 & 3 & $s$ & 2351 & 156 & 1.81 \\
\hline
\end{tabular}

As Figuras 6.16, 6.17, 6,18 e 6.19, apresentam o melhor padrão de corte obtido nos exemplos da Tabela 6.24.
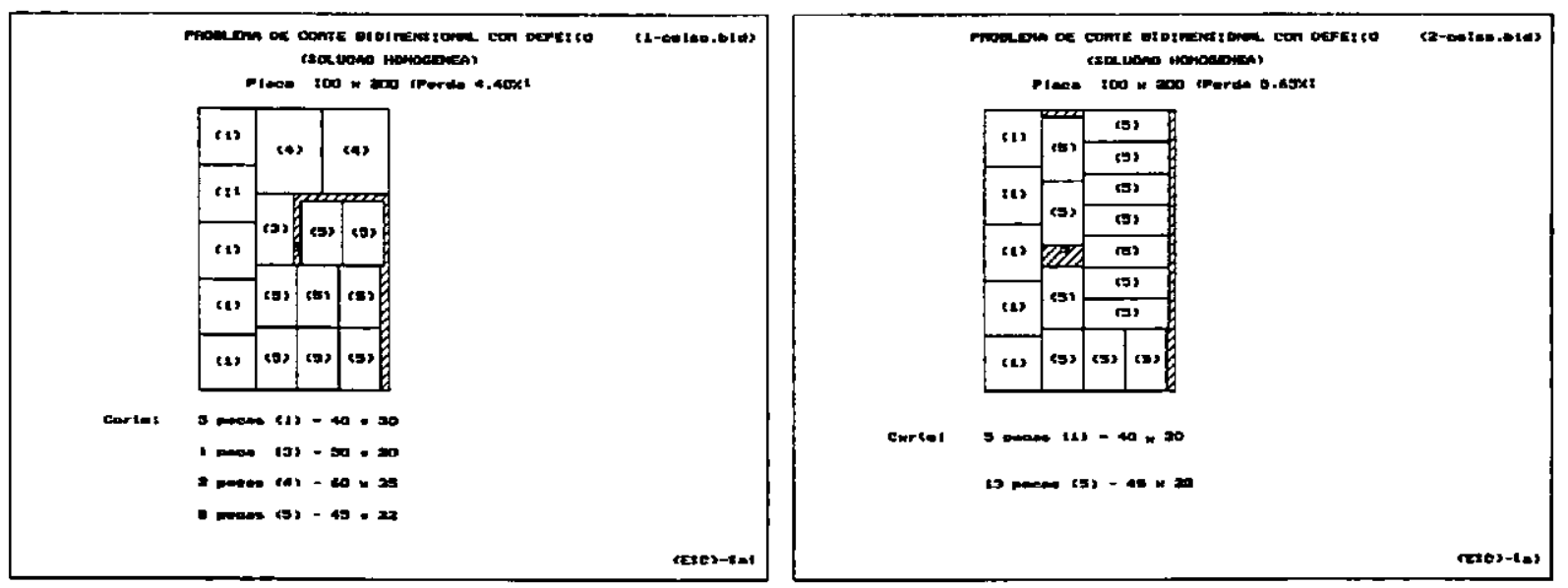

Figura 6.16 - Exemp1o 1 (solução=166) e exemplo 2 (solução=167) 


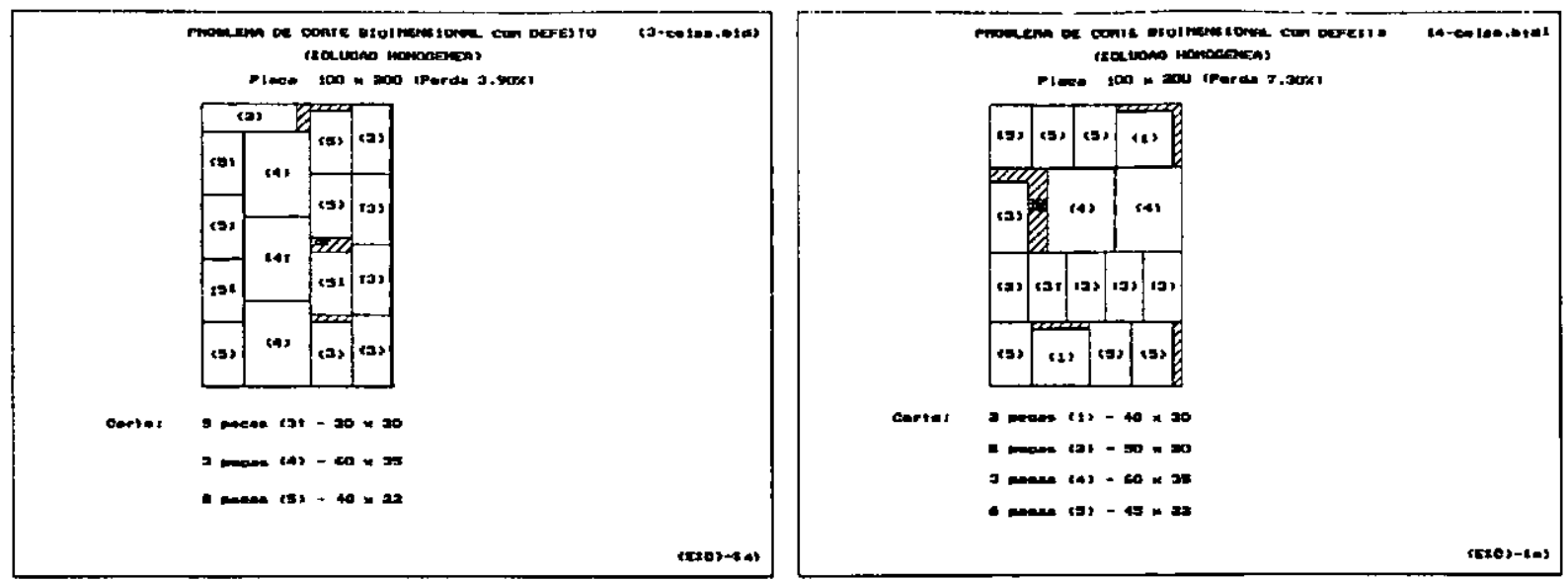

Figura 6.17 - Exemplo 3 (solução=166) e exemplo 4 (solução=158)
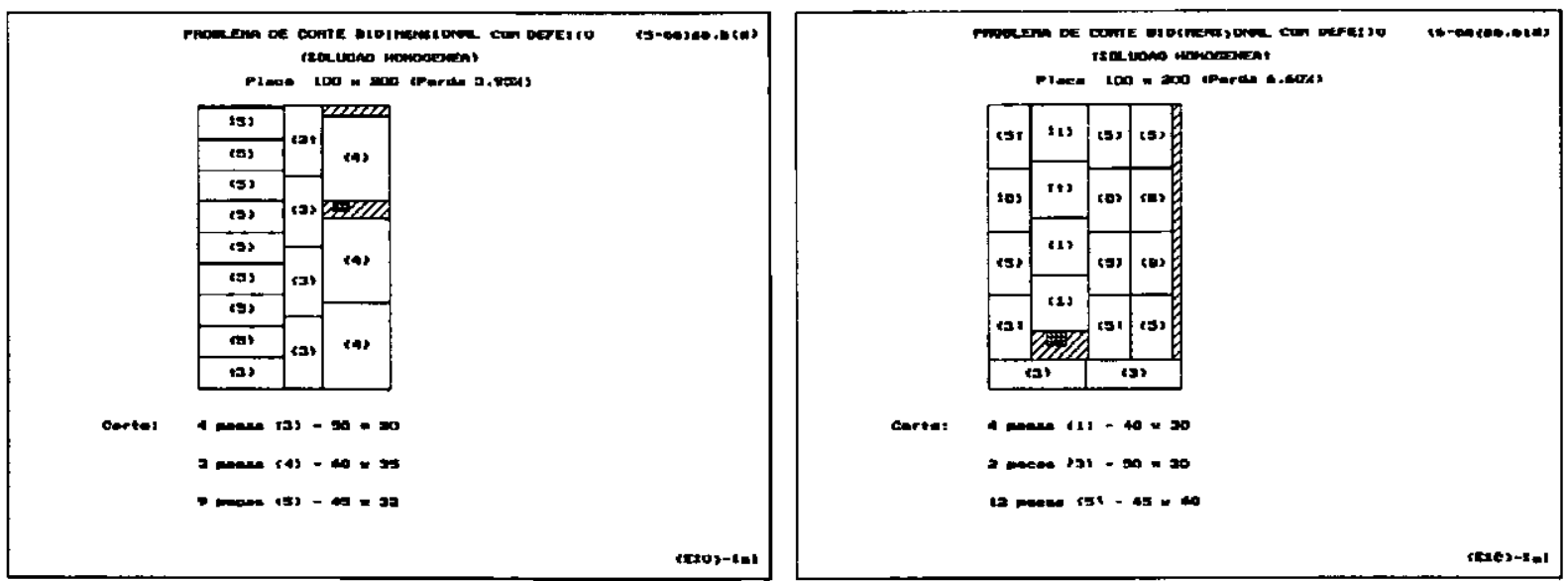

Figura 6.18 - Exemplo 5 (solução=167) e exemplo 6 (solução=164)
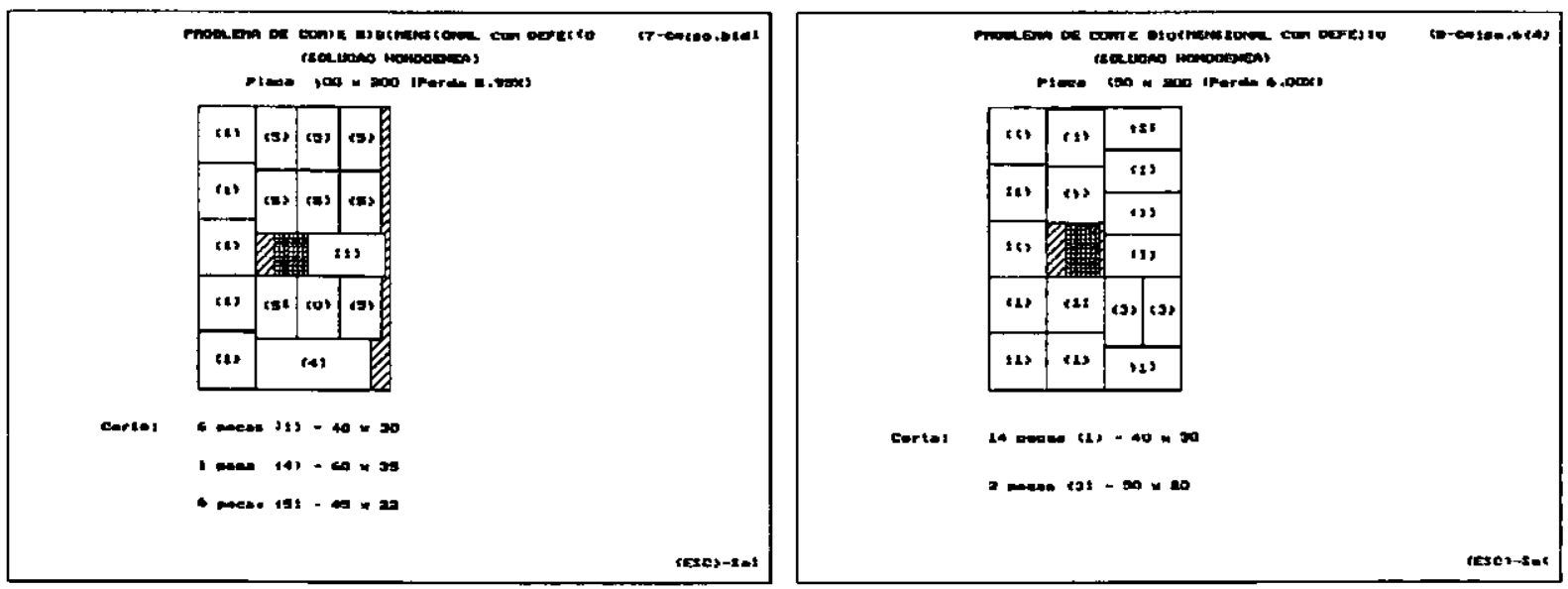

Figura 6.19 - Exemplo 7 (solução=159) e exemplo 8 (solução=156)

6.5. Problema com limitação no número de tipo de peças

o problema com limitação no número de tipos de 
peças, conforme a seção 2.2.2, surgiu devido à restrição do número de saídas do equipamento de corte. Embora ele ocorra, na prática, com serras automáticas de grande porte, não é muito explorado na iiteratura.

o problema foi implementado para o caso restrito.

A seguir, são apresentados alguns resultados obtidos limitando o número de tipo de peças nos exemplos de Wang (1983) e Oliveira e Ferreira (1990) (mostrados na seção 6.2).

Utilizando os mesmos parâmetros da seção 6.2 e limitando o número de tipos de peças em 2 e 3, nos exemplos W2 e W3, obtiveram-se os resultados da Tabela 6.25. As Figuras 6.20 e 6.21 apresentam os padrões obtidos.

Tabela 6.25 - Exemplos de Wang (1983) com limitação no número de tipo de peças

\begin{tabular}{|c|c|c|c|c|}
\hline Exemplo & No de tipos & Solução & No nós $^{\circ}$ & $\mathrm{t}(\mathrm{s})$ \\
\hline W1 & 2 & 0.8623 & 411 & 2.14 \\
\hline & 3 & 0.9238 & 315 & 1.21 \\
\hline W3 & 2 & 0.8407 & 699 & 3.35 \\
\hline & 3 & 0.9368 & 329 & 1.15 \\
\hline
\end{tabular}
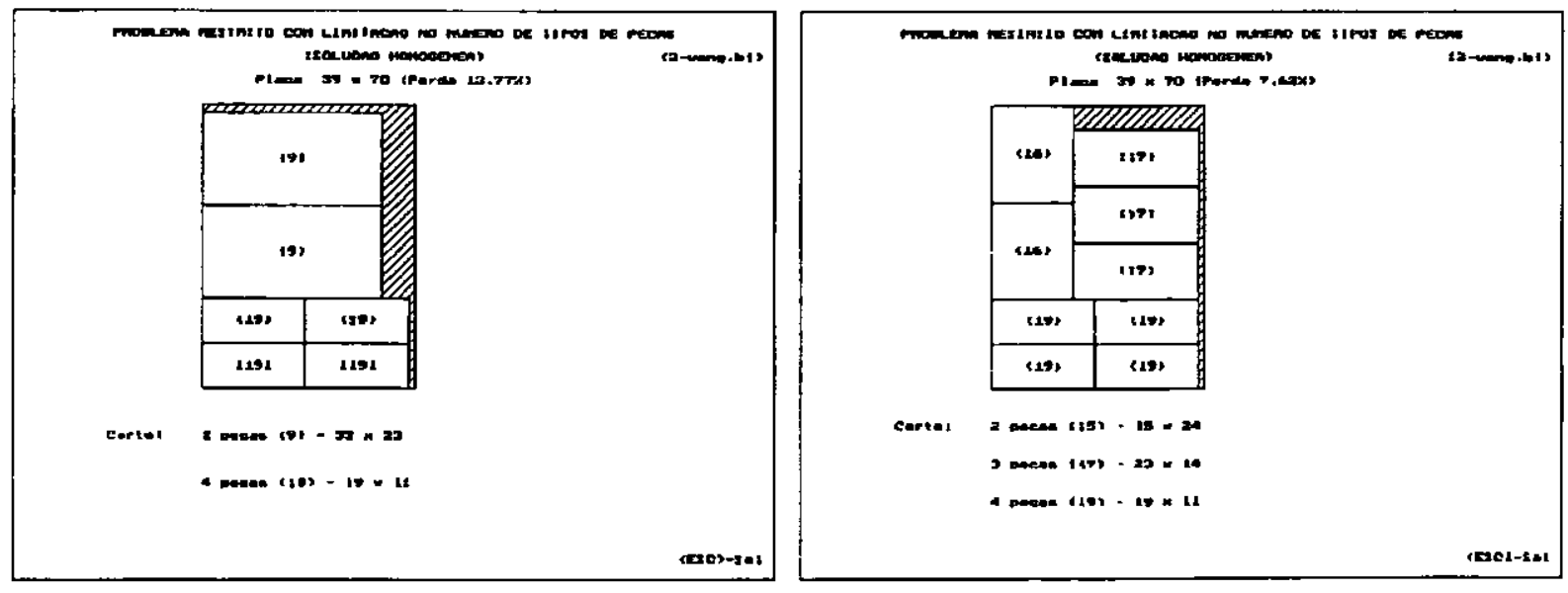

Figura 6.20 - Exemplo W2 com limitaçăo de 2 e 3 tipos de peças 

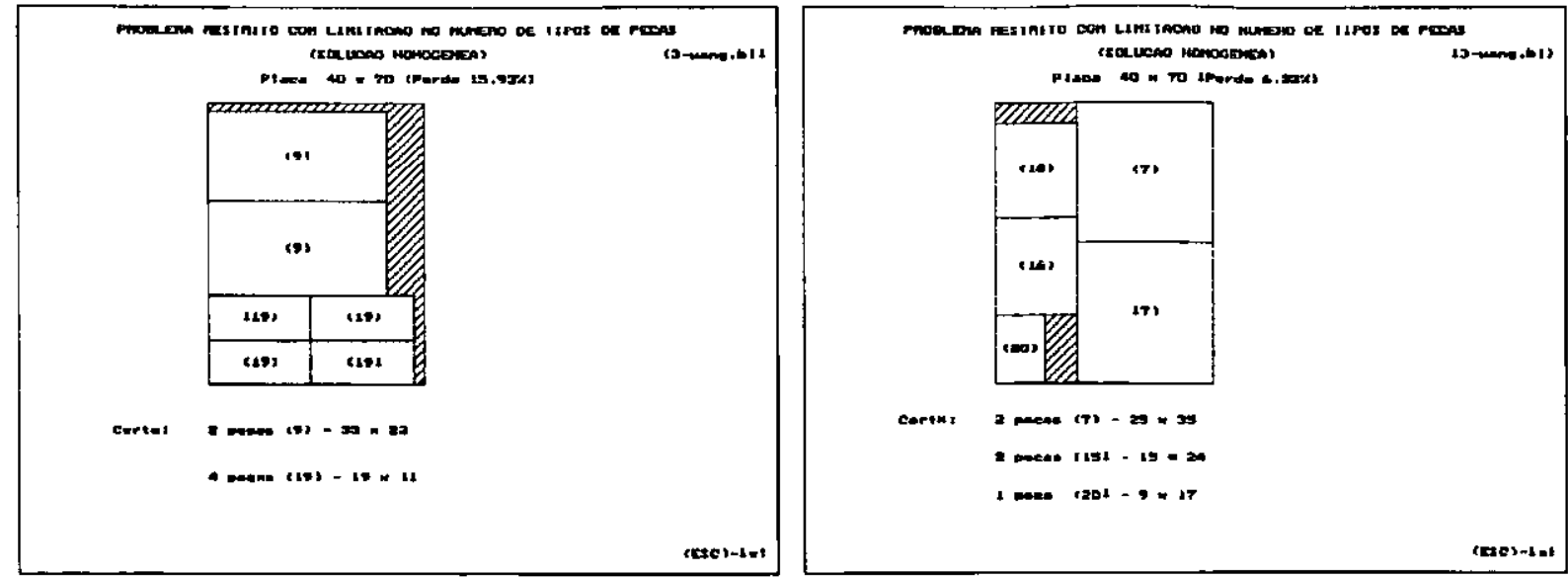

Figura 6.21 - Exemplo W3 com limitação de 2 e 3 tipos de peças

o mesmo procedimento foi repetido com os exemplos de Oliveira e Ferreira. Os resultados são apresentados na Tabela 6.26 e os padrōes de corte nas Figuras 6.22 e 6.23. A profundidade utilizada na estratégia backtracking foi 5 e 3 para OF1 e OF2, respectivamente.

Tabela 6.26 - Exemplos de Oliveira e Ferreira (1990) com limitação no número de tipo de peças

\begin{tabular}{|c|c|c|c|c|}
\hline Exemplo & № de tipos & Solução & № nós & $t(s)$ \\
\hline OFI & 3 & 0.9689 & 10357 & 25.04 \\
\hline & 4 & 0.9539 & 6331 & 11.64 \\
\hline OF2 & 3 & 0.9129 & 4521 & 11.69 \\
\hline & 4 & 0.9379 & 4139 & 9.83 \\
\hline
\end{tabular}
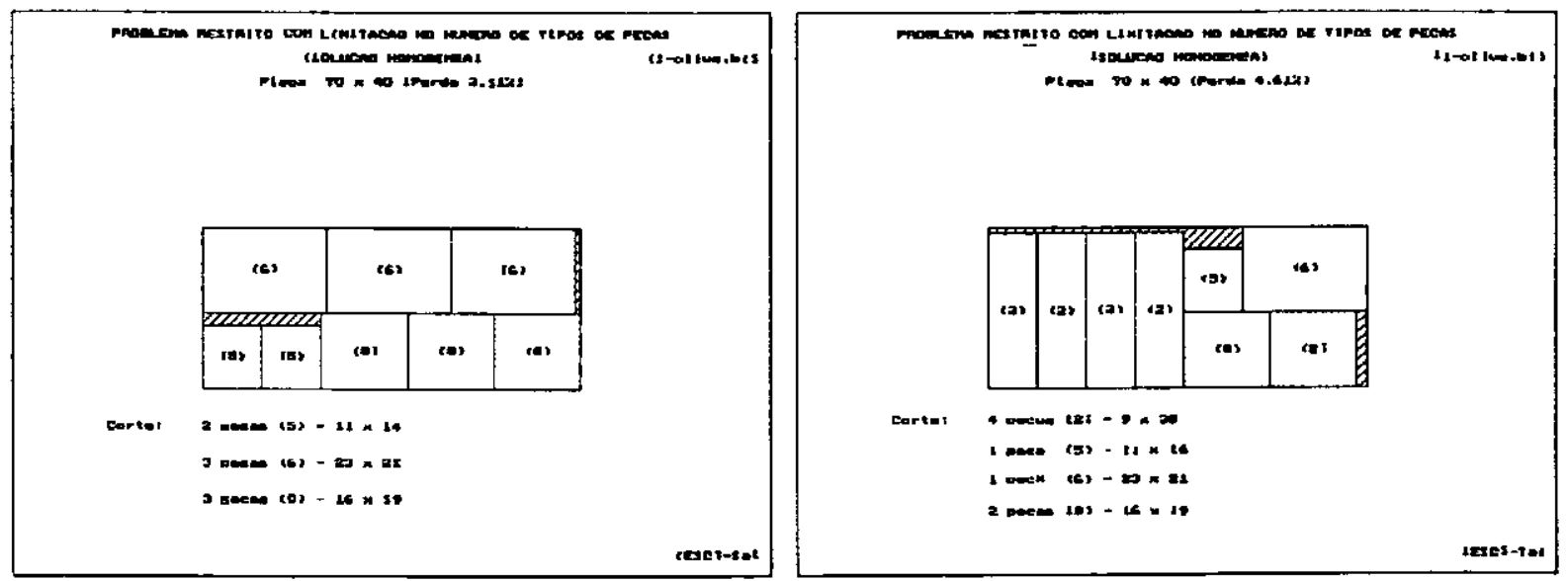

Figura 6.22- Exemplo OFl com limitação de 3 e 4 tipos de peças 

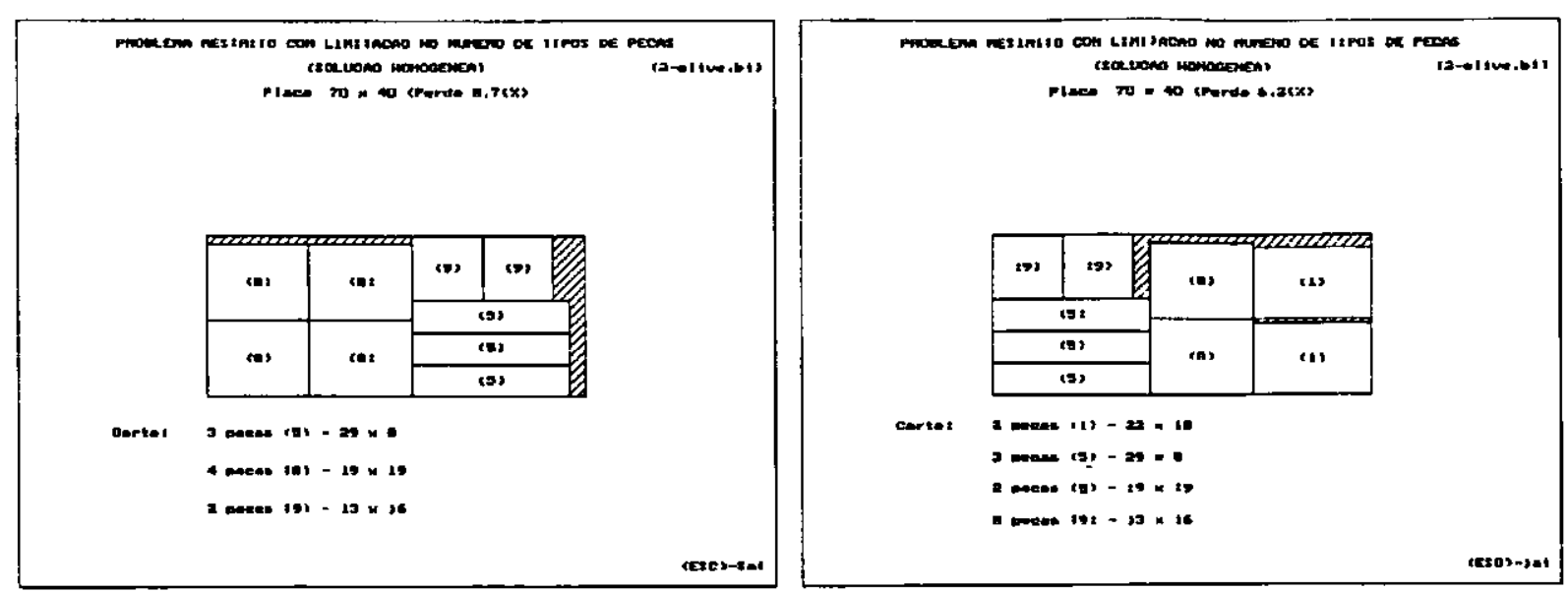

Figura 6.23- Exemplo OF2 com limitação de 3 e 4 tipos de peças

\subsection{Problema com corte-cabeça}

Conforme foi citado na seção 2.2 .3 , não há registro, na literatura, de métodos de solução para esta classe de problemas, embora se encontre este problema na prática.

A seguir, são apresentados alguns resultados, variando a limitação mínima e máxima da posição do corte e também o número total de giros, comentado na seção 3.2.5.

Considere um problema com uma placa de dimensões $(1000,1000)$ e 5 tipos de peças com dimensões $(143,277)$, $(357,215),(369,156),(221,139)$ e $(493,138)$. Uma solução cabeça, com os parâmetros no grafo $\mathrm{E} / \mathrm{OU}$ de limite de profundidade igual a $3, \lambda_{1}=10 \%$ e $\lambda_{2}=95 \%$, é apresentada na Figura 6.24, com valor $0.9701(17.47 \mathrm{~s})$. Neste padrão não houve limitação para a posição do corte e também no número total de giros. 


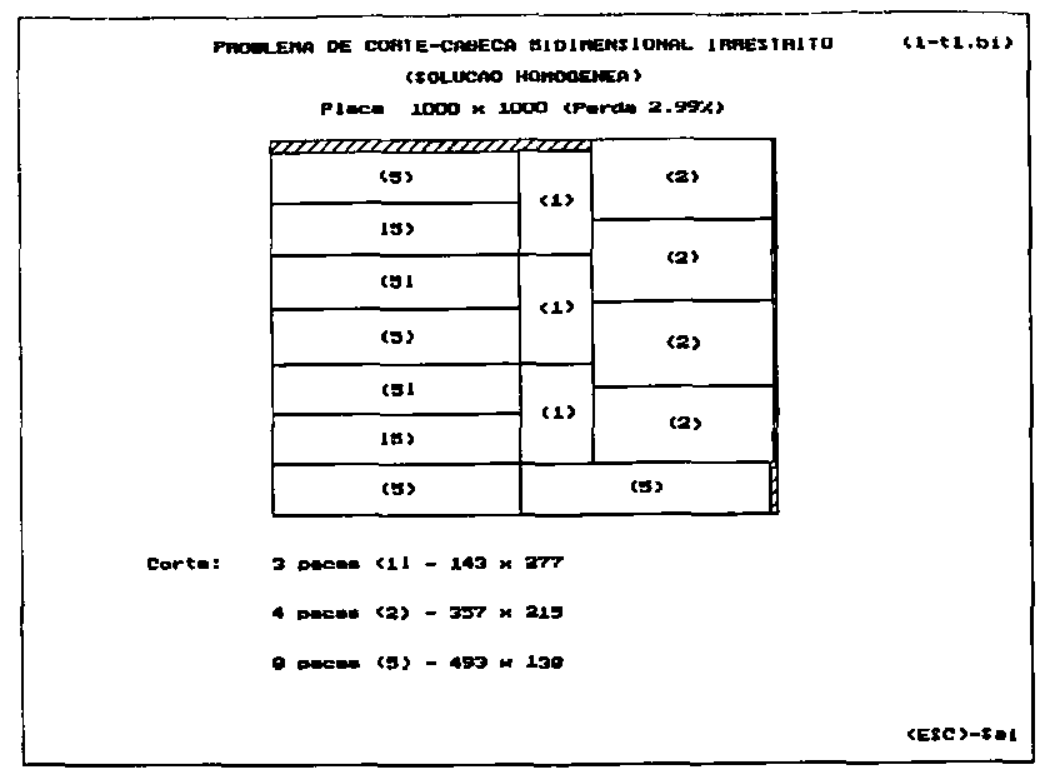

Figura 6.24 - Solução cabeça

Com a limitação da posição de corte no intervalo [100,300], obteve-se uma solução 0.9623 de com 4.5s. A Figura 6.25 apresenta o padrão de corte obtido. Observe que o cortecabeça agora está na horizontal, isto é, tem um giro.

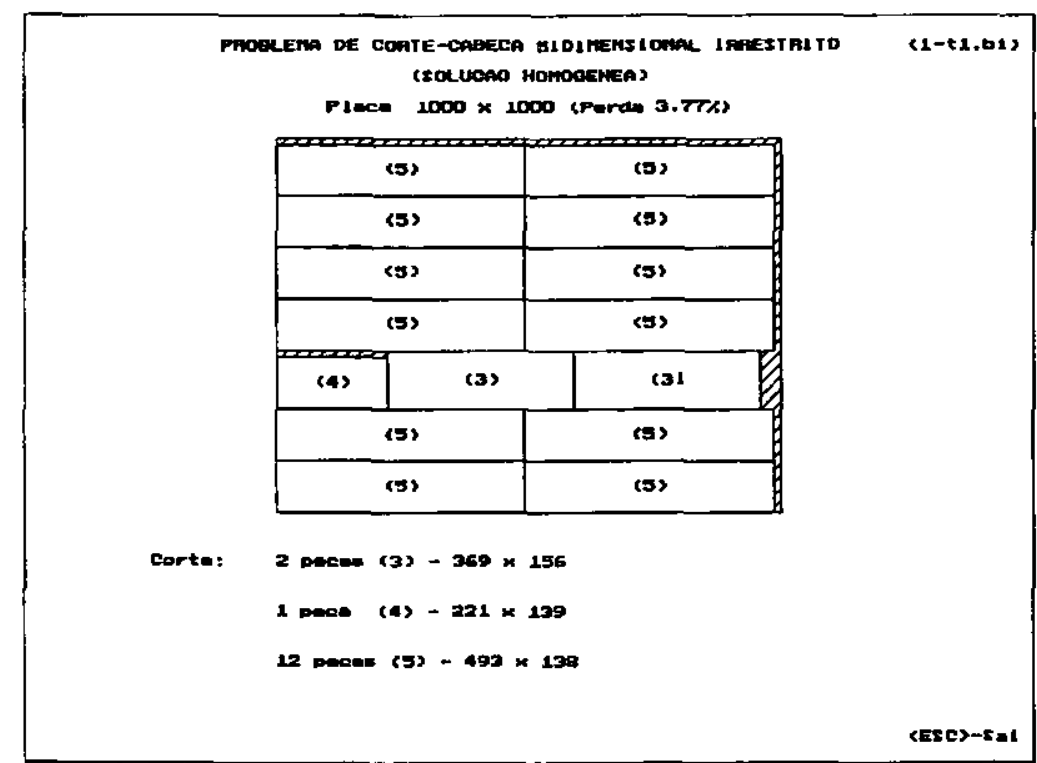

Figura 6.25 - Solução cabeça com limitação na posição do corte

Limitando o número de giros em 2, obteve-se o mesmo padrão da Figura 6.26.

A seguir, é apresentado um outro exemplo com uma 
placa $(100,100)$ e 10 peças de dimensões $(16,12)$, $(10,14)$, $(42,15),(19,22),(26,23),(26,25),(31,26),(39,34),(15,38)$ e $(33,45)$. A solução obtida, sem nenhuma restrição, é apresentada na Figura 6.26, com valor 0.9908 e tempo computacional de $46.8 \mathrm{~s}$.

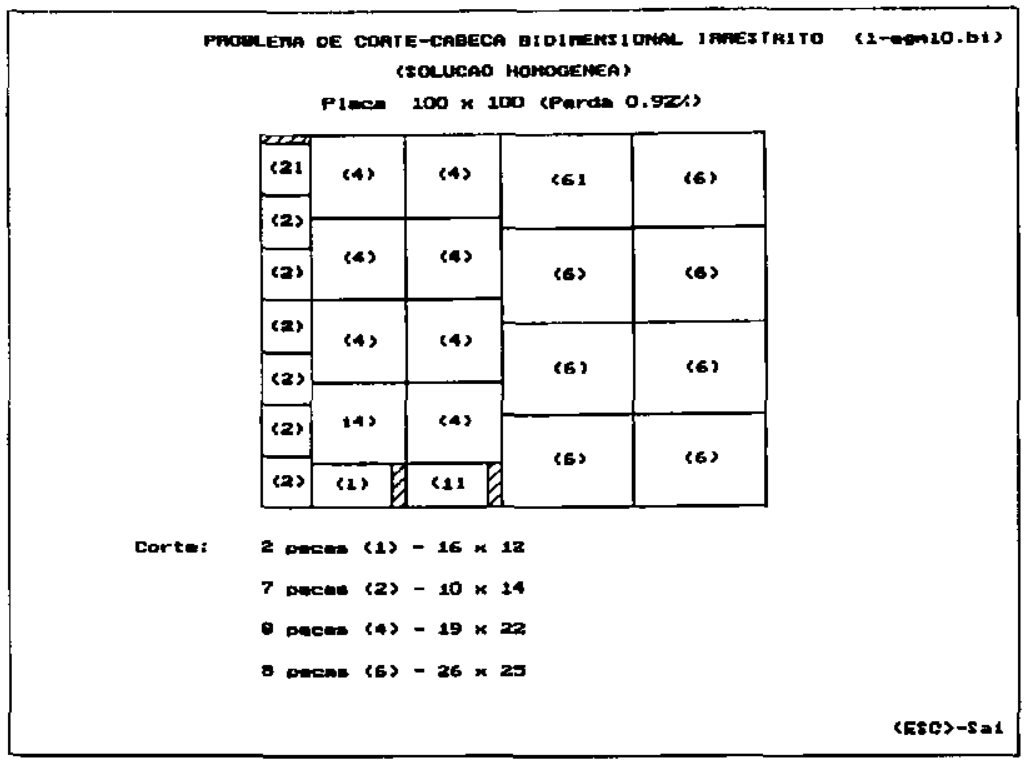

Figura 6.26 - Solução cabeça

Com uma limitação mínima de 12 unidades na posição do corte, tem-se uma solução de 0.9800 , com um tempo computacional de $2.74 \mathrm{~s}$ (Figura 6.27). Observe que o corte foi feito de maneira horizontal, satisfazendo a restrição de limitação.

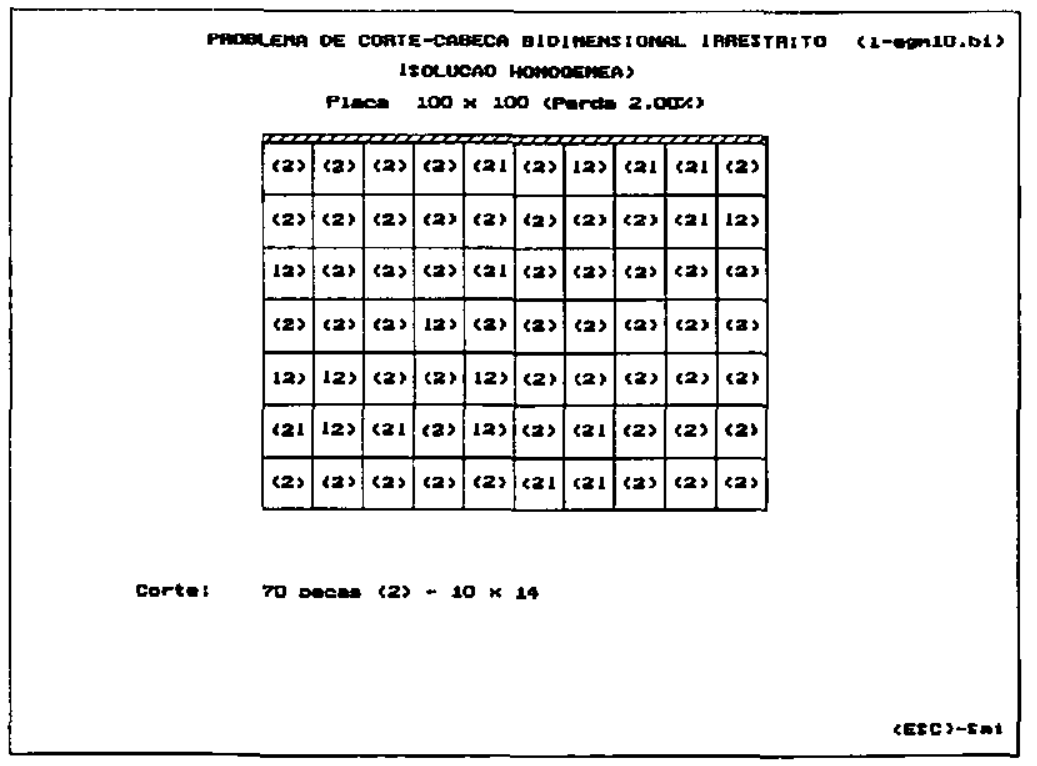

Figura 6.27 - Solução cabeça com limitação na posição do corte 
Observe que com um limite para a posição do corte, o tempo computacional diminui bastante, aumentando também a perda obtida.

\subsection{Problema com peças do tipo L}

A implementação do problema com peças do tipo L e/ou retangulares foi desenvolvida para o caso irrestrito. Foram necessárias alterações na estrutura de dados utilizada, já que neste problema são necessários mais dois parâmetros para armazenar as dimensões de cada peça, seja ela do tipo L ou retangular.

No algoritmo foi necessário implementar diferentes maneira de gerar dois novos nós, já que neste tipo de problema é possivel realizar cortes guilhotinados e/ou degrau.

Os testes foram feitos com exemplos onde as dimensões das peças $\ell_{i}^{1}, w_{i}^{1}, \ell_{1}^{2}, w_{i}^{2}, i=1, \ldots, m$, foram geradas aleatoriamente e, em seguida, arredondados, dentro dos respectivos intervalos $[0.2 \mathrm{~L}, 0.4 \mathrm{~L}],[0.2 \mathrm{~W}, 0.4 \mathrm{~W}],[0.4 \mathrm{~L}, 0.6 \mathrm{~L}], \mathrm{e}[0.4 \mathrm{~W}, 0.6 \mathrm{~W}]$. A Tabela 6.27, a seguir, apresenta a média dos resultados obtidos com uma classe de 20 exemplos. Utilizou-se profundidade máxima de 3 na estratégia de busca e parâmetros $\lambda_{1}=1 \%$ e $\lambda_{1}=95 \%$.

Tabela 6.27 - Exemplos com peças do tipo L

\begin{tabular}{|c|c|c|}
\hline $\mathrm{m}$ & Solução & $t(\mathrm{~s})$ \\
\hline 3 & 0.7560 & 13.17 \\
\hline 4 & 0.8576 & 24.42 \\
\hline 5 & 0.8880 & 42.02 \\
\hline
\end{tabular}

Lembre-se que o limitante inferior deste problema, apresentado na seção 4.2.1.3, calcula pelo menos duas soluções em cada nó e, escolhe a melhor entre elas.

A seguir, é apresentado um exemplo com uma placa 
de dimensões $(100,100)$ e 3 tipos de peças com dimensões $(30,30,30,30),(30,35,50,40)$ e $(55,55,55,55)$. A Figura 6.28 ilustra o padrão de corte obtido, com valor 0.9200 e tempo computacional de 19.01s.

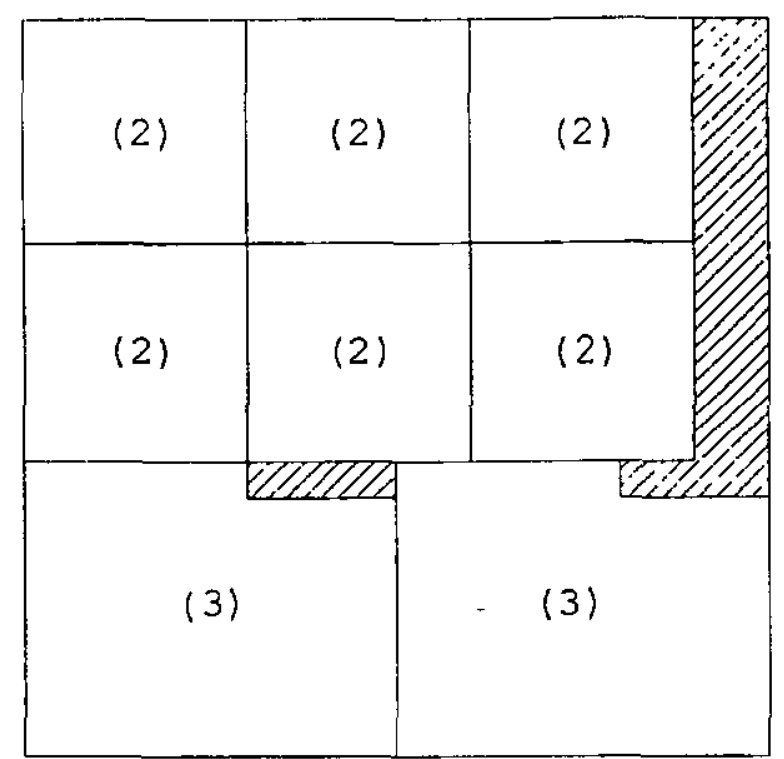

Figura 6.28 - Solução com peças do tipo L $(m=3)$

Para tentar melhorar os resultados alcançados com os problemas com peças do tipo $L$, deve-se, em pesquisas futuras, estudar limitantes inferiores diferentes, combinando peças diferentes na formação de soluções homogêneas compostas e, também heuristicas diferentes para a escolha dos cortes a serem realizados.

A implementação computaciónal da abordagem em Grafo E/OU permite que se combinem diferentes tipos de problemas sem muita dificuldade. Assim sendo, por exemplo, é fácil implementar, a partir das implementações anteriores, um problema restrito com corte-cabeça e limitação no número máximo de tipo de itens. Além disso, a abordagem em Grafo E/OU também permite que se incluam outras restrições, não consideradas neste estudo, com relativa facilidade. 
7. Aplicação do Problema de Corte numa Indústria de Esquadrias Metálicas

Deu-se, neste trabalho, ênfase na aplicação de uma abordagem em grafo E/OU para problemas de corte, em particular, para o problema de determinar o melhor padrão de corte para um objeto, produzindo itens com tamanhos, quantidades e valores de utilidade fornecidos. Além disso, restrições de processo e/ou formas geométricas foram estudadas utilizando-se da abordagem em grafo E/OU. Conforme a classificação de Dyckhoff (1990), os problemas de corte estudados nesta tese são do tipo $2 / \mathrm{B} / \mathrm{O}^{*}$, isto é, bidimensionais; itens devem ser selecionados para comporem o padrão, apenas uma unidade do objeto é considerada, sendo que os itens podem ser repetidos em grande quantidade ou não, terem tamanhos variados ou não. observe que nos problemas estudados, não havia demanda associada aos itens (apenas tamanhos, quantidades e valores de utilidade eram associados). Quando uma demanda deve ser satisfeita, de modo que vários objetos em estoque devem ser cortados para atendê-la, o problema é referido por problema de Corte de Estoque (Cutting Stock Problem), enquanto que o problema estudado nesta tese é chamado simplesmente de problema de corte. (Nos artigos pioneiros de Gilmore e Gomory, 1961, 1965 e 1966, estes problemas eram chamados de Problemas da Mochila - Knap- 
sack Problem, independentemente da dimensão). Os problemas de corte são de fundamental importância na resolução de problemas de corte de estoque. Na clássica abordagem de geração de colunas (Gilmore e Gomory, 1963), um problema de corte deve ser resolvido a cada iteração do método simplex, constituindo-se no gerador de colunas. Outras abordagens de solução são utilizadas na prática, principalmente quando há itens com baixa demanda. A seguir, será vista uma heuristica gulosa que, a cada iteração, gera o melhor padrão de corte e o utiliza o quanto for necessário.

Foi feito um estudo de caso numa Indústria de Esquadrias Metálicas, onde se determina uma seqüência de padrões de corte para atender uma demanda com uma perda mínima de material.

Considere $k$ placas retangulares de dimensões $\left(L_{j}, W_{j}\right)$, onde $L_{j}$ é o comprimento e $W_{j}$ a largura da placa $j$, em quantidade $B_{j}, j=1, \ldots, k$, e um conjunto de $m$ peças retangulares de dimensão $\left(\ell_{i}, w_{1}\right), i=1, \ldots, m$, onde $\ell_{i}$ é comprimento e $w_{i}$ a largura da peça $i$, conforme o exemplo da Figura 7.1. o problema consiste em cortar exatamente $b_{1}$ peças (neste caso, $b_{i}$ é demanda, pois deve ser atendida), $i=1, \ldots, \mathrm{m}$, a partir das placas retangulares, maximizando seu aproveitamento. Assim, se por um lado, os padrões não devem produzir mais do que $b_{i}$ unidades da peça $i$, várias placas devem ser cortadas, de modo que o número total de peças tipo $i$ cortadas seja exatamente igual a $b_{i}$.

- algoritmo utilizado para a resolução deste problema foi do tipo iterativo guloso (heuristica de aspiração, Hinxmam (1980)), onde, a cada iteração, determina-se a placa que apresenta o melhor aproveitamento, ou seja, o melhor padrão de corte, e, após o corte, as disponibilidades das placas e demandas das peças são atualizadas. 

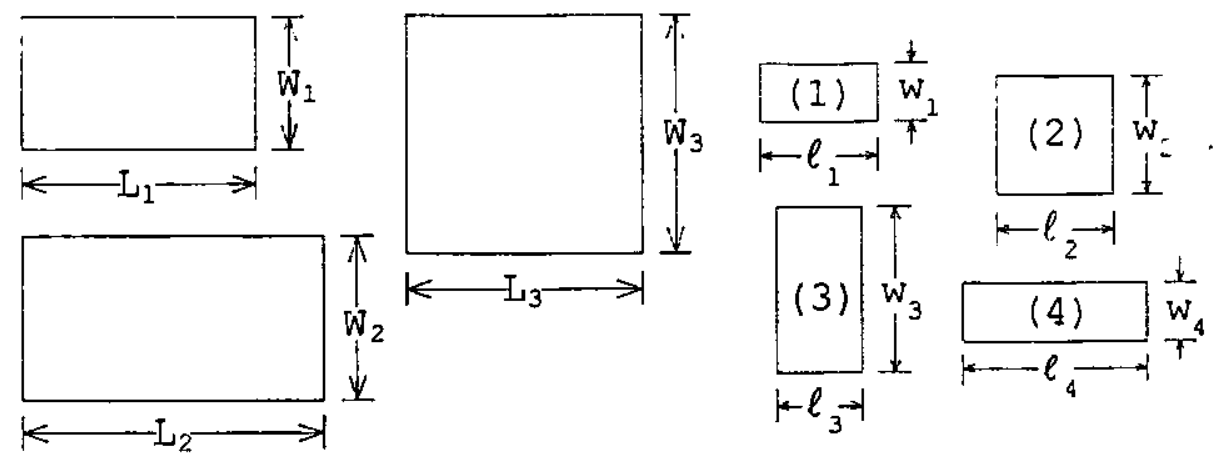

Figura 7.1 - Problema de corte com k placas $(k=3)$

\subsection{Algoritmo Guloso}

Considere os seguintes dados:

k: número de placas retangulares $\left(L_{j}, W_{j}\right), j=1, \ldots, k$

$L_{j}$ : comprimento da placa $j, j=1, \ldots, k$

$W_{j}$ : largura da placa $j, j=1, \ldots, k$

$B_{j}$ : disponibilidade da placa $j, j=1, \ldots, k$

$\mathrm{m}$ : número de peças retangulares $\left(\ell_{i}, w_{i}\right), i=1, \ldots, \mathrm{m}$

$\ell_{i}$ : comprimento da peça $i, i=1, \ldots, m$

$w_{i}$ : largura da peça $i, i=1, \ldots, m$

$b_{i}$ : demanda da peça $i, i=1, \ldots, m$

$\mathrm{a}^{*}$ : vetor associado ao melhor padrão

$k^{*}$ : tipo da placa referente ao melhor padrão

$\beta^{*}$ : número de repetições do padrão $a^{*}$ na placa $k^{*}$

\section{Infcio}

Enquanto (demanda das peças não for atendida) e (houver disponibilidade de placas) faça:

- Determine o melhor padrão de corte para a placa tipo j com $B_{j}>0, j=1, \ldots, k$.

- Armazene o melhor padrão de corte encontrado (a*: melhor padrão de corte encontrado, $\mathrm{k}^{*}$ : tipo da placa referente ao melhor padrão).

- Corte a placa $k^{*}$, conforme o padrão $\mathrm{a}^{*}$, o maior número 
de vezes possivel $\left(\beta^{*}=\min \left\{\left\lfloor\frac{b_{i}}{a_{i}^{*}}\right\rfloor, B_{k^{*}}\right\}\right)$. Durante este processo a demanda das peças e a disponibilidade da placa $k^{*}$ é atualizada $b_{i}=b_{1}-\beta^{*} \cdot a_{i}^{*}, i=1, \ldots, m_{i} B_{k}=B_{k} \cdot-\beta^{*}$.

Fim enquanto

Fim

\subsection{Exemplo Prático}

A seguir, nas Tabelas 7.1 e 7.2 , são apresentados os resultados obtidos com o algoritmo guloso, usando dados fornecidos por uma Indústria de Esquadrias Metálicas (Icometal Indústria e Comércio de Esquadrias Metálicas Ltda., situada em Campinas). A linguagem utilizada na implementação computacional, assim como o equipamento utilizados estão relacionados no capítulo 6 .

A rigor, os dados fornecidos pela empresa são de clientes variados. Um pré-processamento foi feito para agrupar itens idênticos e uma ordenação (comprimentos em ordem crescente) nos itens.

Para este exemplo foram gerados 34 tipos de padrōes de corte, em 4.17s, com uma perda total de 18.32\% (Figura 7.2).

Tabela 7.1 - Dados das placas $(k=4)$

\begin{tabular}{|c|c|c|c|}
\hline Placa & $L_{j}$ & $W_{j}$ & $B_{j}$ \\
\hline 1 & 1000 & 2000 & 105 \\
\hline 2 & 1200 & 2000 & 85 \\
\hline 3 & 1000 & 3000 & 70 \\
\hline 4 & 1200 & 3000 & 58 \\
\hline
\end{tabular}


Tabela 7.2 - Dados das peças $(\mathrm{m}=35)$

\begin{tabular}{|c|c|c|c|}
\hline$i$ & $\ell_{1}$ & $w_{1}$ & $b_{1}$ \\
\hline 1 & 350 & 780 & 2 \\
\hline 2 & 350 & 1000 & 4 \\
\hline 3 & 500 & 900 & 24 \\
\hline 4 & 500 & 1845 & 4 \\
\hline 5 & 580 & 1845 & 2 \\
\hline 6 & 670 & 780 & 2 \\
\hline 7 & 670 & 1000 & 4 \\
\hline 8 & 730 & 780 & 2 \\
\hline 9 & 730 & 840 & 24 \\
\hline 10 & 730 & 1425 & 24 \\
\hline 11 & 730 & 2000 & 50 \\
\hline 12 & 765 & 840 & 2 \\
\hline 13 & 765 & 2000 & 2 \\
\hline 14 & 770 & 840 & 2 \\
\hline 15 & 770 & 1430 & 2 \\
\hline 16 & 770 & 2000 & 4 \\
\hline 17 & 780 & 900 & 11 \\
\hline 18 & 840 & 900 & 3 \\
\hline
\end{tabular}

\begin{tabular}{|c|c|c|c|}
\hline$i$ & $\ell_{i}$ & $w_{1}$ & $b_{1}$ \\
\hline 19 & 840 & 1090 & 8 \\
\hline 20 & 900 & 1000 & 2 \\
\hline 21 & 900 & 1365 & 10 \\
\hline 22 & 900 & 1430 & 6 \\
\hline 23 & 900 & 1780 & 2 \\
\hline 24 & 900 & 2000 & 70 \\
\hline 25 & 910 & 1365 & 2 \\
\hline 26 & 910 & 1785 & 2 \\
\hline 27 & 910 & 2000 & 2 \\
\hline 28 & 935 & 1365 & 2 \\
\hline 29 & 935 & 1785 & 2 \\
\hline 30 & 935 & 2000 & 2 \\
\hline 31 & 1000 & 1090 & 32 \\
\hline 32 & 1000 & 1175 & 2 \\
\hline 33 & 1030 & 2020 & 2 \\
\hline 34 & 1090 & 1430 & 8 \\
\hline 35 & 1175 & 1780 & 2 \\
\hline
\end{tabular}

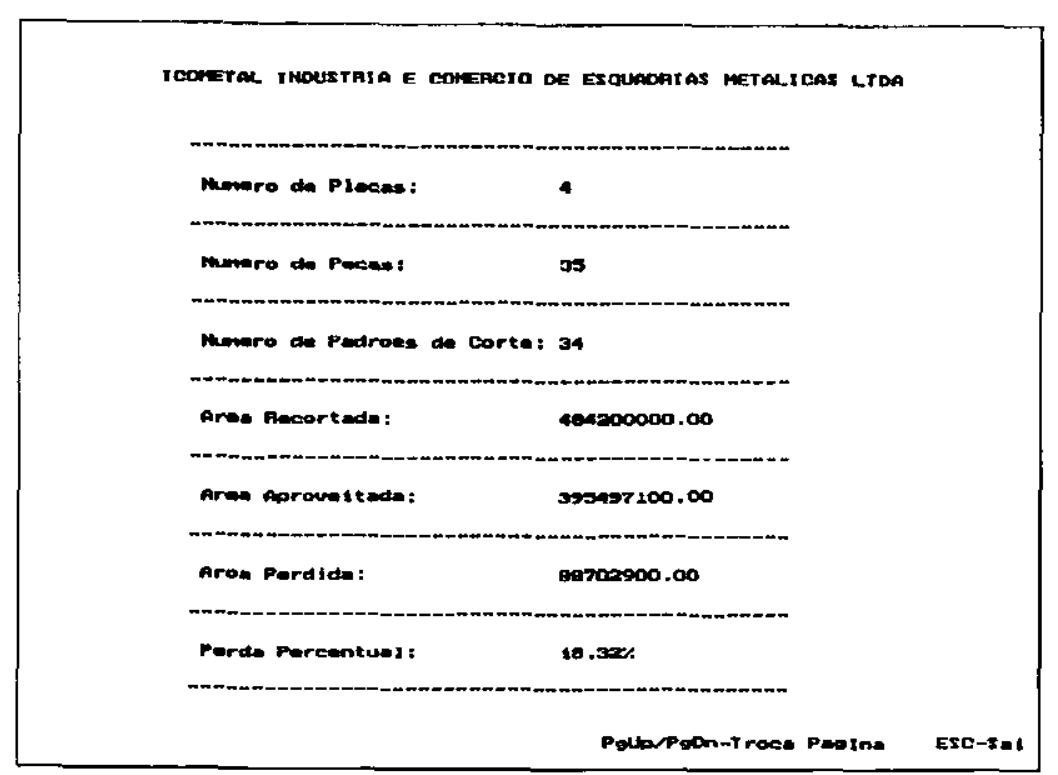

Figura 7.2 - Relatório obtido com a execução do problema 
Como o algoritmo é guloso, a perda dos primeiros padrões obtidos é pequena. Note, na Figura 7.3, que o padrão i se repete 12 vezes na placa $(1000,2000)$, com perda $0.508 ; 0$ padrão 2 é repetido 2 vezes na placa $(1200,2000)$, com perda $1.18 \%$ e, assim, sucessivamente.
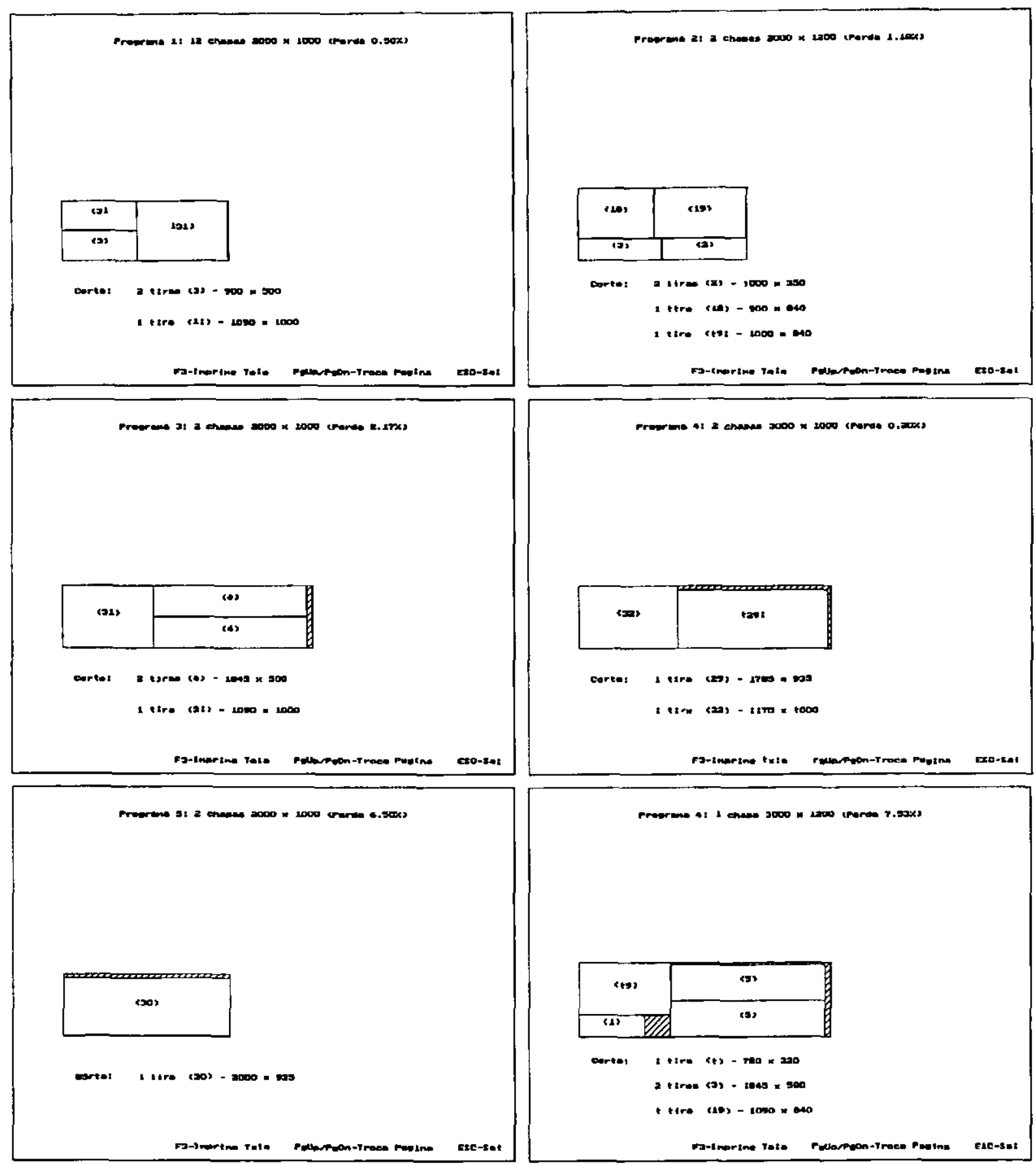

Figura 7.3 - Seis melhores padrões de cortes 
Nos últimos padrões de corte, a perda é muito grande (Figura 7.4), o que sugere um algoritmo interativo, de maneira que o usuário possa introduzir peças com valores de utilidade menores, seja sob a forma de novos pedidos ou de pecas para estoque.
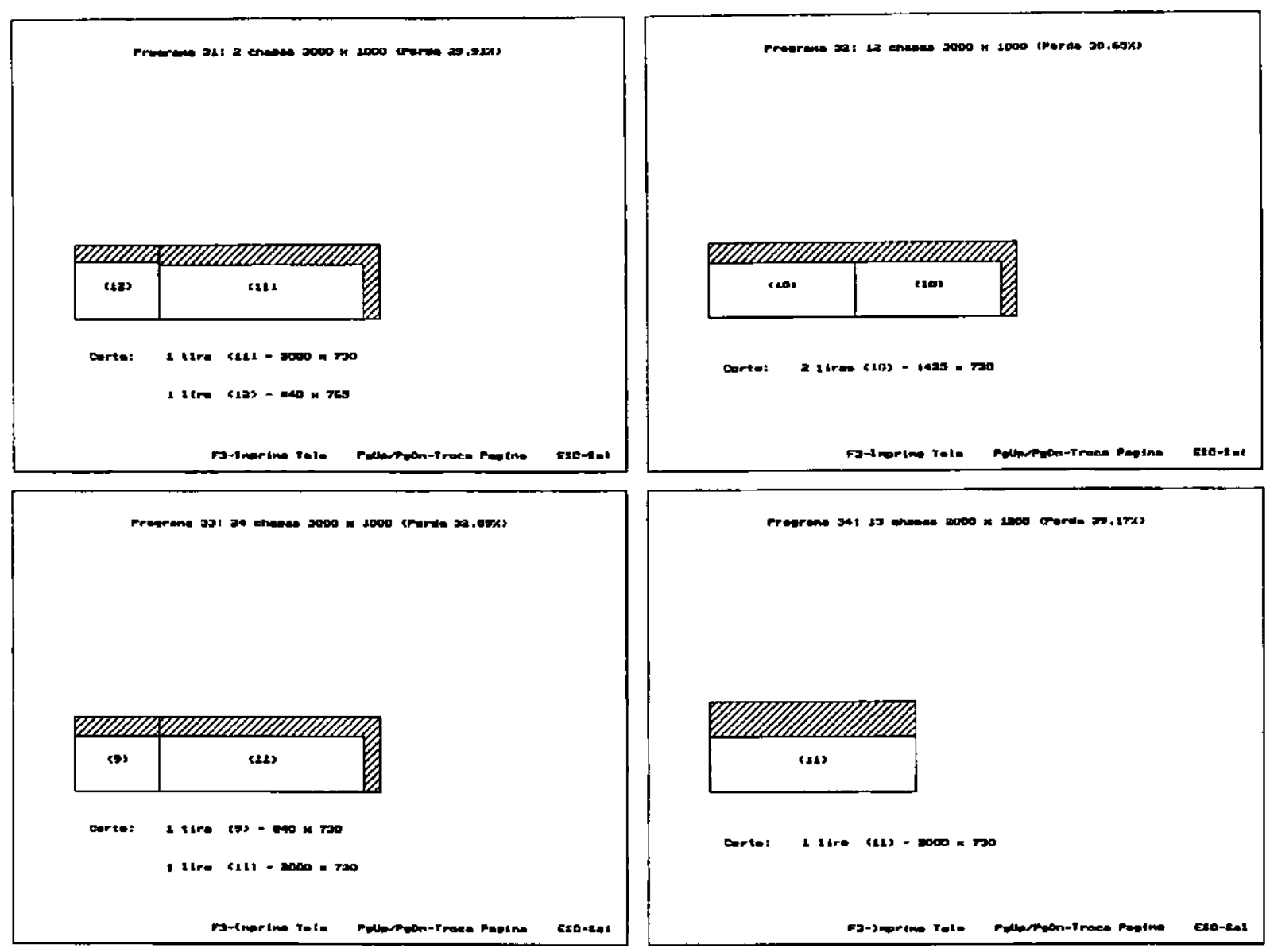

Figura 7.4 - Últimos padrões de cortes

Utilizando a heuristica $\mathrm{H} 6$ apresentada no capitulo 5, que diminui o conjunto de discretização, obtiveram-se os resultados da Tabela 7.3. Nesta tabela a primeira coluna mostra a variação de $\delta$, a segunda, a perda percentual obtida, a terceira, o número de padrões de corte (NPC) e, a última, o tempo computacional obtido. Note que, com $\delta=30 \%$, o resultado obtido apresenta uma perda muito próxima da perda obtida, sem a diminuição dos conjuntos de discretização, com um tempo computacional inferior. Embora, do ponto de vista prático, a di- 
7. Aplicação do Problema de Corte numa Indústria de Esquadrias Metálicas103

minuição do tempo, neste caso, seja irrelevante, com o aumento de placas e peças, pode tornar-se significátivo.

Tabela 7.3 - Resultados obtidos com a heuristica H6

\begin{tabular}{|c|c|c|c|}
\hline$\delta$ & Perda & NPC & $t(s)$ \\
\hline $5 z$ & 18.928 & 34 & 2.69 \\
\hline $10 z$ & 18.528 & 33 & 2.25 \\
\hline $20 z$ & 19.028 & 33 & 1.70 \\
\hline 308 & 18.428 & 36 & 1.76 \\
\hline
\end{tabular}




\section{Conclusões e Perspectivas Futuras}

Ib A resolução de Problemas de corte e Empacotamento é de grande importância técnica e econômica em aplicaçōes industriais e, além disso, é um desafio acadêmico devido à dificuldade de encontrar métodos que apresentem soluções exatas em tempos computacionais razoáveis.

Este trabalho propôs a extensão da abordagem em grafo E/OU (Morabito, 1989, 1992; Arenales, 1993), para a resolução de Problemas de Corte e Empacotamento que envolvam cortes e objetos mais gerais, bem como processos de cortagem mais elaborados.

O estudo considerou problemas irrestritos e restritos, cortes guilhotinados e não-guilhotinados, estagiados e não-estagiados, entre outros. Em particular, a abordagem em grafo E/OU foi estendida para tratar os seguintes casos não considerados nos trabalhos anteriores:

- diferentes limitantes inferiores (problema irrestrito e estagiado);

- problema restrito e estagiado;

- problema com placa defeituosa;

- problema com corte-cabeça;

- problema com limitação no número de tipos de itens;

- problemas não guilhotinado (com peças do tipo L) . 
Pôde-se verificar a versatilidade do método baseado na representação em grafo E/OU para tratar diversas situações do problema de corte e, também, que sua implementação computacional apresenta bons resultados, com tempos computacionais razoáveis, demonstrando ser uma poderosa ferramenta na resolução de problemas de corte e empacotamento.

Uma outra contribuição deste trabalho foi na investigação de diferentes tipos de limitantes no processo de busca, levandorse em conta as caracteristicas de cada classe de problema.

Para a implementação computacional, desenvolveuse uma estrutura de dados (apresentado no anexo 1) que trata a representação em grafo E/OU de maneira genérica, permitindo, assim, que se incluam restricões e diferentes itens sem muita dificuldade. Portanto, é possivel adaptar, por exemplo, esta abordagem para o problema de corte tridimensional sem maiores dificuldades.

Como perspectivas para novas pesquisas, tem-se 0 problema com peças do tipo L, onde o cálculo dos limitantes inferiores podem ser melhorados. Uma alternativa é a combinacão de peças de tipos diferentes, conforme a Figura 8.1, para formar uma solução homogênea composta (Figura 8.2). Isso pode ser uma alternativa mais eficiente do ponto de vista computacional, do que aumentar o limite de profundidade de busca em mais um nível no problema com solução homogênea simples.
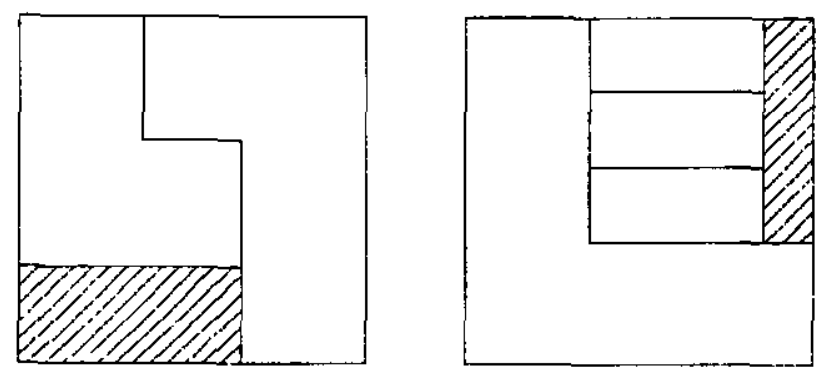

Figura 8.1 - Combinação de diferentes tipos de peças 


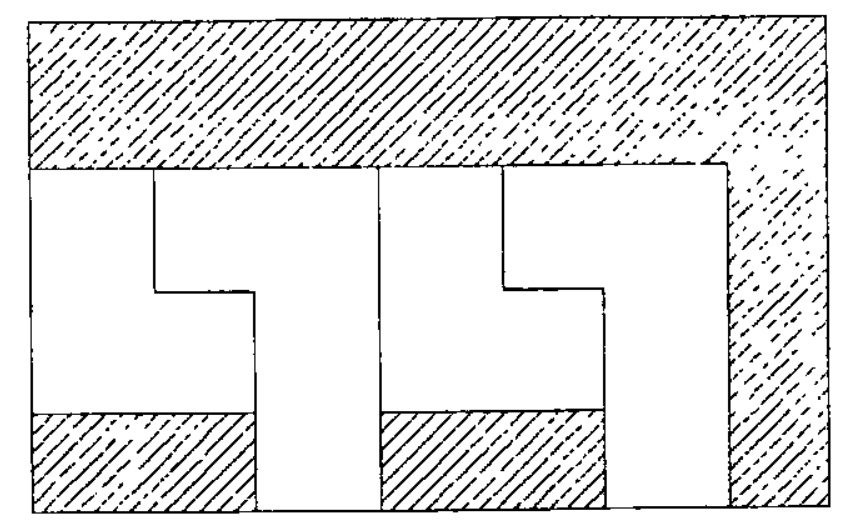

Figura 8.2 - Solução homogênea composta

A implementação do padrão de corte nãoguilhotinado de 1- ordem, seção 2.2.5, pode ser desenvolvida usando a estrutura de dados apresentada neste trabalho, incluindo algumas informações nos nós do grafo e no código computacional. Observe que este padrão pode ser gerado com o problema de peças do tipo $L$, implementado nesta tese.

Um outro tópico seria a investigação de buscas alternativas, visando diminuir o tempo computacional, tais como buscas híbridas, onde a combinação de backtracking e hill-climbing poderia ser feita até um certo nivel de profundidade, ou dos tamanhos dos objetos intermediários, quando então os nós seriam resolvidos por programação dinâmica ou por alguma heurística mais elaborada, dependendo do problema.

Uma outra perspectiva para o uso da abordagem em grafo E/OU é na resolução do problema com padrão de corte tabuleiro. Este padrão de corte é do tipo guilhotinado 2estágios, conforme ilustra a Figura 8.3. E importante em problemas de corte que surgem na industria de móveis, pois apesar de apresentar perdas maiores do que padrões 2-estágios, é mais fácil de ser cortado, acelerando a produção em períodos de alta demanda. Isto pode ser fundamental, pois a serra pode ser - gargalo de produção (Morabito e Arenales, 2000). 


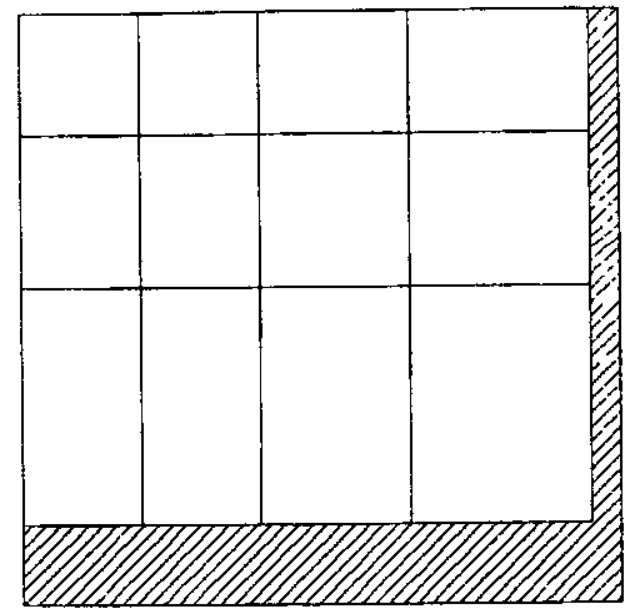

Figura 8.3 - Padrão de corte tabuleiro

Há expectativas de que alguns outros problemas importantes de corte e empacotamento possam ser tratados pela abordagem em grafo E/OU, já que reștriçōes de processo de corte puderam ser incorporadas na busca sem dificuldades, como demonstrado nesta tese, tais como, problemas de empacotamento tridimensionais, onde ocorrem restrições de peso e estabilidade. Além disso, o empacotamento deve levar em conta uma ordem de desempacotamento. Isto poderia ser visto como um problema de corte de objeto não homogêneo; já padrões de corte gerando - mesmo número de itens não são equivalentes. Além do problema .de corte com itens do tipo L, tratado nesta tese, outras "irregularidades" podem ser investigadas. 


\section{Anexo 1}

Este anexo contém as seções 4 e 5.1 do relatório técnico de Gonçalves-Vianna et al: (2000a). A seção 4, do relatório técnico, trata da estrutura de dados e da implementação do algoritmo da abordagem em grafo E/OU estudado nesta tese. A seção 5.1 apresenta os resultados obtidos com a geração do conjunto de discretização.

\section{Implementação Computacional}

O algoritmo descrito foi implementado na linguagem Pascal, utilizando o compilador Borland Pascal versão 7.0, em um microcomputador Pentium, $167 \mathrm{Mhz}$ com 32 Mbytes de RAM.

Inicialmente, foi feita a implementação da geração do conjunto de discretização utilizando as fórmulas de Christofides e Whitlock (1977), descritas na seção 3.2 .1 de Gonçalves-Vianna et al. (2000a).

Como as fórmulas são recursivas, escreveu-se uma rotina de geração de cortes também usando a técnica de programação de recursividade.

A recursividade é uma técnica em que uma rotina, no processo de execução de suas tarefas, chama a si própria. Por este motivo, é necessária uma área de memória para salvar 
- seu contexto antes dessa chamada recursiva (pilha de registros), a fim de que este possa ser restaurado ao final dessa chamada. Sua principal vantagem é a redução do código-fonte da rotina; entretanto, o uso de recursividade apresenta algumas desvintagens, entre elas o baixo desempenho na execução, devido ao tempo gasto no gerenciamento da pilha de registros e o espaço por ela ocupado, e a dificuldade de depuração dos programas (Villas et al., 1993).

Foram feitos diversos testes com a rotina recursiva, observando-se que o tempo computacional aumenta exponencialmente em função da dimensão do problema (veja seção 5.1 de Gonçalves-Vianna et al.(2000a)). Os dados foram gerados novamente, em un microcomputador Pentium II, com 128 Mbytes de RAM; entretanto o tempo computacional obtido é grande quando comparado com o tempo obtido de uma versão não recursiva.

Portanto, apesar da clareza e elegância do algoritmo recursivo na implementação das fórmulas de Christofides e Whitlock (1977), o desempenho ficou muito longe do esperado.

A rotina foi, então, implementada de maneira iterativa; o código ficou bem mais extenso e não tão fácil de se compreender, mas o desempenho do algoritmo compensa estas perdas.

Exemplos de comparações entre as duas técnicas de programação, recursiva e iterativa, para a geração do conjunto de discretização são vistas no próximo capítulo.

A estrutura de dados utilizada para o armazenamento dos conjuntos de discretizaçåo ( $\mathrm{X}$ e $Y$ ), lembrando que eles são definidos inicialmente e, durante o processo de busca, são facilmente determinados para qualquer nó (x,y), foi uma lista sequiencial usando alocação estática. Neste tipo de alocaçăo, a estrutura de dados utilizada deve estar completamente definida e é alocado um espaço finito e pré-determinado de memória, não permitindo alteração durante o processo de execução do programa. 
No caso do conjunto de discretização, foi definido un vetor (em Pascal, array) com no máximo 100 posições. Portanto, se o conjunto tiver apenas 20 elementos, as demais posições ficarão vazias, porém ocupando espaço de memória. Caso seja necessário, não é possirrel ter mais de 100 cortes, já que o tamanho máximo do vetor deve ser definido durante a fase de programação. A vantagem desta estrutura de dados é o acesso direto a cada posição do vetor. Um exemplo deste tipo de estrutura armazenando un vetor de números inteiros é ilustrado pela Figura A.1.

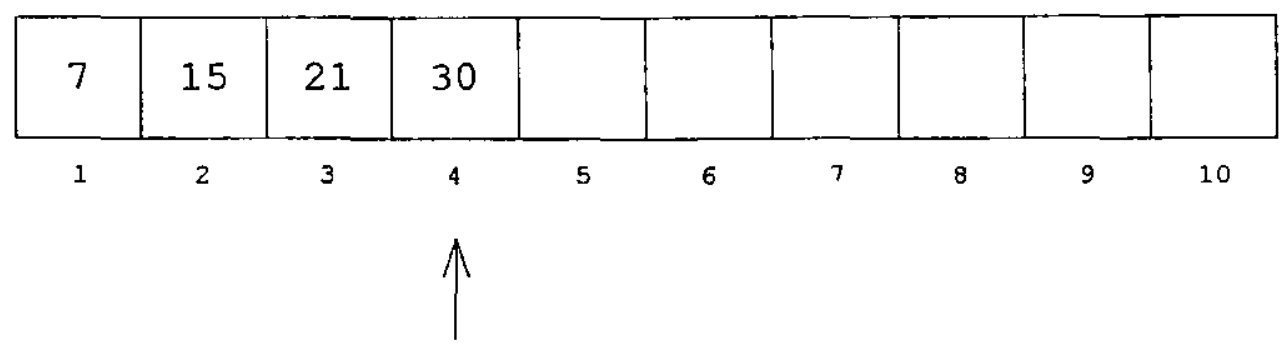

Figura A.1 - Lista sequencial

Também implementou-se a geração do conjunto utiIizando uma lista encadeada usando alocação dinâmica (Figura A.2). Este tipo de alocação permite que a estrutura de dados não tenha um tamanho pré-definido, ficando limitado à memória do computador.

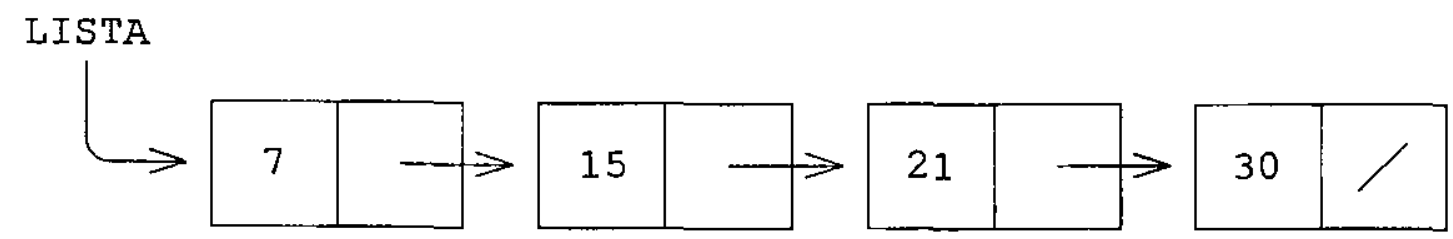

Figura A.2 - Lista encadeada

Note que são alocados apenas os elementos que são definidos; entretanto, para acessar o último elemento da lista, é necessário percorrer todos os anteriores. Este tipo de estrutura também oferece uma flexibilidade para o caso de muitas inserções e remoções de elementos na lista. 
Um outro tipo de estrutura de dados, que pode ser utilizado para a representação do conjunto de discretização, é uma árvore binária ordenada (Figura A.3). Nesta estrutura, assim como na estrutura com listas encadeadas, não é necessário definir seu tamanho previamente.

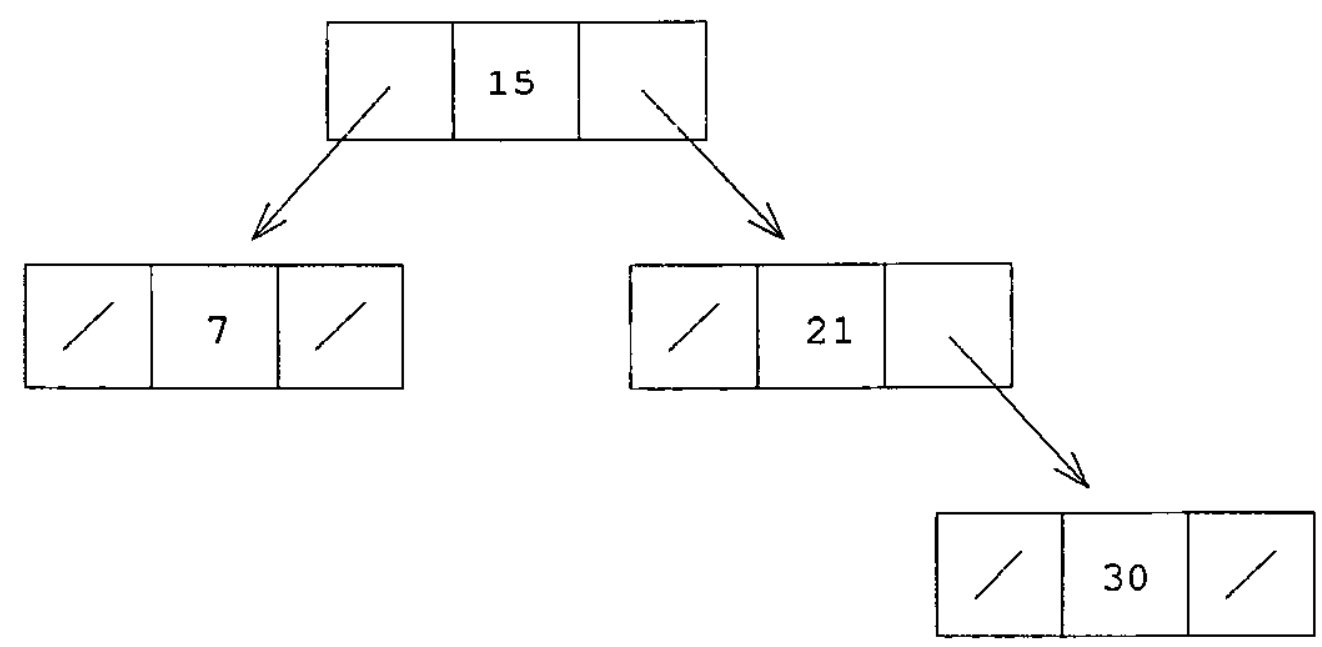

Figura A.3 - Arvore binária ordenada

Este tipo de estrutura necessita de um tempo computacional maior que a lista encadeada para sua construção, entretanto, como ela está ordenada, o tempo computacional para a procura de um elemento é menor.

No caso do conjunto de discretização, após a implementação usando dois tipos de estrutura de dados, lista seqüêncial e lista encadeada, optou-se pela primeira, já que a heuristica utilizada (vista na seção 3.3, de Gonçalves-Vianna et al., 2000a) limita o tamanho do conjunto e o acesso aos elementos da lista sequiencial é mais rápido, uma vez que, depois dos conjuntos de discretização gerados, basta percorrêlos para gerar os conjuntos de um determinado nó.

$\mathrm{Na}$ implementação do algoritmo de busca, utilizou-se alocação dinâmica para a representação do grafo, tendo sido armazenados os seguintes dados para cada nó: 


\begin{tabular}{|c|}
\hline Informações do nó $\mathrm{N}$ \\
\hline Endereço do nó $\mathrm{N}_{1}$ \\
\hline Endereço do nó $\mathrm{N}_{2}$ \\
\hline
\end{tabular}

Figura A.4 - Dados armazenados em cada nó do grafo em problemas guilhotinados

As informações do nó $\mathrm{N}$ se referem à dimensão do objeto representado pelo nó, ao valor $\mathrm{V}(\mathrm{N})$ obtido até o nó e aos limitantes inferior e superior, entre outros dados. Este conjunto de informações varia de acordo com o problema e as restrições impostas por ele.

Este tipo de estrutura permite que se tenha um grafo gerado conforme a Figura A.5. Lembre que o algoritmo armazena um único caminho do grafo.

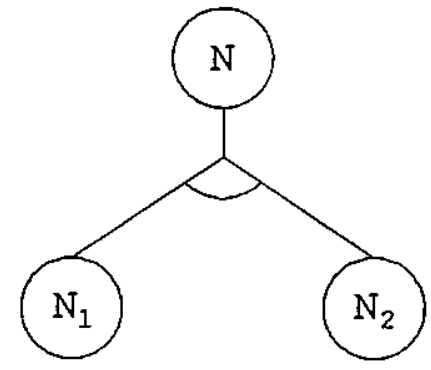

Figura A.5 - Estrutura do nó armazenado

Com este tipo de estrutura, se o problema permitir gerar mais que dois nós (por exemplo, o problema de corte não-guilhotinado), basta que se inclua nos dados do nó o endereço dos demais nós, ou seja,

\begin{tabular}{|c|}
\hline Informações do nó $\mathrm{N}$ \\
\hline Lista encadeada com o en- \\
dereço dos nós gerados \\
\hline
\end{tabular}

Figura A.6 - Dados armazenados em cada nó do grafo em problemas não-guilhotinados 
Note que o tamanho da Iista encadeada depende do número de sucessores e, no caso do corte não-guilhotinado, cada nó do grafo gera no máximo 5 novos nós (Figura A.7).

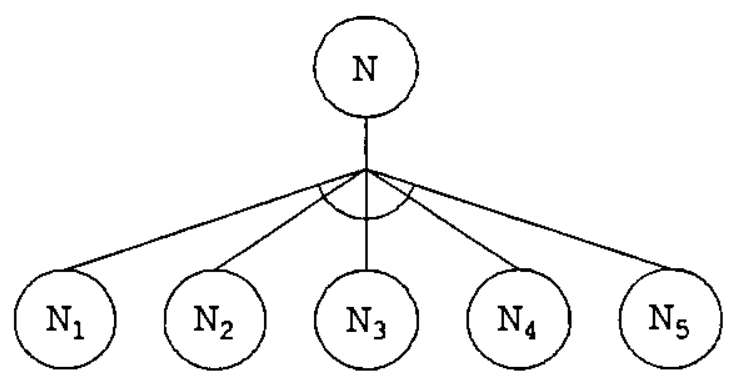

Figura A.7 - Estrutura do nó gerado pelo corte não-guilhotinado

A implementação do problema bidimensional irrestrito foi comparada com a implementação feita por Morabito (1992). Nesta implementação, a estrutura de dados foi definida de forma que cada nó do grafo armazene as informações dos dois nós $\left(\mathrm{N}_{1}\right.$ e $\left.\mathrm{N}_{2}\right)$ gerados após o corte, ou seja,

\begin{tabular}{|l|l|}
\hline Informações do nó anterior \\
\hline Informações sobre o nó $\mathrm{N}_{1}$ \\
\hline Informações sobre o nó $\mathrm{N}_{2}$ \\
\hline
\end{tabular}

FiguraA.8 - Dados armazenados em cada nó do grafo em problemas guilhotinados (Morabito, 1992)

que pode ser esquematizada pela Figura A.9.

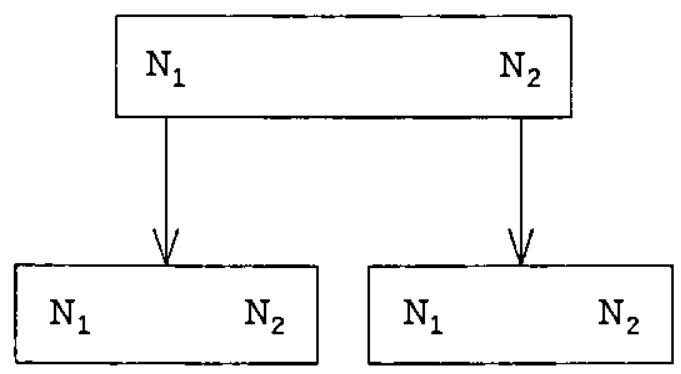

Figura A.9 - Estrutura gerada por Morabito (1992) 
Para o problema de corte bidimensional guilhotinado, estes dois tipos de estruturas são equivalentes (Figuras A.5 e A.9). Entretanto, para um problema que permita outros tipos de corte, por exemplo, o corte não-guilhotinado, esta segunda estrutura necessita de mais memória.

Os resultados computacionais obtidos com esta implementação são apresentados na próxima seção.

\section{Resultados Computacionais}

Nesta seção são apresentados os resultados computacionais da geração do conjunto de discretização (seção 3.2.1 de Gonçalves-Vianna, 2000a) e do algoritmo BT-HC descrito na seção 3.2.4 (Gonçalves-Vianna, 2000a) para o problema de corte bidimensional irrestrito, alterando o modo de seleção de pontos do conjunto de discretização.

\subsection{Conjunto de discretização}

Para análise dos resultados obtidos na geração do conjunto de discretização foram gerados exemplos aleatoriamente. Estes exemplos foram divididos em duas classes, exemplos pequenos e grandes, de acordo com Morabito (1992).

- Exemplos pequenos: nesta classe de problema, os conjuntos de discretização resultam com poucos elementos. Os valores $\ell_{i} e$ $w_{i}, i=1, \ldots, m$, foram gerados aleatoriamente $e$, em seguida, arredondados, dentro dos intervalos [0.25L,0.75L] e $[0.25 \mathrm{~W}, 0.75 \mathrm{~W}]$, respectivamente.

- Exemplos grandes: os conjuntos de discretização resultam com muitos elementos, tendo sido os valores $\ell_{i}$ e $w_{i}, i=1, \ldots, m$, gerados aleatoriamente e, em seguida, arredondados, dentro dos intervalos $[0.10 \mathrm{~L}, 0.50 \mathrm{~L}]$ e $[0.10 \mathrm{~W}, 0.50 \mathrm{~W}]$, respectivamen- 
te.

A Tabela A.1 mostra os resultados obtidos na geração dos conjuntos de discretização dos problemas pequenos. A fórmula utilizada para o cálculo foi apresentada na seção 3.2.1 (de Gonçalves-Vianna, 2000a), entretanto, para a geração das Tabelas A.1 e A.2, não se considerou a regra de simetria. A tabela foi dividida em 9 colunas, onde a primeira indica o número de exemplos contidos numa classe de problemas e, a segunda, terceira e quarta se referem ao número de peças (m) e dimensōes da placa $(L, W)$, respectivamente. Nas duas colunas seguintes, tem-se a média aritmética do número de elementos dos conjuntos $\mathrm{X}$ e $\mathrm{Y}$ juntamente com o desvio padrão. As últimas três colunas referem-se ao tempo computacional obtido, em segundos, utilizando na geração dos conjuntos a recursividade com alocação dinâmica (1), a recursividade com alocação estática (2) e o algoritmo iterativo com alocação estática (3). Note que, são apresentados dois tempos computacionais distintos para cada classe de problemas, o tempo obtido em um microcomputador Pentium, $167 \mathrm{Mhz}$, com 32 Mbytes de RAM (1inha superior), e o tempo obtido com um microprocessador Pentium II, $200 \mathrm{Mhz}$, com 128 Mbytes de RAM (linha inferior).

Nas tabelas, os tempos computacionais indicados por (*) foram superiores a uma hora. 
Tabela A.1 - Discretização nos exemplos pequenos

\begin{tabular}{|c|c|c|c|c|c|c|c|c|}
\hline Qte & $\mathrm{m}$ & I & $\bar{W}$ & $|x|$ (DP) & $|Y|(D P)$ & $\begin{array}{c}t(s) \\
(1)\end{array}$ & $\begin{array}{c}t(s) \\
(2)\end{array}$ & $\begin{array}{c}t(s) \\
(3)\end{array}$ \\
\hline 100 & 5 & 100 & 100 & $15.40(5.28)$ & $13.50(5.52)$ & $\begin{array}{l}0.05 \\
0.02\end{array}$ & $\begin{array}{l}0.06 \\
0.03\end{array}$ & $\begin{array}{l}0.00 \\
0.00\end{array}$ \\
\hline 100 & 10 & 100 & 100 & $34.70(8.34)$ & $36.50(7.74)$ & $\begin{array}{l}0.29 \\
0.10\end{array}$ & $\begin{array}{l}0.16 \\
0.05\end{array}$ & $\begin{array}{l}0.00 \\
0.00\end{array}$ \\
\hline 100 & 20 & 100 & 100 & $56.80(2.93)$ & $56.20(3.52)$ & $\begin{array}{l}1.44 \\
0.35\end{array}$ & $\begin{array}{l}0.78 \\
0.17\end{array}$ & $\begin{array}{l}0.00 \\
0.01\end{array}$ \\
\hline 100 & 30 & 100 & 100 & $65.90(2.34)$ & $65.20(2.23)$ & $\begin{array}{l}6.06 \\
0.86\end{array}$ & $\begin{array}{l}2.92 \\
0.41\end{array}$ & $\begin{array}{l}0.01 \\
0.00\end{array}$ \\
\hline 100 & 5 & 1000 & 1000 & $17.70(6.83)$ & $15.30(9.02)$ & $\begin{array}{l}1.16 \\
0.37\end{array}$ & $\begin{array}{l}0.56 \\
0.17\end{array}$ & $\begin{array}{l}0.00 \\
0.01\end{array}$ \\
\hline 100 & 10 & 1000 & 1000 & $48.10(13.50)$ & $49.50(19.58)$ & $\begin{array}{l}3.23 \\
1.00\end{array}$ & $\begin{array}{l}1.53 \\
0.46\end{array}$ & $\begin{array}{l}0.01 \\
0.01\end{array}$ \\
\hline 100 & 20 & 1000 & 1000 & $139.80(31.88)$ & $143.30(22.67)$ & $\begin{array}{r}13.81 \\
3.36\end{array}$ & $\begin{array}{l}7.44 \\
1.52\end{array}$ & $\begin{array}{l}0.01 \\
0.01\end{array}$ \\
\hline 100 & 30 & 1000 & 1000 & $250.00(36.00)$ & $280.00(28.00)$ & $\begin{array}{r}63.89 \\
7.96\end{array}$ & $\begin{array}{r}29.85 \\
3.89\end{array}$ & $\begin{array}{l}0.02 \\
0.02\end{array}$ \\
\hline 100 & 50 & 1000 & 1000 & $359.20(32.23)$ & $405.20(25.69)$ & $\begin{array}{r}194.12 \\
26.74\end{array}$ & $\begin{array}{l}95.49 \\
13.38\end{array}$ & $\begin{array}{l}0.06 \\
0.03\end{array}$ \\
\hline 50 & 5 & 3000 & 3000 & $12.80(6.21)$ & $9.40(4.22)$ & $\begin{array}{l}2.64 \\
0.90\end{array}$ & $\begin{array}{l}1.24 \\
0.44\end{array}$ & $\begin{array}{l}0.01 \\
0.01\end{array}$ \\
\hline 50 & 10 & 3000 & 3000 & $49.00(22.91)$ & $54.20(29.58)$ & $\begin{array}{r}10.12 \\
2.91\end{array}$ & $\begin{array}{l}4.96 \\
1.31\end{array}$ & $\begin{array}{l}0.02 \\
0.00\end{array}$ \\
\hline 50 & 20 & 3000 & 3000 & $218.00(71.61)$ & $135.20(34.37)$ & $\begin{array}{r}37.23 \\
9.62\end{array}$ & $\begin{array}{r}18.45 \\
4.36\end{array}$ & $\begin{array}{l}0.07 \\
0.01\end{array}$ \\
\hline 50 & 30 & 3000 & 3000 & $365.20(67.49)$ & $263.00(37.14)$ & $\begin{array}{r}139.87 \\
21.73\end{array}$ & $\begin{array}{l}71.44 \\
10.68\end{array}$ & $\begin{array}{l}0.09 \\
0.02\end{array}$ \\
\hline 50 & 50 & 3000 & 3000 & $660.60(37.98)$ & $700.00(98.68)$ & $\begin{array}{c}\left(^{*}\right) \\
68.60\end{array}$ & $\begin{array}{c}\left(^{*}\right) \\
35.03\end{array}$ & $\begin{array}{l}0.13 \\
0.05\end{array}$ \\
\hline 50 & 50 & 5000 & 5000 & $842.80(109.21)$ & $1005.20(165.39)$ & $\begin{array}{c}\left(^{*}\right) \\
132.35\end{array}$ & $\begin{array}{c}\left(^{*}\right) \\
66.13\end{array}$ & $\begin{array}{l}0.23 \\
0.09\end{array}$ \\
\hline
\end{tabular}


Tabela A.2 - Discretização nos exemplos grandes

\begin{tabular}{|c|c|c|c|c|c|c|c|c|}
\hline Qte & $m$ & $\bar{L}$ & $\bar{W}$ & $|x|(D P)$ & $|Y|(D P)$ & $\begin{array}{l}t(s) \\
(1)\end{array}$ & $\begin{array}{l}t(s) \\
(2)\end{array}$ & $\begin{array}{l}t(s) \\
(3)\end{array}$ \\
\hline \begin{tabular}{ll|}
100 \\
\end{tabular} & 5 & 100 & 100 & $49.80(10.65)$ & $52.40(17.96)$ & $\begin{array}{l}1.54 \\
0.43\end{array}$ & $\begin{array}{l}0.71 \\
0.20\end{array}$ & $\begin{array}{l}0.00 \\
0.00\end{array}$ \\
\hline 100 & 10 & 100 & 100 & $73.70(4.17)$ & $76.00(6.23)$ & $\begin{array}{r}10.45 \\
2.27\end{array}$ & $\begin{array}{l}4.74 \\
1.03\end{array}$ & $\begin{array}{l}0.00 \\
0.00\end{array}$ \\
\hline 100 & 20 & 100 & 100 & $83.70(3.61)$ & $84.20(2.23)$ & $\begin{array}{l}51.94 \\
13.70\end{array}$ & $\begin{array}{c}23.55 \\
6.17\end{array}$ & $\begin{array}{l}0.00 \\
0.00\end{array}$ \\
\hline 100 & 30 & 100 & 100 & $88.20(1.17)$ & $88.50(1.28)$ & $\begin{array}{r}190.09 \\
71.55\end{array}$ & $\begin{array}{l}99.34 \\
32.27\end{array}$ & $\begin{array}{l}0.01 \\
0.00\end{array}$ \\
\hline 100 & 5 & 1000 & 1000 & $70.70(42.67)$ & $97.40(70.70)$ & $\begin{array}{r}11.57 \\
4.09\end{array}$ & $\begin{array}{l}5.74 \\
1.86\end{array}$ & $\begin{array}{l}0.01 \\
0.01\end{array}$ \\
\hline 100 & 10 & 1000 & 1000 & $323.40(130.66)$ & $276.30(60.32)$ & $\begin{array}{l}45.03 \\
15.67\end{array}$ & $\begin{array}{c}22.09 \\
7.05\end{array}$ & $\begin{array}{l}0.00 \\
0.01\end{array}$ \\
\hline 100 & 20 & 1000 & 1000 & $541.30(65.84)$ & $565.10(91.14)$ & $\begin{array}{l}403.91 \\
171.32\end{array}$ & $\begin{array}{c}196.94 \\
76.92\end{array}$ & $\begin{array}{l}0.03 \\
0.01\end{array}$ \\
\hline 100 & 30 & 1000 & 1000 & $656.50(17.50)$ & $666.00(23.00)$ & $\begin{array}{c}(*) \\
384.67\end{array}$ & $\begin{array}{c}(*) \\
171.71\end{array}$ & $\begin{array}{l}0.06 \\
0.00\end{array}$ \\
\hline 100 & 50 & 1000 & 1000 & $735.80(29.92)$ & $756.40(11.72)$ & $\begin{array}{c}\left(^{*}\right) \\
915.12\end{array}$ & $\begin{array}{c}(*) \\
303.01\end{array}$ & $\begin{array}{l}0.09 \\
0.04\end{array}$ \\
\hline 50 & 5 & 3000 & 3000 & $124.40(74.95)$ & $101.80(69.71)$ & $\begin{array}{l}49.63 \\
16.40\end{array}$ & $\begin{array}{c}23.23 \\
7.42\end{array}$ & $\begin{array}{l}0.01 \\
0.01\end{array}$ \\
\hline 50 & 10 & 3000 & 3000 & $364.00(34.97)$ & $432.60(213.94)$ & $\begin{array}{c}\left(^{*}\right) \\
31.64\end{array}$ & $\begin{array}{c}\left(^{*}\right) \\
14.23\end{array}$ & $\begin{array}{l}0.05 \\
0.03\end{array}$ \\
\hline 50 & 20 & 3000 & 3000 & $1329.00(133.43)$ & $1337.00(224.56)$ & $\begin{array}{c}\left(^{*}\right) \\
412.44\end{array}$ & $\begin{array}{c}\left(^{*}\right) \\
185.21\end{array}$ & $\begin{array}{l}0.10 \\
0.04\end{array}$ \\
\hline 50 & 30 & 3000 & 3000 & $1804.80(147.21)$ & $1757.00(115.54)$ & $\begin{array}{c}(*) \\
1019.23\end{array}$ & $\begin{array}{c}(*) \\
433.09\end{array}$ & $\begin{array}{l}0.15 \\
0.06\end{array}$ \\
\hline 50 & 50 & 3000 & 3000 & $2076.80(55.36)$ & $1898.40(72.17)$ & $\begin{array}{l}(*) \\
(*)\end{array}$ & $\begin{array}{l}\left(^{*}\right) \\
(*)\end{array}$ & $\begin{array}{l}0.25 \\
0.09\end{array}$ \\
\hline 50 & 50 & 5000 & 5000 & $2898.00(61.24)$ & $2880.80(186.17)$ & $\begin{array}{l}\left.l^{*}\right) \\
(*)\end{array}$ & $\begin{array}{l}(*) \\
(*)\end{array}$ & $\begin{array}{l}0.60 \\
0.15\end{array}$ \\
\hline
\end{tabular}

Observe que o tempo computacional para a geração dos conjuntos de discretização cresce exponencialmente com o tamanho do problema. A execução dos problemas em processadores mais velozes (tempos computacionais apresentados na linha inferior de cada classe de problema) não torna viável a utiliza- 
Ção da técnica de recursividade, pois apesar do tempo computacional diminuir bastante na execução destes problemas, ele ainda é muito grande em relação ao tempo obtido com o algoritmo recursivo, além de na prática ser inviável, pois os computadores utilizadós têm uma memória menor que 128 Mbytes. Logo, pode-se concluir que a aplicação da recursividade na geração dos conjuntos não é um bom exemplo de sua utilização, sendo de grande valia para outras aplicações.

Nos gráficos A.1 e A.2, a seguir, é possível observar que o tempo cresce exponencialmente conforme o tamanho do problema. Note também que o uso de um microprocessador mais veloz e uma quantidade maior de memória RAM diminui significativamente o tempo computacional, porém ainda é muito maior comparado ao tempo obtido com o processo iterativo.
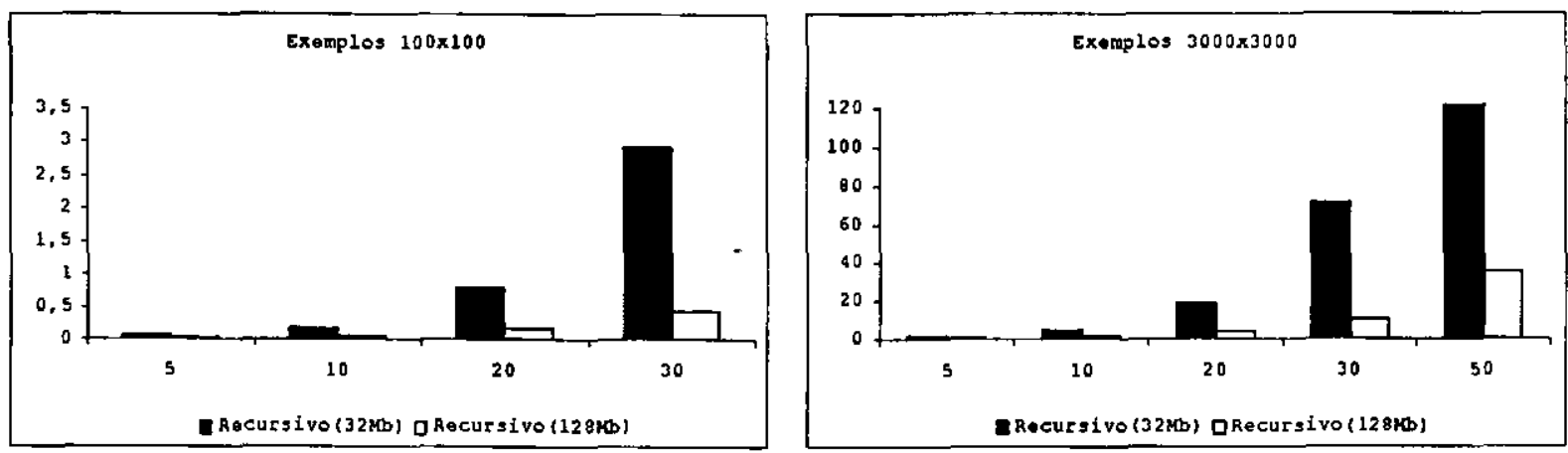

Gráfico A.1 - Discretização nos exemplos pequenos
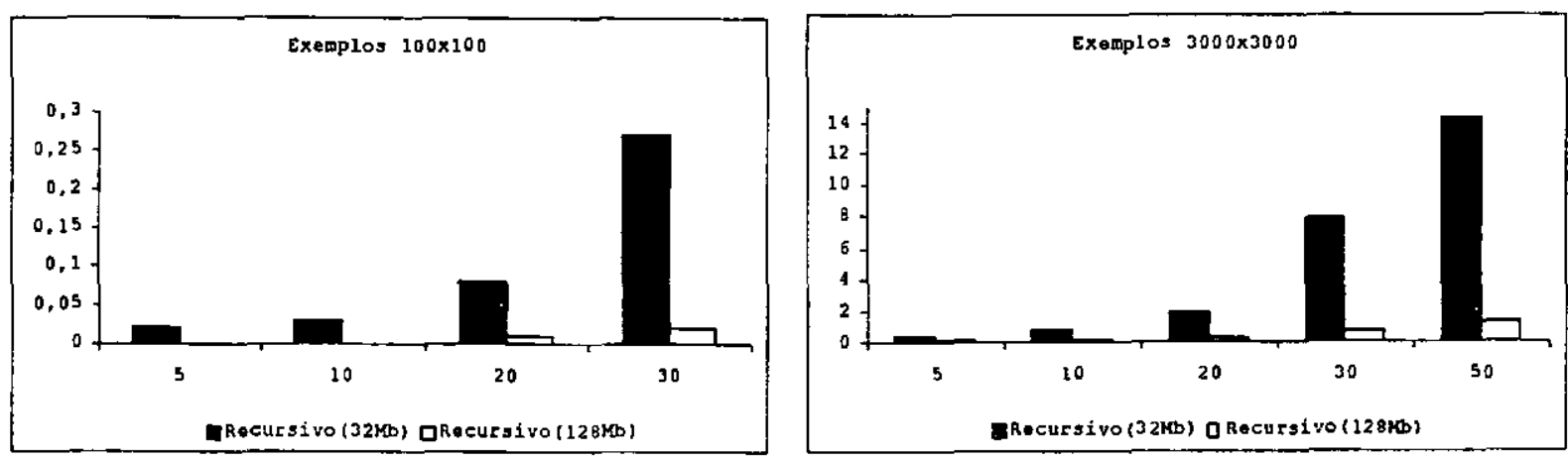

Gráfico A.2 - Discretização nos exemplos grandes

A seguir, nas Tabelas A.3 e A.4, os conjuntos foram novamente gerados, considerando a regra de simetria, 
apresentada na seção 3.2.1 (de Gonçalves-Vianna, 2000a). O tamanho dos conjuntos diminui visivelmente, assim como o tempo computacional, resultando na diminuição do espaço de busca do problema.

Tabela A.3 - Discretização nos exemplos pequenos (com simetria)

\begin{tabular}{|c|c|c|c|c|c|c|c|c|}
\hline Qte & $\mathrm{m}$ & $\mathrm{L}$ & $w$ & $|x|(D R)$ & $|Y|(D P)$ & $\begin{array}{c}t(s) \\
(1)\end{array}$ & $\begin{array}{c}t(s) \\
(2)\end{array}$ & $\begin{array}{c}t(s) \\
(3)\end{array}$ \\
\hline 100 & 5 & 100 & 100 & $2.80(0.75)$ & $2.50(1.12)$ & $\begin{array}{l}0.03 \\
0.01\end{array}$ & $\begin{array}{l}0.02 \\
0.00\end{array}$ & $\begin{array}{l}0.00 \\
0.00\end{array}$ \\
\hline 100 & 10 & 100 & 100 & $5.40(1.69)$ & $6.20(1.17)$ & $\begin{array}{l}0.05 \\
0.01\end{array}$ & $\begin{array}{l}0.03 \\
0.00\end{array}$ & $\begin{array}{l}0.00 \\
0.00\end{array}$ \\
\hline 100 & 20 & 100 & 100 & $11.00(1.26)$ & $10.20(1.66)$ & $\begin{array}{l}0.17 \\
0.03\end{array}$ & $\begin{array}{l}0.08 \\
0.01\end{array}$ & $\begin{array}{l}0.00 \\
0.00\end{array}$ \\
\hline 100 & 30 & 100 & 100 & $16.60(1.62)$ & $16.10(1.76)$ & $\begin{array}{l}0.55 \\
0.04\end{array}$ & $\begin{array}{l}0.27 \\
0.02\end{array}$ & $\begin{array}{l}0.00 \\
0.00\end{array}$ \\
\hline 100 & 5 & 1000 & 1000 & $2.90(1.37)$ & $2.20(1.40)$ & $\begin{array}{l}0.24 \\
0.05\end{array}$ & $\begin{array}{l}0.13 \\
0.03\end{array}$ & $\begin{array}{l}0.00 \\
0.00\end{array}$ \\
\hline 100 & 10 & 1000 & 1000 & $5.00(1.26)$ & $5.70(1.35)$ & $\begin{array}{l}0.51 \\
0.11\end{array}$ & $\begin{array}{l}0.25 \\
0.05\end{array}$ & $\begin{array}{l}0.01 \\
0.00\end{array}$ \\
\hline 100 & 20 & 1000 & 1000 & $10.40(2.46)$ & $9.70(2.19)$ & $\begin{array}{l}1.37 \\
0.25\end{array}$ & $\begin{array}{l}0.64 \\
0.13\end{array}$ & $\begin{array}{l}0.00 \\
0.00\end{array}$ \\
\hline 100 & 30 & 1000 & 1000 & $16.00(1.43)$ & $17.50(1.55)$ & $\begin{array}{l}2.88 \\
0.41\end{array}$ & $\begin{array}{l}2.72 \\
0.24\end{array}$ & $\begin{array}{l}0.03 \\
0.00\end{array}$ \\
\hline 100 & 50 & 1000 & 1000 & $23.00(2.83)$ & $26.00(3.16)$ & $\begin{array}{c}11.05 \\
0.82\end{array}$ & $\begin{array}{l}4.76 \\
0.46\end{array}$ & $\begin{array}{l}0.01 \\
0.00\end{array}$ \\
\hline 50 & 5 & 3000 & 3000 & $2.00(1.41)$ & $1.60(1.36)$ & $\begin{array}{l}0.68 \\
0.16\end{array}$ & $\begin{array}{l}0.35 \\
0.09\end{array}$ & $\begin{array}{l}0.00 \\
0.00\end{array}$ \\
\hline 50 & 10 & 3000 & 3000 & $4.80(2.23)$ & $5.40(2.42)$ & $\begin{array}{l}1.19 \\
0.35\end{array}$ & $\begin{array}{l}0.80 \\
0.15\end{array}$ & $\begin{array}{l}0.01 \\
0.00\end{array}$ \\
\hline 50 & 20 & 3000 & 3000 & $10.80(1.17)$ & $9.40(2.24)$ & $\begin{array}{l}3.98 \\
0.72\end{array}$ & $\begin{array}{l}1.87 \\
0.34\end{array}$ & $\begin{array}{l}0.00 \\
0.00\end{array}$ \\
\hline 50 & 30 & 3000 & 3000 & $15.60(2.42)$ & $13.80(1.72)$ & $\begin{array}{r}16.12 \\
1.20\end{array}$ & $\begin{array}{l}7.82 \\
0.67\end{array}$ & $\begin{array}{l}0.00 \\
0.00\end{array}$ \\
\hline 50 & 50 & 3000 & 3000 & $25.00(1.90)$ & $24.60(3.01)$ & $\begin{array}{r}29.63 \\
2.40\end{array}$ & $\begin{array}{c}14.31 \\
1.32\end{array}$ & $\begin{array}{l}0.02 \\
0.02\end{array}$ \\
\hline 50 & 50 & 5000 & 5000 & $25.80(2.79)$ & $26.20(3.87)$ & $\begin{array}{r}51.60 \\
4.28\end{array}$ & $\begin{array}{c}24.48 \\
2.34\end{array}$ & $\begin{array}{l}0.03 \\
0.02\end{array}$ \\
\hline
\end{tabular}


Tabela A.4 - Discretização nos exemplos grandes (com simetria)

\begin{tabular}{|c|c|c|c|c|c|c|c|c|}
\hline Qte & $\bar{m}$ & $\mathrm{I}$ & $\bar{W}$ & $|x|(D P)$ & $|\mathrm{Y}|$ (DP) & $\begin{array}{l}t(s) \\
(1)\end{array}$ & $\begin{array}{l}t(s) \\
(2)\end{array}$ & $\begin{array}{c}t(s) \\
(3)\end{array}$ \\
\hline 100 & 5 & 100 & 100 & $12.20(3.66)$ & $14.10(7.49)$ & $\begin{array}{l}0.04 \\
0.01\end{array}$ & $\begin{array}{l}0.03 \\
0.01\end{array}$ & $\begin{array}{l}0.00 \\
0.00\end{array}$ \\
\hline 100 & 10 & 100 & 100 & $24.00(3.87)$ & $26.10(6.17)$ & $\begin{array}{l}0.19 \\
0.04\end{array}$ & $\begin{array}{l}0.09 \\
0.02\end{array}$ & $\begin{array}{l}0.00 \\
0.00\end{array}$ \\
\hline 100 & 20 & 100 & 100 & $33.70(3.61)$ & $34.20(2.23)$ & $\begin{array}{l}0.86 \\
0.14\end{array}$ & $\begin{array}{l}0.36 \\
0.06\end{array}$ & $\begin{array}{l}0.01 \\
0.00\end{array}$ \\
\hline 100 & 30 & 100 & 100 & $38.20(1.17)$ & $38.50(1.28)$ & $\begin{array}{l}2.09 \\
0.33\end{array}$ & $\begin{array}{l}1.04 \\
0.16\end{array}$ & $\begin{array}{l}0.00 \\
0.00\end{array}$ \\
\hline 100 & 5 & 1000 & 1000 & $10.90(5.84)$ & $15.10(9.37)$ & $\begin{array}{l}0.35 \\
0.15\end{array}$ & $\begin{array}{l}0.29 \\
0.07\end{array}$ & $\begin{array}{l}0.00 \\
0.00\end{array}$ \\
\hline 100 & 10 & 1000 & 1000 & $37.90(20.41)$ & $29.00(7.46)$ & $\begin{array}{l}1.48 \\
0.39\end{array}$ & $\begin{array}{l}0.68 \\
0.18\end{array}$ & $\begin{array}{l}0.01 \\
0.00\end{array}$ \\
\hline 100 & 20 & 1000 & 1000 & $84.10(31.19)$ & $104.10(46.35)$ & $\begin{array}{l}6.23 \\
1.32\end{array}$ & $\begin{array}{l}3.06 \\
0.60\end{array}$ & $\begin{array}{l}0.01 \\
0.00\end{array}$ \\
\hline 100 & 30 & 1000 & 1000 & $157.00(17.00)$ & $166.00(23.00)$ & $\begin{array}{c}19.01 \\
3.07\end{array}$ & $\begin{array}{l}8.96 \\
1.46\end{array}$ & $\begin{array}{l}0.03 \\
0.02\end{array}$ \\
\hline 100 & 50 & 1000 & 1000 & $235.80(29.92)$ & $256.40(11.72)$ & $\begin{array}{l}79.46 \\
10.95\end{array}$ & $\begin{array}{c}38.94 \\
5.32\end{array}$ & $\begin{array}{l}0.02 \\
0.01\end{array}$ \\
\hline 50 & 5 & 3000 & 3000 & $16.80(8.30)$ & $15.00(8.49)$ & $\begin{array}{l}2.19 \\
0.54\end{array}$ & $\begin{array}{l}1.01 \\
0.24\end{array}$ & $\begin{array}{l}0.01 \\
0.01\end{array}$ \\
\hline 50 & 10 & 3000 & 3000 & $28.40(1.36)$ & $33.60(14.01)$ & $\begin{array}{l}3.63 \\
0.99\end{array}$ & $\begin{array}{l}1.70 \\
0.46\end{array}$ & $\begin{array}{l}0.01 \\
0.00\end{array}$ \\
\hline 50 & 20 & 3000 & 3000 & $121.60(32.78)$ & $133.00(53.56)$ & $\begin{array}{c}20.04 \\
4.19\end{array}$ & $\begin{array}{l}8.73 \\
1.90\end{array}$ & $\begin{array}{l}0.02 \\
0.01\end{array}$ \\
\hline 50 & 30 & 3000 & 3000 & $340.80(113.39)$ & $301.20(77.90)$ & $\begin{array}{l}63.50 \\
13.58\end{array}$ & $\begin{array}{c}30.78 \\
6.33\end{array}$ & $\begin{array}{l}0.04 \\
0.01\end{array}$ \\
\hline 50 & 50 & 3000 & 3000 & $577.00(55.13)$ & $405.00(66.84)$ & $\begin{array}{r}158.14 \\
33.18\end{array}$ & $\begin{array}{c}123.41 \\
16.14\end{array}$ & $\begin{array}{l}0.07 \\
0.02\end{array}$ \\
\hline 50 & 50 & 5000 & 5000 & $558.00(130.33)$ & $517.00(148.21)$ & $\begin{array}{r}1045.16 \\
40.49\end{array}$ & $\begin{array}{c}516.74 \\
20.16\end{array}$ & $\begin{array}{l}0.10 \\
0.03\end{array}$ \\
\hline
\end{tabular}

Entretanto, nos exemplos, quando L $>100$ (comprimento) ou $W>100$ (largura), o tamanho do conjunto de discretização é muito grande, o que, às vezes, inviabiliza o processo de busca. Note nestas tabelas que com o uso da simetria, o tempo computacional utilizando a técnica de recursividade di- 
minuiu bastante, sendo nos problemas pequenos, muitas vezes próximos dos tempos obtidos com o processo iterativo.

Utilizando a heuristica H3, apresentada na seção 3.3 (de Gonçalves-Vianna, 2000a), que limita o tamanho dos conjuntos de discretização, obtêm-se os resultados apresentados nas Tabelas A.5 e A.6, com $|X|<100$ e $|Y|<100$.

Tabela A.5 - Discretização nos exemplos pequenos com $|\mathrm{X}|<100$ e $|\mathrm{Y}|<100$ (Heurística H3)

\begin{tabular}{|c|c|c|c|c|c|c|c|c|}
\hline Qte & $\mathrm{m}$ & $\mathrm{L}$ & $\mathrm{W}$ & $|\mathrm{X}|(\mathrm{DP})$ & $|\mathrm{Y}|(\mathrm{DP})$ & $\mathrm{t}(\mathrm{s})$ & $\mathrm{t}(\mathrm{s})$ & $\mathrm{t}(\mathrm{s})$ \\
& & & & & & & \\
$(2)$ & $(3)$ \\
\hline 100 & 20 & 1000 & 1000 & $89.10(4.23)$ & $87.40(5.78)$ & 13.02 & 12.74 & 0.03 \\
& & & & & 3.37 & 3.52 & 0.01 \\
\hline 100 & 30 & 1000 & 1000 & $88.50(1.50)$ & $97.00(1.00)$ & 158.87 & 82.30 & 0.06 \\
& & & & & 7.96 & 14.60 & 0.01 \\
\hline 100 & 50 & 1000 & 1000 & $93.40(4.20)$ & $94.60(5.18)$ & 304.12 & 419.75 & 0.04 \\
& & & & & & 26.73 & 62.33 & 0.02 \\
\hline 50 & 20 & 3000 & 3000 & $89.60(6.53)$ & $86.80(10.54)$ & 48.28 & 34.65 & 0.08 \\
& & & & & & 9.63 & 9.37 & 0.02 \\
\hline 50 & 30 & 3000 & 3000 & $92.30(3.74)$ & $90.20(6.14)$ & 147.06 & 206.08 & 0.11 \\
& & & & & & 21.75 & 39.03 & 0.02 \\
\hline 50 & 50 & 3000 & 3000 & $91.80(3.94)$ & $93.50(3.61)$ & $(*)$ & $(*)$ & 0.17 \\
& & & & & 68.65 & 189.46 & 0.06 \\
\hline 50 & 50 & 5000 & 5000 & $92.80(4.83)$ & $92.10(5.63)$ & 2040.01 & 4265.03 & 3.06 \\
& & & & & & 132.35 & 296.12 & 0.09 \\
\hline
\end{tabular}

O tempo computacional com o uso da heurística de Beasley (1985) cresce um pouco com o uso da técnica iterativa, mas também com a técnica recursiva, já que o processo repetese várias vezes até que o tamanho do conjunto de discretização seja menor que o desejado. Com isto, quando compara-se os tempos computacionais de ambas as técnicas, descarta-se mesmo a recursiva (Gráficos A.3 e A.4). 
Tabela A.6 - Discretização nos exemplos grandes com $|\mathrm{X}|<100$ e $|\mathrm{Y}|<100 \quad$ (Heuristica H3)

\begin{tabular}{|c|c|c|c|c|c|c|c|c|}
\hline Qte & $\mathrm{m}$ & $\mathrm{L}$ & $\mathrm{W}$ & $|\mathrm{X}|(\mathrm{DP})$ & $|\mathrm{Y}|(\mathrm{DP})$ & $\begin{array}{c}t(\mathrm{~s}) \\
(1)\end{array}$ & $\begin{array}{c}t(\mathrm{~s}) \\
(2)\end{array}$ & $\begin{array}{c}\mathrm{t}(\mathrm{s}) \\
(3)\end{array}$ \\
\hline 100 & 10 & 1000 & 1000 & $83.10(12.59)$ & $71.30(12.02)$ & 87.06 & 16.70 & 0.02 \\
& & & & & & 15.64 & 3.76 & 0.01 \\
\hline 100 & 20 & 1000 & 1000 & $85.20(7.97)$ & $88.30(8.23)$ & 1808.47 & 127.99 & 0.03 \\
& & & & & & 171.03 & 14.54 & 0.01 \\
\hline 100 & 30 & 1000 & 1000 & $89.00(1.00)$ & $94.50(4.50)$ & $(*)$ & 484.77 & 0.02 \\
& & & & & & 502.22 & 39.17 & 0.01 \\
\hline 100 & 50 & 1000 & 1000 & $91.00(1.63)$ & $94.33(0.94)$ & $(*)$ & $(*)$ & 0.09 \\
& & & & & & 613.23 & 97.12 & 0.01 \\
\hline 50 & 5 & 3000 & 3000 & $50.00(15.34)$ & $58.60(23.09)$ & 77.45 & 19.42 & 0.02 \\
& & & & & & 16.40 & 5.05 & 0.02 \\
\hline 50 & 10 & 3000 & 3000 & $80.00(13.48)$ & $84.80(12.70)$ & 109.60 & 36.43 & 0.05 \\
& & & & & & 31.62 & 9.21 & 0.01 \\
\hline 50 & 20 & 3000 & 3000 & $88.67(11.09)$ & $89.00(8.83)$ & 2603.17 & 319.26 & 0.09 \\
& & & & & & 273.64 & 40.37 & 0.03 \\
\hline 50 & 30 & 3000 & 3000 & $93.67(4.50)$ & $93.00(5.35)$ & $\left(^{*}\right)$ & 10391.1 & 0.08 \\
& & & & & & 1092.23 & 234.37 & 0.03 \\
\hline 50 & 50 & 3000 & 3000 & $92.50(1.50)$ & $96.00(2.00)$ & $\left(^{*}\right)$ & $(*)$ & 0.08 \\
& & & & & & 1590.12 & 407.22 & 0.03 \\
\hline 50 & 50 & 5000 & 5000 & $94.80(5.21)$ & $92.00(4.67)$ & $\left(^{*}\right)$ & $(*)$ & 0.13 \\
& & & & & & 2011.34 & 576.33 & 0.04 \\
\hline
\end{tabular}
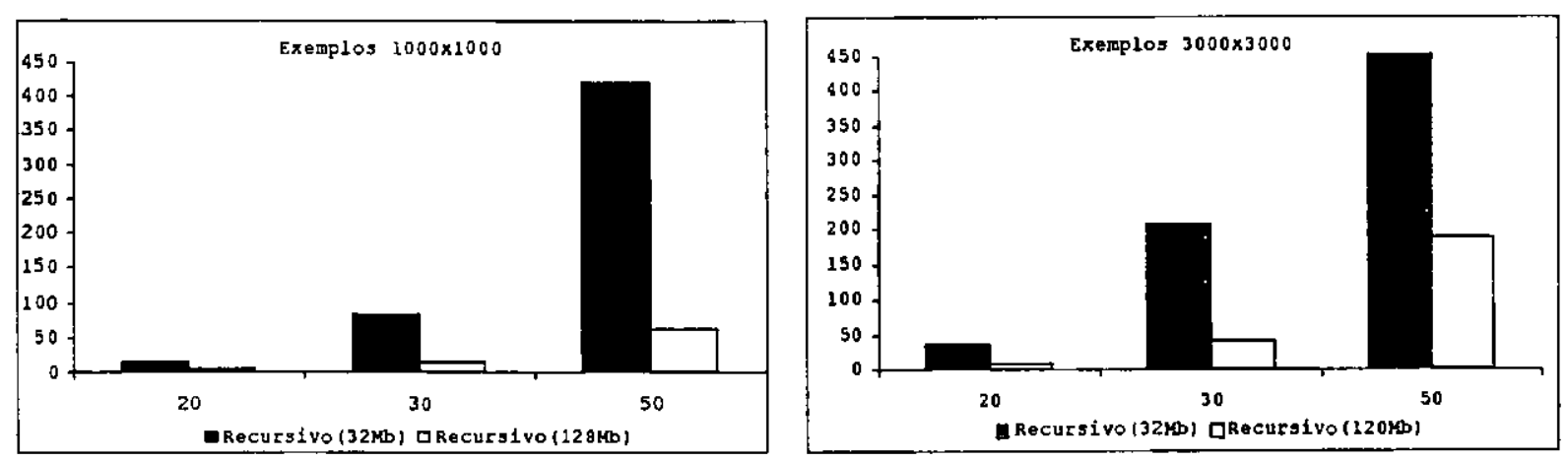

Gráfico A.3 - Discretização nos exemplos pequenos com $|\mathrm{X}|<100$ e $|\mathrm{Y}|<100 \quad$ (Heurística H3) 

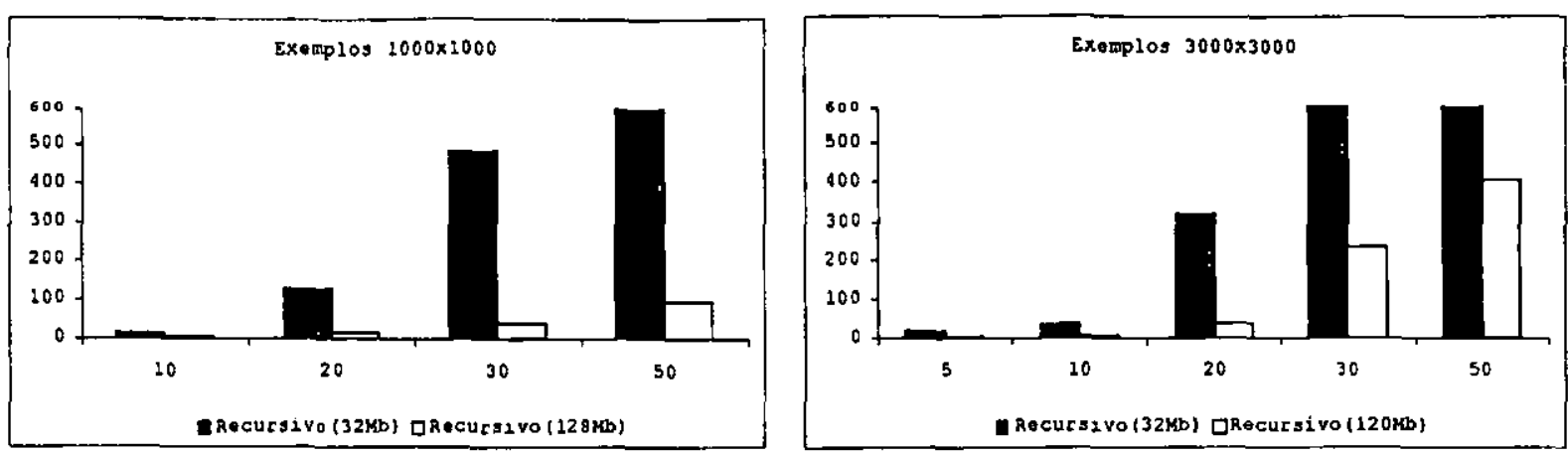

Gráfico A.4 - Discretização nos exemplos grandes com $|\mathrm{X}|<100$ e $|\mathrm{Y}|<100 \quad$ (Heuristica H3) 


\section{Anexo 2}

Formulação Matemática do Problema de Corte Bidimensional Guilhotinado Restrito em 2-Estágios

Considere uma placa de dimensões $(L, W)$ e m peças de dimensões $\left(\ell_{i}, w_{i}\right)$ com valor de utilidade $v_{1}, i=1, \ldots, m$, e $b_{1}$ a quantidade máxima de peça do tipo i no padrão.

o problema de corte bidimensional guilhotinado restrito em 2-estágios tem por objetivo determinar o padrão de corte ótimo de modo que a soma dos valores de utilidades das peças alocadas na placa seja maximizada e, as restrições de Iimitação do número de peças alocadas bem como do número de estágios não sejam violadas.

\section{Modelo Matemático}

O modelo matemático é semelhante ao modelo irrestrito, apresentado na seção 4.2.3, incluindo apenas as restrições de Iimitação do número máximo de peças: 


$$
a_{i}=\sum_{j=1}^{m} \sum_{k=1}^{k_{1}} \alpha_{k j}^{i} \cdot \beta_{k j} \leq b_{i}, i=1, \ldots, m
$$

onde $a_{i}$ é o número de peças do tipo i no padrão. Note que estas restriçōes são não-lineares.

Assim, a formulação matemática do problema é:

$$
\begin{aligned}
\text { maximizar } & \sum_{1=1}^{m} \sum_{j=1}^{m} \sum_{k=1}^{k_{j}} \alpha_{k j}^{i} \cdot \beta_{k j} \cdot v_{1} \\
\text { sujeito a : } & \sum_{i=1}^{m} \alpha_{k j}^{1} \cdot l_{i} \leq L, j=1, \ldots, m ; k=1, \ldots, k_{j} \\
& \sum_{j=1}^{m} w_{j} \cdot \sum_{k=1}^{k_{j}} \beta_{k j} \leq w \\
& \sum_{j=1}^{m} \sum_{k=1}^{k_{j}} \alpha_{k j}^{i} \cdot \beta_{k j} \leq b_{1}, i=1, \ldots, m \\
& \alpha_{k j}^{1} \geq 0, \beta_{k j} \geq 0, \text { inteiro,j }=1, \ldots, m
\end{aligned}
$$

O modelo matemático do problema é não-linear, dificultando sua resolução. Gramani (1997) propôs um método de resolução baseado na Relaxação Lagrangiana e no Método do Subgradiente.

\section{Relaxação Lagrangiana e Método do Subgradiente}

Utilizando Relaxação Lagrangiana, inicialmente, relaxa-se as restrições não-lineares do modelo de corte, reduzindo o problema a uma sequiencia de problemas irrestritos.

A função lagrangiana é dada por:

$$
L(\alpha, \beta, \lambda)=\sum_{i=1}^{m} \sum_{j=1}^{m} \sum_{k=1}^{k_{1}} \alpha_{k j}^{i} \cdot \beta_{k j} \cdot v_{1}+\sum_{1=1}^{m} \lambda_{i} \cdot\left(b_{1}-\sum_{j=1}^{m} \sum_{k=1}^{k_{j}} \alpha_{k j}^{i} \cdot \beta_{k j}\right)
$$


E, o problema lagrangiano é:

$$
\begin{aligned}
h(\lambda)=\operatorname{maximizar} & \sum_{i=1}^{m} \sum_{j=1}^{m} \sum_{k=1}^{k_{1}}\left(v_{i}-\lambda_{1}\right) \cdot \alpha_{k j}^{i} \cdot \beta_{k j} \cdot v_{i}+\sum_{i=1}^{m} \lambda_{i} \cdot b_{i} \\
\text { sujeito a: }: & \sum_{i=1}^{m} \alpha_{k j}^{i} \cdot l_{i} \leq L, j=1, \ldots, m ; k=1, \ldots, k_{j} \\
& \sum_{j=1}^{m} w_{j} \cdot \sum_{k=1}^{k} \beta_{k j} \leq w \\
& \alpha_{k j}^{i} \geq 0, \beta_{k j} \geq 0, \text { inteiro, j }=1, \ldots, m
\end{aligned}
$$

Note que para cada $\lambda$, ○ problema lagrangiano produz subproblemas irrestritos que podem ser resolvidos pelo método da seção 4.2.3. e, fornece um limitante superior da solução ótima do problema restrito. Para determinar o multiplicador lagrangiano que fornece o menor limitante superior utiliza-se o método do subgradiente. Para mais detalhes, veja Gramani (1997) e Gonçalves-Vianna (2000b). 


\section{Referências Bibliográficas}

ARENALES, M. Uma Teoria para o Problema de Corte. São Carlos: USP, 1993. Tese (Livre-docência) - Instituto de Ciências Matemáticas de São Carlos, Universidade de São Paulo, 1993.

ARENALES, M., MORABITO, R. An AND/OR-graph approach to the solution of two-dimensional non-guillotine cutting problems. European Journal of Operational Research. 84, 599-617, 1995.

ARENALES, M., MORABITO, R., YANASSE, H. (eds) Special issue: cutting and packing problems. Pesquisa Operacional. 19(2), 107-299, 1991 .

BEASLEY, J. Algorithms for unconstrained two-dimensional guillotine cutting. Journal of the operational Research Society. $36,297-306,1985$.

BISCHOFE, E., WAESCHER, G. (eds) Special issue: cutting and packing. European Journal of Operational Research. 84(3), 1995 .

BROWN, A. Optimun Packing and Depletion. New York: Elsevier Science, 1971. 
CARNIERI, C., MENDOZA, G.A., LUPOLD, W.G. OptimaI Cutting of Dimension Parts from Lumber with defect: a Heuristic Solution Procedure. Forest Products Journal. 66-72, 1993.

CHRISTOFIDES, N., HADJICONSTANTINOU, E. An exact algorithm for orthogonal 2-D cutting problems using guillotine cuts. European Journal of Operational Research. 83, 21-38, 1995.

CHRISTOFIDES, N., WHITLOCK, C. An algorithm for two-dimensional cutting problems. Operations Research. 25, $30-44,1977$.

DOWSLAND, K., DOWSLAND, W. Packing Problems. European Journal of Operational Research. 56, 2-14, 1992.

DYCKHOFF, H. A Typology of cutting and packing problems. European Journal of Operational Research. 44, 145-159, 1990.

DYCKHOFF, H., ABEL, D., GAT, T. Trim Loss and Related Problems. Omega: 13, 59-72, 1985.

DYCKHOFF, H., FINKE, U. Cutting and Packing in Production and Distribution: Typology and Bibliography. Heidelberg: Springer, 1992 .

DYCKHOFE, H., SCHEITHAUER, G., TERNO, J. Cutting and Packing. In Annotated Bibliographies in Combinatorial optimization, edited by M. Amico, F. Maffioli and S. Martello. New York: Wiley, 393-414, 1997.

DYCKHOFE, H., WAESCHER, G. (eds) Special issue: cutting and packing. European Journal of Operational Research. 44(2), 1990 . 
GILMORE, P., GOMORY, R. A Linear Programing Approach to the Cutting-Stock Problem. Operations Research. 9, 849-859, 1961 .

GILMORE, P., GOMORY, R. A Linear Programing Approach to the Cutting Stock Problem - Part II. Operations Research. 11, $863-888,1963$.

GILMORE, P., GOMORY, R. Multistage cutting stock problems of two and more dimensions. Operations Research. 14, 94-120, 1965 .

GILMORE, P., GOMORY, R. The Theory and Computation of Knapsack Functions. Operations Research. 14, 1045-1074, 1966.

GOLDEN, B. Approaches to the cutting stock problem. AIIE Transactions. 8, 265-274. 1976.

GONÇALVES-VIANNA, A. C., ARENALES, M., MORABITO, R. Estrutura de dados utilizada na abordagem em Grafo E/OU para a Resolução de Problemas de Corte. Relatório Técnico nㅇ 126, ICMCUSP. 2000 a.

GONÇALVES-VIANNA, A. C., ARENALES, M. e GRAMANI, M. C. N. Two-Stage and Constrained Two-Dimensional Guillotine Cutting Problems, artigo em preparação. 2000 b.

GRAMANI, M. C. N. Problema de corte bidimensional guilhotinado e restrito em 2-estágios. São Carlos: USP, 1997. Dissertação (Mestrado) - Instituto de Ciências Matemáticas de São Carlos, Universidade de São Paulo, 1997. 
HAHN, S. On the Optimal Cutting of Defective Sheets. Operations Research. 16, 1100-1114, 1968.

HERZ, J. Recursive Computational Procedure for Two Dimensional Stock Cutting. IBM Journal of Research and Development. 16, 462-469， 1972.

HIFI, $M$. The DH/KD algorithm: a hybrid approach for unconstrained two-dimensional cutting problems. European Journal of Operational Research. 97, 41-52, 1997.

HINXMAN, A. The trim-loss and assortment problems: a survey. European Journal of Operational Research. 5, 8-18, 1980.

LIROV, Y. (ed.) Special issue: cutting problem, geometric resource allocation. Mathematical and Computer Modelling. $16(1), 1992$.

MARTELLO, S. (ed.) Special issue: Knapsack, packing and cutting - Part I: One dimensional knapsack problems. INFOR, $32(2), 1994 \mathrm{a}$.

MARTELLO, S. (ed.) Special issue: Knapsack, packing and cutting - Part II: Multidimensional knapsack and cutting stock problems. INFOR. $32(4), 1994$ b.

MORABITO, R. Corte de Estoque Bidimensional. São Carlos: USP, 1989. Dissertação (Mestrado) - Instituto de Ciências Matemáticas de São Carlos, Universidade de São Paulo, 1989.

MORABITO, R. Uma Abordagem em Grafo E/OU para o Problema do Empacotamento: Aplicaçăo ao Carregamento de Paletes e Contêineres. São Carlos: USP, 1992. Tese (Doutorado) - Escola de Engenharia de São Carlos, Universidade de São Paulo, 1992. 
MORABITO, R., ARENALES, M. An AND/OR-graph approach to the container loading problem. International Transactions in Operational Research. 1, 59-73, 1994.

MORABITO, R., ARENALES, N.. Performance of two heuristics for solving large scale two-dimensional guillotine cutting problems. INFOR. 33(2), 145-155, 1995.

MORABITO, R., ARENALES, M. Staged and constrained two-dimensional guillotine cutting problems: An AND/OR-graph approach. European Journal of Operational Research. 94, 548-560, 1996 .

MORABITO, R., ARENALES, M. Optimizing the cutting of stock plates in a furniture company. International Journal of Production Research. $38(12), 2725-2742,2000$.

MORABITO, R., ARENALES, M., ARCARO, V. F. An AND-OR-Graph representation to generate cutting patterns for the twodimensional cutting problem. In: Alio-Euro Workshop on Practical Combinatorial optimization. Rio de Janeiro, 1-20, 1989.

MORABITO, R., ARENALES, M., ARCARO, V. F. An AND-OR-graph approach for two-dimensional cutting problems. European Journal of Operational Research. 58, 263-271, 1992.

MORABITO, R., GARCIA, V. The cutting stock problem in a hardboard industry: a case study. Computers \& Operations Research. 25, 469-485, 1998.

MORABITO, R., MORALES, S. A simple and effective recursive procedure to the manufacturer's pallet loading problem. Journal of the Operational Research Society. 49, 819-828, 1998 . 
MORABITO, R., MORALES, S., WIDMER, J. A. Loading optimization of palletized products on trucks. Transportation Research. Part E 36, 285-296, 2000.

MUKHACHEVA, E.A (ed.) Decision Making Under Conditions of Uncertainty: Cutting-Packing Problems. Ufa, Russia: The International Scientific Collection, 1997.

NILSSON, N.J. Problem-solving methods in artificial intelligence. New York: McGraw-Hill, 1971.

OLIVEIRA, J., FERREIRA, J. An improved version of Wang's algorithm for two-dimensional cutting problems. European Journal of Operational Research.. 44, 256-266, 1990.

PEARL, J. Heuristic: intelligence search strategies for computer problem solving. Addison-Wesley, Reading, Massachussetts, 1984 .

RICH, E. Artificial Intelligence. New York: McGraw-Hill, 1983.

SALKIN, H., DE KLUYVER, C. The Knapsack Problem: A Survey. Naval Research Logistics Quartely 22, 127-144, 1975.

SALOMÃO, S. N. A. Uma abordagem em grafo E/OU para o problema de corte bidimensional não-guilhotinado. São Carlos: USP, 1993. Dissertação (Mestrado) - Instituto de Ciências Matemáticas de são Carlos, Universidade de São Paulo, 1993.

SICUP, Special Interest Group on Cutting and Packing, http://www.prodlog.wiwi.unihalle.de/sicup.

SWEENEY, P., PATERNOSTER, E. Cutting and packing problems: a 
categorized application-oriented research biblidgraphy. Journal of the Operational Research Society. 43, 691-706.,. 1992 .

VILLAS, M. V., FERREIRA, A. G. M., LEROY, ‥ G., MIRANDA, C., BOCKMAN, C. L. Estruturas de dados: conceitos e técnicas de implementaçao. Rio de Janeiro: Campus, 1993.

WANG, P. Two algorithms for constrained two-dimensional cutting stock problems. Operations Research. 31, 573-587, 1983. 